\title{
COPLANAR INTERDIGITATED BAND ELECTRODES FOR ELECTROSYNTHESIS
}

Cécile Belmont, $\quad$ March 1994.

A thesis submitted for the degree of Doctor of Philosophy at the University of Edinburgh.

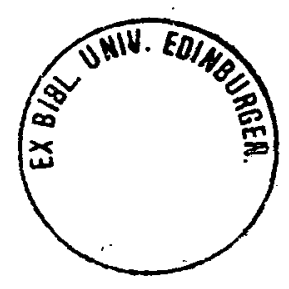




\section{ABSTRACT}

The behaviour of coplanar cathodic and anodic band electrodes was investigated and their use for standard syntheses was proven to be considerably advantageous, when compared to other techniques.

Electrode arrays were fabricated by screen printing platinum, silver or carbon inks. The inter-electrode distances were in the range $1 \mathrm{~mm}$ to $250 \mu \mathrm{m}$ for a constant band width of $1 \mathrm{~mm}$.

The mass transport was characterised for different inter-electrode distances and flow conditions. Figures compared positively with other cells. Two acceptable mathematical models were derived for the estimation of the resistance between coplanar band electrodes and were compared with results obtained experimentally or by simulation

Due to their excellent physical and chemical properties, platinum electrodes were found to be particularly well suited for the three syntheses investigated.

The furan methoxylation, being carried out in a resistive solvent, was chosen to highlight the advantage of minimising the ohmic drop. It was also shown that the formation of by-product could be limited by acid neutralisation on the adjacent band. Vigorous mixing conditions were not crucial. With the $250 \mu \mathrm{m}$ inter-electrode array, DHDMF could be produced with a current efficiency of $87 \%$. This compared extremely well with other cells and furthermore the energy consumption could be reduced to $1.4 \mathrm{kWh} . \mathrm{kg}^{-1}$, which represented a saving of at least $50 \%$.

The importance of having small ohmic losses was also encountered for the Kolbe reaction, where the applied voltage was set at high values. However the printed platinum film was too porous and a passivation of the electrode was noticed.

The advantage of having small inter-electrode distances was stressed by investigating the propylene epoxidation, which is a coupled reaction. Propylene oxide was produced at a rate of $0.12 \mathrm{~mol} . \mathrm{h}^{-1} . \mathrm{dm}^{-2}$ for an energy consumption of $2.0 \mathrm{kWh} \cdot \mathrm{kg}^{-1}$. This technique was thus found to be very competitive.

Finally the possibility of using this method for the production of hypochlorite by electrolysis of sea water was investigated. 


\section{Acknowledgement}

The three years spent for this PhD were very enjoyable. It would not have been the same without the great help of Dr. H. H. Girault, who was always coming out with an extraordinary number of new ideas every day, and who showed me that research in Science could be motivating and lively. The support of Dr. C. Comninellis was also most appreciated.

I am very grateful to Electricité de France - Direction des Recherches, who financed this project, and to the Ecole Polytechnique Fédérale de Lausanne, where most of the experimental work was done.

Finally, I would like to thank all the people who have been working with me in Scotland as well as in Switzerland. Their constant scientific, linguistic and moral support was essential. 


\section{Declaration}

I declare that the work presented in this thesis is my own unless otherwise stated by reference. 


\section{Symbols and units}
A
electrode area $/ \mathrm{m}^{2}$
Cgeom
dimensionless constant related to the array geometry
c concentration / $\mathrm{M}$
D diffusion coefficient $/ \mathrm{m}^{2} \cdot \mathrm{sec}^{-1}$
$e_{\text {th }} \quad$ electrode thickness / $\mathrm{mm}$
F Faraday constant C.mol ${ }^{-1}$
i current / A
I current density / A.m-2
$\mathrm{J} \quad$ cell constant $/ \mathrm{cm}^{-1}$
$\mathrm{k}_{\mathrm{m}} \quad$ mass transfer coefficient $/ \mathrm{m} \cdot \mathrm{sec}^{-1}$
$\mathrm{L} \quad$ cell equivalent length / $\mathrm{m}$
$\mathrm{l}_{\mathrm{b}} \quad$ length of exposed band / $\mathrm{mm}$
$\mathrm{l}_{\mathrm{eq}} \quad$ equivalent length / $\mathrm{mm}$
$\mathrm{n}_{\mathrm{b}} \quad$ total number of bands in the array
$R_{\text {array }} \quad$ total resistance between the bands of an array / $\Omega$
$R_{\text {bu }} \quad$ resistance between two bands of unit length $/ \Omega \mathrm{m}$
$R_{\text {th }} \quad$ resistance associated with the electrode thickness / $\Omega$
$2 \mathrm{~V}_{\mathrm{o}} \quad$ applied differential potential / V
$\bar{v} \quad$ mean flow velocity / $\mathrm{m}^{-\mathrm{sec}^{-1}}$,
$\mathrm{W}_{\mathrm{e}} \quad$ electrode bandwidth / $\mathrm{mm}$
$\mathrm{W}_{\mathrm{g}} \quad$ inter-electrode bandgap / $\mathrm{mm}$

$\begin{array}{ll}\phi & \text { potential / V } \\ \Lambda \mathrm{NaCl} & \text { sodium chloride molar conductivity } / \mathrm{cm}^{2} \Omega^{-1} \mathrm{~mol}-1 \\ \rho & \text { resistivity / } \Omega \mathrm{m} \\ \nu & \text { kinematic viscosity } / \mathrm{m}^{2} \cdot \mathrm{sec}^{-1}\end{array}$

Other symbols which have been adopted are specifically referred to in the text. 


\section{Table of contents}

Title

Abstract

Acknowledgement

Declaration

Symbols and units

CHAPTER 1 - Introduction

1-1 Advantages and limitations of electrosynthesis 1

1-2 Cost estimation of an installation

1-3 Existing reactors

1-3-1 Classification of the operational modes

1-3-2 Classical cells

1-3-2-1 Tank cells

1-3-2-2 Filter-press cells

1-3-2-3 Capillary gap cells

1-3-2-4 Rotating electrode cells 10

1-3-2-5 Swiss Roll cell

1-3-2-6 Volumetric electrodes cells

1-3-2-7 Packed bed cells

1-3-2-8 Comparison of the cell performances

1-4 Parameters influencing the limiting current

1-5 Definition of figures of merit

1-5-1 Fractional conversion

1-5-2 Material yield

1-5-3 Current efficiency

1-5-4 Overall selectivity

1-5-5 Energy consumption

1-5-6 Cell voltage

1-5-7 Energy efficiency

1-5-8 Electroactive area per unit volume 26

1-5-9 Mass transport coefficient $\quad 26$

1-5-10 Space time and space velocity 26

1-5-11 Space time yield 27

1-6 Objectives

CHAPTER 2 - Experimental $\quad 30$

2-1 Electrode fabrication and cell arrangement 30

2-1-1 Choice and description of the method 30

2-1-2 Electrode materials 32

2-1-3 Description of the different arrays 33

2-1-4 Description of the reactors 
2-2-1 Characterisation of the electrode surface 38

2-2-2 Resistance determination 39

2-2-3 Electrosynthesis

CHAPTER 3 - Physical properties 42

3-1 Investigation of the effect of flow on the limiting current 42

3-1-1 Determination of the mass transfer coefficient in a parallel

$\begin{array}{ll}\text { plate cell } & 42\end{array}$

3-1-2 Determination of the mass transfer coefficient with band arrays 46

3-2 Characterisation of the printed platinum electrode 53

3-2-1 Determination of the electrode thickness 53

3-2-2 Evolution of the printed electrode surface 53

3-2-2-1 Surface characterisation by Scanning Electron Microscopy 54

3-2-2-2 Surface characterisation by electrochemical means 54

3-3 Determination of the inter-electrode resistance 61

3-3-1 Analytical method 61

3-3-2 Numerical method 66

3-3-3 Experimental results 67

3-3-4 Comparison and interpretation of the results 71

CHAPTER 4 - Methoxylation of furan $\quad 78$

$\begin{array}{ll}\text { 4-1 Bibliography } & 78\end{array}$

4-2 Calibration and preliminary experiments $\quad 80$

4-2-1 Investigation of the electrochemical system 80

4-2-2 Product and reactant analysis $\quad 85$

4-3 Synthesis with two parallel plate electrodes in flow cells $\quad 87$

4-4 Synthesis with coplanar interdigitated electrodes 90

4-4-1 Experimental results 90

4-4-2 Effect of the convection on the cell performance 91

4-4-3 Effect of the applied voltage on the cell performance 93

4-4-4 Effect of the inter-electrode distance on the cell performance 96

4-5 Conclusion 100

CHAPTER 5 - The Kolbe synthesis 102

5-1 Bibliography 102

5-2 Calibration and preliminary experiments 104

5-2-1 Investigation of the electrochemical system 104

5-2-2 Product and reactant analysis 106

5-3 Synthesis in a two parallel plate cell 108

5-4 Synthesis with platinum coplanar band electrodes $\quad 110$

$\begin{array}{ll}5-5 \text { Conclusion } & 116\end{array}$

CHAPTER 6 - The epoxidation of propylene 117

6-1 Bibliography 117

6-2 Calibration and preliminary experiments 121 
6-3 Synthesis with coplanar interdigitated electrodes

6-3-1 Experimental results $\quad 124$

6-3-2 Effect of the convection on the cell performance 126

6-3-3 Effect of the applied voltage on the cell performance 129

6-3-4 Effect of the temperature on the cell performance 132

6-3-5 Effect of sodium bromide concentration on the cell performance 134

6-3-6 Effect of the inter-electrode distance on the cell performance 137

6-4 Conclusion

CHAPTER 7 - Electrolysis of sea water $\quad 142$

$\begin{array}{ll}7-1 \text { Bibliography } & 142\end{array}$

7-2 Analysis of active chlorine $\quad 146$

7-3 Investigation of a variety of electrode materials $\quad 147$

7-4 Electrolysis with coplanar band arrays $\quad 153$

7-5 Conclusion and further work 160

$\begin{array}{ll}\text { APPENDIX } & 161\end{array}$

$\begin{array}{ll}\text { Publications } & 165\end{array}$

$\begin{array}{ll}\text { Courses and conferences } & 166\end{array}$

$\begin{array}{ll}\text { REFERENCES } & 167\end{array}$ 


\section{CHAPTER 1}

\section{Introduction}

\section{1-1 Advantages and limitations of electrosynthesis}

Electrochemical techniques make up one of the major divisions of instrumental analytical chemistry, however, preparative electrochemistry is still in an early stage of development. A large number of articles concerning electrosynthesis are published every year but the number of industrial applications is not of consequence. Organic chemists and engineers have been unaware or misinformed of the potential of such techniques.

The reason for this reluctance can be explained by many factors. Literature is often too specialised for chemists only looking for preparative instructions. Due to the solubility properties of the compounds of interest, electrolyses are generally performed in organic solvents, which are not the solvents of predilection for electrochemists because of their high resistivity. $\mathrm{pH}$ conditions tend to vary during the synthesis and are difficult to control. The equipment is very different from the glassware classically used for purely organic processes. Good mixing conditions are necessary for efficient transformations, thus a pumping system must usually be included. Large electrodes are needed for industrial production and their price can be very important, especially when noble metals are the electrode materials. Furthermore, due to dissolution, surface adsorption or simple deformation, their life time is not infinite and they need to be replaced regularly. Another inconvenience of electrochemical 
synthesis is the long reaction time and the low concentration of the product obtained [1]. The choice of reactor can also be problematical.

On the other hand when the lack of confidence in electrosynthesis practicability is overlooked and with fruitful collaboration, very good results can be obtained. BASF, Monsanto, Asahi and ICI are companies whose industrial electrosyntheses have proved to be very profitable. Following their example, more firms are now interested in the several advantages offered by electrochemical processes, of which the main advantage is probably the product selectivity. The rate of reduction or oxidation of a reactant in a direct synthesis can be controlled very accurately by adjusting the electrode potentials to the corresponding value. Another approach is the in situ generation of an intermediate which subsequently undergoes reaction to form the product. This is very advantageous in the case of halogens for example, as their transport is not without danger. Also with this method, the concentration of the intermediate is kept constant, thus limiting the formation of by-products. The number and the quantity of starting materials can usually be lowered considerably by using electrochemical means and in most cases the electricity is used very efficiently. Alternative synthetic routes can also be taken for the production of given compounds. This constitutes another contribution in the economical gain. This benefit is very likely to become even more important as the price of electricity is very stationary compared to the price of chemicals or other forms of energy. The simplicity of the manipulations must also be seriously considered. Finally with more and more restrictive regulations on gaseous and liquid waste emissions, the most attractive point for the industrialist is the antipollution aspect of the process. 


\section{1-2 Cost estimation of an installation}

Before building up a new chemical plant, the percentage return on the total capital invested needs to be carefully estimated. It is defined by the following equation:

$$
\% \text { return on capital }=\frac{\text { sales value }- \text { total product cost }}{\text { capital invested }}
$$

For a profitable process, this percentage must reach 15 to $25 \%$. The amount of money required to set up a plant is imposed by the price of the land, the building, the equipment needed and the price of all the chemicals, whereas direct and overhead costs, marketing and distribution, research and development costs intervene in the total product cost. Direct costs include the price of raw materials, electrolysis, labour, maintenance and replacement of equipment (electrodes, membranes...), and utilities necessary for parallel treatments (such as heat exchange, distillation and pumping). Insurance, administration, safety, medical services, quality control and laboratory costs are classified as overhead costs.

For electrochemists, optimising the return on investment is possible by selecting the most appropriate cells. The fluid distribution in a cell influences the current efficiency, the material yield and the selectivity of the process. Selectivity can be improved with ionic membranes, this is however associated with a decrease in the current efficiency and a considerable increase in the cell costs. The electrode material used for the anode, where oxidation takes place, must have good electron transfer properties. Unless the reaction considered occurs easily at low potentials, noble metals are often needed. Platinum for example always gives good results. Noble metals, being expensive, are usually used as films on inert surfaces and have to be regenerated regularly. The material used for the 
cathode is not as critical and stainless steel is often chosen. The return on the investment can also be improved by electrolysing under the best experimental conditions. The cost of the electrolysis is related to the electrical power cost, the reactor investment cost and the cost of stirring the electrolyte. These terms are closely dependent on the current density. It is thus one of the most important parameters to optimise. At low values for example, the productivity is not very high, and at higher values, thus at a higher cell voltage, the productivity is greater, but by-products might be synthesised, thereby reducing the selectivity. Eventually, the solvent might also be electrolysed, reducing the current efficiency. An expression for the optimum value was developed by D. Pletcher and F. Walsh [2], and it clearly shows that the electrode and the mass transport costs should be minimised as well as the total cell resistance, the last of these being equal to the combination of the electrode, the electrolyte and the circuit resistances.

\section{1-3 Existing reactors}

\section{1-3-1 Classification of the operational modes}

A very large number of cells have already been tested for different systems. The most representative of these will be dealt with later, but before going into details, general descriptions will be introduced.

A given electrosynthesis can be carried out in three different types of reactors: simple batch, single pass or back-mix reactors. In the simple batch reactor, all the reactants are introduced before the synthesis, the reaction is stopped after a certain time and the products contained in the electrolyte can then be isolated. Reaction and residence times are equal. This process requires termination of the reaction, it is thus time consuming and not very suited for industrial processes. In contrast, the single pass reactor is a 
continuous process reactor. The reactant mixture is flowed through and the products are extracted from the mixture leaving the reactor. The composition of the mixture changes with the residence time of the species in the cell. In the back-mix reactor or continuously stirred reactor, a large volume of electrolyte is introduced in a well stirred tank and reactants are added continuously to keep their concentrations constant with time. Products are also extracted continuously. The latter reactors are probably the most efficient for industrial syntheses.

In order to avoid side reactions, or simply for safety purposes, membranes sometimes separate the cell into two compartments: one for the anolyte, where oxidation takes place and one for the catholyte, where the reduction occurs. Good performance membranes are now available commercially (Nafion, Ionac...). For longer life time a supporting cloth is usually necessary. These cells are described as divided cells, as opposed to undivided cells.

Finally the electrical mode of connection is also very characteristic of a cell. This is especially important when cathodes and anodes are placed in series. A reactor is either monopolar or bipolar. In a monopolar configuration all the electrodes are connected to the power generator poles (negative or positive). The potential is well controlled but connections are not always easy to make. Furthermore, the power generator must produce a large current and a low voltage, which is not very favourable, unless several reactors can be put in series. In bipolar reactors, all the electrodes are isolated from the others and only the end plates are connected to the power supply. When a high electric field is applied, the electrodes are polarised, one face acting as a cathode and the other as an anode. The connection mode is thus extremely simple and electrical conditions are easy to fulfil. On the other hand, a potential 
gradient exists on the electrodes. This can in some cases influence the reaction selectivity. The other main disadvantage of such a connection is the large electrical by-passes occurring between non consecutive electrodes. The current efficiency can therefore never reach $100 \%$.

\section{1-3-2 Classical cells}

\section{1-3-2-1 Tank cells}

The main characteristic of tank cells is their simplicity. The construction could not be more simple, easily facilitating manipulations. Yields can often be improved by using cells with better mass transfer control but it is often recommended to carry out preliminary experiments in a beaker type reactor [3]. It can eventually be separated into two compartments, either with a glass frit or a membrane and stirring is obtained with a magnetic stirrer or by bubbling an inert gas through the solution. Two electrodes can then be immersed in the solution and connected to the poles of a power generator. Once the electrolyte composition is determined an appreciation of the feasibility of an electrolysis can be made. This also allows a rapid estimation of the best electrode material and electrolyte composition.

For this reactor to be used industrially, several electrodes need to be placed in a tank, as close together as possible. This has the effect of increasing the ratio of the electrode area with respect to the solution and to limit the ohmic losses in the electrolyte. Electrodes can be connected in monopolar or bipolar configuration. Such reactors are employed for water electrolysis as the mass transport does not have to be efficient. A representation can be found in figure 1.1. It can be noted that in this case, the electrolyte compartments are not completely sealed. Separators only prevent the hydrogen and oxygen mixing for säfety reasons. In most tank cells 
electrodes are vertical plates. However, unlike other cell configurations, their geometry is not restricted. This is a major advantage in electroplating for example. The tank itself can also be used as an electrode.

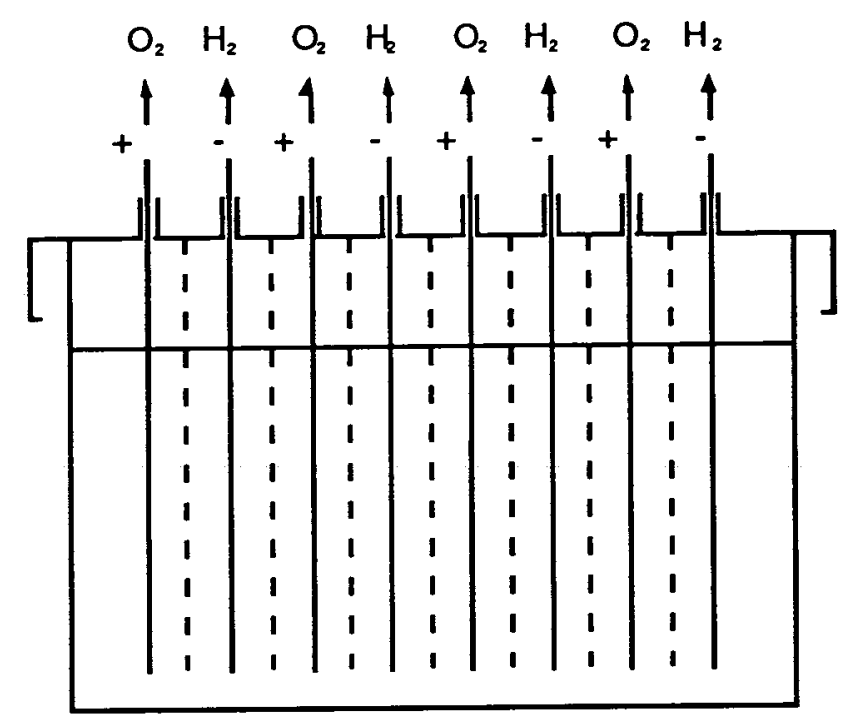

Figure 1.1: Monopolar plate-in tank reactor for water electrolysis.

\section{1-3-2-2 Filter-press cells}

Industrialists have recently shown a lot of interest in filter-press cells, also called parallel-plate cells. They tend to replace mercury bed electrodes now considered as too hazardous. The main applications for these cells are water electrolysis, production of chlorine $\left(5.10^{6}\right.$ tons / year or $15 \%$ of the world production), adiponitrile (200,000 tons / year) [4], sodium hypochlorite and chlorates $(985,000$ tons / year) [5]. Several models are now available commercially with the electrode area in the range $10 \mathrm{~cm}^{2}$ to $16 \mathrm{~m}^{2}$. The FM series from ICI, the Electrosyn and the ElectroMP cells are the most popular. As can be seen in figure 1.2, they are constructed of successive plates, electrodes, gaskets, membranes and eventually 
turbulence promoters. The sealant between the different parts is made by squeezing them mechanically or hydraulically, thus the name of filter-press. The electrolyte is usually forced to flow in closed loops. Two loops must be introduced in the case of a divided cell. The filter-press cells are usually placed vertically to avoid gas accumulation in the compartments, but can also be placed horizontally when the flow is sufficiently high. Turbulence promoters are often intercalated between the electrode and the gaskets to promote turbulence for better species mixing. Again the electrical connections may be monopolar or bipolar.

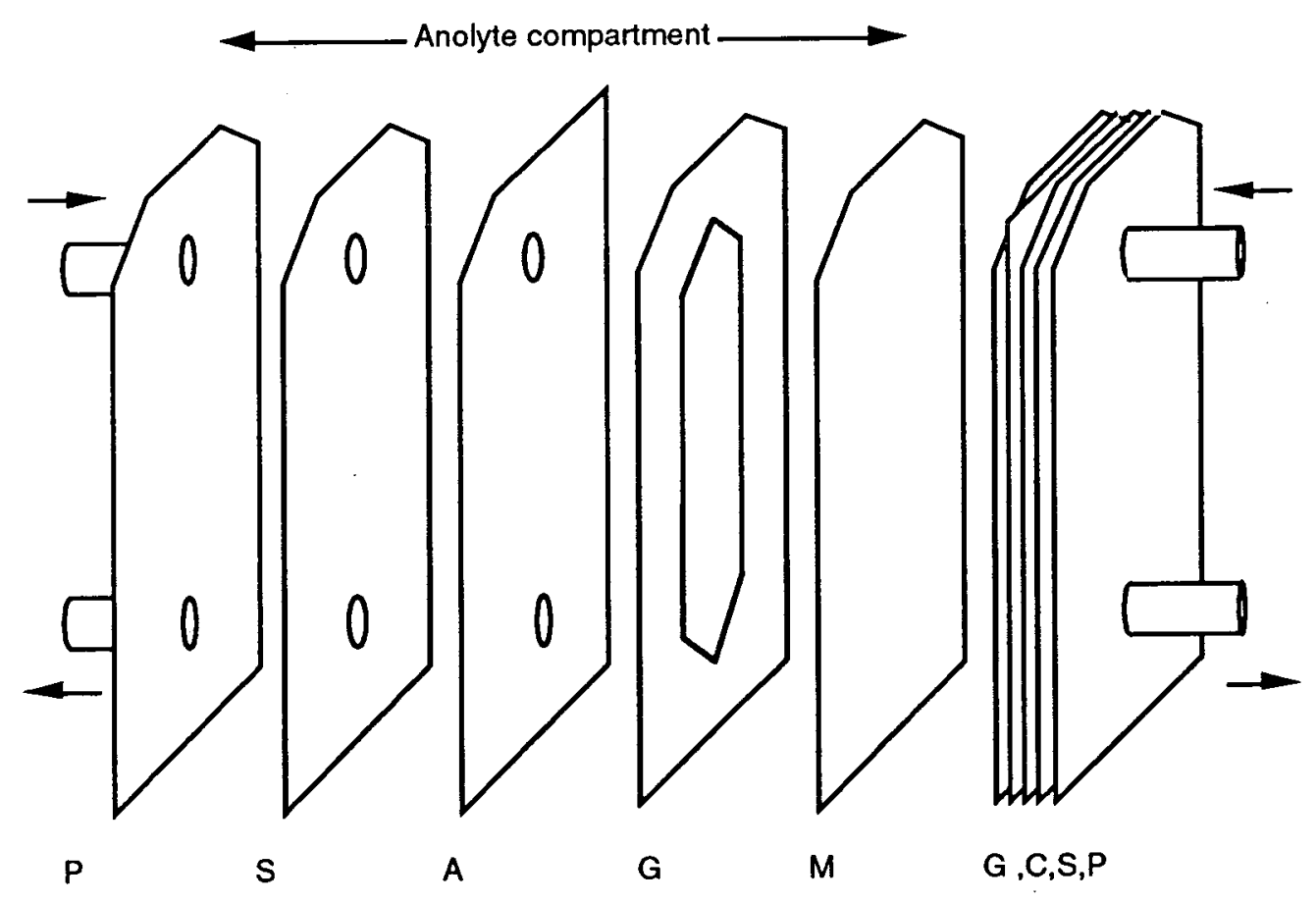

Figure 1.2: Filter -press reactor with end plate $(P)$, isolating and sealing plate (S), anode (A), gasket $(G)$, ionic membrane $(M)$ and cathode $(C)$. 
The reasons for the parallel-plate cell popularity for a large range of reactions can be summarised by its flexibility and the various advantages offered. All the components of the cell have such a simple geometry, thus construction is easy. A wide variety of materials are available for the electrodes, the membranes and the turbulence promoter, and gaskets can be found in different thicknesses. The potential of the electrode is well controlled over the surface. The mass transport is also very well controlled and can be adjusted by changing the flow and by using turbulence promoters. The scale up does not present any additional problems. However, there are disadvantages associated with this cell configuration. For example the distance between electrodes is rather large and cannot be minimised to less than a few millimetres when membranes and turbulence are needed. Sealing is also sometimes problematical.

\section{1-3-2-3 Capillary gap cells}

This reactor was first developed by F. Beck and H. Guthke in 1969. Figure 1.3 shows an improved design of the cell presented in a BASF patent. A stack of plate electrodes isolated by thin spacers are placed on a base plate. The electrolyte is radially pumped through the separators and is recovered at the top of the cell. Only the base and the end plate are connected to the power supply. The cell is thus bipolar and has an undivided configuration. The main industrial applications are the Kolbe reaction (100 tons / year) and the furan methoxylation (100 tons / year) [6]. The cell has numerous advantages. Due to its compact design the electrode area to electrolyte volume ratio is high resulting in an enhanced production. A gain in the power consumption can be achieved by reducing the inter-electrode distance down to $0.3 \mathrm{~mm}$ and thus 
minimising ohmic losses. Manipulations are facilitated as leaks rarely appear and a stack of electrodes can be replaced rapidly. A wide range of materials can be used for the electrode and fabrication is easy for any dimensions.

Disadvantages however cannot be disregarded. Limitations of bipolar systems are the large by-passes occurring between non-consecutive electrodes and difficult potential control. The electrolyte flow requires large pump power and cannot be kept constant throughout the cell. Deposit formation is thus possible, resulting eventually in the closure of channels. Finally, with a small electrode gap width, small electrolyte flow and a large electrode, the danger of short-circuits increases. Furthermore their detection and localisation in the closed cell is impossible.

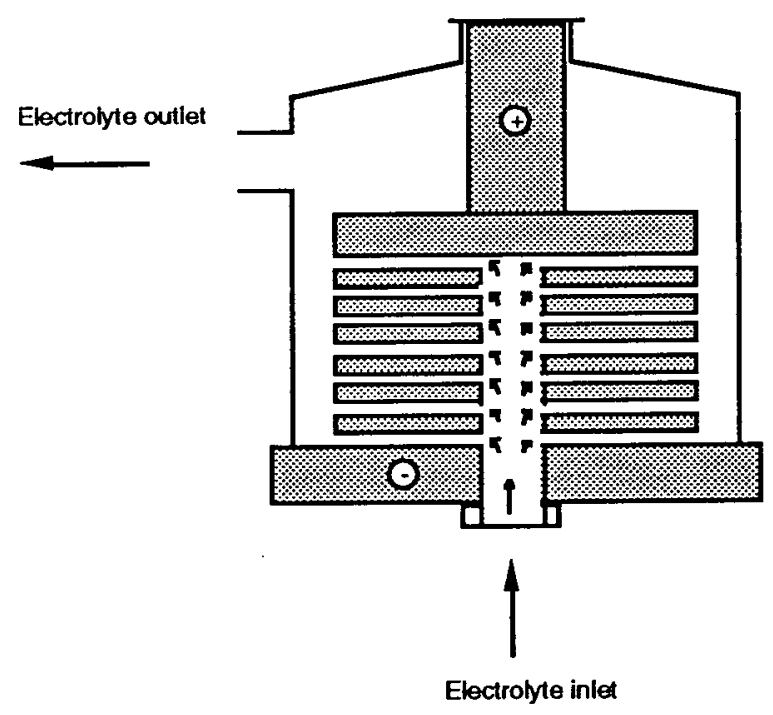

Figure 1.3: Capillary gap cell.

1-3-2-4 Rotating electrode cells

Rotating electrode cells can be classified into two categories. In the cell represented in figure 1.4 (a) the two electrodes are planar and very close to 
each other (typically 0.5 to $1 \mathrm{~mm}$ ). The rotation of the electrode has the effect of forcing the solution to flow radially. The cell thus acts as a pump. The active areas are the same for the anode and the cathode. Cells illustrated in figures 1.4 (b) and (c), are of the tank type with cylindrical anodes rotating inside cathodes. In the first case the electrode areas differ, whereas in the second case, the anodic areas are increased by using discs and can be adjusted to be the same as the fixed cathode. Finally membranes can be added to separate the anolyte from the catholyte and bipolar electrodes can also be used.

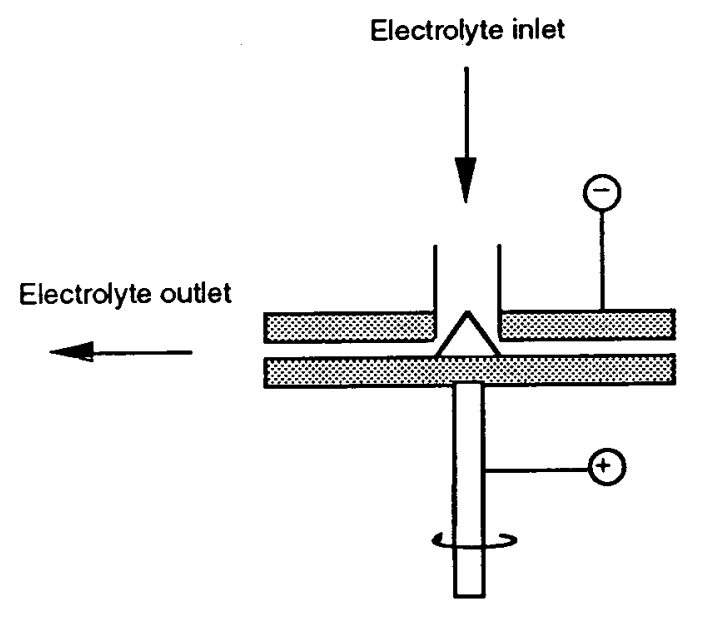

(a)

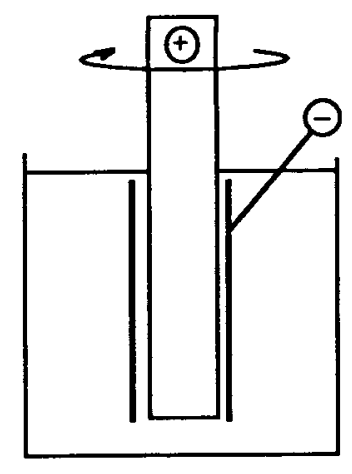

(b)

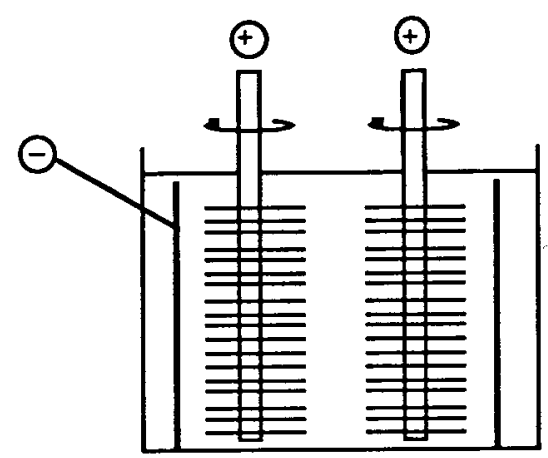

(c)

Figure 1.4: Rotating electrode cells 
Rotating electrode cells are characterised by their excellent mass transport conditions. This is of particular interest for reaction of short-life intermediates, or for reactions with immiscible reactants. H. V. K. Udupa [7] showed the good performance of this cell for several reactions such as the reduction of nitrobenzene and of oxidation of glucose.

However, serious disadvantages make the industrial scale up very difficult. The price of the cell is high. Fabrication and manipulation of the different components is not straight forward, and leaking problems may occur. The electrode rotation requires additional equipment. Finally the large external volume of the reactor might be a problem.

Nevertheless, concentric cylindrical electrode cells are the most popular reactors for small scale precious metal recovery. Several commercialised models exist for photographic silver recovery. Metal ions are converted to metal powder on the cathode surface which can be manually or automatically scraped to facilitate the recovery.

\section{1-3-2-5 Swiss Roll cell}

This type of reactor was first developed by P. M. Robertson and N. Ibl [8]. As can be seen in figure 1.5, it consists of electrode sheets or nets and separators in a sandwich which is spirally wound. The anode is connected to the central axis and the cathode connection is made on the external surface. The electrolyte is flowing from the centre to the exterior between the electrodes, as in the parallel plate configuration. Similarly turbulence promoters can be added to enhance mass transfer regimes. The sandwich may also contain membranes to allow the separation of the anolyte and the catholyte as the electrolyte is forced through the cell. Such a cell was investigated for several typical organic electrosyntheses [9] and has found 
industrial application in the oxidation of alcohols which are electroactive only at large potentials. For example diacetone - L - ketogulonic acid (DAG), a vitamin C intermediate, is produced at a rate of 2 tons / day, via the oxidation of diacetone - sorbose (DAS) [10].

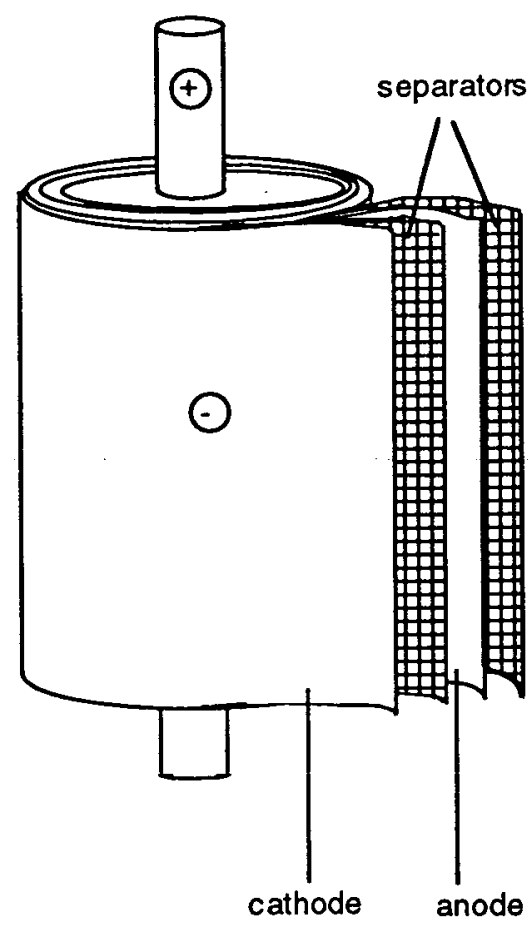

Figure 1.5: Swiss Roll cell.

The main advantage of the Swiss roll cell is its compactness. The inter electrode spacing is small ( 0.2 to $2 \mathrm{~mm}$ ), and both sides of the electrodes are active, bringing the electrode to electrolyte volume ratio to an even higher value. Also electrolyte flow is easily controlled, and finally current supply and distribution do not present any problems.

The vulnerability of the cell is associated with the electrode lengths . A large potential drop occurs thus limiting the current density (2 $-10 \mathrm{~mA} \mathrm{~cm}^{-2}$ ). High pumping energy is needed to force the electrolyte 
through, and furthermore gas evolution can badly interfere with the electrolytic process.

\section{1-3-2-6 Volumetric electrode cells}

The singularity of the three dimensional electrode cells lies in the fact that the electrolyte passes through the electrode, which can either be made of a porous material (fixed bed) or of small particles (fluidised bed). In the first case, the potential is applied by direct contact with a porous feeder electrode, as can be seen in figure 1.6. In the second case, a membrane is needed to keep the particles together. The potential distribution is more complex as both monopolar and bipolar particles electrodes can be found in the bed. The movement of the particles allows excellent mass transfer [11] and regeneration of the electrode surfaces. The well known Nalco process was the major industrial application, but this type of cell is now developed for effluent treatment because of its ability to remove metals to very low levels $[12,13]$.

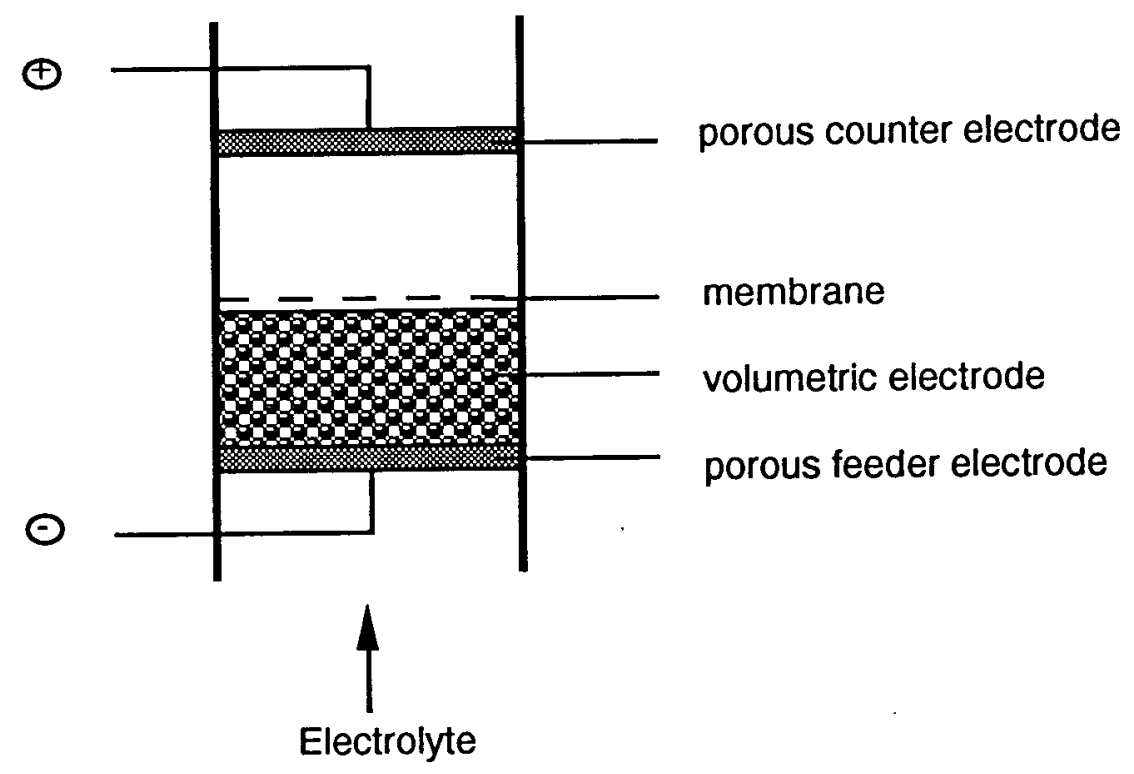

Figure 1.6: Volumetric electrode cell. 
Apart from the excellent mass transfer already mentioned, the cell offers the advantage of having a large electrode area for a small electrolyte volume, and the particles also act as turbulence promoters.

The main disadvantage of the cell is the bad potential distribution, resulting in the formation of unwanted products and high power consumption. Current and liquid flows can be very inhomogeneous if particles agglomerate, and membranes are submitted to a lot of destructive forces. Scale up is also problematical.

\section{1-3-2-7 Packed bed cells}

The concept of a packed bed cell or a trickle tower is very similar to that of volumetric electrodes, and they are also very popular for effluent treatments: for direct or indirect oxidation of cyanides [14] and for metal cyanides [15]. They are constructed of a tower packed with layers of conductive elements, usually carbon Raschig rings, or perforated plates, nets, rods or spheres. Layers are separated by insulating nets. The different elements are held together between two porous feeder electrodes. Therefore electrode layers have a bipolar configuration. A representation can be found in figure 1.7 .

The advantage of these cells is that the inter-electrode spacing is determined by the thickness of the insulating nets and hence can be minimised without modifying the good mass transfer properties.

However, the main disadvantage is the large current by-passes between electrodes. Also, as the electrode is bipolar, reaction only occurs on a small portion of the total area. The fraction of active area varies in the range 10 to $30 \%$ [16]. Furthermore because of the potential gradient, syntheses are not very selective and several by-products are usually obtained. 


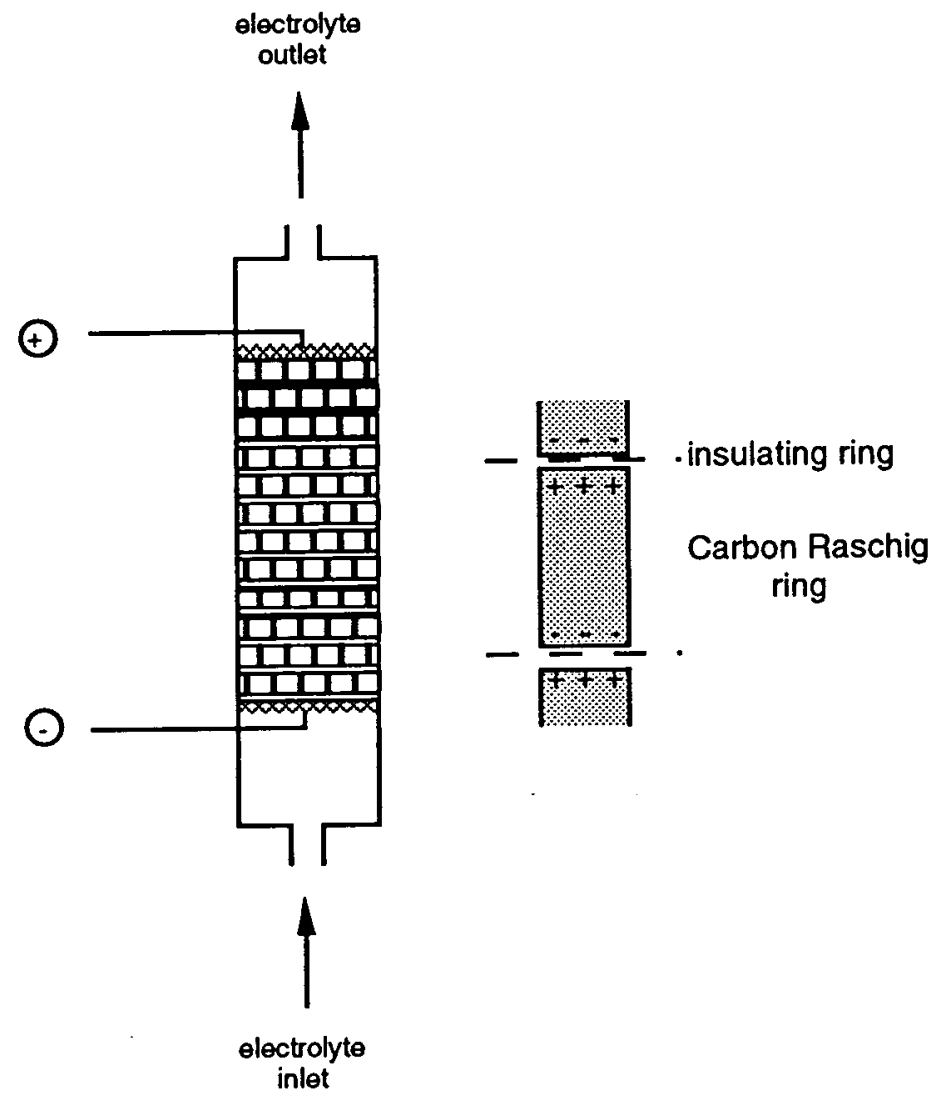

Figure 1.7: Packed bed cell.

1-3-2-8 Comparison of the cell performances

The following table compares the characteristics and properties of the previously described cells.

(As) represents the ratio of the electrode area with respect to reactor volume. 
Table 1.1: Comparison of classical cells.

\begin{tabular}{|c|c|c|c|c|c|c|}
\hline cell type & cell division & connection & mass transfer & As & scale up & cost \\
\hline $\tan k$ & possible & $\begin{array}{c}\text { monopolar } \\
\text { or bipolar }\end{array}$ & bad & low & easy & low \\
\hline filter-press & possible & $\begin{array}{c}\text { monopolar } \\
\text { or bipolar }\end{array}$ & medium & medium & easy & medium \\
\hline capillary gap & impossible & bipolar & medium & medium & easy & medium \\
\hline $\begin{array}{l}\text { rotating } \\
\text { electrode }\end{array}$ & possible & monopolar & good & medium & difficult & high \\
\hline Swiss Roll & $\begin{array}{l}\text { partially } \\
\text { possible }\end{array}$ & monopolar & good & high & difficult & medium \\
\hline $\begin{array}{c}\text { volumetric } \\
\text { electrode }\end{array}$ & possible & $\begin{array}{c}\text { monopolar or } \\
\text { bipolar }\end{array}$ & good & high & difficult & medium \\
\hline packed bed & impossible & bipolar & good & high & easy & medium \\
\hline
\end{tabular}




\section{1-4 Parameters influencing the limiting current}

In an electrosynthesis the rate of reduction or oxidation is closely related to the current measured between the working and the counter electrodes. The understanding of electrochemical phenomena is thus of prime necessity. If the reduction of $O$ to $R$ is considered for example, the reaction can be separated into three steps. The reactant $O$, uniformly distributed in the bulk solution, has to reach the electrode surface before it can be reduced and the product must then leave the electrode surface to prevent passivation:

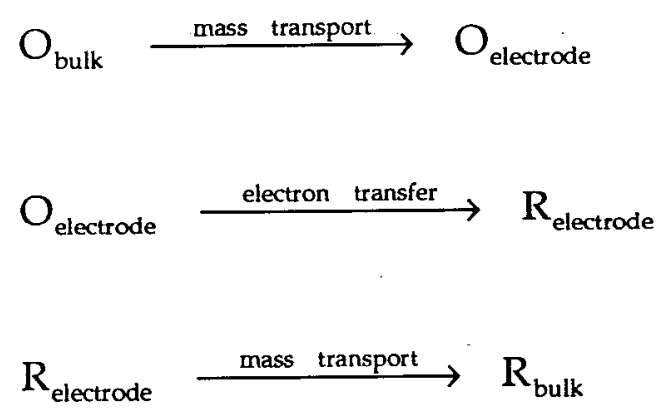

Mass transport and electron transfer are both responsible for limiting the current density.

Three modes of mass transport exist in electrochemical processes: diffusion, migration and convection. Migration is the movement of species due to a potential field. This force affects any ionic species. An excess of electro-inactive species is thus often introduced in the solution so that migration effects of electroactive species can be neglected. Convection is the movement of species due to external mechanical forces such as stirring, agitating the solution or flowing it through a cell. Diffusion is the movement of species due to a concentration gradient. When $O$ is converted to $R$, a boundary layer is formed, where the concentration of $\mathrm{O}$ is lower than that of the bulk. Although convective 
forces do not interfere within this layer, they affect the thickness of the layer $(\delta)$. For normal mixing conditions this thickness is in the order of $100 \mu \mathrm{m}$, whereas in quiescent solutions it increases with time $(\delta=\sqrt{\pi \mathrm{Dt}}$, where $D$ is the diffusion coefficient of species $O$ ).

In electrosynthesis, the electron transfer is promoted by applying a potential difference between a working and a counter electrode. The overpotential at an electrode, $\eta$, is the difference between the actual potential of the electrode $(E)$ and its equilibrium value $\left(E_{e q}\right)$ : which is determined from the Nernst equation:

$$
\eta=E-E_{\text {eq }}=E-\left(E^{\circ}+\frac{R T}{n F} \ln \left(c_{o} / c_{R}\right)\right)
$$

Where $\mathrm{E}^{\circ}$ is the standard potential for the couple $\mathrm{O} / \mathrm{R}$, and $\mathrm{c}_{O}$ and $c_{R}$ are the respective concentrations.

By definition, the sign of the resulting current is positive for an oxidation and negative for a reduction. When the current is only limited by electron transfer, or in other words for rapid mass transport, it can be demonstrated kinematically that the current density observed is related to the overpotential such that:

$$
I=I^{o}\left(e^{\alpha n F \eta / R T}-e^{-(1-\alpha) n F \eta / R T}\right)
$$

Where $I^{\circ}$ is the exchange current density and $\alpha$, the transfer coefficient. 
The latter equation is also defined as the Butler-Volmer equation, and Tafel graphs are obtained by plotting the current density in a logarithmic scale against the overpotential, as represented in figure 1.8:

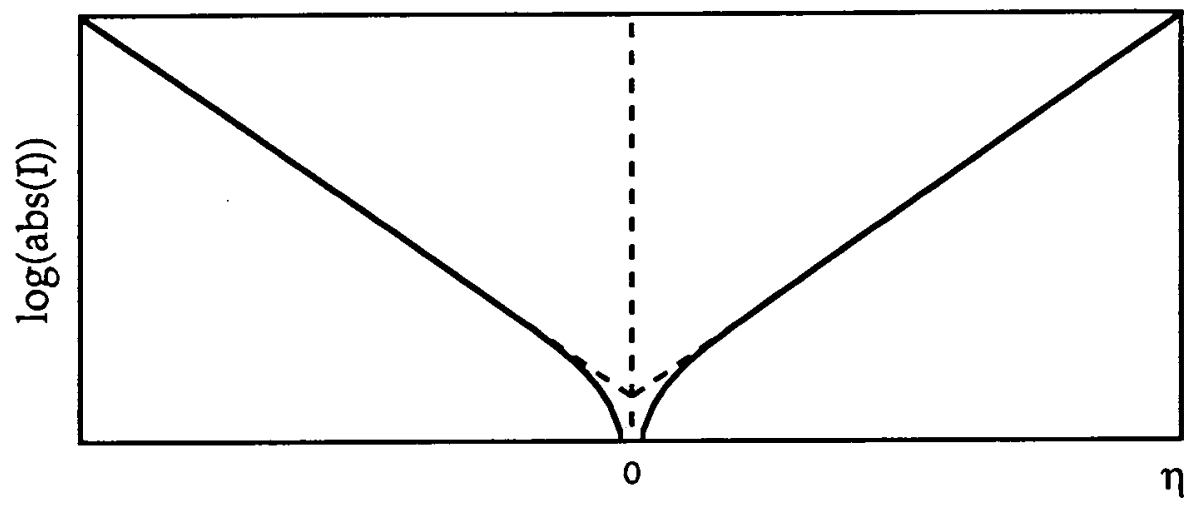

Figure 1.8: Tafel graph for an electron transfer limited process.

When the reaction is limited by mass transport only, the value of the current density is directly proportional to the concentration gradient at: the electrode and by applying the Nernst equation at the electrode surface, it can be demonstrated that:

$$
E \cong E^{o^{\prime}}+\frac{R T}{n F} \ln \left[\frac{\left|I_{d c}\right|-I}{I-\left|I_{d a}\right|}\right]
$$

Where $\mathrm{I}_{\mathrm{dc}}$ and $\mathrm{I}_{\mathrm{da}}$ are the cathodic and anodic steady state limiting current densities determined by:

$$
\left|I_{d}\right|=n F D c / \delta
$$

Figure 1.9 represents the evolution of the current density for an oxidation when the reaction is only limited by mass transport (I), and when it is 
limited by both electron transfer and mass transport (II), which is often the case.

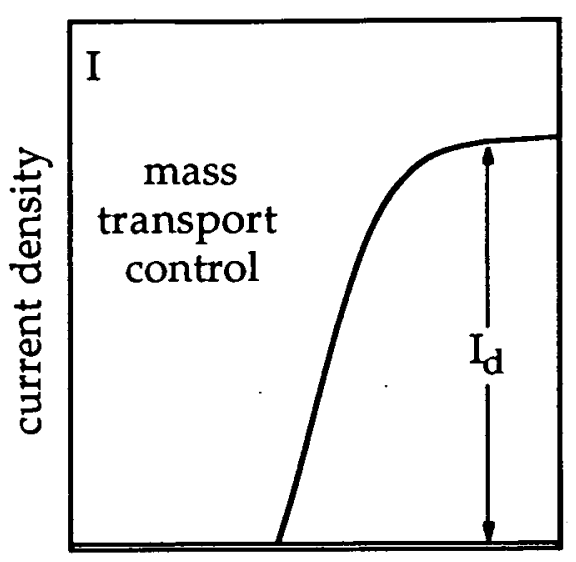

applied voltage

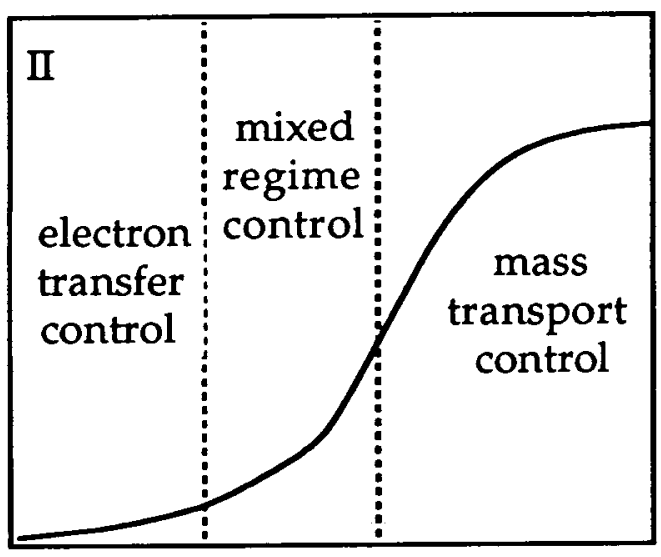

applied potential

Figure 1.9: Current response as the applied potential is increased. I: mass transport control only, II: mixed control.

Electrochemical engineers use a transformed form of equation (1.8), in which the limiting current density is expressed in terms of mass transport [17]:

$$
\mathrm{I}_{\mathrm{lim}}=\mathrm{nFk}_{\mathrm{m}} \mathrm{c}
$$

$k_{m}$, the mass transport coefficient, is dependent on many factors such as the cell geometry and the mixing conditions. Its value can be estimated from the dimensionless Sherwood number (Sh), which is the comparison of the characteristic length, $\mathrm{L}$, of a cell with that of the diffusion layer:

$$
\mathrm{Sh}=\mathrm{k}_{\mathrm{m}} \mathrm{L} / \mathrm{D}=\mathrm{L} / \delta
$$


An empirical equation relates the Sherwood number to three other dimensionless numbers: Re, the Reynolds number, which characterises the flow regime; Sc, the Schmidt number, which expresses the transport properties; and Gr, the Grashof number, which characterises the fluid movement due to differences in gravities:

$$
S h=a \operatorname{Re}^{b} G r^{c} S c^{d}=a\left(\frac{\bar{v} L}{v}\right)^{b}\left(\frac{L^{3} g \rho \Delta \rho}{\mu^{2}}\right)^{c}\left(\frac{v}{D}\right)^{d}
$$

Where $\bar{v}$ is the mean flow velocity, $v$ the kinematic viscosity, $g$ the acceleration due to gravity, $\rho$ the density and $\mu$ the dynamic viscosity.

$a, b, c$ and $d$ are parameters defined by fitting experimental data. In natural convection the Schmidt number does not depend on the value of the Reynolds number, therefore $b$ is zero. In forced convection, differences in density has little effect so that $\mathrm{c}$ is equal to zero.

Maximum efficiency is obtained with large values of $k_{m}$, however compromises must be made to minimise unreasonable pumping costs for example.

\section{1-5 Definition of figures of merit}

Although the percentage return on investment is often considered to be the main criterion for the selection of a cell, the performance of an electrochemical system can be quantified with a large variety of figures of merit [18]. Their comparison allows the optimisation of methods in a 
more scientific approach. A non exhaustive list of the most common can be found below together with their definition for the reduction of $A$ to $P$ :

$$
A+n e^{-} \rightarrow n_{p} P
$$

\section{1-5-1 Fractional conversion}

The fractional conversion, $X_{A}$, is the fraction of reactant consumed by the electrochemical reaction.

$$
\begin{array}{ll}
\text { For simple batch reactors: } & X_{A}=\frac{m_{(0)}-m_{(1)}}{m_{(0)}} \\
\text { For single flow reactors: } & X_{A}=\frac{m_{(\mathbb{N})}-m_{(O U T)}}{m_{(I N)}}
\end{array}
$$

Where $m_{(0)}$ and $m_{(1)}$ are the molar amounts of the reactant at time zero or t. $m_{(I N)}$ and $m_{(\text {OUT })}$ are the molar amounts of the reactant before or after entering the cell.

High values of $X_{A}$ are especially needed when the starting material is not recycled. This however often leads to low flow rate and therefore poor mass transport conditions.

\section{1-5-2 Material yield}

Similarly to classical chemistry the material yield, $\theta_{\mathrm{P}}$, is the ratio of the amount of product obtained with respect to the amount theoretically obtainable:

$$
\theta_{P}=\frac{m_{P}}{n_{P} m_{(0)}}
$$

Where $m_{P}$ is the molar amount of product.

High material yield is usually the first condition to fulfil. 


\section{1-5-3 Current efficiency}

The current efficiency, $\phi$, is the yield based on the amount of electricity consumed $\left(q=\int_{0}^{t} I d t\right)$

$$
\phi=\frac{\text { charge used in forming product }}{\text { total charge }}=\frac{m_{p} n_{p} F}{q}
$$

A value of $\phi$ below $100 \%$ indicates that the back reaction occurs or that by-products are formed. It can also mean that the solvent is electrolysed.

\section{1-5-4 Overall selectivity}

The overall selectivity, $S_{p}$, gives an indication on the purity of the solution:

$$
\mathrm{S}_{\mathrm{P}}=\frac{\text { moles of desired product }}{\text { moles of all products }}
$$

Selectivity should be as close to $100 \%$ as possible to avoid high reactant or energy consumption and to facilitate the purification of the product.

\section{1-5-5 Energy consumption}

Together with the material yield and the current efficiency, the energy consumption is one of the most important figures of merit as it relates the amount of energy needed to produce a given amount of product:

$$
\begin{array}{ll}
\text { molar energy consumption: } & -\mathrm{nFE}_{\mathrm{CELL}} / \phi \\
\text { specific energy consumption: } & -\mathrm{nFE}_{\mathrm{CELL}} / \phi \mathrm{M} \\
\text { volumetric energy consumption: } & -\mathrm{nFE}_{\mathrm{CELL}} / \phi \mathrm{V}_{\mathrm{M}}
\end{array}
$$

Where $V_{M}$ is the molar volume and $M$ the molar mass. 
The energy consumption can only be minimised by selecting electrolysis conditions such that the current is only used for the reaction of interest, and by making the cell voltage as low as practicable.

\section{1-5-6 Cell voltage}

The cell voltage, $\mathrm{E}_{\mathrm{CELL}}$, is the potential applied between the working and the counter electrode and is the combination of several terms:

$$
\begin{aligned}
& \mathrm{E}_{\text {cell }}=\mathrm{E}_{\mathrm{C}}-\mathrm{E}_{\mathrm{A}}-\mathrm{i} R_{\text {cell }}-\mathrm{i} R_{\text {circuit }} \\
& \mathrm{E}_{\text {cell }}=\mathrm{E}_{\text {eq }}^{\mathrm{C}}-\mathrm{E}_{\text {eq }}^{\mathrm{A}}-\left|\eta_{\mathrm{C}}\right|-\left|\eta_{\mathrm{A}}\right|-\mathrm{i} R_{\text {cell }}-\mathrm{i} R_{\text {circuit }}
\end{aligned}
$$

$\mathrm{E}_{\mathrm{eq}}^{\mathrm{C}}$ and $\mathrm{E}_{\mathrm{eq}}^{\mathrm{A}}$ are the equilibrium potentials of the cathode and the anode and their difference may be calculated from the free energy change for the overall reaction:

$$
\Delta G=-n F\left(E_{e}^{C}-E_{e}^{A}\right)
$$

\section{1-5-7 Energy efficiency}

The energy efficiency refers to the ratio of the experimental and theoretical energies:

$$
\gamma_{\mathrm{G}}=\frac{\Delta \mathrm{G}_{\text {cell }} \phi}{\mathrm{E}_{\text {cell }} \mathrm{nF}}=\frac{-\left(\mathrm{E}_{\mathrm{e}}^{\mathrm{C}}-\mathrm{E}_{\mathrm{e}}^{\mathrm{A}}\right) \phi}{\mathrm{E}_{\text {cell }}}
$$

In an ideal system, the current efficiency would be $100 \%$ and the cell potential could be minimised to the electrode equilibrium potential difference. This would result in a $100 \%$ energy efficiency. 


\section{1-5-8 Electroactive area per unit volume}

The electroactive area per unit volume, $A_{S}$, refers to the electroactive area, $A$, with respect to the reactor volume, $V_{R}$ :

$$
A_{\mathrm{s}}=\frac{\text { electroactive area }}{\text { reactor volume }}
$$

In an electrochemical process, the rate of reaction is directly proportional to the current and thus to the electroactive area. Therefore $A_{s}$ should be as high as possible. This explains the recent interest in porous electrodes.

\section{1-5-9 Mass transport coefficient}

The mass transport coefficient, $\mathrm{k}_{\mathrm{m}}$, has already been defined as:

$$
k_{m}=\frac{\left|I_{\lim }\right|}{n F c}=\frac{\left|i_{\lim }\right|}{n F A c}
$$

Usually both mass transport coefficient and electroactive area contribute to the cell performance. It is therefore interesting to calculate their product.

\section{1-5-10 Space time and space velocity}

The space time, $\tau_{\mathrm{ST}}$, is the ratio of reactor volume to volumetric flow rate, Q:

$$
\tau_{\mathrm{ST}}=\frac{\mathrm{V}_{\mathrm{R}}}{\mathrm{Q}}
$$

It is equivalent to the mean residence time of the electrolyte in the reactor. The space velocity, $s$, is the reciprocal ratio: 


$$
\mathrm{s}=\frac{\mathrm{Q}}{\mathrm{V}_{\mathrm{R}}}=\frac{1}{\tau_{\mathrm{ST}}}
$$

\section{1-5-11 Space time yield}

The space time yield, $\rho_{\mathrm{ST}}$, characterises very well the performance of a reactor as it represents the mass of product that can be obtained per unit time $(w / t)$ in a unit volume cell:

$$
\rho_{\mathrm{ST}}=\frac{\mathrm{w} / \mathrm{t}}{\mathrm{V}_{\mathrm{R}}}
$$

This parameter is proportional to many of the figures of merit previously defined, such as the space velocity, the current efficiency and the electroactive area per unit volume.

\section{1-6 Objectives}

A very wide variety of electrolysis reactors have already been proposed and investigated for a large range of applications. Figures of merit differ substantially from one cell to another and from one system to another. Most electrolyses require good mass transport conditions. Pumping systems are often used to promote sufficient mixing. This does not require considerable energy when electrodes are widely separated, but can become a problem with small inter-electrode distances. The interest of having close electrodes is to improve energy consumption and decrease electrlyte heating. These effects are even more pronounced for organic solvents, which are usually very resistive. The design of an electrochemical reactor 
is thus the balance between the optimisation of the mass transport conditions and the energy loss in Joule heating.

To minimise the ohmic loss, cells with small intrinsic resistance have been designed such as the capillary gap cell or the pump cell. The drawback of such approaches is the poor mass transfer. The aim of this work is to apply the microelectrode methodology to the fabrication of novel electrosynthesis cells. The use of microelectrodes in analytical chemistry is now common and allows the acquisition of information otherwise not possible. Microelectrodes have specific features such as steady state diffusional profiles and the ability to work in very resistive media and for these reasons have found many applications, as recently reviewed [19-22]. An interesting aspect of microelectrodes is the concept of interdigitated microband electrodes, which are commonly used for conductivity sensors $[23,24]$ and for amperometric detectors in liquid chromatography $[25,26]$. Such microarrays can be fabricated by photolithography or screen printing. The latter technique is widely used in the electrochemical sensor industry and was chosen for the production of large scale coplanar electrodes. It offers the possibility of producing low price electrodes with good edge definition. Carbon, gold, silver and platinum inks are commercially available but almost any metal could be printed as long as it could be ground into very small particles.

In the first part of this work, the physical properties of the printed electrodes are investigated. Electrode surfaces can be studied by Scanning Electron Microscopy. The roughness is also characterised by electrochemical means. The influence of the mass transport regime is shown. To demonstrate that such electrodes could be advantageous a mathematical expression for the interelectrode resistance is developed and compared with simulated and experimental values. In a further part 
of the work, they are tested for three well documented reactions: the furan methoxylation, the Kolbe synthesis, the propylene epoxidation and the electrolysis of sea water:

furan methoxylation:<smiles>c1ccoc1</smiles>

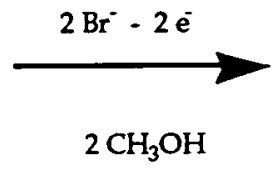

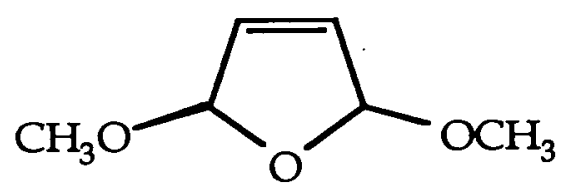

Kolbe synthesis:
$\mathrm{R}-\mathrm{R}+2 \mathrm{CO}_{2}+2 \mathrm{e}^{-}$

propylene epoxidation:

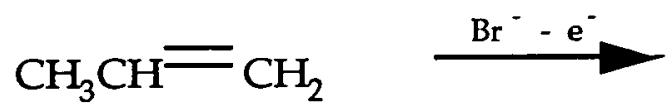

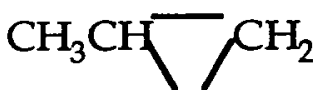

$\mathrm{O}$

The advantage of having small ohmic losses is interesting for the furan methoxylation, which is carried out in an organic solvent, and for the Kolbe synthesis, where the applied voltage is very high. Having small interelectrode distances is also interesting for coupled reactions where the anode and cathode products must react together to form the final product; this is the case for the propylene epoxidation. Finally the possibility of using such electrodes was investigated for the electrolysis of brine or sea water, which is becoming an important industrial reaction for the production of hypochlorite. 


\section{CHAPTER 2}

\section{Experimental}

\section{2-1 Electrode fabrication and cell arrangement}

\section{2-1-1 Choice and description of the method}

Several techniques are available for the fabrication of interdigitated band electrodes: screen printing, photolithography, metal vaporisation and laser ablation. Their combination generates a large number of possibilities in terms of geometry and material. The technique widely used for micro sensors is based on the classical photolithographic methodology. For the case of a gold array on silicon the following steps have to be executed: formation of silicon oxide by baking, deposition of a sublayer (chrome or polyimide for example), gold film deposition, photoresist spin coating, mask align exposure, development, chemical gold etching and finally, photoresist decomposition. This laborious process does however give very good definition, as focusing lenses are used in the exposure step. Arrays can also be obtained by metal deposition followed by timeconsuming laser ablation. The disadvantages of these methods are the fragility of the arrays and limited metal selection. The experimental approach chosen for the fabrication of large scale electrodes with micro inter-electrode distances was that of screen printing. This technique has already been used in the electrochemical sensor industry and geometric areas of up to $1 \mathrm{~m}^{2}$ can easily be printed with a resolution of $50 \mu \mathrm{m}$ for the edge definition. This resolution is poor when compared to the previously mentioned methods, but it was judged sufficient for the early stage of this application. It had the advantages of producing large and robust electrodes 
at relatively low prices. This could be achieved in short time and with almost any substance. The principle of this ancestral technique is that a paste is passed through a screen under the pressure of a squeegee. According to the paste specifications, screens were made of evenly stretched framed stainless steel cloths consisting of $30 \mu \mathrm{m}$ diameter wires with a 325 mesh size (number of wires per inch), covered with $15 \mu \mathrm{m}$ photosensitive films. A representation can be found in figure 2.1. The thickness of the printed film was dependent on the emulsion thickness and the ink composition.

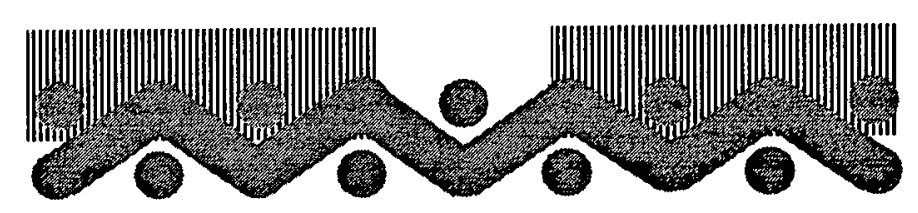

Figure 2.1: Representation of a screen

The screens were positioned under exposure masks, which were designed with ordinary graphic software (Paintbrush on windows) and then exposed to UV light. The resolution was satisfactory for band gaps larger than $200 \mu \mathrm{m}$. Positives of the arrays were then printed on transparencies with a $300 \mathrm{dpi}$ laser printer. The screen printer used for the majority of the arrays, was a manual bench top version (DEK 65, UK) for prototype production. A semi automatic screen printing machine (DFS05 - DickFilm System - Switzerland) was utilised for platinum interdigitated electrodes which were produced in larger quantities. In order to dry the ink and to minimise the electrode resistance, the samples had then to be cured for 24 hours. Curing temperature is dependant on the ink and will be mentioned in due course. 


\section{2-1-2 Electrode materials}

A very wide variety of inks are now commercially available. The number of materials for electrochemical applications is however more limited. Five different pastes were used: carbon, silver, silver chloride, platinum and ruthenium oxide.

Several carbon inks were investigated with ferrocenecarboxylic acid and the Electrador 5000 paste, from Electra (UK), was retained for its good electrochemical properties. This paste consisted of fine carbon particles in a polymer. The arrays were cured at $80^{\circ} \mathrm{C}$ for 24 hours, during which time the electrode resistance decreased from $1 \mathrm{k} \Omega / \mathrm{cm}$ to $40 \Omega / \mathrm{cm}$. This resistance was, however, very high compared with other metallic pastes. The resistance of a silver ink (Johnson Matthey - UK) was only $1 \Omega / \mathrm{cm}$, and it was thus applied to the interdigitated electrode contacts to promote a better potential distribution. Pure silver printed electrodes were also printed for the determination of solution resistance between the bands. This ink was also cured at $80^{\circ} \mathrm{C}$ for 24 hours.

A silver / silver chloride $(60: 40)$ paste was prepared for the fabrication of reference electrodes. This was achieved by mixing the same silver paste with ground silver chloride.

Platinum arrays were printed with an $83 \%$ platinum paste (JM 7601 Johnson Matthey \& Brandberger AG - Switzerland). The curing temperature was $900^{\circ} \mathrm{C}$.

Finally a ruthenium oxide ink (C7111 - Emca-Remex Products - England) was used for the electrolysis of sea water. This ink was printed on a platinum thick film to reduce the resistance to a value close to the platinum film. Figure 2.2 is a graph obtained by thermogravimetry. It shows that after $350^{\circ} \mathrm{C}$, all the solvent is evaporated and no chemical 
changes occur. However, it was found that this inks mechanical stability was improved by curing it at $800^{\circ} \mathrm{C}$.

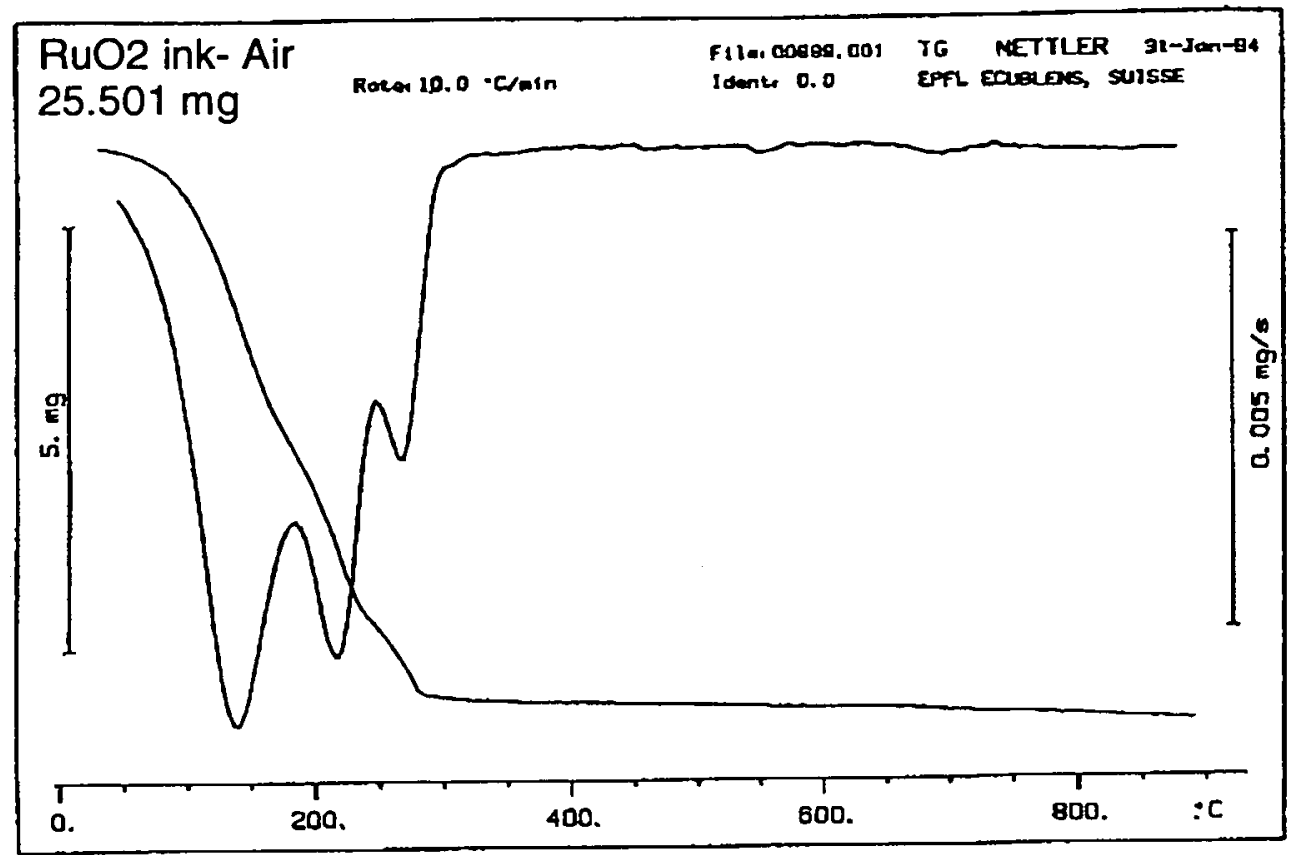

Figure 2.2: Thermogravimetry of a sample of $\mathrm{RuO}_{2}$ ink.

For comparative purposes, syntheses were carried out in filter press cells with plate electrodes. The materials of choice were stainless steel, platinum deposited on titanium, or carbon foil (Goodfellow - UK).

\section{2-1-3 Description of the different arrays}

For the simplest interdigitated arrays the cathode and anode material was identical. Arrays were characterised by the material employed for the ink and the substrate, the total number of bands, $\mathrm{n}_{\mathrm{b}}$, the electrode band width, $\mathrm{W}_{\mathrm{e}}$, the interelectrode band gap, $\mathrm{W}_{\mathrm{g}}$, and the exposed band length, $\mathrm{l}_{\mathrm{b}}$. The different interdigitated electrodes are listed in table 2.1. Figure 2.3 shows the positive for the AG2 array. The choice of substrate was based on the 
curing temperature of the ink. $1 \mathrm{~mm}$ thick PVC substrates were easily cut and could resist high sheer forces, but they could not withstand high temperature. Alumina sheets (Hederman \& Porret - Switzerland) were thus the substrates chosen for platinum arrays. An interdigitated electrode made of carbon and silver / silver chloride was printed. This was done in two steps and required very accurate alignment. The characteristic dimensions of this array (CAGCL) were those of the AG2 array, and a representation can be found in figure 2.4 .

Table 2.1: Characteristics of interdigitated arrays.

$\begin{array}{llllccc}\text { Array } & \text { paste } & \text { substrate } & \mathbf{n}_{\mathbf{b}} & \mathbf{W}_{\mathbf{e}} & \mathbf{W}_{\mathbf{g}} & \mathbf{l}_{\mathbf{b}} \\ \text { name } & & & & / \mathrm{mm} & / \mathrm{mm} & / \mathrm{mm}\end{array}$

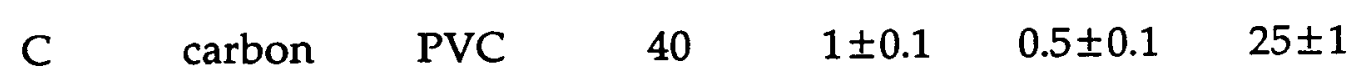

$\begin{array}{llllccc}\text { AG1 } & \text { silver } & \text { PVC } & 30 & 1 \pm 0.1 & 1 \pm 0.1 & 25 \pm 1 \\ \text { AG2 } & \text { silver } & \text { PVC } & 40 & 1 \pm 0.1 & 0.5 \pm 0.1 & 25 \pm 1 \\ \text { AG3 } & \text { silver } & \text { PVC } & 50 & 1 \pm 0.1 & 0.25 \pm 0.05 & 25 \pm 1\end{array}$

PT1 platinum alumina $30 \quad 1 \pm 0.1 \quad 1 \pm 0.1 \quad 20 \pm 1$

$\begin{array}{lllll}\text { PT2 platinum alumina } 40 & 1 \pm 0.1 & 0.5 \pm 0.1 & 20 \pm 1\end{array}$

$\begin{array}{lllll}\text { PT3 platinum alumina } 50 & 1 \pm 0.1 & 0.25 \pm 0.05 & 20 \pm 1\end{array}$

$\begin{array}{lllll}\text { PT4 platinum alumina } & 70 & 0.5 \pm 0.1 & 0.25 \pm 0.05 & 20 \pm 1\end{array}$ 


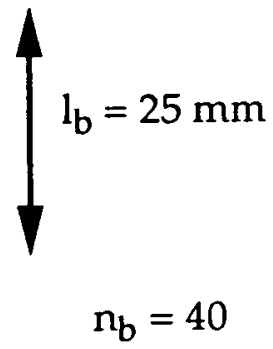

Figure 2.3: Representation of the AG2 array.

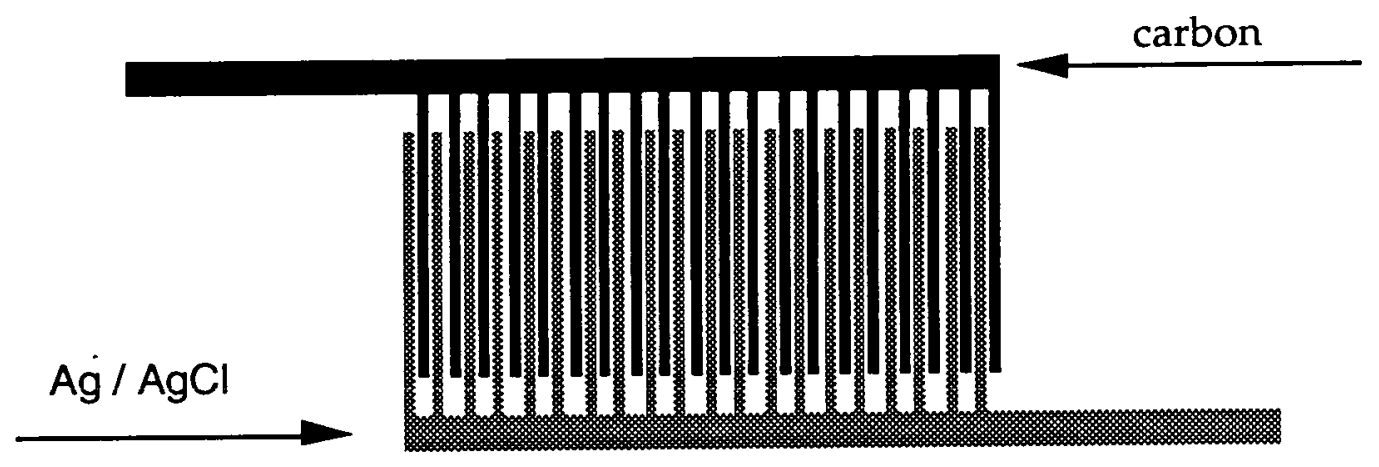

Figure 2.4: Representation of a Carbon - $\mathrm{Ag} / \mathrm{AgCl}$ array.

Finally, $1 \mathrm{~cm}^{2}$ platinum electrodes were printed on alumina for surface studies and analytical purposes.

Contacts were insulated from the bulk solution with varnish or fluorosilicone.

\section{2-1-4 Description of the reactors}

In order to investigate the effect of the mass transport on the limiting current and on different figures of merit, two tank reactors and three flow cells were used. The tank reactors were ordinary or thermostated beaker 
type cells of $150 \mathrm{ml}$ and $250 \mathrm{ml}$ respectively. Agitation was obtained by the rotation of a magnetic stirrer, as can be seen in figure 2.5:

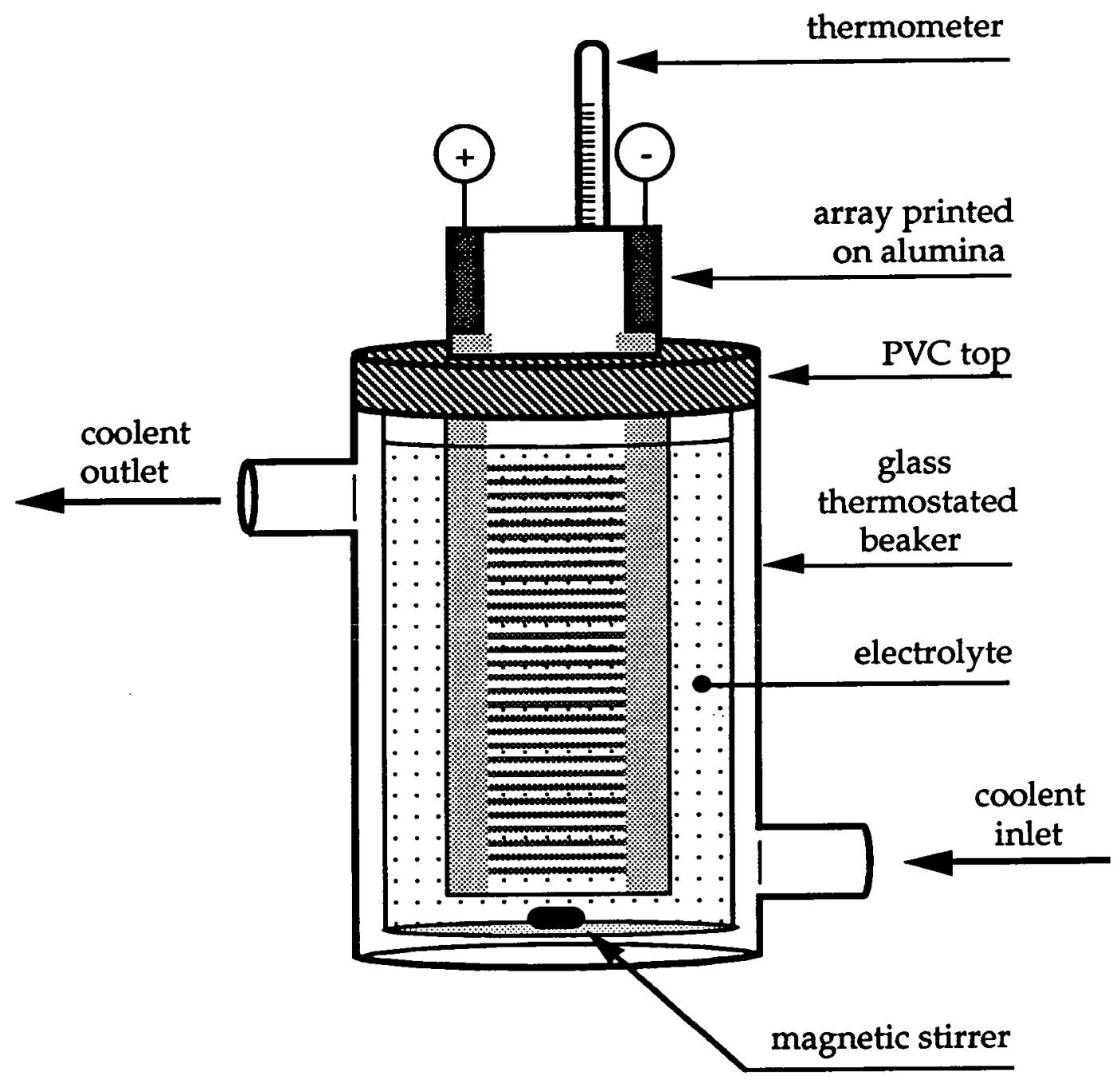

Figure 2.5: thermostated cell.

The first flow cell, only used for the furan methoxylation synthesis, was the FM01 parallel plate cell from ICI, with $160 \times 40 \mathrm{~mm}$ platinum anode and stainless steel cathode separated by a $2 \mathrm{~mm}$ spacer. The second flow cell (cell 2) was designed for smaller electrodes and had the same 
geometry as the cell shown in figure 1.2, but the number of elements was reduced since no membrane was needed. The end plates were made of aluminium, the insulating plate of PVC, and the gasket of VITON. The interelectrode channel was a $25 \times 90 \times 2 \mathrm{~mm}$ parallelogram Experiments were carried out with carbon foil, stainless steel plates or arrays printed on PVC. This cell was however unsuitable for alumina substrates, which were extremely intolerant to sheer stress. A third cell (cell 3), had thus to be designed for alumina sheets. A representation can be found in figure 2.6.

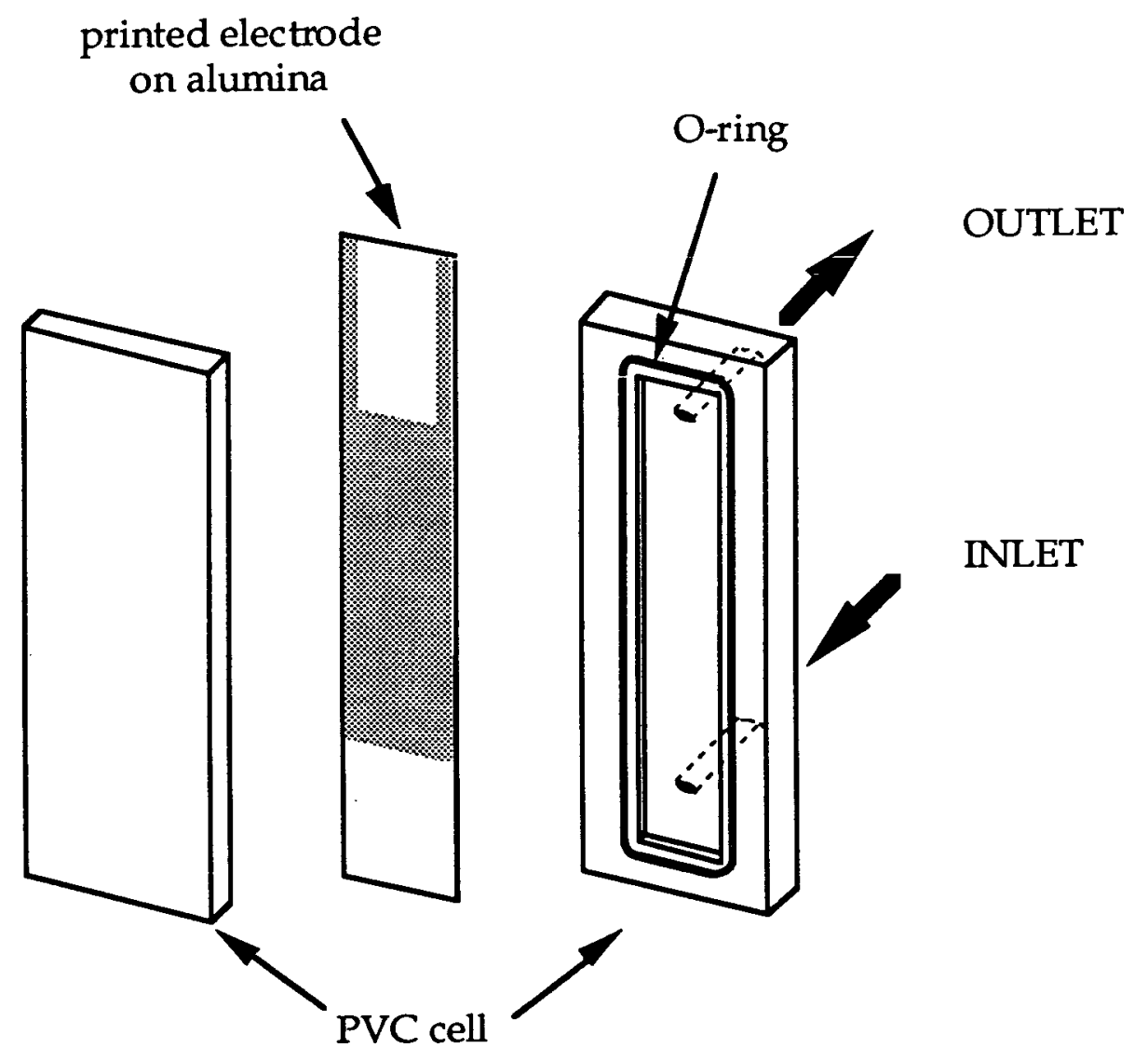

Figure 2.6: Cell 3. 
The problem of leakage was overcome by O-ring sealing. In this cell the internal channel had a cross section of $4 \times 20 \mathrm{~mm}$ and a length of $110 \mathrm{~mm}$. The flow cells were placed in a loop, where the flow was promoted by a pump (EMP40 Totton - UK) and controlled with a flowmeter (GTLK Platon - UK), as can be seen in figure 2.7.

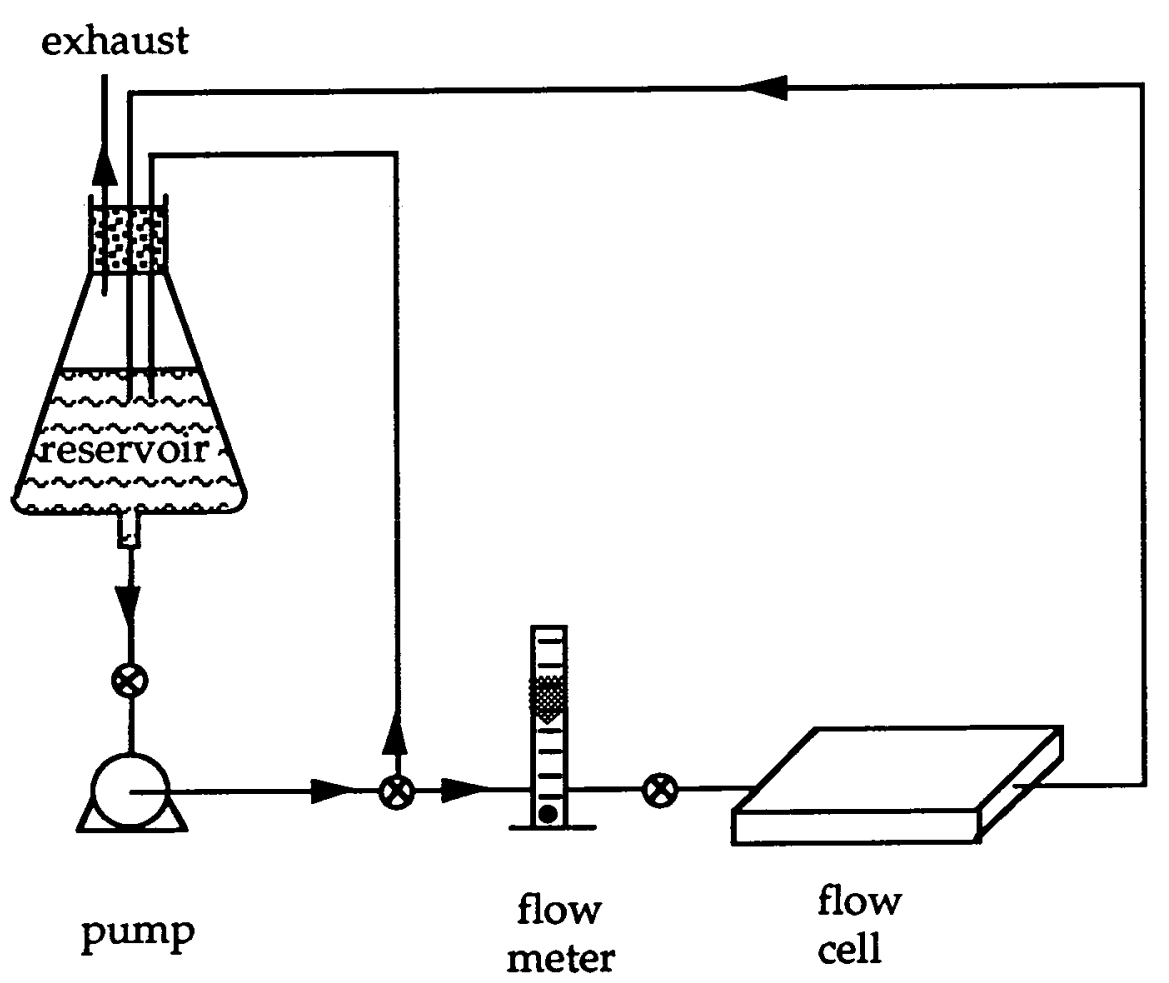

Figure 2.7: Representation of the flow loop .

\section{2-2 Electrical equipment}

\section{2-2-1 Characterisation of the electrode surface}

The printed electrode surface was characterised by means of both physical and electrochemical methods.

The electrode thicknesses were first estimated with an ordinary micrometer. The estimated values were then confirmed by Scanning 
Electron Microscopy (JEOL JSM 6300F). For the latter measurements, array slices had to be cut by microtomy in order to produce sharp angles. The evolution of the electrode porosity was studied with the same Scanning Electron Microscope. This method, however, only allowed qualitative appreciations.

Quantitative results were obtained from electrochemical experiments. This technique consisted of measuring the amount of charge necessary for the oxidation of hydrogen atoms adsorbed on the electroactive surface of the electrode. The procedure was to record cyclic voltammograms and to integrate the corresponding peaks. This was carried out on $1 \mathrm{~cm}^{2}$ printed electrodes and on a smooth electrode for comparison purposes. The electrical equipment needed was a potential ramp generator (PP RI Hi-Tek Instruments - UK), a potentiostat (home made), and an $X Y$ recorder (WX 1200 Graphtec). Eventually a combined ramp generator / potentiostat (Scanning Ministat - Sycopel Scientific Limited - UK) was utilised.

\section{2-2-2 Resistance determination}

The importance and advantage of having close electrodes was shown by measuring the interelectrode resistances. For this purpose, three silver arrays of different band gap (AG1, AG2 and AG3) were dipped in aqueous sodium chloride solutions, with concentrations varying in the range of $5 \times 10^{-3}$ to $0.15 \mathrm{M}$. The resistance between the two coplanar branches was measured with an AC Impedance Analyser (TFA2000 - Sycopel Scientific Limited - UK). The instrument included a potentiostat to control the electrode potentials and a software package for storing and processing data. All the experimental details were set via the computer keyboard. A $10 \mathrm{mV}$ signal was applied and the frequency was varied from 10000 to $1 \mathrm{~Hz}$. The total impedance was continuously measured and recorded 
together with the phase angle. From the stored data, the real and the imaginary parts of the impedance could be calculated, and graphs, such as the Nyquist plot could be produced. The resistances measured varied from 2 to $50 \Omega$; and in this range the accuracy is of the order of $1 \%$. Simulation programs were written with the C700 software for windows and performed on a PC 6486 SX Amstrad.

\section{2-2-3 Electrosynthesis}

Electrolyses were always preceded by preliminary electrochemical studies of the different systems. The equipment needed was a waveform generator, a potentiostat and an $X Y$ recorder, similar to the experiments for electroactive area determination.

In an electrolysis process, the electrode potential had to be set at a given value. The differential potential was applied with a PL320 QMD Thurlby power generator (UK), which had an output of up to $30 \mathrm{~V}$ for $2 \mathrm{~A}$. This also recorded the value of the current passing through the cell, but for better accuracy the amount of electricity was recorded with a IG5N Tacussel integrator. A home made potential reverser was also introduced in the electrical circuit to switch the two coplanar electrode potentials every two minutes. In some cases, the cell temperatures had to be regulated. A thermostated water bath (Julabo F10) allowed temperature control between 0 and $20^{\circ} \mathrm{C}$.

The electrolyte composition was monitored by gas chromatography. An HP 5890 gas chromatograph was equipped with an FID detector and a 20 metre semi-capillary column (530 $\mu \mathrm{m}$ internal diameter), filled with Carbowax $20 \mathrm{M}$. All the analyses of interest could be carried out with this polar column. The injection volume was set at $0.5 \mu l$. The injector and the detector temperatures were set at 200 and $250^{\circ} \mathrm{C}$ respectively, whereas 
the oven temperature was programmed and the values employed can be found in the relevant chapters. The chromatograph was also equipped with a software package, which allowed simple interpretation of the recorded chromatograms, as the concentration of the compounds present in the mixture could directly be obtained from calibration curves stored in the computer memory. The chromatograms could also be stored for further analyses. For the last reaction investigated, hypochlorite concentration was determined by iodometry.

Finally a Knick digital pH-meter was used with an Ingold electrode for acidity measurements. 


\section{CHAPTER 3}

Physical properties

\section{3-1 Investigation of the effect of flow on the limiting current}

The importance of optimising the limiting current in an electrochemical process has already been demonstrated in a previous chapter, and in equation (1.9), it was shown that this limiting current density was proportional to the mass transfer coefficient $k_{m}$. The value of the mass transfer coefficient is characteristic of a cell and also on the hydrodynamic conditions. It is determined here for two parallel plate electrodes and for an interdigitated array.

3-1-1 Determination of the mass transfer coefficient in a parallel plate cell The mass transfer coefficients of a parallel plate cell (cell 2) can be determined from the limiting current for the reduction of ferricyanide, at a concentration of $10 \mathrm{mM}$. Linear sweep voltammograms were recorded for different flow regimes, with two parallel stainless steel plates of $25 \mathrm{~cm}^{2}$ area, and these can be found in figure 3.1. The current values and the calculated mass transfer coefficients are reported in table 3.1. For example at $1.1 \mathrm{dm}^{3} \cdot \mathrm{min}^{-1}$, the limiting current is $30 \mathrm{~mA}$ and from equation (1.9):

$$
\mathrm{k}_{\mathrm{m}}=\frac{-i_{\lim }}{n F A c}=\frac{30 \cdot 10^{-3}}{96500 \times 25 \cdot 10^{-4} \times 10}=1.24 \times 10^{-5} \mathrm{~m} \cdot \mathrm{sec}^{-1}
$$

Where $\mathrm{A}$, the electrode area, is expressed in $\mathrm{m}^{2}$ and $\mathrm{c}$, the ferricyanide concentration, in mol.m $\mathrm{m}^{-3}$. 


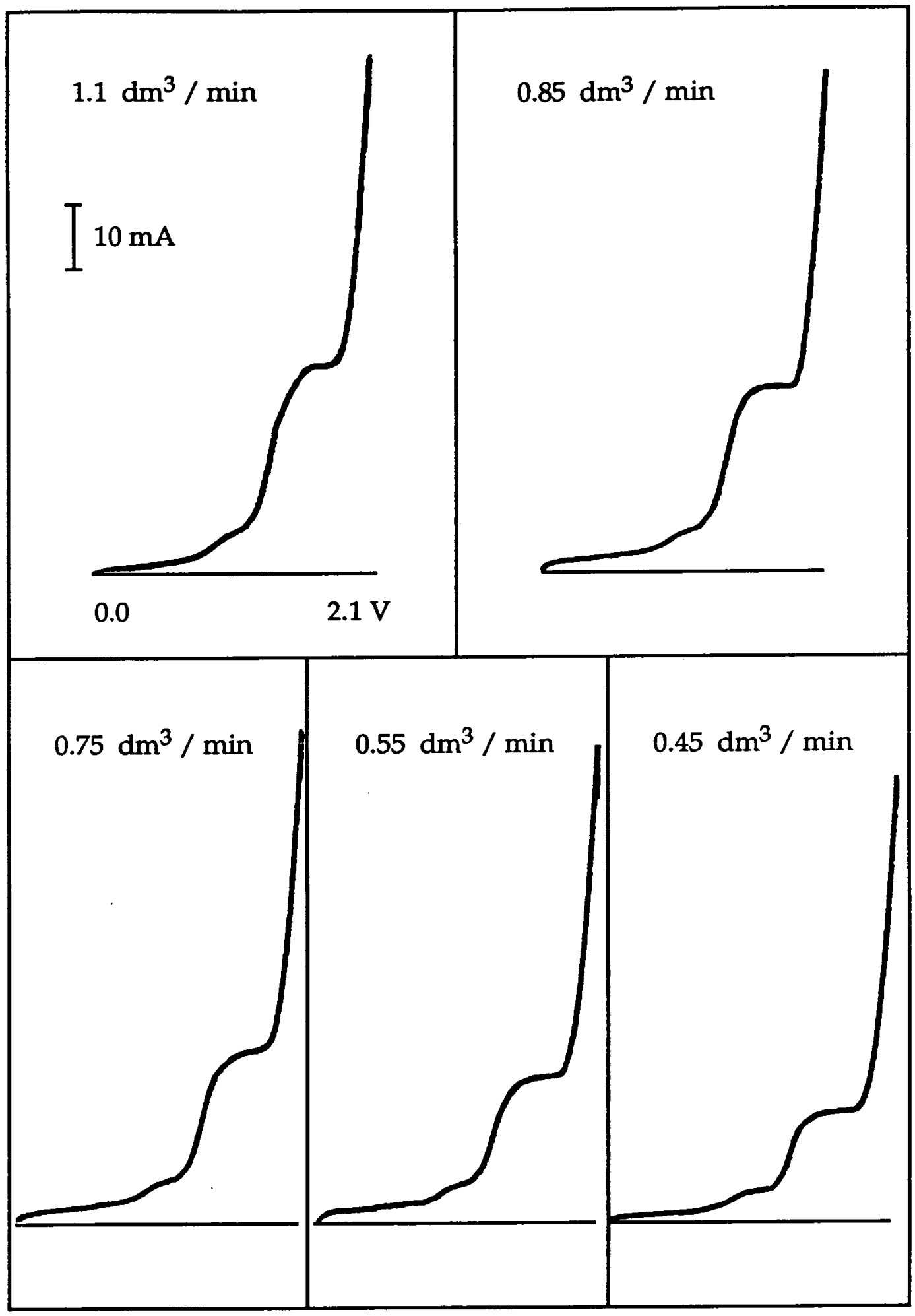

Figure 3.1: Voltammograms of ferricyanide $(10 \mathrm{mM})$ in aqueous solution with $\mathrm{KOH}(0.1 \mathrm{M})$ supporting electrolyte, recorded with two stainless steel plate electrodes in cell 2. Sweep rate $=10 \mathrm{mV}$. sec-1. 
Table 3.1: Limiting current and mass transfer values for two parallel plate electrodes in cell 2.

\begin{tabular}{ccc}
\hline flow $/ \mathbf{d m}^{3} \cdot \mathbf{m i n}^{-1}$ & $\mathbf{i}_{\mathbf{l i m}} / \mathbf{m A}$ & $\mathbf{k}_{\mathbf{m}} / \mathbf{m} \cdot \mathbf{s e c}^{-1}$ \\
\hline 1.1 & 30 & $1.24 \cdot 10^{-5}$ \\
0.85 & 25 & $1.02 \cdot 10^{-5}$ \\
0.75 & 22 & $0.90 \cdot 10^{-5}$ \\
0.55 & 16 & $0.70 \cdot 10^{-5}$ \\
0.45 & 14 & $0.57 .10^{-5}$ \\
\hline
\end{tabular}

In chapter 1 , it was shown that the mass transfer is also correlated to the Sherwood number, and therefore to the Reynolds number, the Schmidt number and the Grashof number (equations (1.8) and (1.9)). The following expression can thus be derived for the mass transfer coefficient under conditions of forced convection:

$$
k_{m}=\operatorname{Sh} \frac{D}{L}=\frac{D}{L} a\left(\frac{\bar{v} L}{\gamma}\right)^{b}\left(\frac{\gamma}{D}\right)^{c}
$$

From all these parameters, only the mean flow velocity, $\bar{v}$, is dependent on the flow rate (flow $=\overline{\mathbf{v}}$. cell cross section). This expression can thus be simplified to emphasise the mass transfer and flow rate dependence:

$$
\ln \left(k_{m}\right)=k_{0}+b \ln (\text { flow })
$$

A logarithmic plot of the experimental mass transfer values with respect to the flow rate values confirms this linear relationship, as can be seen in figure 3.2 . 


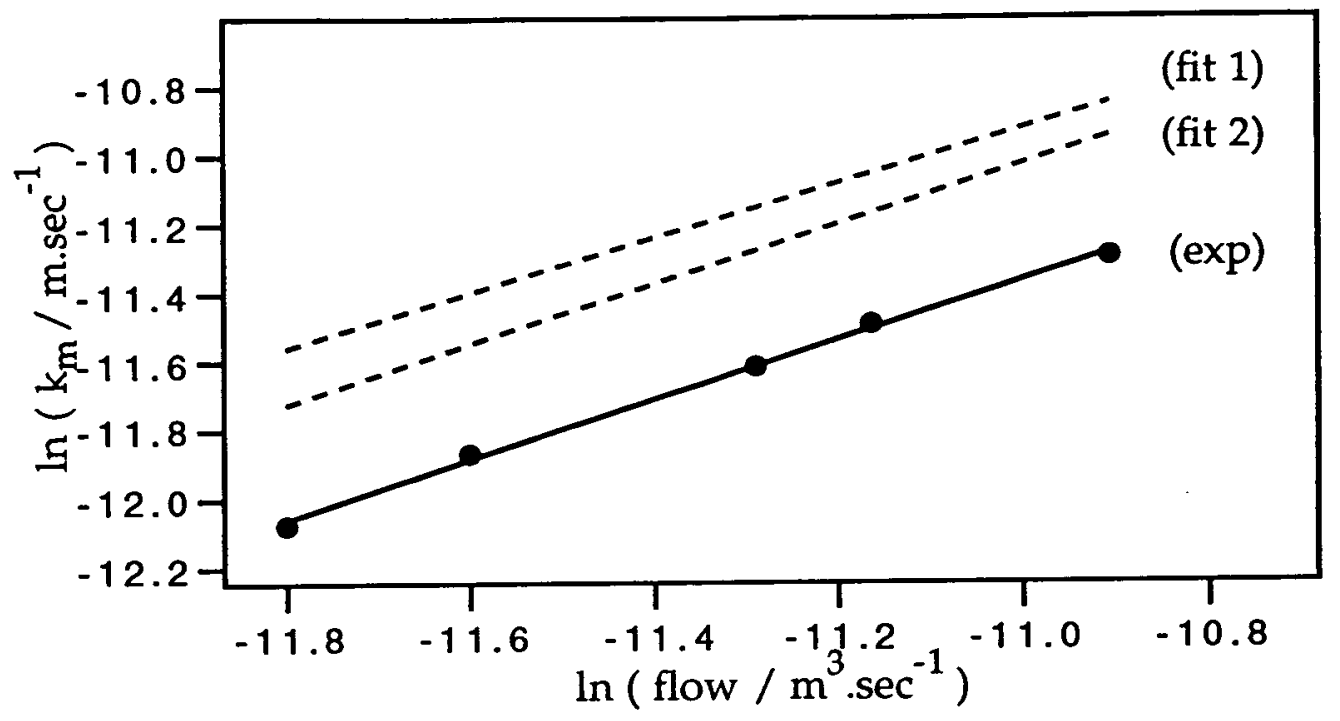

Figure 3.2: Variation of the mass transfer with the flowrate in a logarithmic scale for two parallel plate electrodes in flow cell 2: from experimental data (exp), from equation (3.7) (fit 1), and from equation (3.8) (fit 2).

The determination of $k_{0}$ and $b$ from the slope and the intercept of the straight line give the following equation:

$$
\ln \left(k_{m}\right)=-1.85+0.865 \ln (\text { flow })
$$

The validity of equation (3.2) was also verified for other parallel plate cells in turbulent regimes. The expressions developed by F. Cœuret and A. Storck [17] and by D. J. Pickett and B. Stanmore [27] are given by equation (3.5) and (3.6) respectively:

$$
\begin{aligned}
& \mathrm{Sh}=0.023 \cdot \operatorname{Re}^{0.8} \cdot \mathrm{Sc}^{0.33} \\
& \mathrm{Sh}=0.0278 \cdot \operatorname{Re}^{0.873} \cdot \mathrm{Sc}^{0.21}
\end{aligned}
$$


The two equations, (3.7) and (3.8), can be derived respectively from these expressions in order to relate the mass transfer as a function of flowrate. For the dimensions of cell 2, they correspond to:

$$
\begin{aligned}
& \ln \left(k_{m}\right)=-1.83+0.8 \ln (\text { flow }) \\
& \ln \left(k_{m}\right)=-1.00+0.875 \ln (\text { flow })
\end{aligned}
$$

For $k_{m}$ expressed in $\mathrm{m} \cdot \mathrm{sec}^{-1}$, flow in $\mathrm{m}^{3} \cdot \mathrm{sec}^{-1}$ and with $\mathrm{D}=10^{-9} \mathrm{~m}^{2} \cdot \mathrm{sec}^{-1}$, $\mathrm{v}=0.544 .10^{-6} \mathrm{~m}^{2} \cdot \mathrm{sec}^{-1}$ and $\mathrm{L}=4 \times \frac{\text { cross section }}{\text { cross section perimeter }}=3.7 .10^{-3} \mathrm{~m}$.

Equations (3.7) and (3.8) are also reported in figure 3.2. These two models are given for turbulent regimes, which is however, not the case for our experimental points $(\operatorname{Re}<1400)$. This explains why the theoretical models yield greater mass transfer coefficients than those measured. Differences in cell dimensions and errors made in the estimation of $\mathrm{D}$ and $v$ can also have a small influence. The values obtained for $b$ are, however, very comparable.

\section{3-1-2 Determination of the mass transfer coefficient with band arrays}

Similarly, the mass transfer coefficients can be determined for an interdigitated array (array CAGCL) placed in flow cell 2 (WE: carbon bands, $\mathrm{RE}$ : $\mathrm{Ag} / \mathrm{AgCl}$ bands, $\mathrm{SE}$ : stainless steel plate). Linear sweep voltammograms, recorded for ferrocenecarboxylic acid $(1 \mathrm{mM})$ with $\mathrm{NaCl}$ $(0.1 \mathrm{M})$ in $0.1 \mathrm{M}$ aqueous phosphate buffer, also show a dependence with the flow rate, as can be seen in figure 3.3. An analogy with rotating electrodes can be made, as steady state currents can be obtained, even at high potential sweep rates, by forcing the electrolyte to flow over the electrode. 


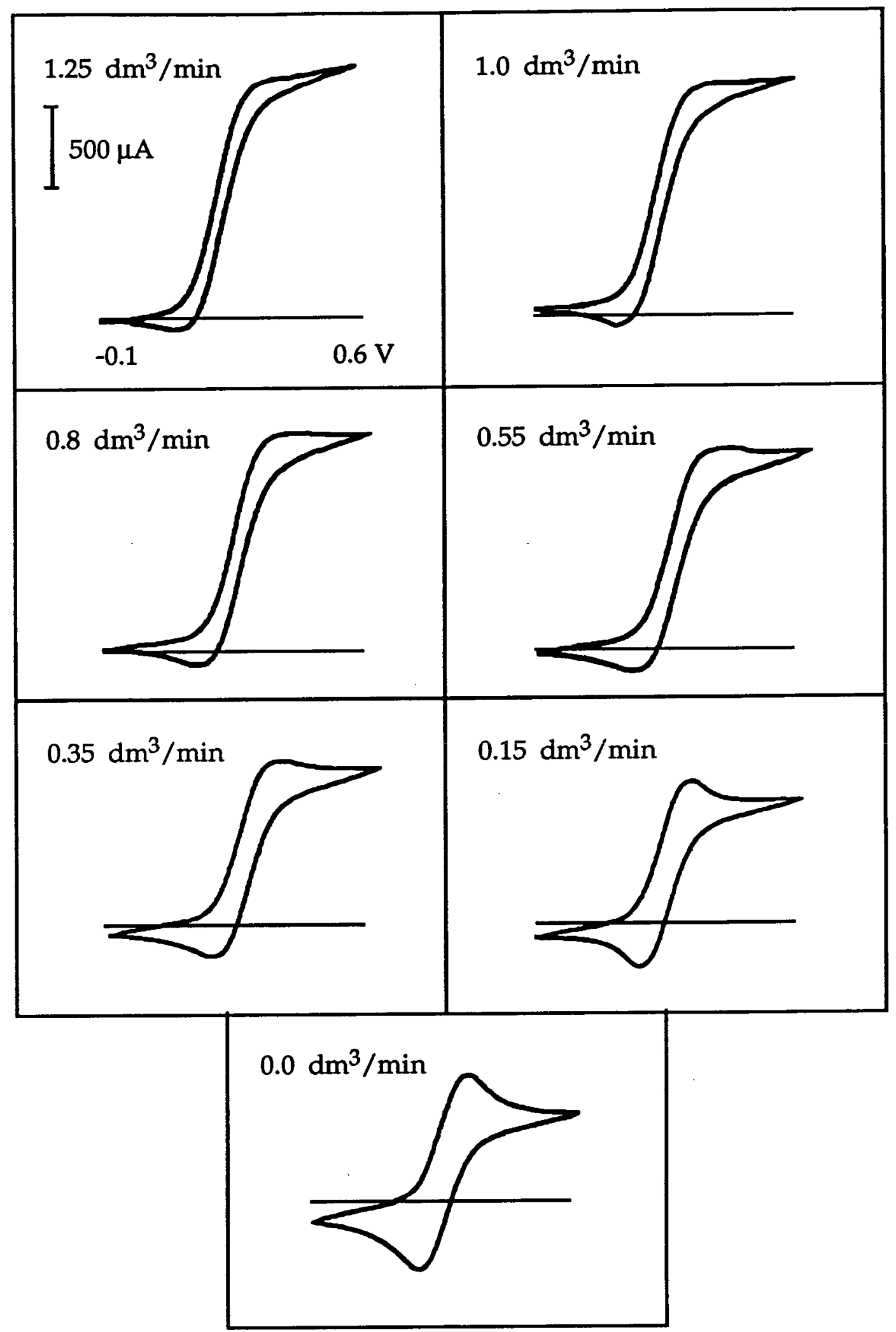

Figure 3.3: Cyclic voltammograms of ferrocenecarboxylic acid (1 $\mathrm{mM}$ ) in aqueous phosphate buffer $(0.1 \mathrm{M})$ with $\mathrm{NaCl}(0.1 \mathrm{M})$ recorded with array CAGCL in cell 2. WE: carbon bands, SE: stainless Steel plate, $\mathrm{RE}: \mathrm{AgCl}$ bands. Sweep rate $=100 \mathrm{mV} \cdot \mathrm{sec}^{-1}$. 
The mass transfer coefficients, calculated from the limiting currents, are shown in table 3.2 .

Table 3.2: Limiting current and mass transfer values for array CAGCL in cell 2.

\begin{tabular}{ccc}
\hline flow $/ \mathbf{d m}^{\mathbf{3}} \cdot \mathbf{m i n}^{-1}$ & $\mathbf{I}_{\mathbf{l i m}} / \mathbf{m A}$ & $\mathbf{k}_{\mathbf{m}} / \mathbf{m}_{\mathbf{s e c}} \mathbf{- 1}$ \\
\hline 1.25 & 1.50 & $3.11 \cdot 10^{-5}$ \\
1.0 & 1.44 & $2.98 \cdot 10^{-5}$ \\
0.8 & 1.33 & $2.76 \cdot 10^{-5}$ \\
0.55 & 1.18 & $2.44 \cdot 10^{-5}$ \\
0.35 & 0.99 & $2.05 \cdot 10^{-5}$ \\
0.15 & 0.77 & $1.59 \cdot 10^{-5}$ \\
0 & 0.54 & $1.12 \cdot 10^{-5}$ \\
\hline
\end{tabular}

Again linearity is observed when the mass transfer coefficients and the flow rates are plotted on a logarithmic scale, as shown in figure 3.4, and the determination of parameters $k_{0}$ and $b$ gives:

$$
\ln \left(k_{m}\right)=-6.87+0.326 \ln (\text { flow })
$$

The mass transfer coefficients obtained with the same cell but with the two parallel plate electrodes are also reported in figure 3.4. Comparison of the two sets of data shows that for the flow regimes investigated, mass transfer is significantly more efficient with the interdigitated array than with the parallel plate electrodes. This is explained by an enhanced mass transport. 


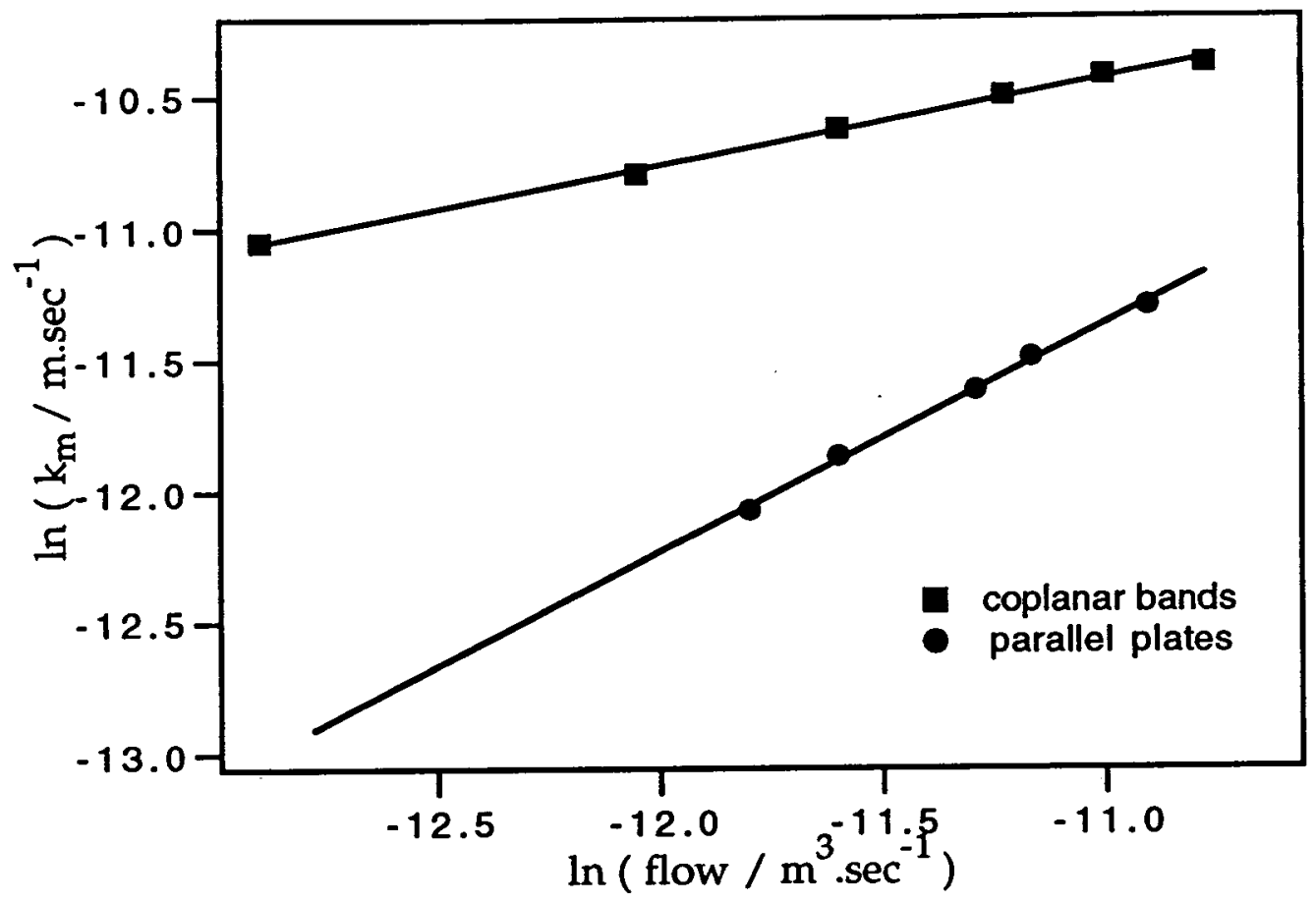

Figure 3.4: Variation of the mass transfers with the flow rate in a logarithmic scale for two parallel plate electrodes and for array CAGCL in flow cell 2.

Furthermore, it can be noted that $b$ is lower for coplanar band electrodes. The mass transfer, with an interdigitated array, is therefore less dependent on the flow rate, than with two parallel plate electrodes. Interdigitated arrays could provide good current efficiency, even in a tank reactor, resulting in a considerable gain in cell conception and energy.

Similar results are obtained for the platinum interdigitated arrays, placed in flow cell 3. Figure 3.5 shows cyclic voltammograms recorded with PT2, one electrode connected to the working electrode terminal and the other connected to the reference and counter terminals of a potentiostat. It can be noticed that for quiescent solutions and low potential sweep rates, a 


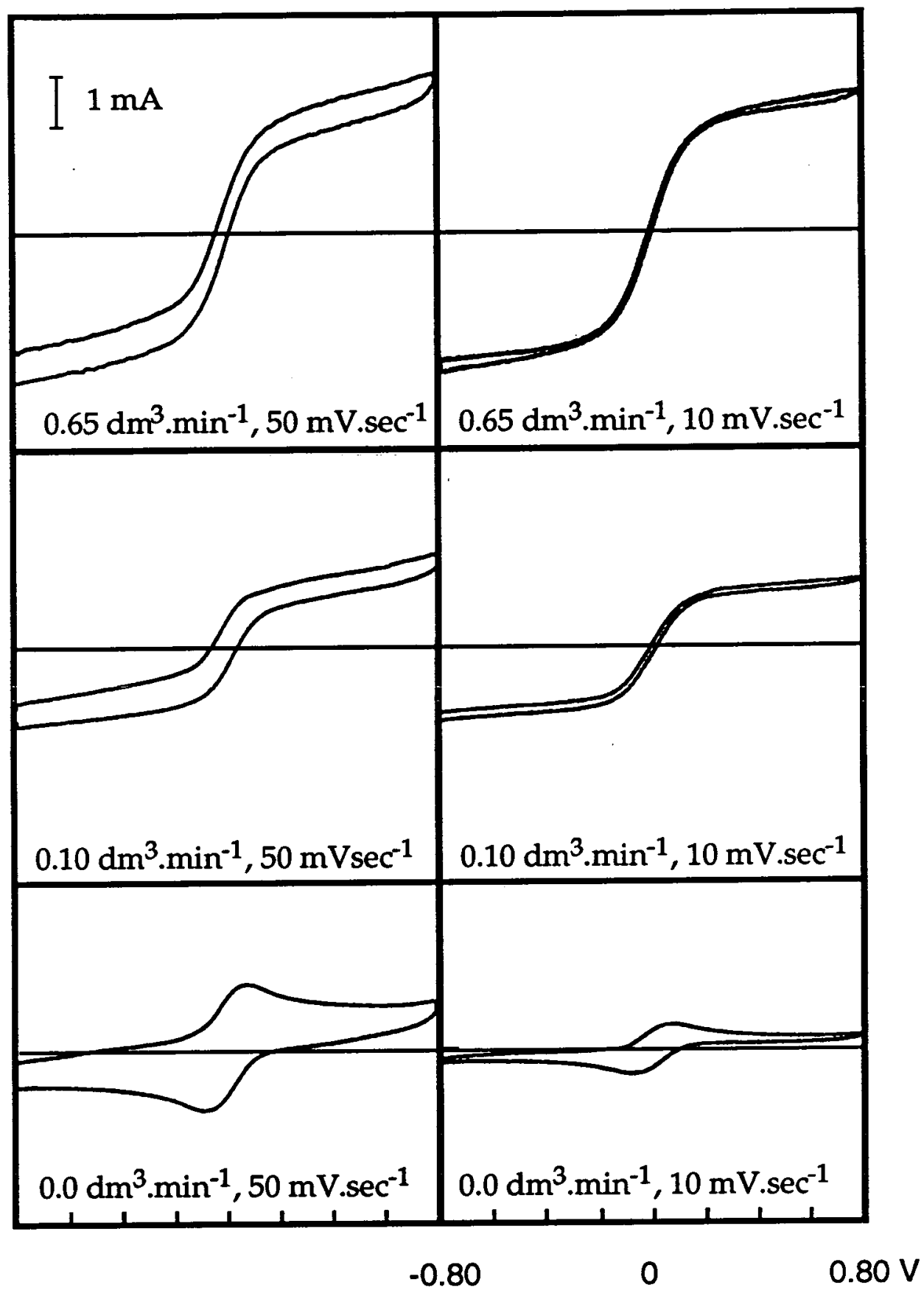

Figure 3.5: Cyclic voltammograms recorded with PT2 in $1 \mathrm{mM}$ potassium ferricyanide and $1 \mathrm{mM}$ potassium ferrocyanide in $0.1 \mathrm{M} \mathrm{NaCl}$ aqueous solution. 
steady state current is obtained. Models for such systems have been developed by K. Aoki [28] and B. Seddon [29, 30]. The respective analytical equations are:

$\mathrm{i}=\left(\mathrm{n}_{\mathrm{b}}-1\right) \mathrm{nFDC} \mathrm{l}_{\mathrm{b}} 0.637 \ln \left(2.55\left(\mathrm{~W}_{\mathrm{e}} / \mathrm{W}_{\mathrm{g}}+1\right)-\frac{0.19}{\left(\mathrm{~W}_{\mathrm{e}} / \mathrm{W}_{\mathrm{g}}+1\right)^{2}}\right)$

$\mathrm{i}=\left(\mathrm{n}_{\mathrm{b}}-1\right) \mathrm{nFDcl}_{\mathrm{b}} 0.637 \cosh ^{-1}\left(\mathrm{~W}_{\mathrm{e}} / \mathrm{W}_{\mathrm{g}}+1\right)$

From these equations, the limiting currents would be 0.1 and $0.085 \mathrm{~mA}$, which is in good agreement with the $0.1 \mathrm{~mA}$ obtained experimentally.

A logarithmic plot of the mass transfer coefficients vs. the flowrate is shown in figure 3.6, and compared with the data calculated from equations (3.5) and (3.6), for parallel plate electrodes placed in the same cell.

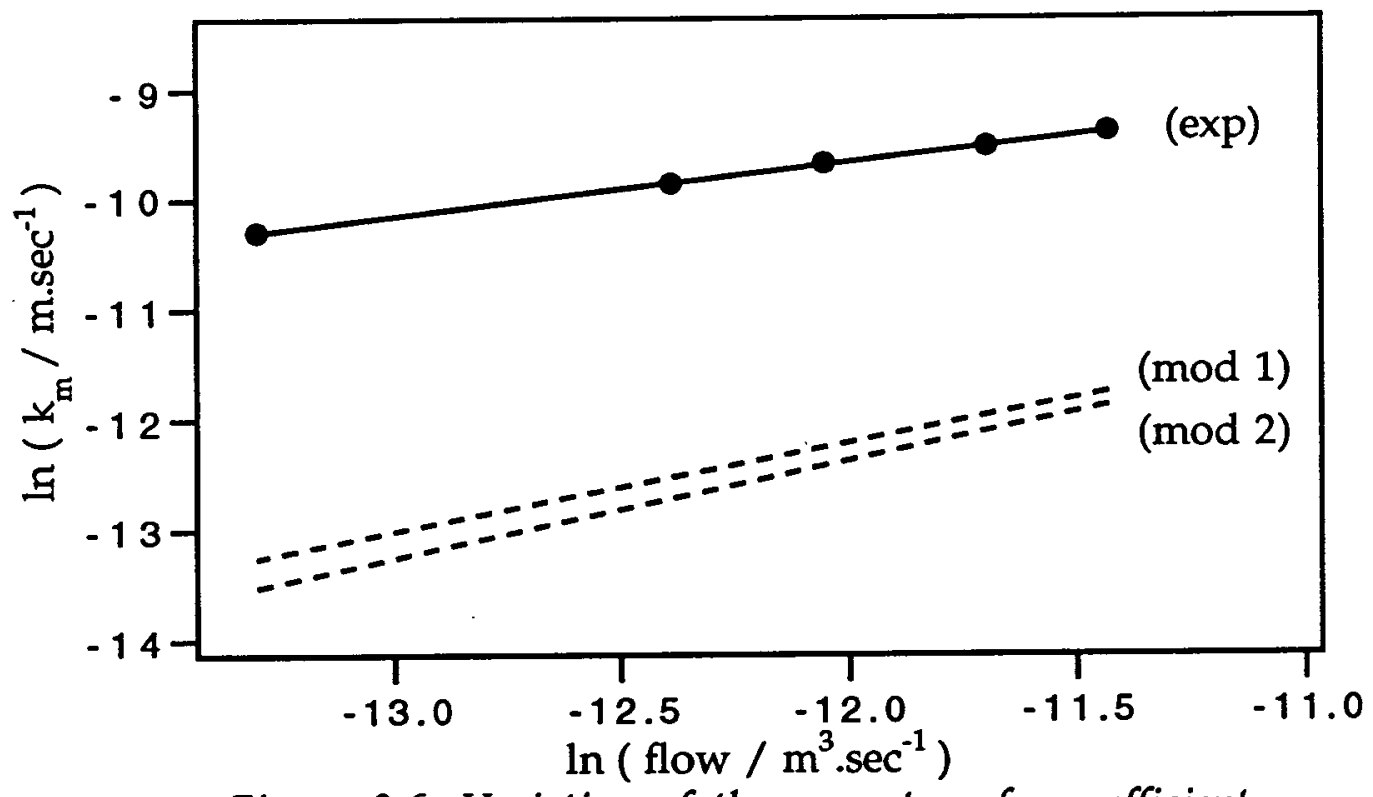

Figure 3.6: Variation of the mass transfer coefficient with the flowrate in a logarithmic scale for PT2 (exp) and two parallel plate electrodes $(\bmod 1)$ and $(\bmod 2)$.

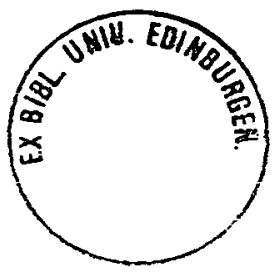


In the case of the platinum interdigitated array PT2, the value of $k_{0}$ and $b$ are -3.89 and 0.48 respectively, and the mass transfer is found to be considerably improved by using this configuration rather than two parallel plate electrodes. Furthermore the flow between two parallel plate electrodes needs to exceed $0.6 \mathrm{dm}^{3} \cdot \mathrm{min}^{-1}$, before the mass transfer becomes equivalent to the mass transfer with PT2, in a tank reactor. Finally, experiments carried out with platinum arrays PT1 and PT3, show that no significant difference is observed in the mass transfer coefficients when the inter-electrode distance is varied from $1 \mathrm{~mm}$ to $250 \mu \mathrm{m}$, especially at high flowrates. This is illustrated by figure 3.7 .

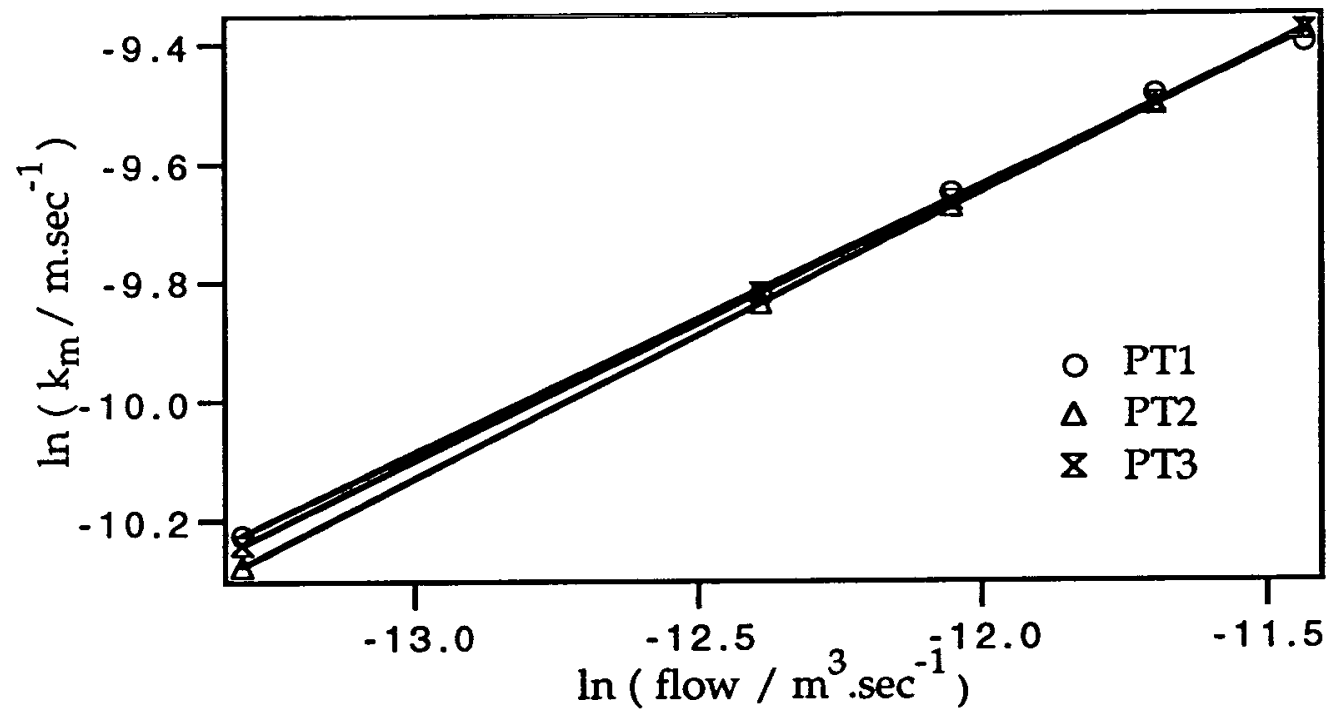

Figure 3.7: Variation of the mass transfer coefficient with the flowrate on a logarithmic scale for PT1, PT2 and PT3. 


\section{3-2 Characterisation of the printed platinum electrode}

To gain a good understanding of the interdigitated array behaviour, a complete characterisation of the electrode is necessary. The thickness and porosity are two parameters to be determined.

\section{3-2-1 Determination of the electrode thicknesses}

The simplest method available for the determination of the printed electrode thickness consists of measuring the thickness with a micrometer. The difference between the bare and the printed substrate thicknesses corresponds to the thickness of the thick film. Although this method would not appear to be very accurate, it can be used for any sample without any prior preparation. The thickness of the printed films depends on the material and is found to vary from one electrode to another, within a range of $4 \mu \mathrm{m}$. The average of the thickness for thick films is $25 \mu \mathrm{m}$ for the silver electrodes and $14 \mu \mathrm{m}$ for the platinum electrodes.

Scanning Electron Microscopy is another method available for these measurements, where samples require preparation, as they need to be sliced. This is possible for silver electrodes printed on PVC substrates, as microtomy allows the electrode and its support to be cut at a sharp angle. The thickness value and variation are in accordance with the previous data. However, the thickness of the platinum film can not be determined as the edge of the electrode is destroyed in the cutting process.

\section{3-2-2 Evolution of the printed electrode surface}

The porosity of the electrode is an important characteristic in the description of an electrode. It can interfere in the rate of an electrochemical process and can vary within the electrode life-time. 
Scanning Electron Microscopy constitutes a qualitative method for the porosity characterisation. Quantitative data can be obtained by electrochemical means.

\section{3-2-2-1 Surface characterisation by Scanning Electron Microscopy}

The porosity evolution of the electrodes was investigated by analysing two printed platinum electrodes: before use (Pt t0), and after 100 hours electrolysis $(\mathrm{Pt} t 1)$. Their scanning electron micrographs are shown in figures 3.8 and 3.9 , for two different magnifications. A net change in the surface can be observed. Before use, the electrode surface is very rough. Platinum on the surface can be found as nano particles or as large agglomerates. After 100 hours electrolysis, the electrode appears to have been electropolished, as the surface is flatter and more homogeneous.The general aspect of the used platinum electrode, however, is still very different from that of a flat metal.

3-2-2-2 Surface characterisation by electrochemical means

Cyclic voltammetry is a technique widely used for metal surface characterisation [31, 32]. Platinum shows typical adsorption and desorption peaks when its potential is swept reversibly between 0 and $1.55 \mathrm{~V}$ vs. NHE. The cyclic voltammogram of a $2.80 \mathrm{~mm}$ diameter, smooth polycrystalline platinum electrode is shown in figure 3.10. Peaks are observed as a result of hydrogen and oxygen adsorption on the surface. Strongly and weakly adsorbed hydrogen is oxidised between 0 and $0.4 \mathrm{~V}$. The platinum surface is then bare. An oxide layer is formed between 0.8 and $1.5 \mathrm{~V}$ prior to oxygen evolution. On the reverse sweep the oxide is reduced at $0.7 \mathrm{~V}$ and the platinum surface is again bare until $0.4 \mathrm{~V}$, where the two types of hydrogen start to adsorb. 


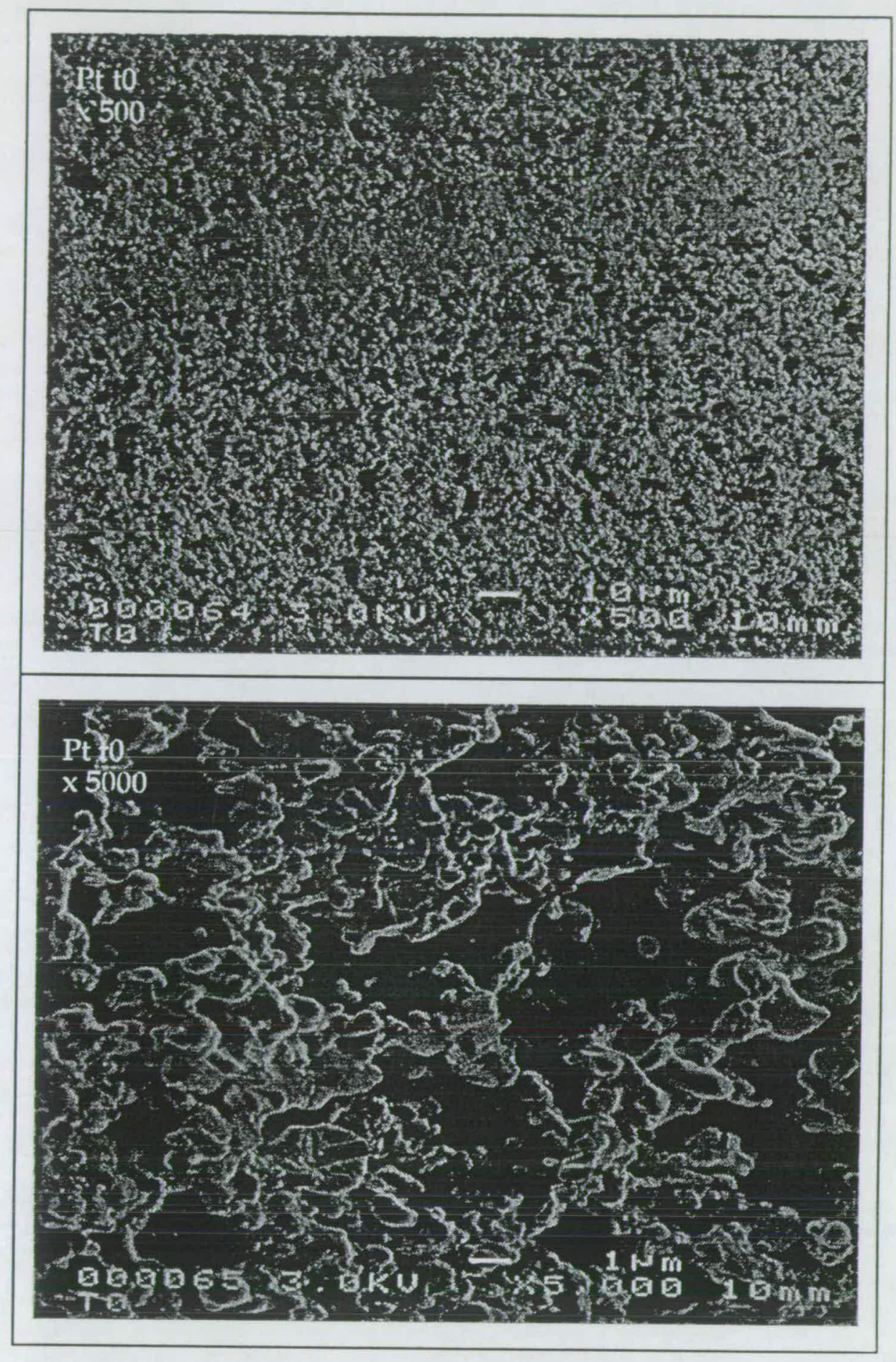

Figure 3.8: Scanning Electron Micrographs of a printed platinum electrode before use. 


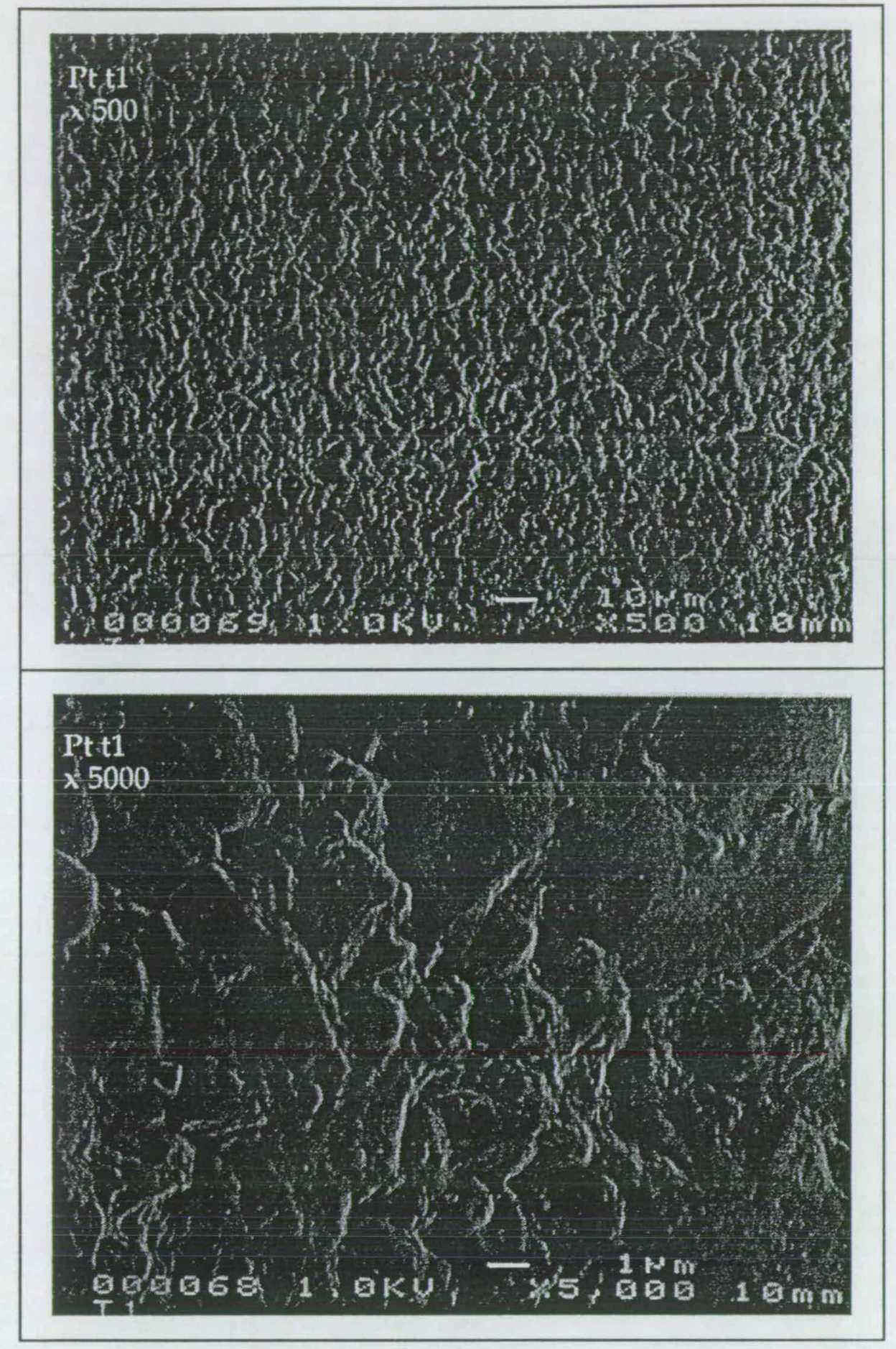

Figure 3.9: Scanning Electron Micrographs of a printed platinum electrode after 100 hours of electrosynthesis. 


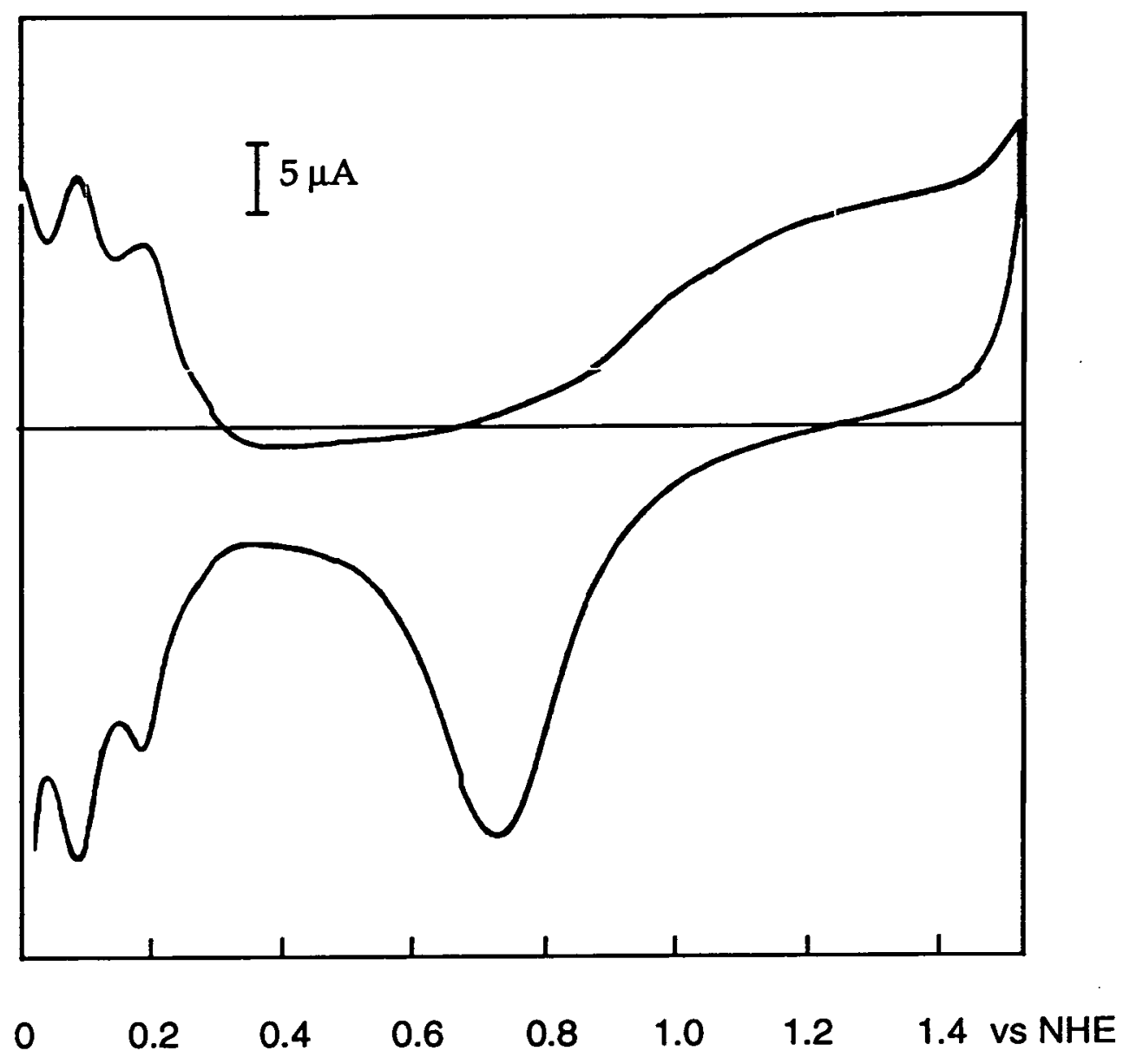

Figure 3.10: Cyclic voltammogram of a smooth polycrystalline platinum electrode in an aqueous solution of $\mathrm{H}_{2} \mathrm{SO}_{4}$, recorded with a calomel reference electrode and a platinum counter electrode at $100 \mathrm{mV} . \mathrm{sec}^{-1}$.

Assuming a monolayer coverage of adsorbed hydrogen, the areas of the desorption peaks correspond to the number of active sites on the electrode surface. The number of electroactive sites, for an ideally flat polycrystalline platinum electrode, can be estimated from the number of platinum atoms present at the surface. As can be seen in figure 3.11, platinum crystallises in a cubic close packed structure, and can take 
different forms of orientation: (100), (110) or (111). The number of charges per unit area varies with the orientation of the exposed face. For example, in the (100) form, 2 platinum atoms are present in an area of $15.35 \times 10^{-20} \mathrm{~m}^{2}$, the number of charges is thus $210 \mu \mathrm{C} . \mathrm{cm}^{2}$. For the (110) and the (111) oriented forms, the number of charges are 150 and $210 \mu \mathrm{C} . \mathrm{cm}^{2}$ respectively. The number of charges associated with a polycrystalline platinum electrode is calculated by averaging this value and can be estimated to $190 \mu \mathrm{C} . \mathrm{cm}^{2}$.

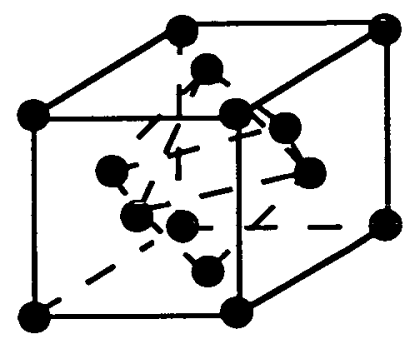

cubic close packed platinum crystal

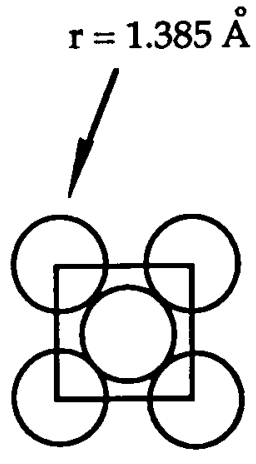

(100)

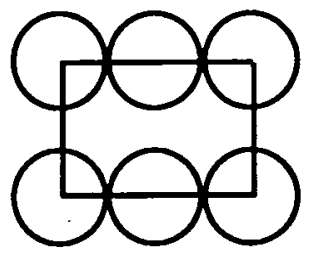

(110)

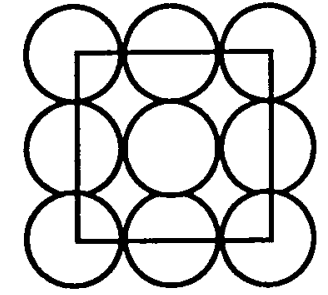

(111)

Figure 3.11: platinum crystal and its different faces. 
The electroactive area of an electrode is determined from the adsorbed hydrogen oxidation peak areas. A roughness factor is then derived by comparing the electroactive area and the real area of the electrode. For the smooth platinum electrode, the integration of the adsorbed hydrogen oxidation peaks gives a charge of $690 \mu \mathrm{C} . \mathrm{cm}^{-2}$, the roughness factor is thus 4.

Similarly, a printed platinum electrode of $1 \mathrm{~cm}^{2}$ was analysed before and after 100 hours electrolysis. Cyclic voltammograms are given in figures 3.12 and 3.13 .

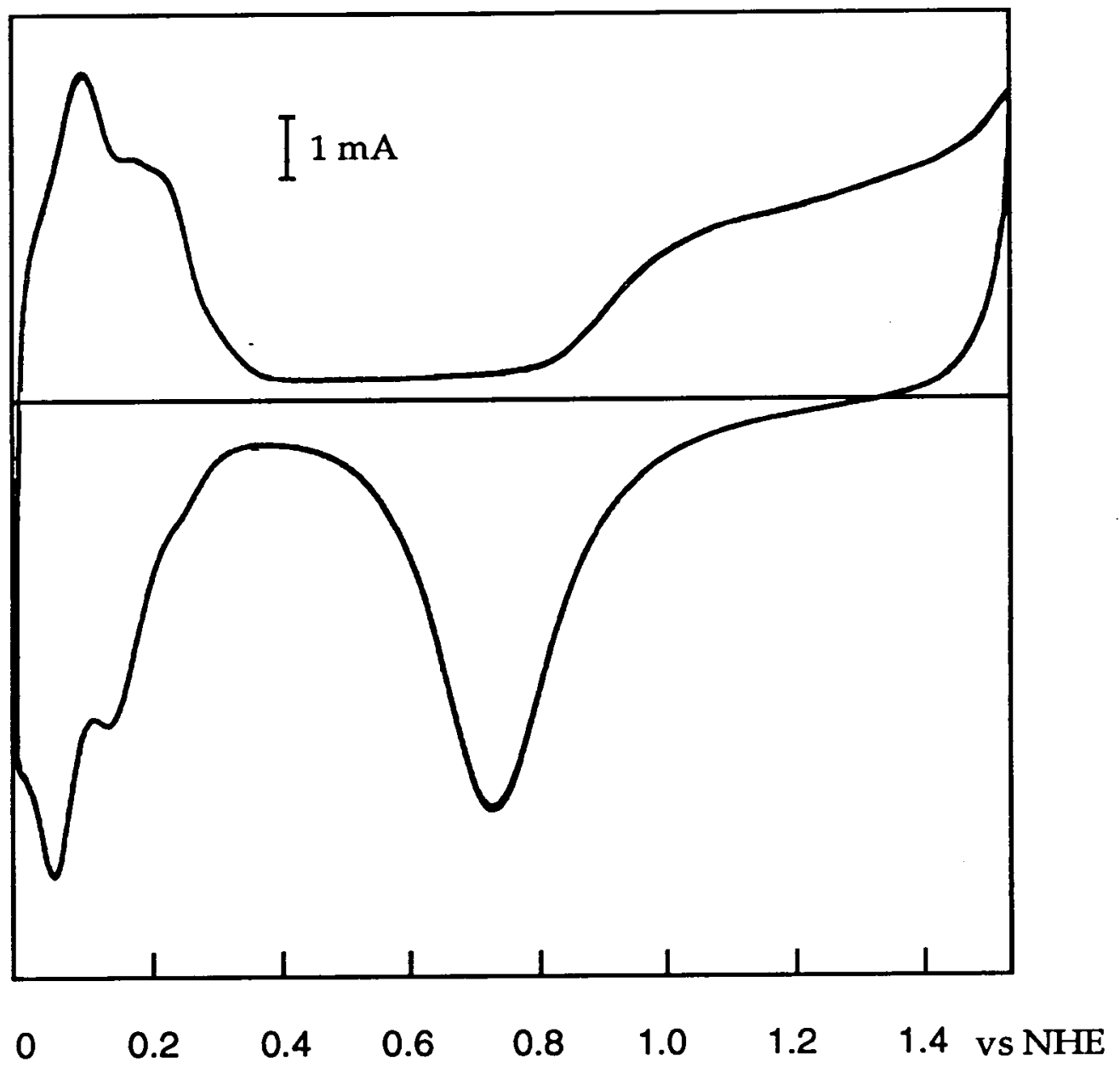

Figure 3.12: Cyclic voltammogram of a $1 \mathrm{~cm}^{2}$ freshly printed platinum electrode in an aqueous solution of $\mathrm{H}_{2} \mathrm{SO}_{4}$, recorded with a calomel reference electrode and a platinum counter electrode at $100 \mathrm{mV} . \mathrm{sec}^{-1}$. 


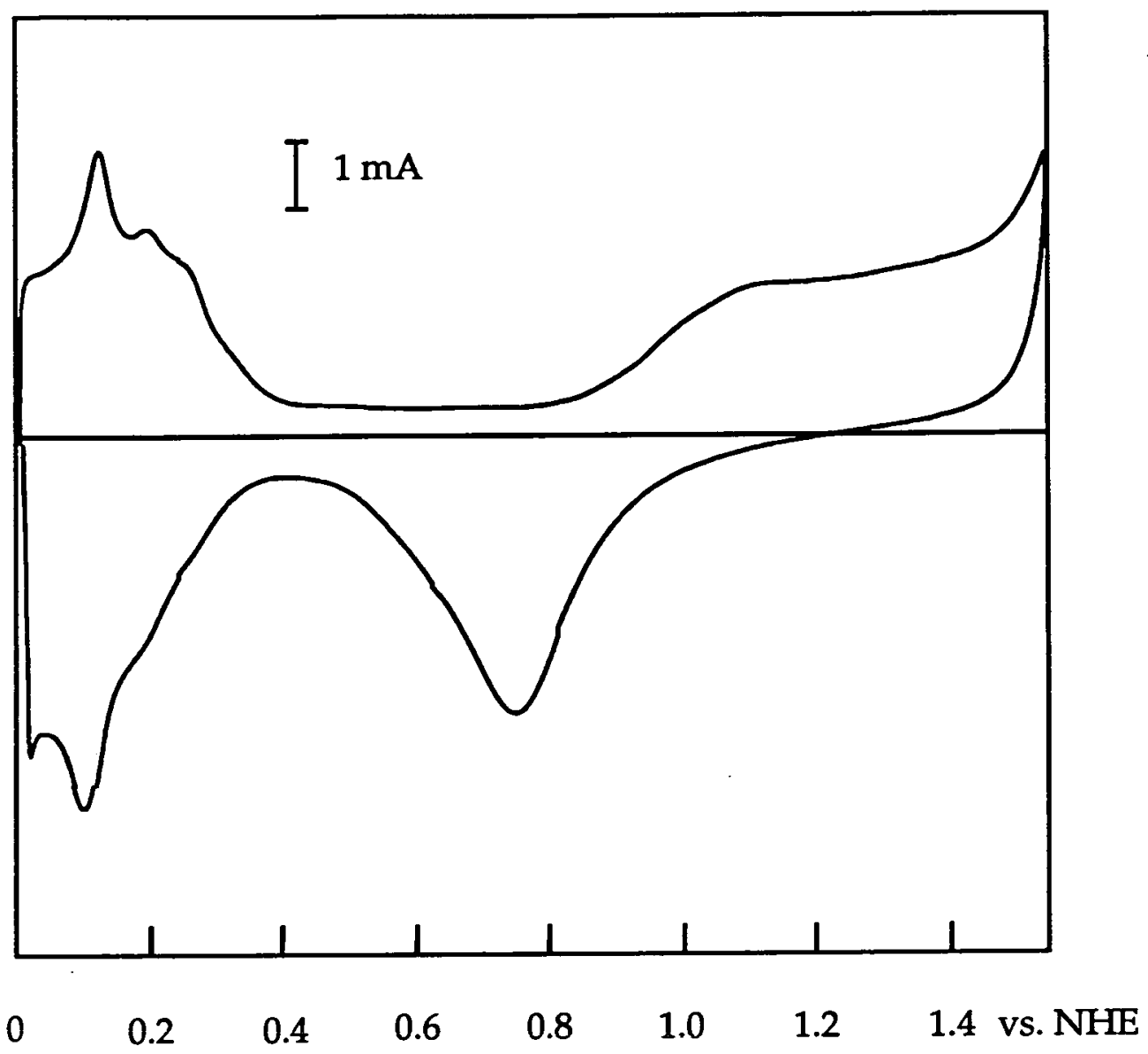

Figure 3.13: Cyclic voltammogram of a $1 \mathrm{~cm}^{2}$ printed platinum electrode after 100 hours electrolysis in an aqueous solution of $\mathrm{H}_{2} \mathrm{SO}_{4}$, recorded with a calomel reference electrode and a platinum counter electrode at $100 \mathrm{mV} \cdot \mathrm{sec}^{-1}$.

Although hydrogen tends to form weaker bonds, the general behaviour of the printed electrodes is very similar to a smooth platinum electrode. However, the oxidation of the adsorbed hydrogen atoms gives rise to a much larger current. The integration of the corresponding peaks gives 9.15 and $6.64 \mathrm{mC}$. From this the roughness factor can be calculated and is found to decrease from 48 to. 35 . The polishing effect of electrosynthesis, previously observed by Scanning Electron Microscopy, is thereby confirmed quantitatively. 


\section{3-3 Determination of the inter-electrode resistance}

One of the main interests in having coplanar band anodes and cathodes separated by gaps of micro dimensions is in limiting the ohmic loss due to the electrolyte resistance. The resistance between two parallel band electrodes is inversely proportional to both the inter-electrode distance and the exposed areas. However, the determination of this resistance is not straightforward, and can only be carried out by applying known equations. An analytical and a numerical method are presented here and compared with experimental data, obtained with three silver arrays.

\section{3-3-1 Analytical method}

In order to derive an expression for the resistance between two bands, an interdigitated array can be decomposed into elementary portions, as shown in figure 3.14. Electrodes are defined by $X_{1}$ and $X_{2}$ or by $-X_{1}$ and $-X_{2}$, one electrode being polarised at zero and the other at $2 \mathrm{~V}_{0}$. In an interdigitated device each band is divided to interfer with its two adjacent bands. Thus $\left(X_{2}-X_{1}\right)$ represents half of the band width $\left(W_{e}\right)$ and $2 X_{1}$ is the inter-electrode gap $\left(\mathrm{W}_{\mathrm{g}}\right)$. The model is for infinite bands and therefore the phenomena occurring at the end of the bands are not considered.

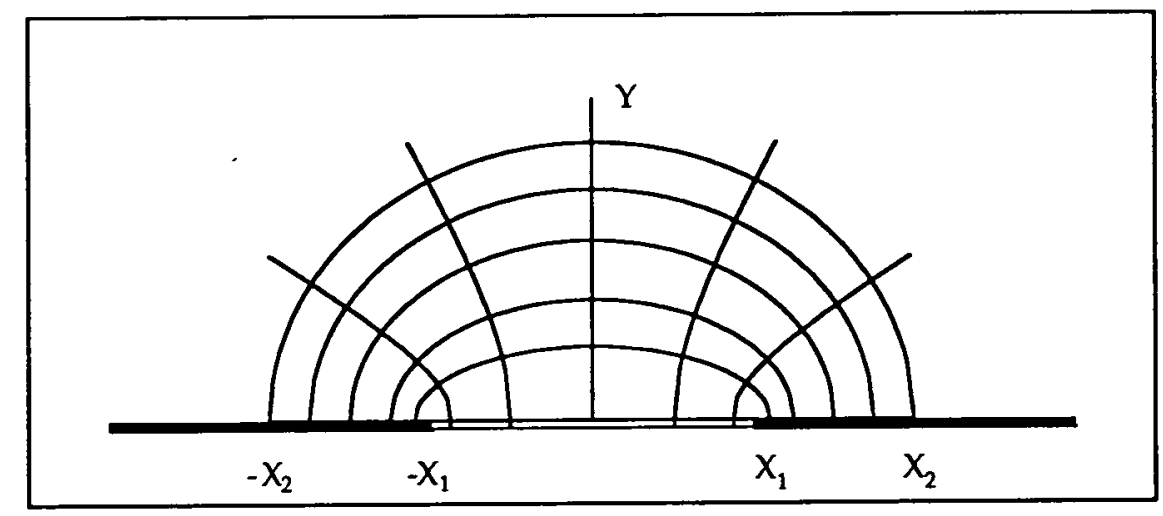

Figure 3.14: representation of two parallel half band electrodes with their equipotential and flux lines. 
Outside the submicron thick diffuse layers, the conductivity of a solution is assured by the movement of ionic species. Therefore for the estimation of a resistance, diffusion and convection forces can be ignored and the flux of charged species $\mathrm{j}$ is assumed to occur by migration only:

$$
\mathrm{nFj}=-\rho^{-1} \operatorname{grad} \phi
$$

Where $\rho$ is the resistivity of the solution and $\phi$ the potential.

Assuming a steady state condition, the divergence of the flux is zero, thus:

$$
\rho^{-1}\left(\frac{\partial^{2} \phi}{\partial X^{2}}+\frac{\partial^{2} \phi}{\partial Y^{2}}\right)=0
$$

Under these conditions the migration current, $i$, per unit length of electrode over the interval $X_{1}$ to $X_{2}$ is given by:

$$
i=\int_{X_{1}}^{X_{2}} \rho^{-1}\left(\frac{\partial \phi}{\partial Y}\right)_{Y=0} d X
$$

Similar equations have been solved by using conformal mapping techniques [33-35]. The corresponding change of variable is:

$$
\begin{aligned}
& x=\cosh u \cos v \\
& y=\sinh u \sin v
\end{aligned}
$$

where $\mathrm{x}$ and $\mathrm{y}$ are dimensionless variables defined by: 


$$
\begin{aligned}
& x=X / X_{1} \\
& y=Y / X_{1}
\end{aligned}
$$

and $\mathrm{v}$ is the dimensionless potential:

$$
\mathrm{v}=\pi \phi / 2 \mathrm{~V}_{\mathrm{o}}
$$

If equation (3.15) is derivatised by $x$ and equation (3.16) by $y$, the main property of the transformation can easily be demonstrated:

$$
\left(\frac{\partial u}{\partial x}\right)_{y=0,1<x<x_{2}}=\left(\frac{\partial v}{\partial y}\right)_{y=0,1<x<x_{2}}
$$

Hence equation (3.14) can be integrated:

$$
\mathrm{i}=\frac{2 \mathrm{~V}_{\mathrm{o}}}{\pi \rho} \cosh ^{-1}\left(\mathrm{X}_{2} / \mathrm{X}_{1}\right)
$$

Equipotential lines shown in fig 3.14 are hyperbola of equation:

$$
\frac{x^{2}}{\cos ^{2} v}-\frac{y^{2}}{\sin ^{2} v}=1
$$

and the lines of flux between the two electrodes are ellipses given by:

$$
\frac{x^{2}}{\cosh ^{2} u}+\frac{y^{2}}{\sinh ^{2} u}=1
$$

The current distribution along the electrode can be derived from equation (3.21) by calculating the current for bands of infinitesimal width, $\delta x$ : 


$$
i(x)=\frac{2 V_{0}}{\pi \rho} \cosh ^{-1}\left(\frac{x+\delta x}{x}\right)
$$

Figure 3.15 illustrates this variation on the electrode taking $\delta x=0.01$ and $2 V_{0} /(\pi \rho)=1$.

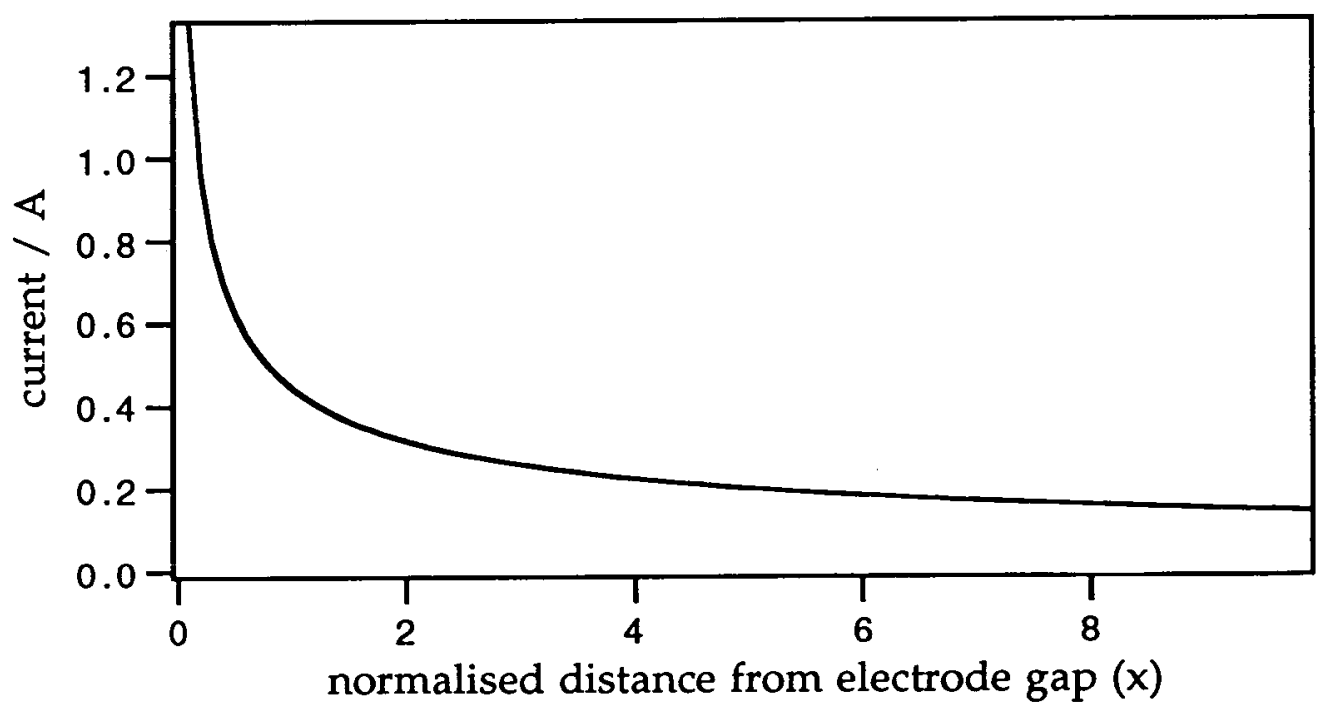

Figure 3.15: Current distribution on a band electrode, as the distance from the gap is increased.

The current being related to the resistance of the solution $\left(2 \mathrm{~V}_{\mathrm{O}}=\mathrm{Ri}\right)$, an expression can be derived for the resistance between two bands of unit length, $R_{b u}[\Omega \times$ m]:

$$
\mathrm{R}_{\mathrm{bu}}=\frac{\pi \rho}{\cosh ^{-1}\left(\mathrm{X}_{2} / \mathrm{X}_{1}\right)}
$$


Or in other terms:

$$
\mathrm{R}_{\mathrm{bu}}=\frac{\pi \rho}{\ln \left(\left(\mathrm{W}_{\mathrm{e}} / \mathrm{W}_{\mathrm{g}}+1\right)+\sqrt{\left(\mathrm{W}_{\mathrm{e}} / \mathrm{W}_{\mathrm{g}}+1\right)^{2}-1}\right)}
$$

For an array, the equivalent length $l_{e q}$ is defined as the band length $l_{b}$ times the number of gaps between electrodes, $\left(n_{b}-1\right)$. The total resistance $R_{\text {array }}$ is then given by this equation:

$$
R_{\text {array }}=\frac{R_{b u}}{l_{\text {eq }}}=\frac{R_{b u}}{\left(l_{b} \times\left(n_{b}-1\right)\right)}
$$

In order to obtain this solution, lines of flux and equipotential lines are assumed to be elliptical and hyperbolic respectively, neglecting the fluxes which are very distant from the electrodes. The model developed by Aoki et al [28] took them into account and they derived another expression for the current by solving the two dimensional equation (3.13) with the Schwarz-Christoffel transformation. From this another expression for the resistance between two bands of unit length is derived:

$$
\mathrm{R}_{\mathrm{bu}}{ }^{\prime}=\frac{\pi \rho}{\ln \left(2.55\left(\mathrm{~W}_{\mathrm{e}} / \mathrm{W}_{\mathrm{g}}+1\right)-\frac{0.19}{\left(\mathrm{~W}_{\mathrm{e}} / \mathrm{W}_{\mathrm{g}}+1\right)^{2}}\right)}
$$

Both these models have been used for the estimation of diffusional currents and have shown good correlation with experimental results [30]. 


\section{3-3-2 Numerical method}

The resistance between two coplanar band electrodes can be estimated using a numerical method, which consists of solving equation (3.14) by simulating the electrolyte potential in the region above the electrodes. As can be seen in figure 3.16, the domain is segmented into regular rectangles in order to form a grid. Half of an electrode, charged at $2 \mathrm{~V}_{0}$, lies in the $X$-axis, between ( 0 ) and (WIDTH), and half of the other electrode, charged at $O \mathrm{~V}_{\mathrm{O}}$ lies between (XDIM-WIDTH) and (XDIM).

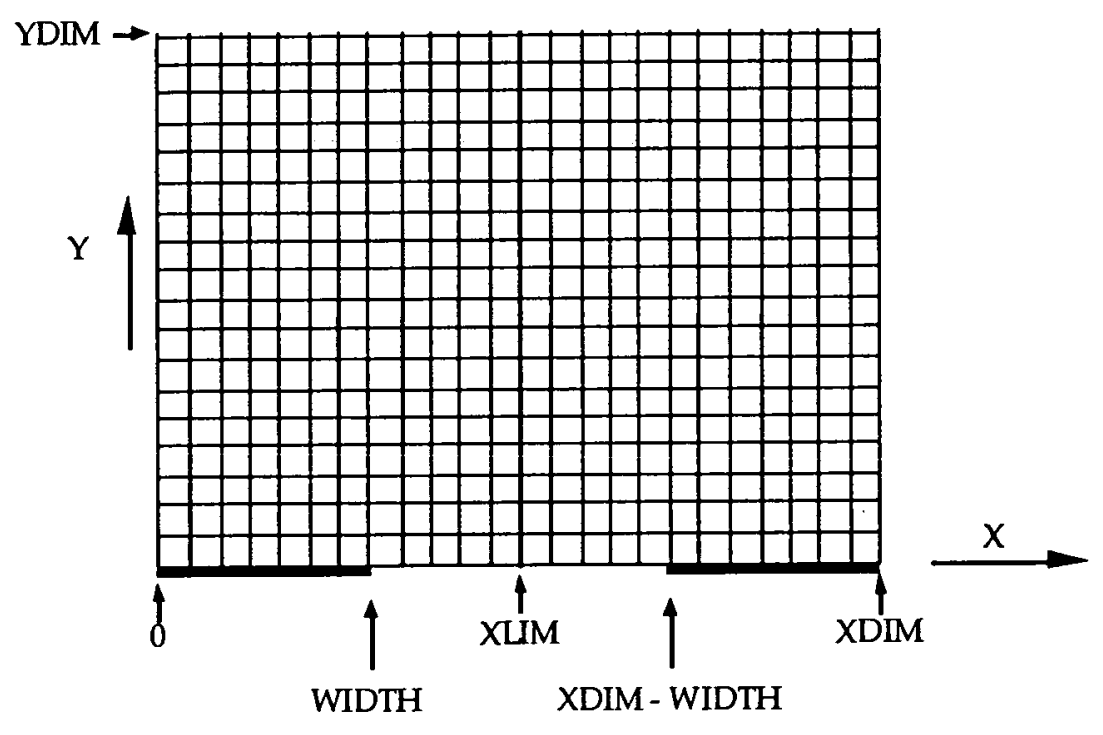

Figure 3.16: Uniform two dimensional space grid used for the simulation of the resistance between two band electrodes.

The boundary conditions are:

- for $X \in[0, W I D T H]$, and $Y=0, \phi=2 V_{0}$.

- for $X \in[(X D I M-W I D T H), X D I M]$, and $Y=0, \phi=0$.

- for $\mathrm{X}=\mathrm{XLIM}$, and $\mathrm{Y} \in[0, \mathrm{YDIM}], \phi=\mathrm{V}_{\mathrm{O}}$.

The principle of the simulation program consists of calculating the electrolyte potential for each point, and to calculate iteratively until 
values converge. The potential of the electrolyte at one point, $N[i, j]$ is calculated from its initial value, $O[i, j]$, and from the values taken by the surrounding points. In the general case:

$$
N[i, j]=O[i, j]+0.25(O[i-1, j]+O[i+1, j]+O[i, j-1]+O[i, j+1]-4 O[i, j])
$$

The total current passing through the electrode, is then the sum of all the currents associated to the boxes in contact with the electrode, and the current passing through a box is determined from equation (3.12):

$$
i_{\text {box }}=\frac{\Delta \phi}{\rho}=\frac{(N[i, 1]+N[i+1,1]) / 2}{\rho}
$$

$A$ version of the program written in $C$ can be found in appendix 1 . The number of points and iterations is limited by the amount of memory available for the storage of the data. For our simulations the number of points on the $x$-axis is limited to 40 for 1000 iterations. The value obtained after 1000 iterations is very stable, but curve fitting is necessary to estimate the current value for a larger number of points on the $x$-axis.

\section{3-3-3 Experimental results}

The electrolyte resistance between the band electrodes of an interdigitated array is determined by impedance measurements. The measurement consists of imposing a sinusoidal signal of small amplitude $(10 \mathrm{mV})$ and of frequency varying from 10000 to $1 \mathrm{~Hz}$ during the analysis. The amplitude of the resulting current, and its phase shift with the voltage, are measured. At any frequency $(\omega)$, a system can be assumed to behave 
like a capacitance (C), and a resistance (R) in series. The impedance is a complex number which combines $R$ and $C$ so that:

$$
E=Z \text {. I }
$$

$\mathrm{E}$ and I are the voltage and current phasors. For a single resistance, current and voltage are in phase and $Z$ is equal to $R$. For a single capacitance, the difference in phase is $90^{\circ}$ and $\mathrm{Z}$ is equal to $-\mathrm{j} / \omega \mathrm{C}$.

Results can be presented on a Nyquist plot, where the imaginary part of the impedance is plotted against the real part. In this case, the shape of the curves are characteristic of the elements present in the equivalent circuits. For example, the Randles equivalent circuit for a simple electron transfer reaction, combines the electrode and the electrolyte resistance, $R_{u}$, and the double layer capacitance, $C_{\mathrm{dl}}$. The reaction resistance is resolved into the charge transfer resistance, $R_{c t}$, and a Warburg impedance, $Z_{w}$, dependent on the diffusion coefficient for the system. The Warburg impedance has the particular property of having real and imaginary parts of the same amplitude. This equivalent circuit and its associated Nyquist plot is shown in figure 3.17 .

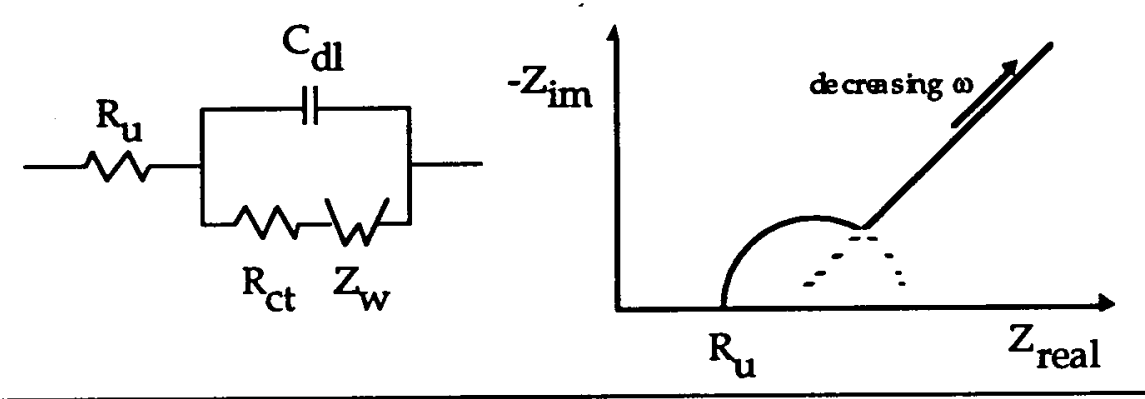

Figure 3.17: Randles equivalent circuit and Nyquist plot for a simple electron transfer reaction. 
At high frequency, capacitive effects can be neglected and the resistance associated with the electrode and the electrolyte, can be determined directly from the Nyquist plot.

The resistance of the solution is directly proportional to the cell geometrical constant, $J$, and to the solution resistivity, $\rho$, which itself is related to the electrolyte concentration, $c$, and molar conductivity, $\Lambda$ :

$$
R=\rho J=\frac{1}{\Lambda c} J
$$

According to the first Kolrausch principle, the molar conductivity of a strong electrolyte depends on the electrolyte nature and concentration:

$$
\Lambda=\Lambda^{\circ}-\mathrm{A} \sqrt{\mathrm{c}}
$$

Where $\Lambda^{0}$ is the molar conductivity for infinitely dilute solutions.

Impedance analyses are carried out for three silver arrays having different bandgaps (AG1, AG2 and AG3), and with sodium chloride concentration ranging between $5 \times 10^{-3}$ to $0.1 \mathrm{M}$. Figure 3.18 shows the superimposed Nyquist plots obtained with the array AG2. Similar plots are produced with the two other arrays, and the resistances measured at high frequencies are reported in table 3.3. 


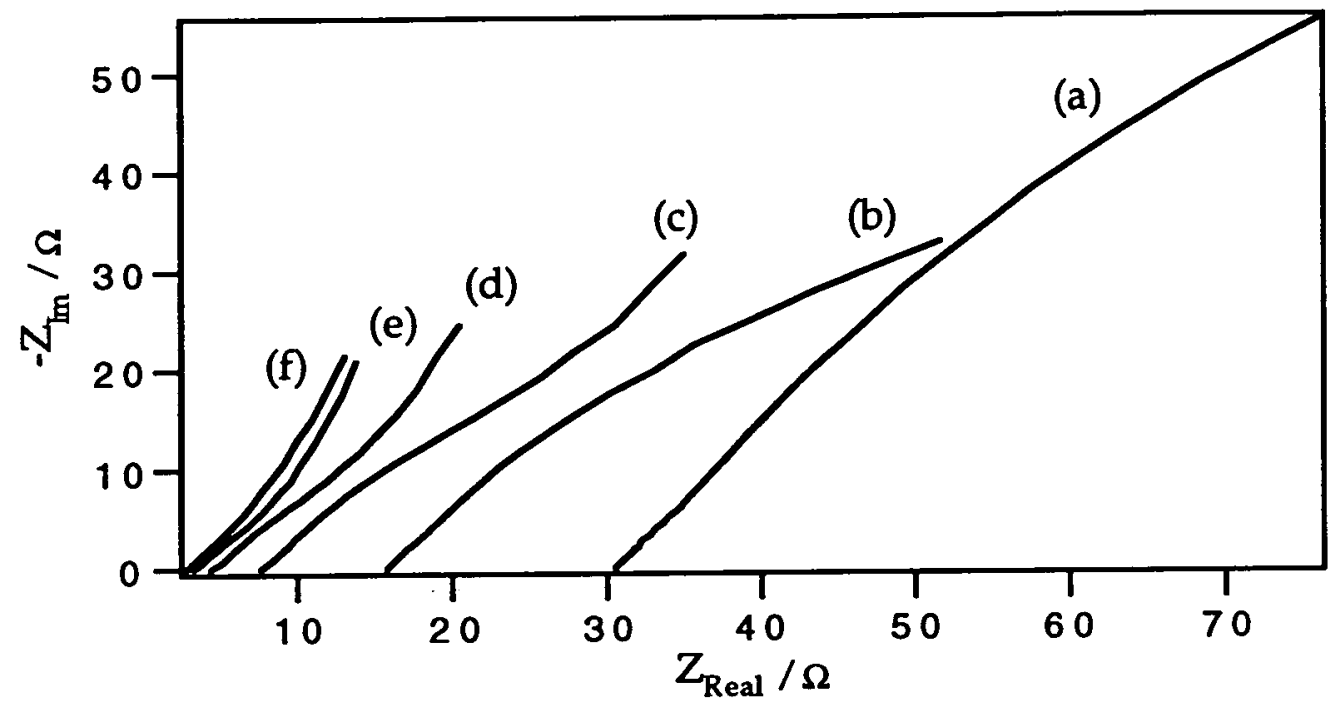

Figure 3.18: Superimposed Nyquist plots obtained with silver array AG2, for different sodium chloride concentrations: (a) $5 \mathrm{mM},(b) 10 \mathrm{mM}$, (c) $25 \mathrm{mM}$, (d) $50 \mathrm{mM},(e) 100 \mathrm{mM}$ and (f) $150 \mathrm{mM}$.

Table 3.3 : resistances measured with three silver band arrays for different sodium chloride concentrations.

\begin{tabular}{cccc}
\hline $\begin{array}{c}\mathrm{NaCl} \\
\begin{array}{c}\text { concentration / } \\
\text { mmol.dm }\end{array}\end{array}$ & $\begin{array}{c}\text { Resistance } \\
\text { measured with } \\
\text { array AG1 / } \Omega\end{array}$ & $\begin{array}{c}\text { Resistance } \\
\text { measured with } \\
\text { array AG2 } / \Omega\end{array}$ & $\begin{array}{c}\text { Resistance } \\
\text { measured with } \\
\text { array AG3 / } \Omega\end{array}$ \\
\hline 5 & 45.75 & 30.55 & 23.50 \\
10 & 23.30 & 15.75 & 12.00 \\
25 & 10.70 & 7.65 & 6.00 \\
50 & 6.05 & 4.35 & 3.55 \\
100 & 3.65 & 3.10 & 2.65 \\
150 & 3.05 & 2.70 & 2.30 \\
\hline
\end{tabular}


When the measured resistances are plotted against the inverse of the sodium chloride concentration, as in figure 3.19 , it can be seen that a linear response is obtained. The molar conductivity can thus be assumed to be constant for the concentration range considered. Its value can be set at $108 \mathrm{~cm}^{2} \Omega^{-1} \mathrm{~mol}^{-1}$, which is the molar conductivity of sodium chloride, at infinite dilution and at $18^{\circ} \mathrm{C}$. The resistance of the electrode, given by the intercept on the lines on the y-axis, where the solution has theoretically no resistance, is found to be $1.5 \Omega$ for the three arrays.

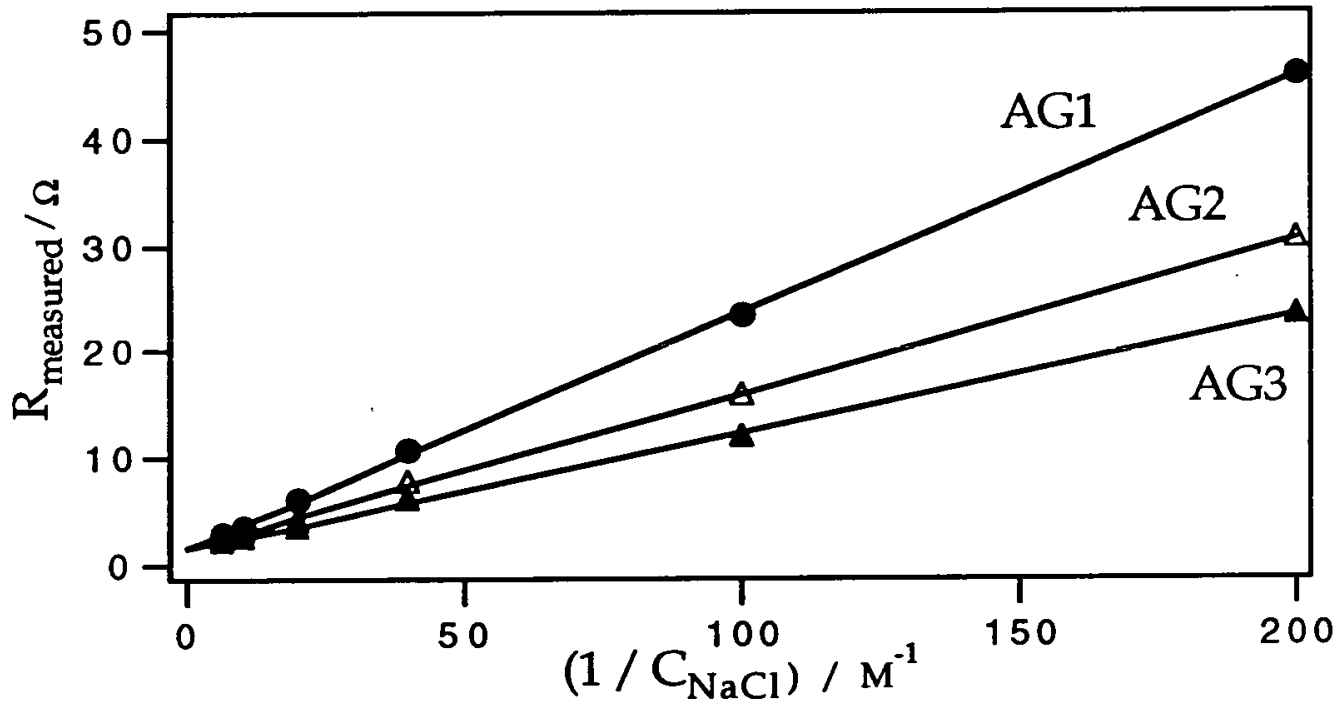

Figure 3.19: Resistances measured with three silver coplanar band arrays as a function of inverse sodium chloride concentration.

\section{3-3-4 Comparison and interpretation of the results}

The resistance between the coplanar bands of an array depends on the concentration of the electrolyte and on the array equivalent length, therefore a dimensionless constant $C_{\text {geom }}$ is introduced, which depends only on the electrode width and the inter-electrode gap. It corresponds to 
the resistance multiplied by the equivalent length, and divided by the resistivity:

$$
C_{\text {geom }}=R_{\text {array }} \frac{l_{\text {eq }}}{\rho}
$$

Experimental and theoretical geometrical constants are compared in table 3.4.

Table 3.4: dimensionless constants, $C_{g e o m}$, for the three silver arrays, obtained with different methods.

\begin{tabular}{|c|c|c|c|c|}
\hline $\begin{array}{l}\text { Silver } \\
\text { array }\end{array}$ & $\begin{array}{l}\text { analytical } \\
\text { conformal } \\
\text { mapping }\end{array}$ & $\begin{array}{l}\text { method } \\
\text { Schwarz } \\
\text { Christoffel }\end{array}$ & $\begin{array}{l}\text { numerical } \\
\text { method }\end{array}$ & $\begin{array}{l}\text { experimental } \\
\text { method }\end{array}$ \\
\hline AG1 & 2.38 & 1.94 & 2.25 & 1.74 \\
\hline AG2 & 1.78 & 1.55 & 1.91 & 1.56 \\
\hline AG3 & 1.37 & 1.23 & 1.48 & 1.47 \\
\hline
\end{tabular}

Values obtained by simulation are consistent with the experimental data, especially for small inter-electrode distances. However better accuracy would be obtained by simulating bigger matrices on a more powerful computer. As can be seen in figure 3.20, the first model, which assumes elliptical current lines, also presents good correlation for small inter-electrode gaps, but the second model, derived using the SchwarzChristoffel transformation, seems to fit better with the experimental data. 


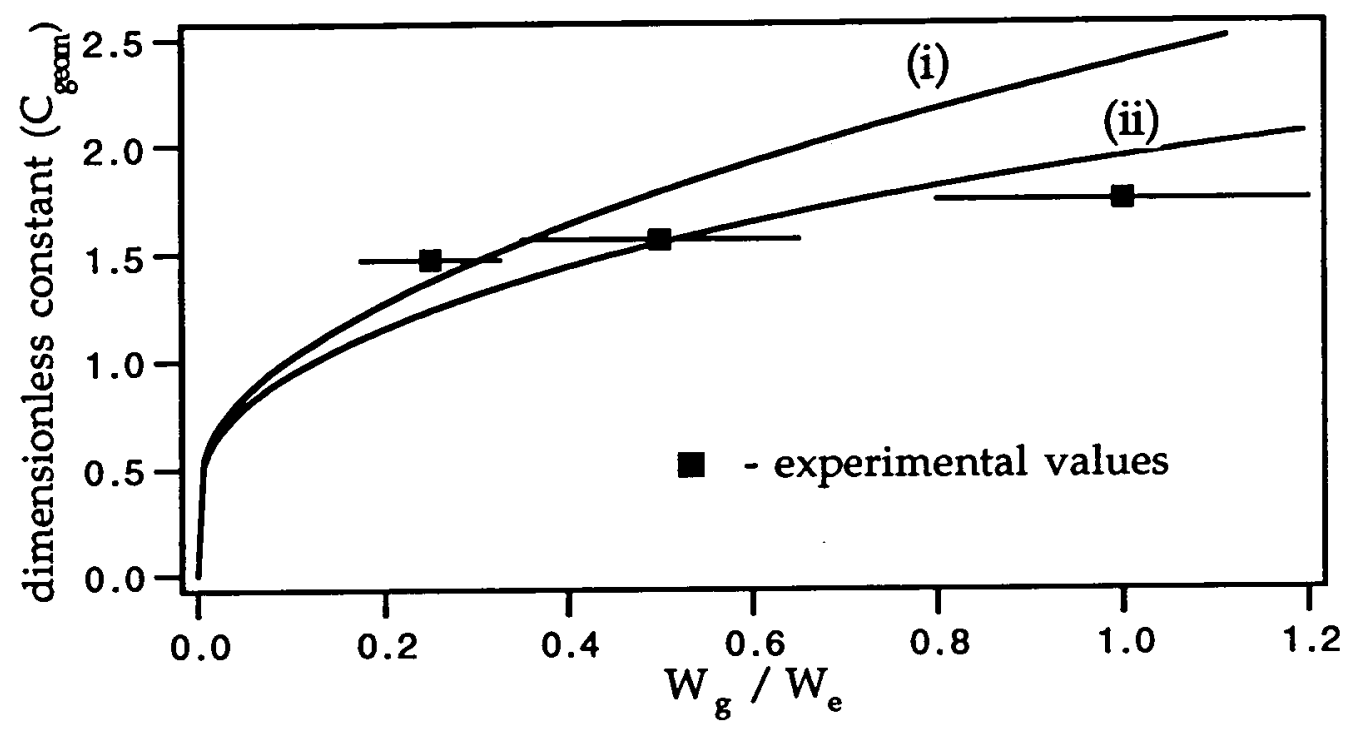

Figure 3.20: Variation of the dimensionless constant with $W_{g} / W_{e}:$ (i) from equation (3.26) and (ii) from equation (3.28).

For these two models, the thickness of the electrode, $\mathrm{e}_{\mathrm{th}}$, was not taken into account. The resistance between two parallel plates of surface $e_{\text {th }} \times l_{\text {eq, }}$ and separated by $W_{g}$ is given by:

$$
R_{\mathrm{th}}=\frac{\rho W_{g}}{e_{\mathrm{th}} 1_{\mathrm{eq}}}
$$

For a $25 \mu \mathrm{m}$ thick electrode, the corresponding geometrical constants do not vary dramatically but when compared with the experimental data in figure 3.21, the first model appears to be the most appropriate one. 


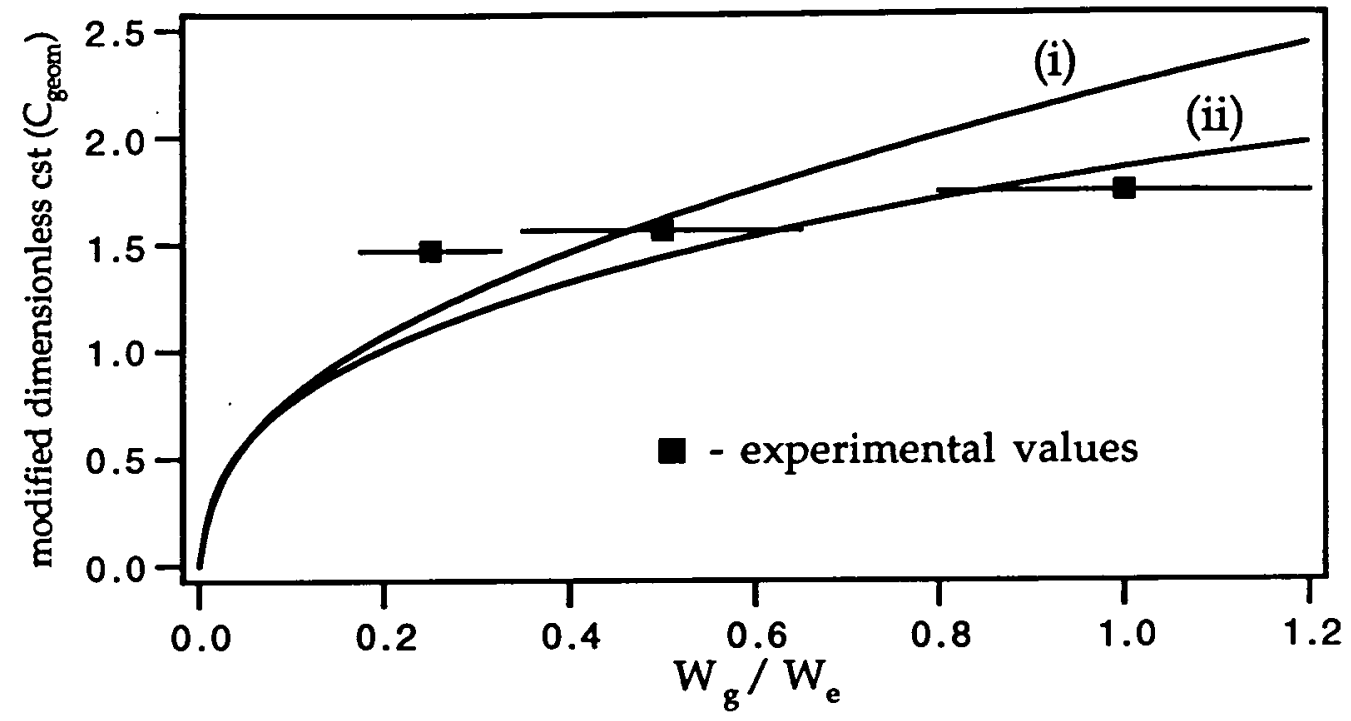

Figure 3.21: The variation of the modified dimensionless constant with $W_{g} / W_{e}$, for a $25 \mu \mathrm{m}$ thick electrode: (i) from equation (3.26) and (ii) from equation (3.28).

Nevertheless, it is worthwhile to note that for large inter-electrode gaps the two analytical models are able to estimate the ohmic losses, and therefore the discussion which follows gives a conservative value of the ohmic loss savings which can be achieved by the above approach. In order to demonstrate that ohmic losses can be reduced by using band arrays, the cell constant $(J=R / \rho)$ is calculated for the different arrays and compared with the cell constant of a parallel cell. In the case of the FMO1 cell from ICI $(16 \times 4 \times 0.3 \mathrm{~cm})$ the geometrical constant is:

$$
\mathrm{J}=\frac{0.3}{16 \times 4}=0.0047 \mathrm{~cm}^{-1}
$$

If a plate is replaced by a band array of the same area $\left(16 \times 4 \mathrm{~cm}^{2}\right)$ the cell constant can be determined from equations (3.26) and (3.28). Fig 3.22 
shows the variation of this constant with the electrode and the gap widths.
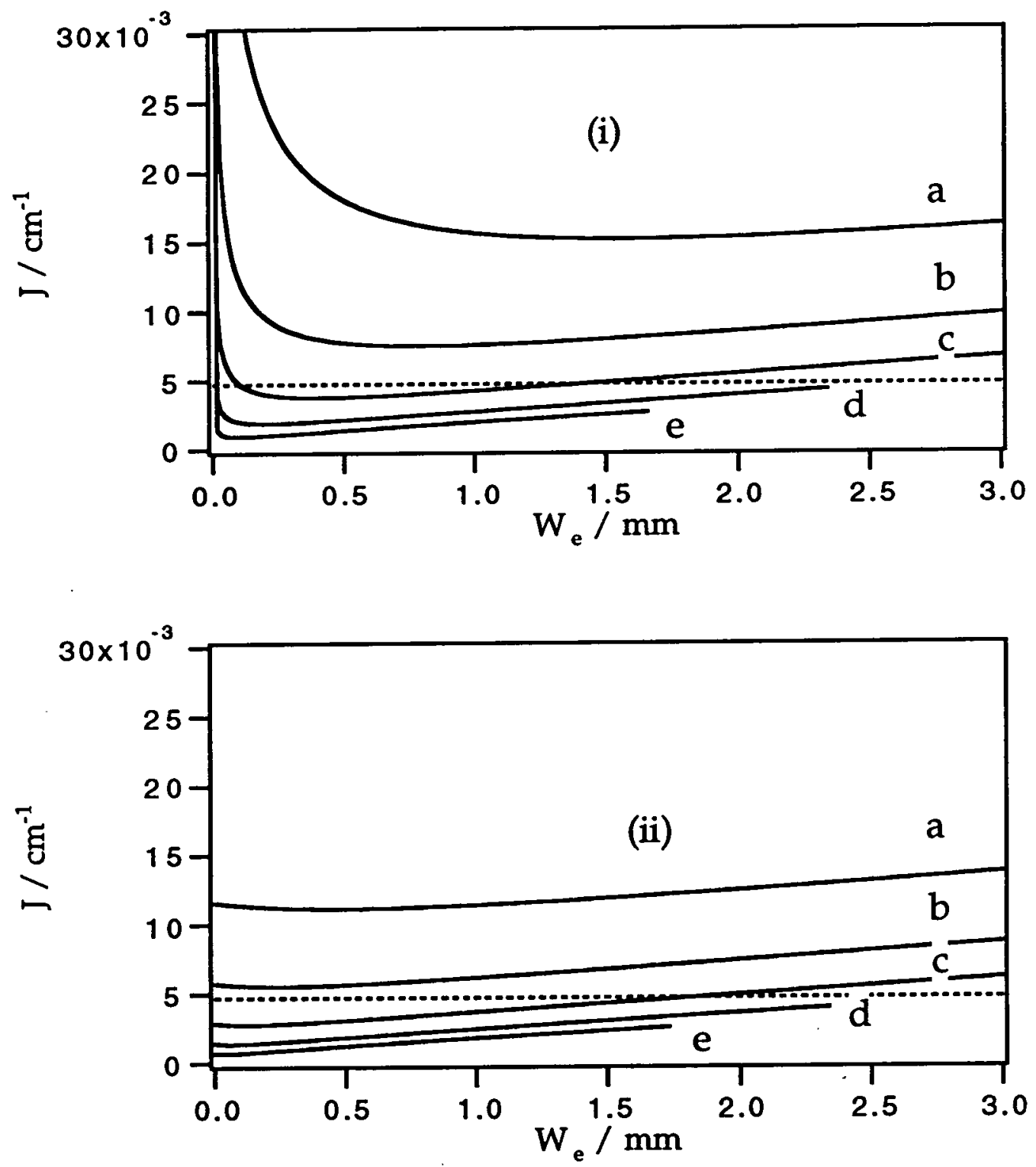

Figure 3.22: The variation of the geometrical constant with the electrode width for different band gaps: (i) from equation (3.26), (ii) from equation (3.28) (a) $W_{g}=2 \mathrm{~mm},(b) W_{g}=1 \mathrm{~mm}$, (c) $W_{g}=0.5 \mathrm{~mm}$, (d) $W_{g}=0.25 \mathrm{~mm}$, (e) $W_{g}=0.125 \mathrm{~mm}$ and (---) ICI FM01 geometrical constant. 
It is clear that the more closely spaced the bands, the smaller the resistance. For $250 \mu \mathrm{m}$ inter-electrode gaps, ohmic losses can be reduced by $50 \%$ in comparison to what would be obtainable with the ICI cell. The graphs also show that there is an optimum electrode width $W_{e, o p t}$ for each inter-electrode spacing for which the geometrical constant is at a minimum. The relationships between the two sizes are completely linear as shown in fig 3.23.

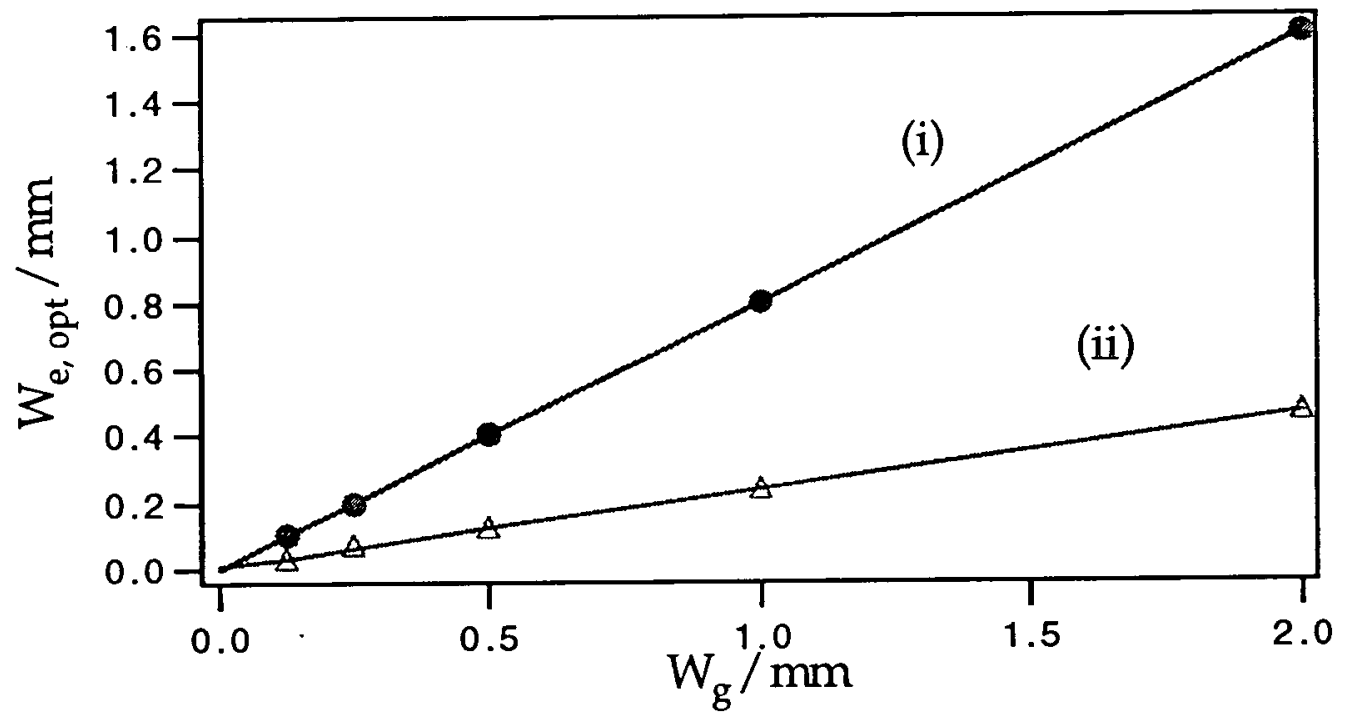

Figure 3.23: The variation of the optimal electrode width $W_{e, o p t}$ with the bandgap: (i) from equation (3.26) and (ii) from equation (3.28).

The proportionality factors are different for the two models, but for the first model, where it is more important to optimise the width to gap ratio, the band width should be such that:

$$
\mathrm{W}_{\mathrm{e}}=0.8 \mathrm{~W}_{\mathrm{g}}
$$


However, when designing interdigitated electrode systems, the ohmic loss within the band electrode itself must be considered, especially if the electrode material is not a good conductor. In the case of screen printed metal this is not a significant problem, however, when fabricating carbon band electrodes, a compromise must be made between the reduction of ohmic loss in the solution and the corresponding increase in the ohmic loss in the electrode. 


\section{CHAPTER 4}

\section{Methoxylation of furan}

\section{4-1 Bibliography}

Furan is a compound rich in $\pi$-electrons. It can be easily oxidised to 2,5-dihydro-2,5-dimethoxyfuran (DHDMF), which then leads to intermediates used for the manufacture of nylon, pyridine and other useful products. DHDMF can be prepared chemically, but this presents several disadvantages: large quantities of bromine are needed, the product obtained is contaminated by halogen impurities and it is also liable to decomposition. N. Clauson-Kaas et al [36] first proposed an ECEC electrochemical mechanism in 1952. The general procedure is the same as for the chemical approach, except that the process is carried out via the in situ electrogeneration of bromine in methanol, which in turn oxidises furan, according to the following scheme :

anode:

$$
2 \mathrm{Br}^{-} \rightarrow \mathrm{Br}_{2}+2 \mathrm{e}^{-}
$$

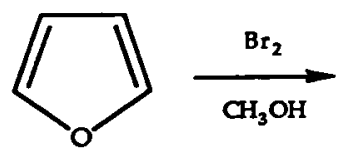

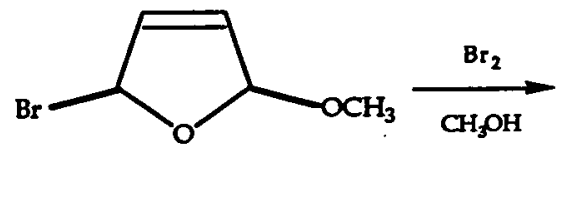

$+\mathrm{Br}^{-}+\mathrm{H}^{+}$

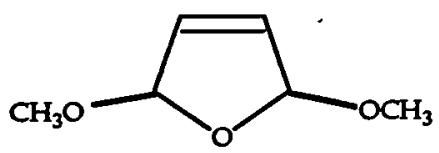

$+\mathrm{Br}^{-}+\mathrm{H}^{+}$

cathode:

$2 \mathrm{CH}_{3} \mathrm{OH}+2 \mathrm{e}^{-} \rightarrow \mathrm{H}_{2}+2 \mathrm{CH}_{3} \mathrm{O}^{-}$ 
The identity of the intermediate is not certain but it is thought to be highly reactive. DHDMF is sensitive to local acidic conditions.

A large number of cells have been investigated. A pump cell [37] was first developed with graphite electrodes. A good mass transfer was produced.

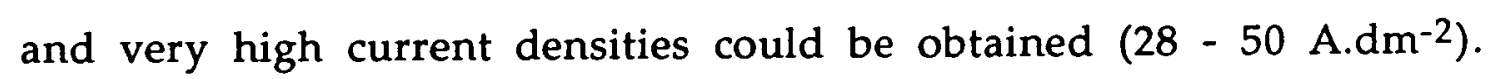
Production of $0.8 \mathrm{~mol} \cdot \mathrm{dm}^{-2} \cdot \mathrm{h}^{-1}$ could be obtained for an energy of 3 kWh.kg-1, with $80 \%$ current efficiency and $85 \%$ material yield. Experiments were carried out on a bipolar packed bed cell [38], made of layers of graphite pellets, separated by polyethylene nets, and packed at random between two graphite feeder electrodes. R. E. W. Jansson et al obtained similar material yield and current efficiencies with these two cells [38-39] before K. Kusakabe et al maximised these yields to $90 \%$, for a production rate of $0.018 \mathrm{~mol} . \mathrm{dm}^{-2} \cdot \mathrm{h}^{-1}[40]$.

A tubular flow cell [41] was constructed of a platinum wire cathode inside a graphite tube anode. It gave good material yield ( $80 \%)$, but the current efficiency was much lower $(25 \%)$.

With a perforated graphite electrode, rotating in a graphite vessel [42], the current efficiency was slightly enhanced $(54 \%)$, but it was less than that obtained with the bipolar packed bed cell.

For all these experiments, methanolic solutions containing furan and bromide salt were used. Krishnan et al showed that when $\mathrm{NH}_{4} \mathrm{Br}$ was used instead of $\mathrm{NaBr}$, the yield was not improved and recovery of the product was more tedious. It was then found that a high $\mathrm{NaBr}$ concentration could give rise to a decrease of current efficiency [40], because of bromine consumption:

$$
\mathrm{Br}_{2}+\mathrm{Br}^{-} \rightarrow \mathrm{Br}_{3}^{-}
$$


A decrease in the overall current efficiency was also observed when the cell voltage was set at too high a level [40]. This was assumed to be caused by furan polymerisation and successive reactions of DHDMF.

The furan methoxylation was approached in a very different way by E. Raoult et al [43] and K. H. Simmrock [44], who carried out the experiment by direct oxidation of furan to DHDMF on a platinum grid electrode, using a membrane to separate $\mathrm{H}^{+}$ions and other undesired species produced during the electrosynthesis. The reactor is very well described by C. Moinet et al [45]. However the membranes available did not allow a complete separation of the species and current efficiencies were not competitive. Finally M. J. Medeiros, M. I. Montenegro and D. Pletcher [46] carried out the furan methoxylation with a platinum microelectrode in order to determine the rate constant for the initial step of the reaction. Simulations [47] with appropriate rate constants showed good consistency with experimental data.

Best material yields were obtained with the pump cell and the bipolar packed bed cell. The advantage of the bipolar packed bed cell was the small inter-electrode distances and thus the small ohmic loss. The disadvantages included current by-passes and large dispersion due to the hydrodynamic conditions which lead to several side reactions. As a result, as many as 11 by-products were produced with this cell. Mixing was more efficient in a pump cell, and the number of by-products formed was reduced to four but the pumping and the maintenance costs could not be neglected.

\section{4-2 Calibration and preliminary experiments}

\section{4-2-1 Investigation of the electrochemical system}

The furan methoxylation was carried out via the electro-oxidation of bromide to bromine. Before investigating the performance of different 
cells, it was therefore important to study this process. Preliminary experiments were achieved with a three electrode system, on a vitreous carbon electrode of $3 \mathrm{~mm}$ diameter, in methanolic sodium bromide solutions, where sodium perchlorate was used as supporting electrolyte. The cyclic voltammograms obtained for different concentrations are reported in figure 4.1. It clearly shows that the peak current is proportional to the sodium bromide concentration.

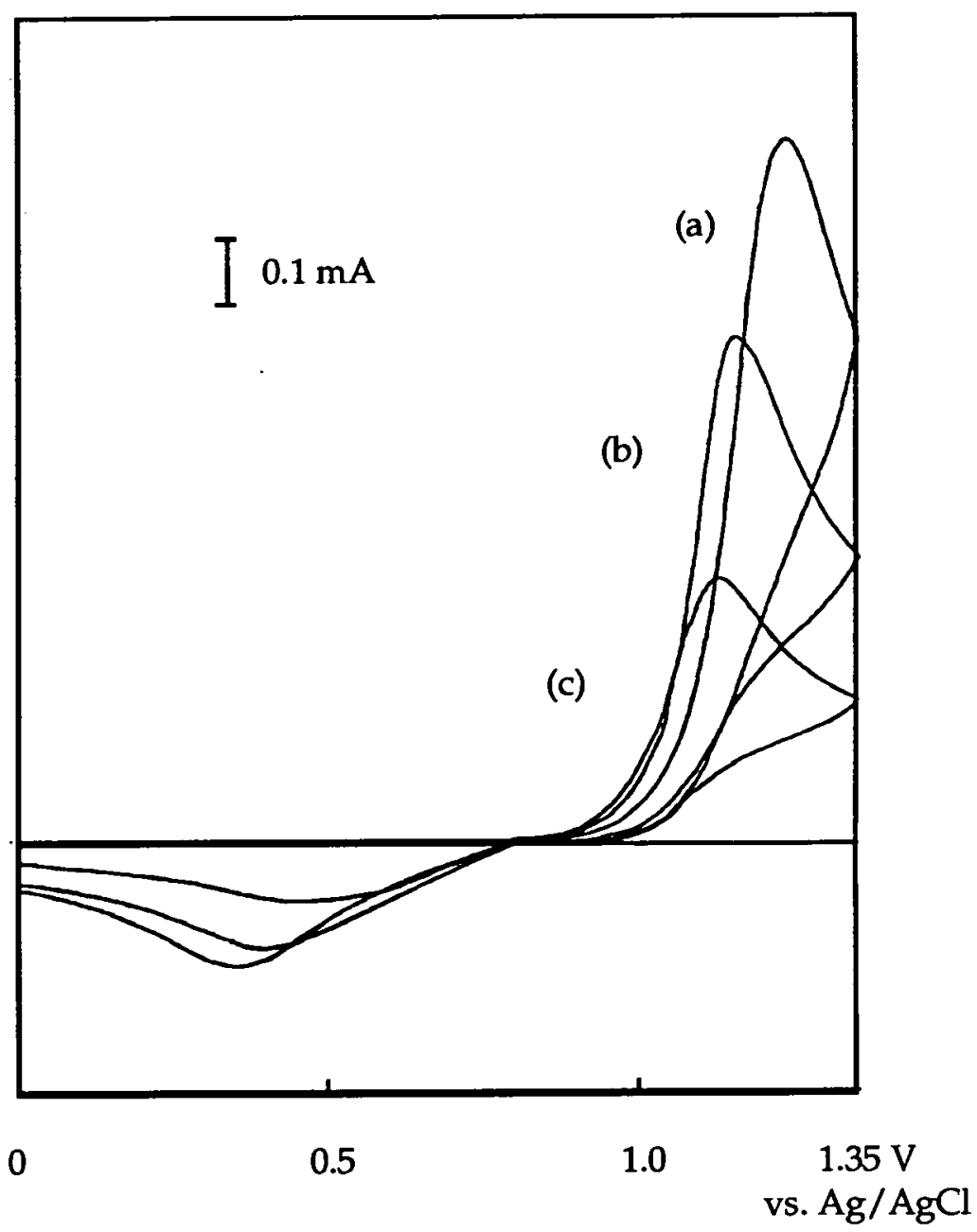

Figure 4.1: Cyclic voltammograms of sodium bromide in methanol with $\mathrm{NaClO}_{4}(0.1 \mathrm{M})$ as supporting electrolyte, recorded on a vitreous carbon disc electrode with an $\mathrm{Ag} / \mathrm{AgCl}$ reference electrode at $100 \mathrm{mV} / \mathrm{sec} . \mathrm{NaBr}$ concentration: (a) $30 \mathrm{mM}$, (b) $20 \mathrm{mM}$, (c) $10 \mathrm{mM}$. 
Bromide oxidation to bromine starts at approximately $1.1 \mathrm{~V}$, when the potential is swept from 0.0 to $1.35 \mathrm{~V}$. A portion of the produced bromine is then reduced on the reverse scan. The non-reversibility of the system is demonstrated by the large difference in potential between the oxidation and the reduction peaks and by the difference in limiting current amplitude. The addition of furan appears to have a catalytic effect on the bromide oxidation. When small amounts of furan were added to a methanolic solution containing sodium bromide $(10 \mathrm{mM})$ and sodium perchlorate $(0.1 \mathrm{M})$, an increase in the current related to the bromide oxidation, was observed. This is illustrated by figure 4.2 .

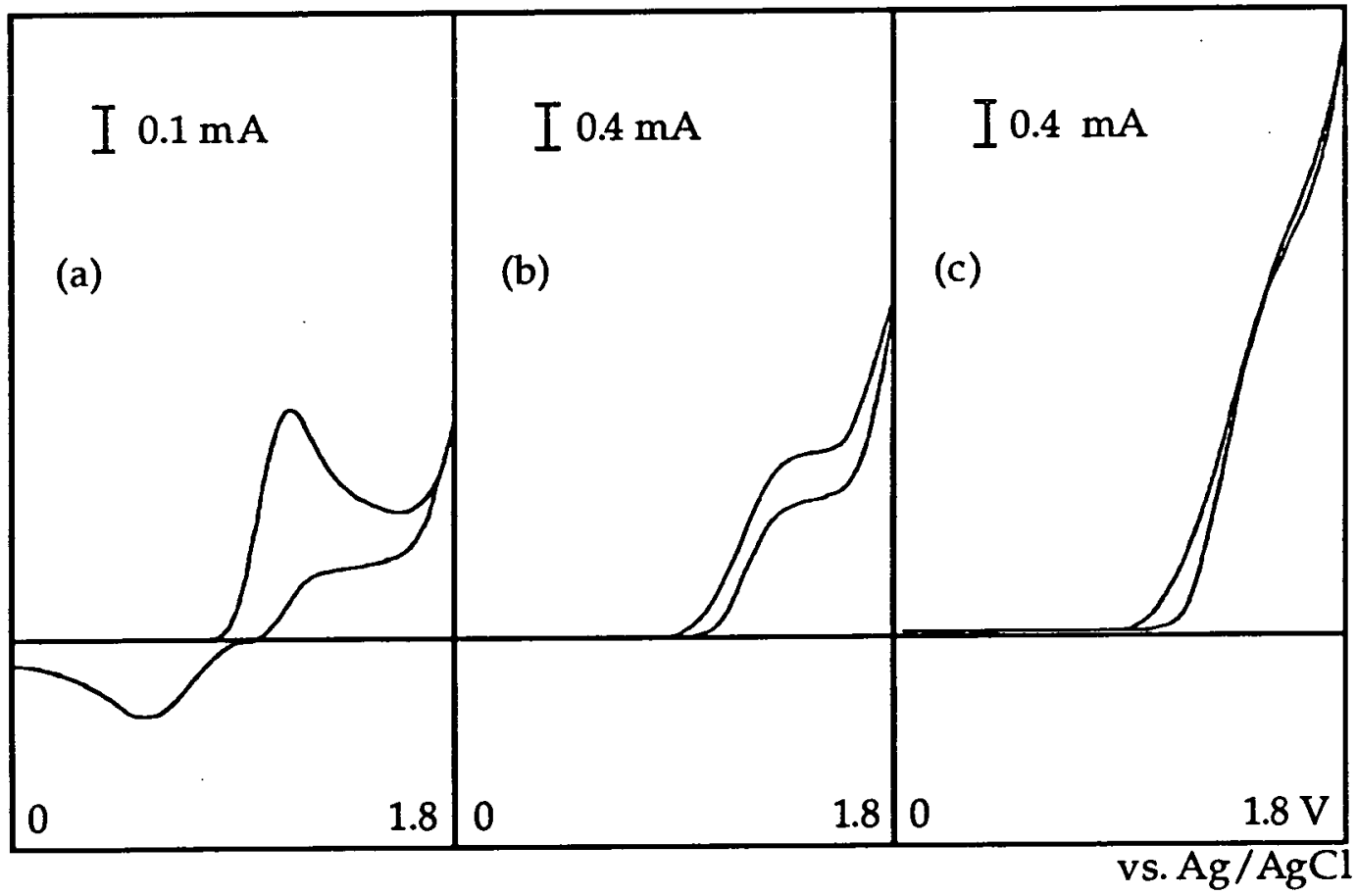

Figure 4.2: Cyclic voltammograms of sodium bromide $(10 \mathrm{mM})$ in methanol with $\mathrm{NaClO}_{4}(0.1 \mathrm{M})$ as supporting electrolyte, recorded on a vitreous carbon disc electrode with a $\mathrm{Ag} / \mathrm{AgCl}$ reference electrode at $100 \mathrm{mV} / \mathrm{sec}$. Furan concentration: (a) $0 \mathrm{mM}$, (b) $0.275 \mathrm{M}$, (c) $0.55 \mathrm{M}$. 
In the absence of furan (a), the bromide oxidation and bromine reduction take place as previously described. However when furan was added up to $0.275 \mathrm{M}(\mathrm{b})$, an increase in the bromide oxidation current was observed, and the bromine reduction no longer occurred. This is due to a fast rate of reaction between bromine and furan. The bromine produced at the electrode is instantly consumed in the methoxylation process. When furan was present in even higher quantity (c), it gave rise to a further increase in the bromide oxidation limiting current, but this oxidation became more difficult to detect as it occurred near the methanol oxidation potential.

As can be seen in figure 4.3 , the bromide oxidation can also be carried out on platinum and again furan addition resulted in an increase in the limiting current. The furan catalytic effect was thus confirmed.

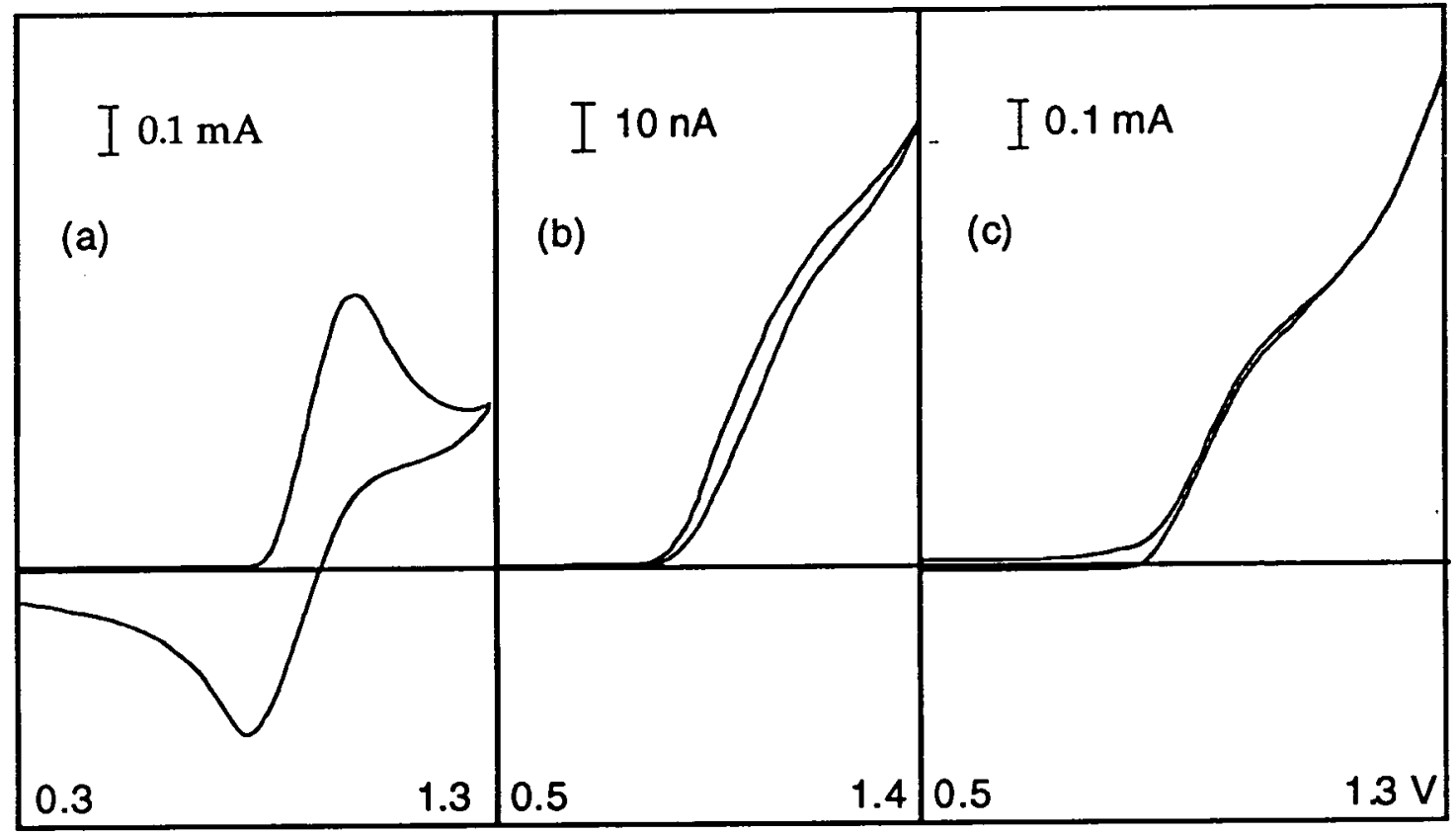

vs. $\mathrm{Ag} / \mathrm{AgCl}$

Figure 4.3: Cyclic voltammograms of sodium bromide $(10 \mathrm{mM})$ in methanol with $\mathrm{NaClO}_{4}(0.1 \mathrm{M})$ as supporting electrolyte, recorded on platinum disc electrodes with a $\mathrm{Ag} / \mathrm{AgCl}$ reference electrode at $100 \mathrm{mV} / \mathrm{sec}$ : (a) large electrode, no furan added, (b) microelectrode $(25 \mu \mathrm{m}$ diameter) and no furan added, (c) microelectrode and $0.14 M$ furan. 
The voltammograms recorded with a printed interdigitated carbon array, shown in figure 4.4, illustrate the possibility of using carbon ink as the electrode material. The behaviour of these electrodes is very comparable to flat metallic electrodes, and furthermore it can be verified that increasing the flow gives an increase in the limiting current.

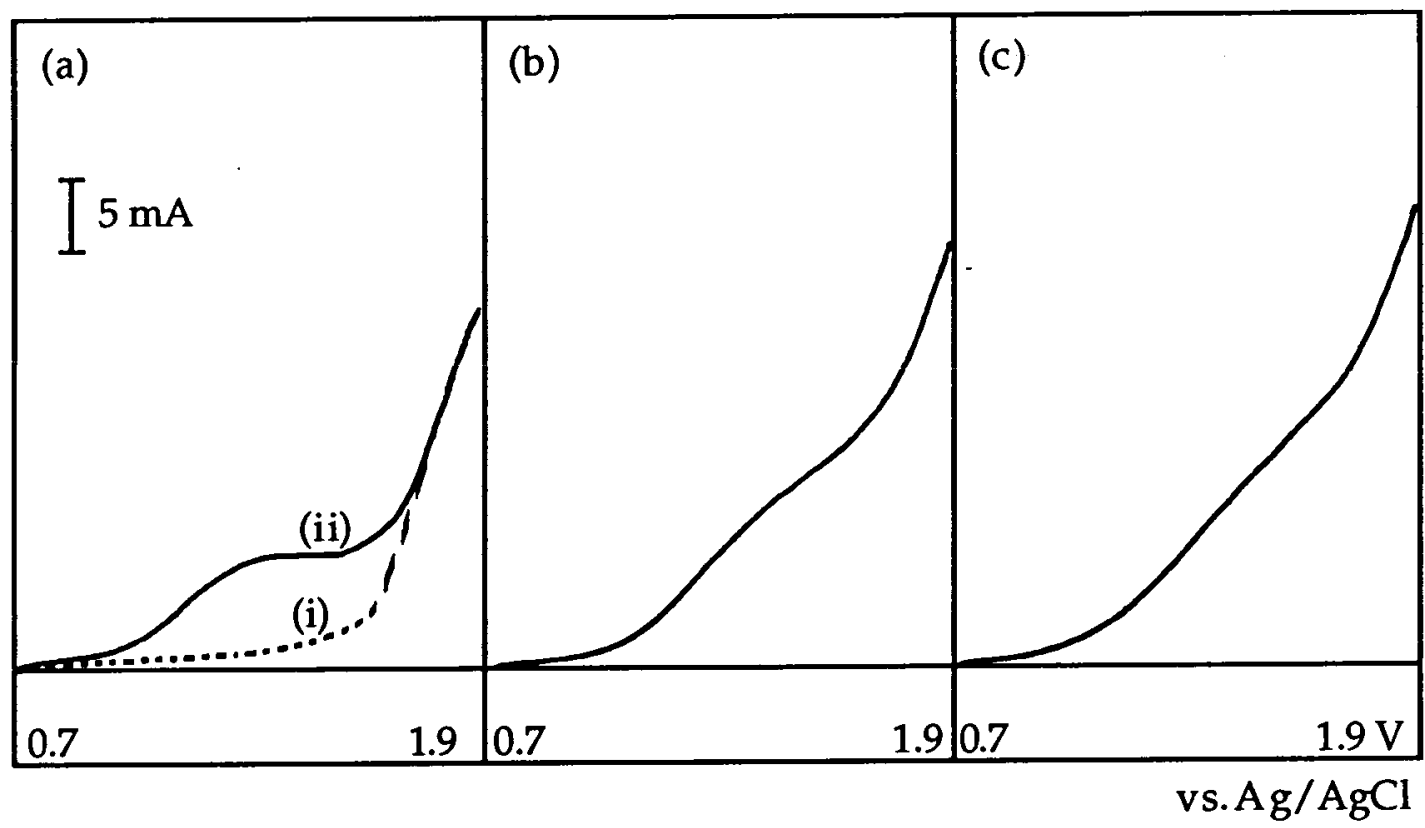

Figure 4.4: Voltammograms of sodium bromide in methanol with $\mathrm{NaClO}_{4}(0.1 \mathrm{M})$ as supporting electrolyte, recorded in flow cell 2 on the carbon bands from array CAGCL electrodes with $\mathrm{Ag} / \mathrm{AgCl}$ bands as reference electrode and a stainless steel plate as counter electrode. $100 \mathrm{mV} / \mathrm{sec}$. (a) no flow (i) $[\mathrm{NaBr}]=0.0 \mathrm{mM}$, (ii) $[\mathrm{NaBr}]=10 \mathrm{mM},($ b)

$$
\begin{gathered}
{[\mathrm{NaBr}]=10 \mathrm{mM}, \text { flow }=0.35 \mathrm{dm}^{3} \cdot \mathrm{min}^{-1},(\mathrm{c})[\mathrm{NaBr}]=10 \mathrm{mM},} \\
\text { flow }=0.55 \mathrm{dm}^{3} \cdot \mathrm{min}^{-1} .
\end{gathered}
$$




\section{4-2-2 Product and reactant analysis}

The concentration of the different organic species present in the electrolyte was monitored by gas chromatography, on a Carbowax column. The temperature program consisted of a 2 minute plateau at $60^{\circ} \mathrm{C}$, followed by an increase of $30^{\circ} \mathrm{C} / \mathrm{min}$. up to $170^{\circ} \mathrm{C}$. Helium at 30 psi was the carrier gas. In these conditions furan has a retention time of 0.8 minutes, DHDMF is detected after 4.7 minutes and the methanol peak appears after 1.0 minute. Calibration graphs obtained by injecting $0.5 \mu \mathrm{l}$ standards show a linear relationship between the amount injected and the area of the peaks, as can be seen in figure 4.5. This method allowed the product to be detected in a large concentration range. The lowest detectable level can be set at $0.01 \%$.

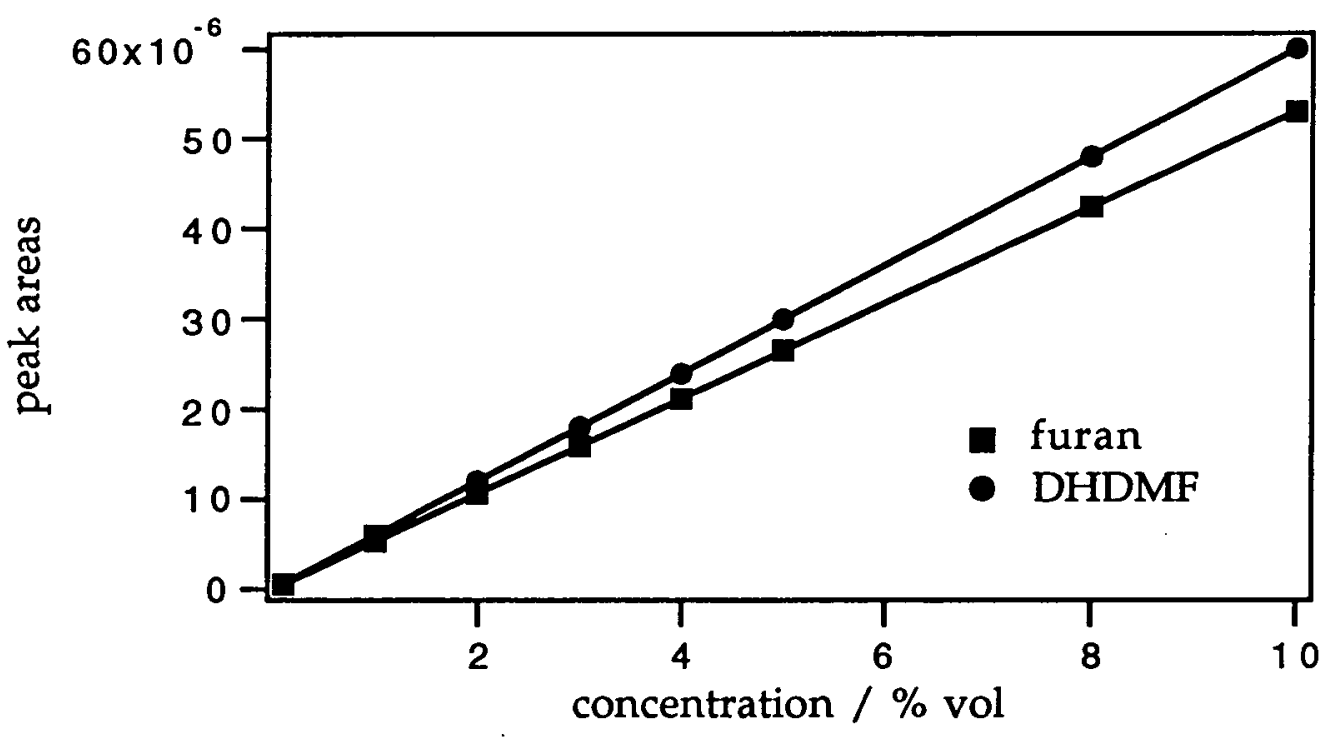

Figure 4.5: Furan and DHDMF calibration by Gas Chromatography. 
Figure 4.6 shows examples of chromatograms obtained at the beginning and at the end of an electrosynthesis.

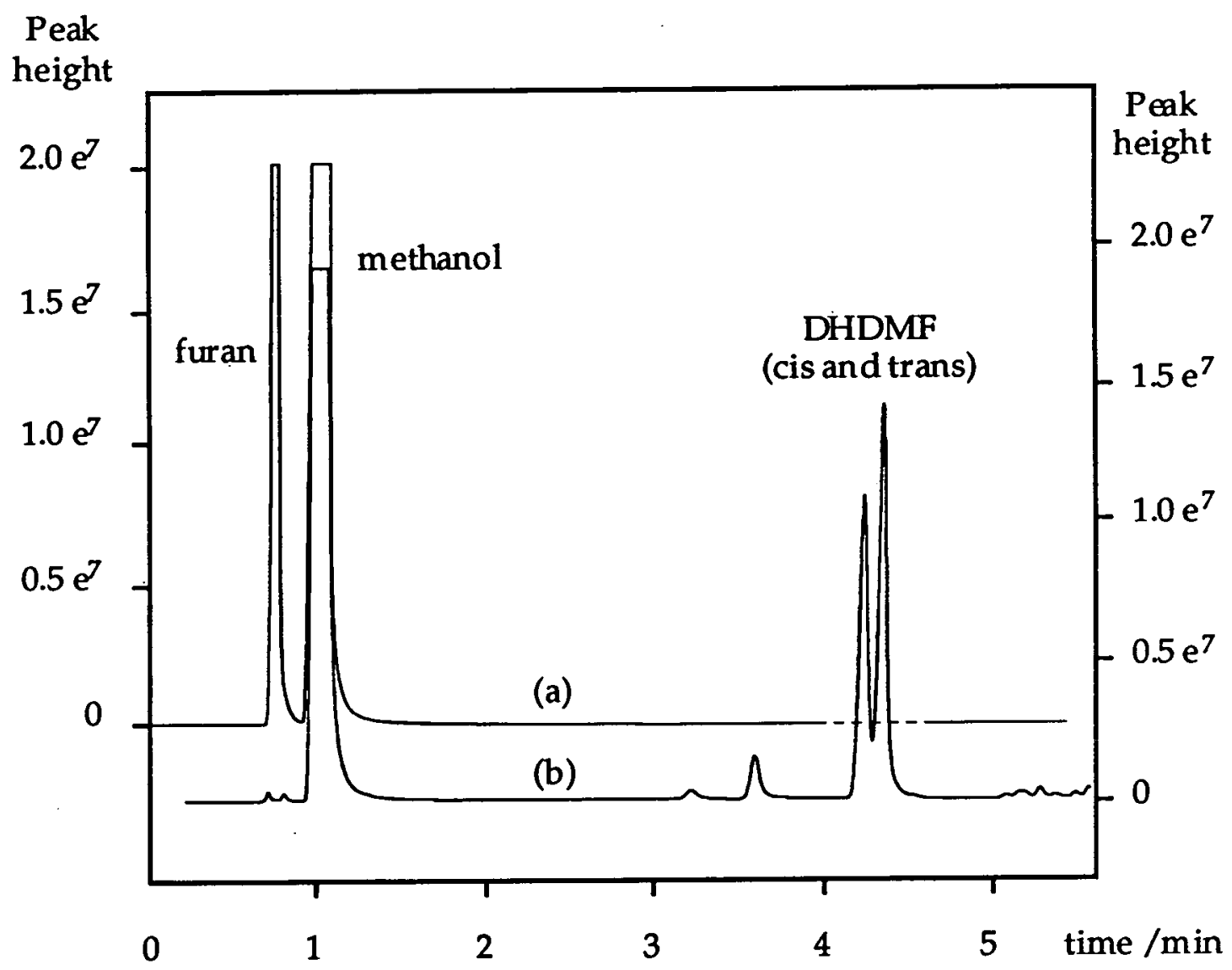

Figure 4.6: Chromatograms of electrolyte recorded (a) at the beginning and (b) at the end of an electrosynthesis with a platinum array PT3.

In order to assess the performance of interdigitated arrays, syntheses were carried out under several experimental conditions and were always performed until exhaustive consumption of furan. For an additional comparison, electrosyntheses were also performed with two parallel plate electrodes in the ICI cell and in flow cell 2. 


\section{4-3 Synthesis with two parallel plate electrodes in flow cells}

The performance of two filter-press cells were then determined. Several parameters have to be regularly recorded when investigating the performance of a cell. These include the concentration of the different compounds and the associated amount of electricity consumed. The values corresponding to the experiments in flow cell 2 and in the FM01 cell from ICI are found in table 4.1 and 4.2 respectively. The experimental conditions were the same for the two cells: the applied voltage was set at $3 \mathrm{~V}$, the electrolyte had a total volume of $250 \mathrm{ml}$ and it was forced to flow at $0.75 \mathrm{dm}^{3} \cdot \mathrm{min}^{-1}$. The sodium bromide concentration was $0.1 \mathrm{M}$ and furan was present at $10 \%$. The anode material was coated platinum for the FM01 cell and carbon foil for cell 2. The electrosyntheses were stopped after 17 hours. The current densities, $1.2{\mathrm{~A} . \mathrm{dm}^{-2}}^{-2}$ for flow cell 2 and 0.7 A. $\mathrm{dm}^{-2}$ for the FM01 cell, were found to be constant over the time scale of the electrosynthesis.

For these two experiments, the decrease in the furan concentration and the increase in the DHDMF concentrations were found to be linearly proportional to the electrosynthesis time. Figure 4.7, for example, illustrates the evolution of the concentrations for the experiment carried out with flow cell 2.

The material yields, the current efficiencies, the energy consumption and the rate of production are calculated after 17 hours, from the data given in table 4.1 and 4.2 , and are reported in table 4.3 : 
Table 4.1: Concentrations and amount of charges recorded at different time during the furan methoxylation in flow cell 2.

\begin{tabular}{cccc}
\hline $\begin{array}{c}\text { time } \\
\text { / hours }\end{array}$ & $\begin{array}{c}\text { number of } \\
\text { charge } \\
/ \mathrm{C}\end{array}$ & $\begin{array}{c}\text { furan } \\
\text { concentration } \\
/ \mathrm{M}\end{array}$ & $\begin{array}{c}\text { DHDMF } \\
\text { concentration } \\
/ \mathrm{M}\end{array}$ \\
\hline 0 & 0 & 1.375 & 0 \\
2 & 2,160 & 1.26 & 0.03 \\
4 & 4,320 & 1.20 & 0.05 \\
8 & 8,640 & 1.08 & 0.11 \\
10 & 10,800 & 0.95 & 0.14 \\
13 & 14,040 & 0.87 & 0.19 \\
17 & 18,360 & 0.81 & 0.25 \\
\hline
\end{tabular}

Table 4.2: Concentrations and amount of charges recorded at different time during the furan methoxylation in the FM01 cell from ICI.

\begin{tabular}{cccc}
\hline $\begin{array}{c}\text { time } \\
\text { / hours }\end{array}$ & $\begin{array}{c}\text { number of } \\
\text { charge } \\
/ \mathrm{C}\end{array}$ & $\begin{array}{c}\text { furan } \\
\text { concentration } \\
/ \mathrm{M}\end{array}$ & $\begin{array}{c}\text { DHDMF } \\
\text { concentration } \\
/ \mathrm{M}\end{array}$ \\
\hline 0 & 0 & 1.375 & 0 \\
2 & 2,160 & 1.24 & 0.03 \\
4 & 4,320 & 1.15 & 0.05 \\
8 & 8,640 & 1.05 & 0.11 \\
10 & 10,800 & 1.01 & 0.14 \\
13 & 14,040 & 098 & 0.19 \\
17 & 18,360 & 0.95 & 0.125 \\
\hline
\end{tabular}




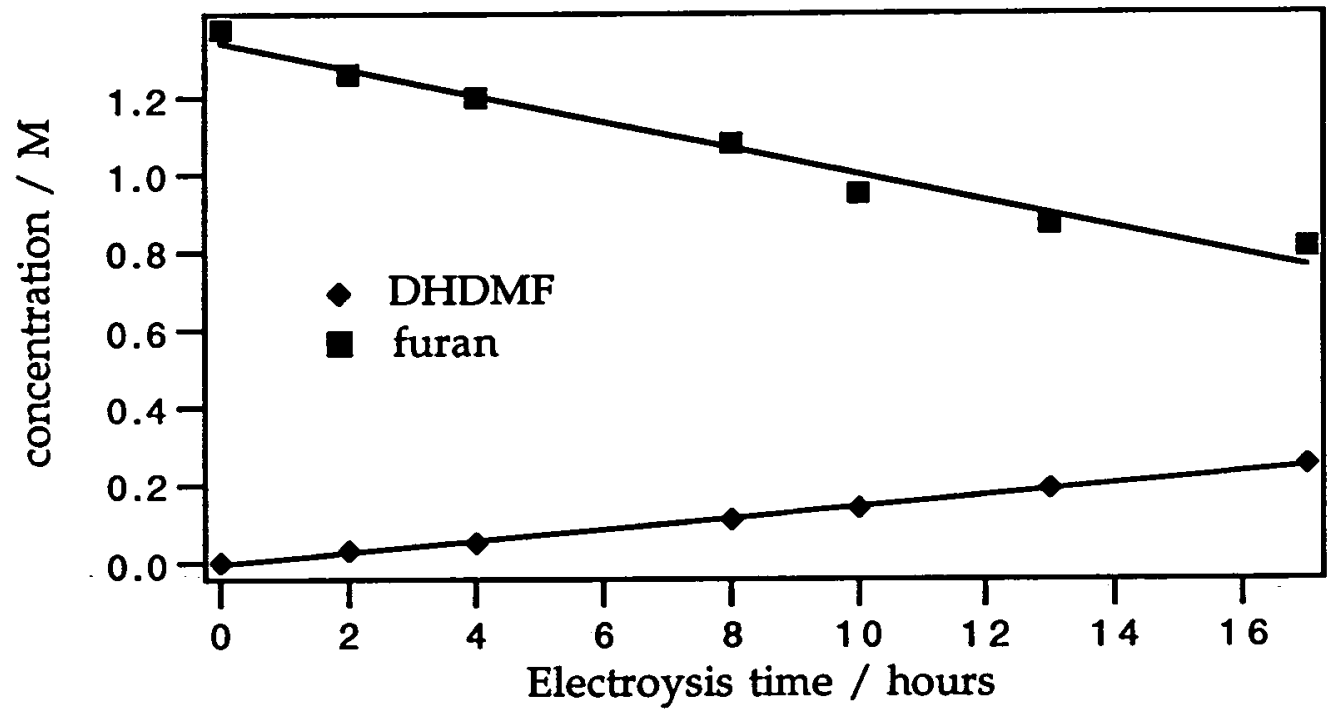

Figure 4.7: Evolution of the furan and the DHDMF concentration with time during an electrosynthesis in cell 2.

Table 4.3: Figures of merit for two parallel plate cells.

\begin{tabular}{lcc}
\hline cell & flow cell 2 & FM01 \\
\hline material yield / \% & 18.2 & 9.1 \\
current efficiency / \% & 66 & 33 \\
energy consumption / kWh.kg-1 & 1.87 & 3.74 \\
production rate / mol.dm ${ }^{-2} \cdot \mathrm{h}^{-1}$ & 0.015 & 0.003 \\
\hline
\end{tabular}


These figures show that the hydrodynamic mixing regimes in cell 2 are more favourable for the methoxylation of furan. However, this is very low compared to the bipolar packed bed cell performances [40] where a material yield of $90 \%$ can be reached with a current efficiency of $90 \%$ and an energy consumption of $3 \mathrm{kWh} . \mathrm{kg}^{-1}$. This relates well with the experiments carried out by N. R. Tomov and R: E. W. Jansson [39], who obtained a current yield about 3 times bigger in a bipolar packed bed cell than in a parallel plate cell.

\section{4-4 Synthesis with coplanar interdigitated electrodes}

\section{4-4-1 Experimental results}

A large number of experiments have been performed with coplanar interdigitated electrodes in order to show the effect of convection, applied voltage and size of the inter-electrode bandgap, on the overall array performances. Although carbon ink can give good analytical results for small time scale experiments, printed carbon arrays are found to be totally inappropriate for synthesis. Indeed, the resistance of the bands increases dramatically with time, until it becomes infinite, when the electrode has dissolved in the solvent. Platinum arrays are thus the electrode of predilection for electrosynthetic purposes. Similarly as for the previous experiments carried out with the parallel plate electrodes, product concentrations and associated quantities of electricity consumed need to be regularly determined. Experiments take place in flow cell 3 or in the tank reactor described in chapter 2, and are stopped when no furan remains in the electrolyte. From all the experiments carried out it should be stressed that although traces of several by-products are found, effectively only one major coproduct has any affect on the yields. This is highlighted 
by figure 4.6. In contrast with the parallel plate electrodes, high current densities are recorded for comparable applied voltage and bromide concentration. They are found to be constant with time and to vary in the range 3.5 to $18.7 \mathrm{~A} . \mathrm{dm}^{-2}$, depending on the experimental conditions. Current efficiencies and energy consumptions are very stable with time. Their final values for different experimental conditions can be found in table 4.4, where current densities, electrosynthesis time, final DHDMF concentrations, material yields and production rates are also reported.

\section{4-4-2 Effect of the convection on the cell performance}

For this electrochemical experiment, the dominant mass transport regimes are convection and diffusion. In the flow cell, at the given flow rate, the Reynolds number is low $(\operatorname{Re}=300)$ and convection is purely laminar. In the tank cell, however, the convection is more complex as it is due to the combination of the random processes of magnetic stirred agitation and gas evolution. Hydrogen formed at the cathodes rises vertically against the array, thus producing a micro flow. Results of experiment 4-6 (see table 4.4) are analysed here. As can be seen in figure 4.8 , for both tank cell and flow cell, the furan conversion into DHDMF increased very regularly with the amount of charge passed through the cell per unit volume of electrolyte, to reach comparable values for both cells. Furthermore, the experiments carried out in the tank reactor and in the flow cell with array PT2 at 3 and $5 \mathrm{~V}$ show that the flow conditions have little effect on current efficiency and energy consumption. This is extremely interesting as it implies that syntheses can be performed in a tank reactor instead of a flow cell, suppressing pumping cost and removing all the problems associated with complex installations. 
Table 4.4: Figures of merit for the methoxylation of furan carried out with different experimental conditions, with platinum coplanar band electrodes.

\begin{tabular}{|c|c|c|c|c|c|c|c|c|c|c|}
\hline $\begin{array}{c}\text { Experi- } \\
\text { ment }\end{array}$ & Array & $\begin{array}{c}\text { flow / } \\
\text { dm }^{3} \cdot \min ^{-1}\end{array}$ & $\begin{array}{c}\text { applied } \\
\text { voltage / } \\
\text { V }\end{array}$ & $\begin{array}{c}\text { current } \\
\text { density / } \\
\text { A.dm-2 }\end{array}$ & $\begin{array}{c}\text { final } \\
\text { time / h }\end{array}$ & $\begin{array}{c}\text { final } \\
\text { [DHDMF] } \\
\text { mol.dm-3 }\end{array}$ & $\begin{array}{c}\% \\
\text { material } \\
\text { yield }\end{array}$ & $\begin{array}{l}\text { \% current } \\
\text { efficiency }\end{array}$ & $\begin{array}{c}\text { energy } \\
\text { consumption } \\
\text { / kWh.kg-1 }\end{array}$ & $\begin{array}{l}\text { production } \\
\text { rate / } \\
\text { mol.dm }{ }^{-2} \cdot h^{-1}\end{array}$ \\
\hline 1 & PT1 & - & 3 & 4.7 & 47.8 & 0.064 & 46 & 61 & 2.0 & 0.054 \\
\hline 2 & PT2 & 0.2 & 2.5 & 3.5 & 50.1 & 0.45 & 33 & 68 & 1.5 & 0.045 \\
\hline 3 & PT2 & 0.2 & 3 & 6.2 & 45.1 & 0.78 & 57 & 75 & 1.6 & 0.086 \\
\hline 4 & PT2 & 0.2 & 5 & 18.7 & 26.6 & 1.04 & 76 & 70 & 2.9 & 0.244 \\
\hline 5 & PT2 & - & 3 & 5 & 20.4 & 0.87 & 63 & 83 & 1.4 & 0.159 \\
\hline 6 & PT2 & - & 5 & 15 & 20.5 & 1.03 & 75 & 67 & 3.1 & 0.188 \\
\hline 7 & PT3 & - & 3 & 14 & 14.3 & 1.08 & 78 & 87 & 1.4 & 0.226 \\
\hline 8 & PT4 & - & 3 & 8.5 & 26.11 & 0.73 & 53 & 75 & 1.6 & 0.120 \\
\hline
\end{tabular}




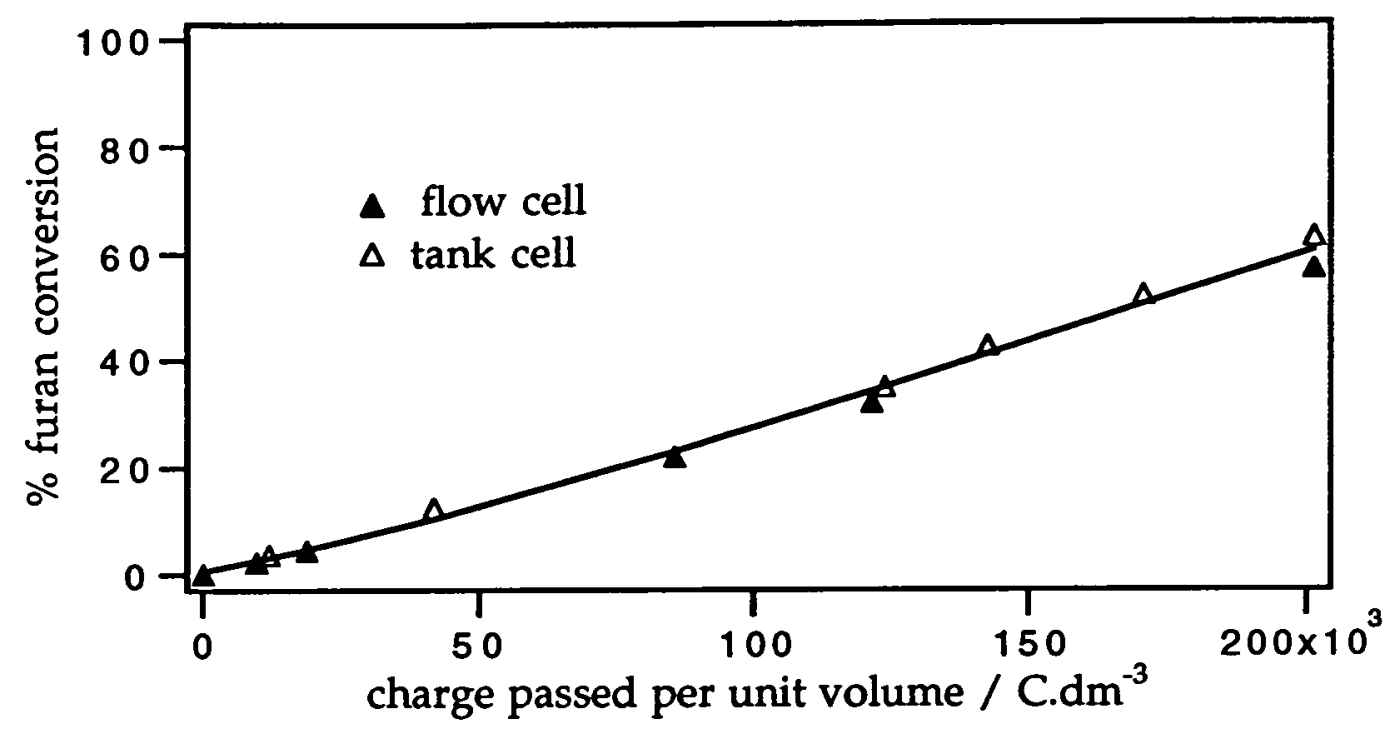

Figure 4.8: Evolution of the furan conversion into DHDMF with the amount of electricity passed through the cell, for electrosyntheses carried out in a tank reactor or in flow cell 3, with array PT2, and an applied potential of $3 \mathrm{~V}$.

\section{4-4-3 Effect of the applied voltage on the cell performance}

The effect of the applied potential on the cell performance is characterised by analysing the results obtained with experiment 2-4 and 5, 6 (see table 4.4). Figure 4.9 represents the increase of the furan conversion into DHDMF with the amount of charge passed through the cell, for syntheses carried out in the flow cell with array PT2, at three different potentials. As in figure 4.8, a very good correlation exists for the three applied voltages. However it should be noticed that the electrosynthesis time and the material yield are particularly affected by the value of the applied voltage. The material yield for example varies from 33 to $76 \%$ when the potential is increased from 2.5 to $5 \mathrm{~V}$, and the electrosynthesis time is reduced from 50 to 26 hours. It thus appears that the degradation of DHDMF is more pronounced for a long electrosynthesis time occurring at low applied voltage. 


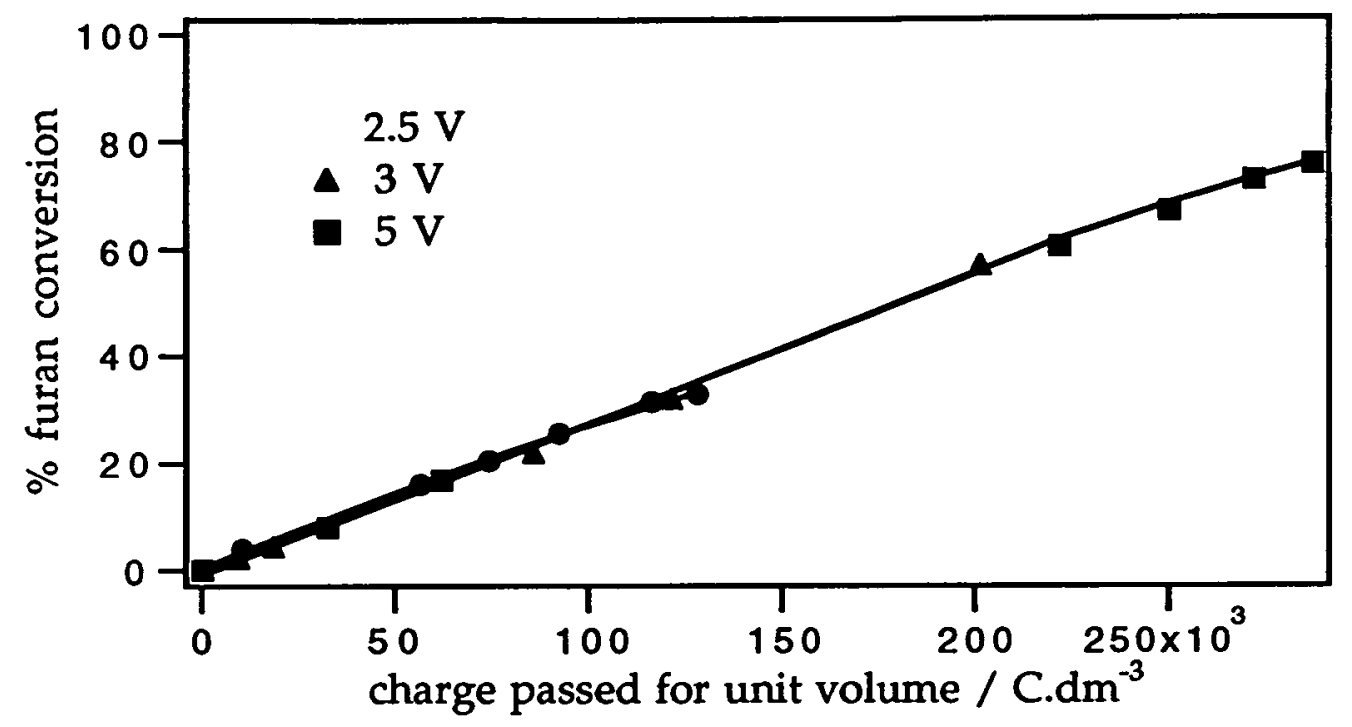

Figure 4.9: Evolution of the furan conversion into DHDMF with the amount of electricity passed through the cell for unit volume electrolyte, for electrosyntheses carried out at different potentials in a tank reactor with array PT2.

The values of the material yield are also reported in figure 4.10 , with the corresponding current efficiency and energy consumption.

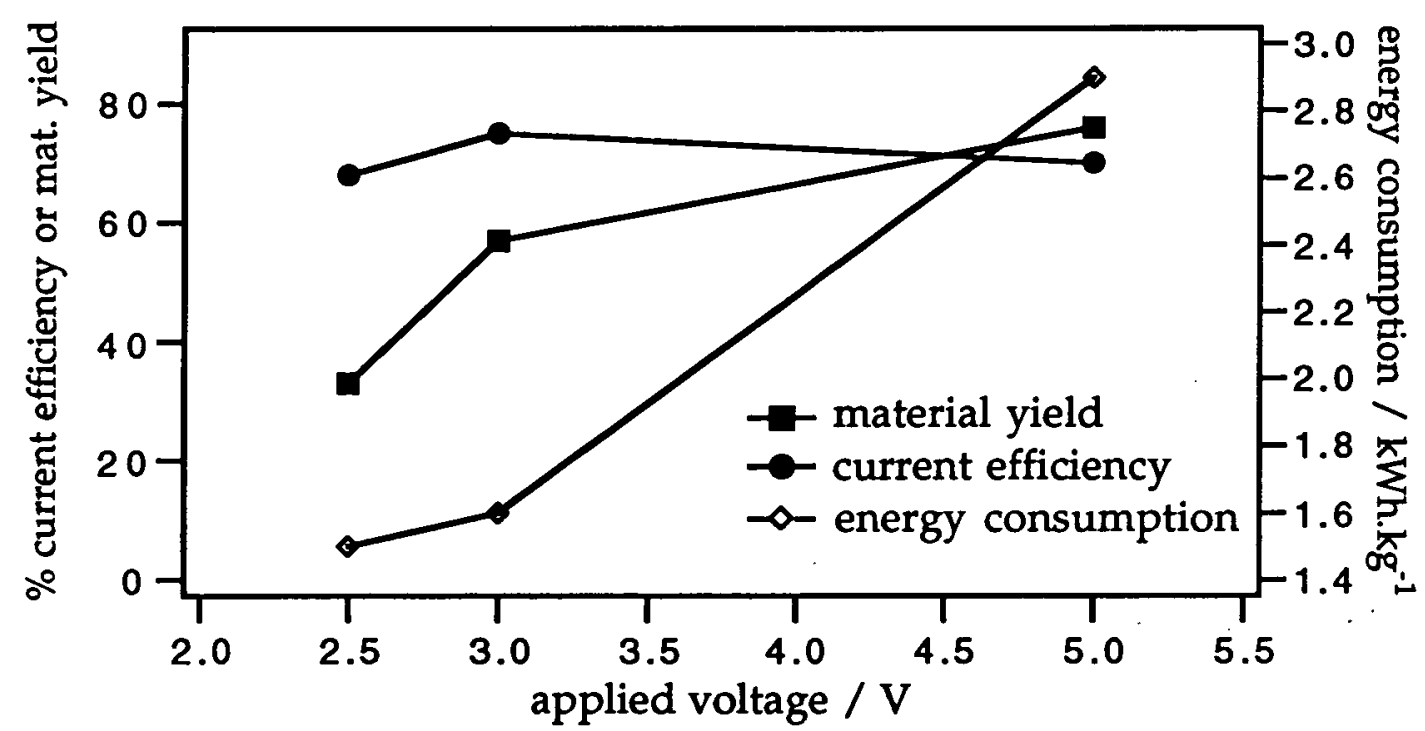

Figure 4.10: Effect of the applied voltage on the three figures of merit for electrosynthesis performed in a tank reactor with array PT2. 
The current yield is affected by the applied voltage to a lesser extent than the material yield. It varies in the range of 68 to $75 \%$, with the optimum value obtained at $3 \mathrm{~V}$. The experiments carried out by M. J. Medeiros et al [46] on platinum microdisc electrodes showed that a steady-state plateau could be obtained for the sodium bromide oxidation in methanol. The bromide oxidation potential at the platinum array is however difficult to determine with accuracy as the solvent electrolysis occurs at the same potential. It can, however, be estimated as $3 \mathrm{~V}$. The energy consumption varies sensibly with the applied potential, its value almost doubling when the voltage is increased from 3 to $5 \mathrm{~V}$. It is therefore more advantageous to carry out the synthesis at low voltage. The choice of the optimum applied voltage results from a compromise and can be set at $3 \mathrm{~V}$. However, in this compromise, the importance of the production rate is not taken into account. When DHDMF has to be produced in large quantities however, higher voltages should be chosen, even though this is to the detriment of the energy consumption. Figure 4.11 illustrates the influence of the applied voltage on the production rate, for the coplanar band arrays with two different convection regimes, and also for the parallel plate electrodes. From this figure, it can be seen that good mixing conditions become necessary when high voltages are applied, or in other words to gain high production rates. Finally, it should be stressed that DHDMF is produced with considerably higher rates when coplanar band arrays are used, rather than parallel plate electrodes. 


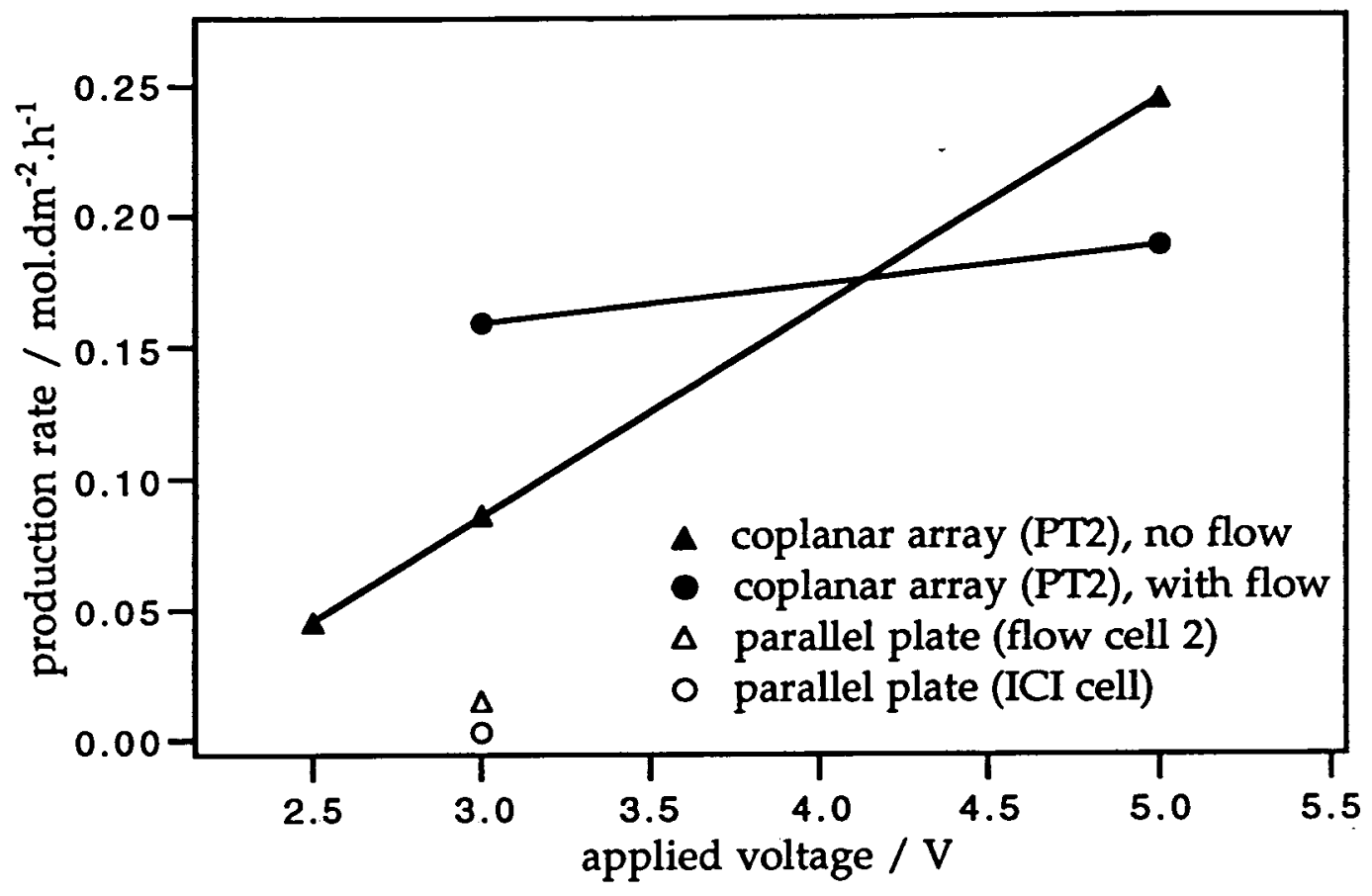

Figure 4.11: Effect of the applied voltage on the production rate for different cells and different convection regimes.

\section{4-4-4 Effect of the inter-electrode distance on the cell performance}

The advantage of having small inter-electrode distances was illustrated by performing electrosyntheses in the tank reactor on arrays with $1 \mathrm{~mm}$ bandwidth electrodes and inter-electrode distances varying in the range $1 \mathrm{~mm}$ to $250 \mu \mathrm{m}$ (experiments 1,5 and 7). Figure 4.12 shows the evolution of the furan conversion into DHDMF for three different arrays, as the amount of electricity passed through the cell was increased. Reducing the bandgap has the effect of increasing the material yields. This is an important aspect and a possible explanation of such a phenomenon is the neutralisation of the protons, responsible for the DHDMF degradation, by the methanolic ions produced at the adjacent band electrode. The effect of decreasing the bandgap is also illustrated in figure 4.13, where the current efficiencies, the material yields and the energy consumptions are reported. 


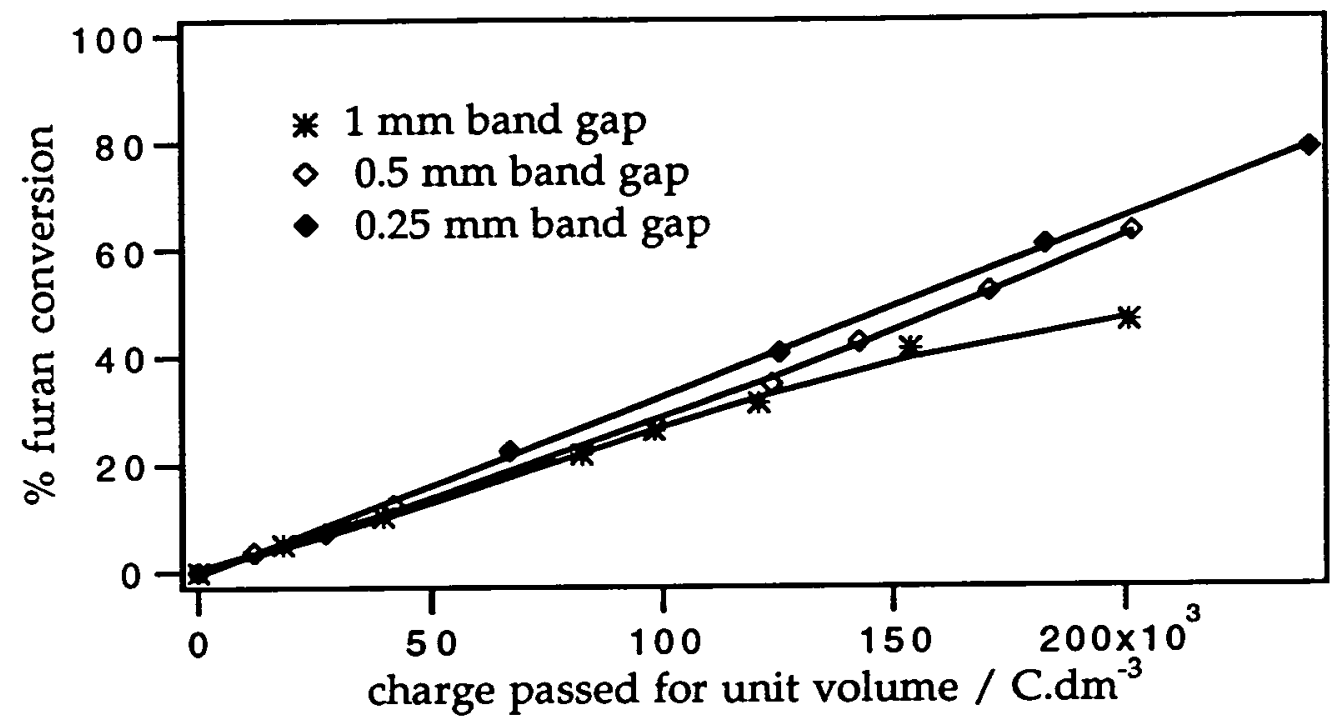

Figure 4.12: Evolution of the furan conversion into DHDMF with the amount of electricity passed through the cell for unit volume of electrolyte and for electrosyntheses performed on different platinum arrays in a tank reactor with an applied potential of $3 \mathrm{~V}$.

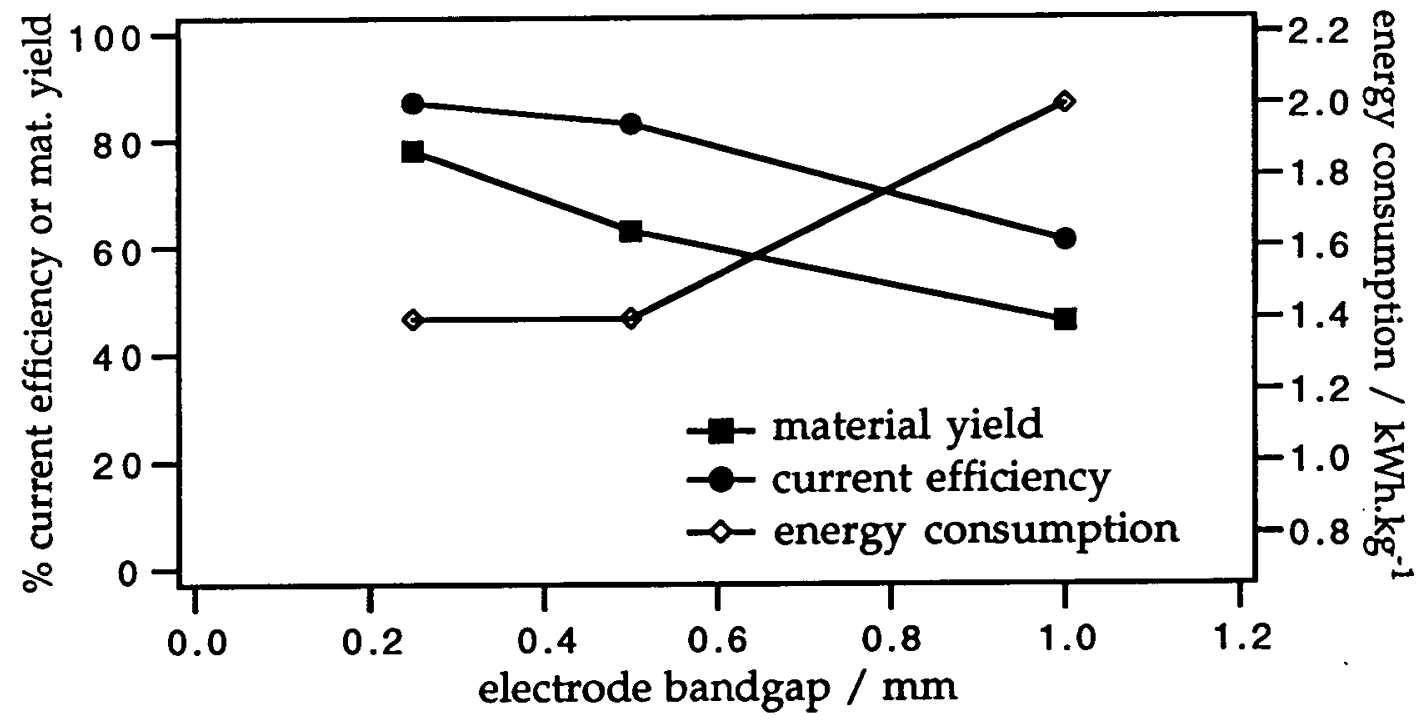

Figure 4.13: Effect of the electrode bandgap on the three figures of merit for electrosynthesis performed in a tank reactor with an applied voltage of $3 \mathrm{~V}$. 
As with the material yield, the current efficiency is optimised by decreasing the bandgap and reaches a value of $87 \%$ for a $250 \mu \mathrm{m}$ gap. A further improvement can be expected by reducing the inter-electrode distance. The thickness of the diffusion layer depends on many factors, such as the type and amount of convection, the geometry of the electrode and the presence of gas evolution [48]. In our case, it can be estimated to be in the order of 50 to $100 \mu \mathrm{m}$, which is less than the smallest inter-electrode distance investigated here. It would be interesting to decrease the interelectrode distances to values comparable to the diffusion layer thickness. This should be possible by serigraphy, but would require a dust-free environment.

The energy consumption also decreases with the bandgap but stabilises at $1.4 \mathrm{kWh} . \mathrm{kg}^{-1}$ below $500 \mu \mathrm{m}$, although this value is higher than the value estimated thermodynamically $\left(0.6 \mathrm{kWh} . \mathrm{kg}^{-1}\right)$. This figure of merit compares particularly favourably with the performance of a bipolar packed bed, considered so far as the most efficient cell for this reaction [40]. Indeed the energy consumption is decreased by a factor of 2 .

The current density is also significantly affected by the value of the inter-electrode distance. As a consequence higher production rates are obtained for small bandgaps. This is illustrated by figure 4.14, where production rates and current densities are reported as functions of inter-electrode distances. 


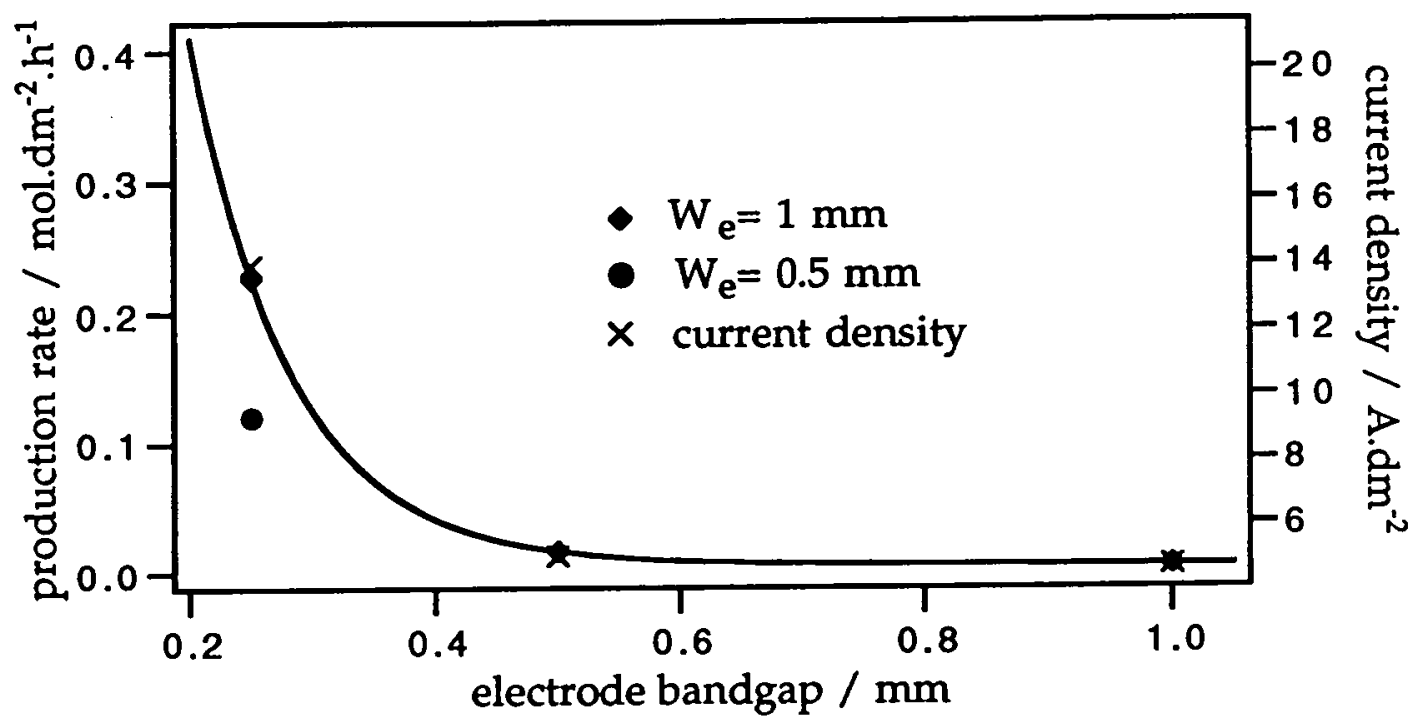

Figure 4.14: Variation of the production rate with the electrode bandgap, for band electrode of $1 \mathrm{~mm}$ and $0.5 \mathrm{~mm}$ width.

Again it is confirmed that a small inter-electrode distance is essential for the good performance of the cell. For the $250 \mu \mathrm{m}$ bandgap array with an applied potential of $3 \mathrm{~V}$ and with no flow, the production rate reaches a value of 0.23 mol.dm-2.h-1 This compares extremely well with production rates obtained, for similar experimental conditions, with the pump cell $\left(0.8 \mathrm{~mol} . \mathrm{dm}^{-2} \cdot \mathrm{h}^{-1}\right)$ and the bipolar packed bed cell $\left(0.018 \mathrm{~mol} \cdot \mathrm{dm}^{-2} \cdot \mathrm{h}^{-1}\right)$. In this comparison it should be noticed that the geometry of these three cells differs considerably. In the pump cell the entire surface of the electrode is active. In contrast, with the bipolar configuration, each electrode acts as a cathode on one side, and as an anode on the other side. A large portion of the electrode is thus inactive. In chapter 3, it was shown that the current density on coplanar band electrodes decreases extremely rapidly as the distance from the gap is increased. This means that, as with the bipolar packed bed cell, only a small portion of the electrode is effective. In this chapter, it was also 
shown that reducing the electrode bandwidth should increase the fraction of active area. Unfortunately, results obtained with array PT4 show that reducing the band width from 1 to $0.5 \mathrm{~mm}$ worsens the performance of the array. This could be due to the small increase in the electrode resistance or to the irregularity of the array. However without more data it is not possible to suggest an optimal bandwidth.

\section{4-5 Conclusion}

Although carbon ink is a very advantageous product and gives good results on a short time scale, its use for electrosyntheses in organic media must be abandoned unless better polymer binders can be found. In contrast the behaviour of platinum arrays is very satisfactory. From all the experiments carried out, the selectivity of the methoxylation of furan performed on coplanar band electrodes must be stressed. In contrast with classical electrode configurations, very good results can be obtained in a tank reactor. This has the immense advantage of limiting the pumping and the maintenance costs. The optimal experimental conditions appears to be attained with the smallest inter-electrode distances and when the differential potential is set at $3 \mathrm{~V}$. The performance of a $250 \mu \mathrm{m}$ bandgap array immersed in a tank reactor, for example, compares favourably with the performance of a bipolar packed bed cell and the pump cell, considered until now as the most efficient cells. Table 4.5 gives a comparative report of the figures of merit obtained with the different cell geometries. 
Table 4.5: Comparative performances of different cell configurations, for the methoxylation of furan.

\begin{tabular}{lccc}
\hline figures of merit & $\begin{array}{c}\text { PT3 in } \\
\text { a tank cell }\end{array}$ & $\begin{array}{c}\text { pump } \\
\text { cell }\end{array}$ & $\begin{array}{c}\text { bipolar } \\
\text { packed } \\
\text { bed cell }\end{array}$ \\
\hline material yield / \% & 78 & 85 & 90 \\
current efficiency / \% & 87 & 80 & 90 \\
energy consumption/ $\mathrm{kWh} \cdot \mathrm{kg}^{-1}$ & 1.4 & 3 & 3 \\
production rate / mol.dm-2.h-1 & 0.23 & 0.8 & 0.018 \\
\hline
\end{tabular}

The $78 \%$ material yield achieved with the interdigitated array is less than with the bipolar packed bed cell, but could be improved by increasing the electrode area with respect to the cell volume in order to limit the total time of reaction and thus the DHDMF degradation. No major change is noticed in the current efficiency. The most favourable aspects is the gain of $50 \%$ in the energy consumption which can be made with the coplanar band electrode geometry. Furthermore the production rate obtained in a tank reactor with this cell geometry is comparable with the rate obtained with the pump cell, which is mainly characterised by its efficient mixing conditions. The methoxylation of furan is thus a good example of electrosynthesis that can be performed with band arrays.

To follow this investigation a cell geometry optimisation, as well as a scale up should be carried out. 


\section{CHAPTER 5}

The Kolbe synthesis

\section{5-1 Bibliography}

The Kolbe synthesis is the oldest and probably the most useful electrosynthesis in organic chemistry. It allows the preparation of coupled products via the anodic oxidation of carboxylic acid salts. The first study of this reaction was carried out in 1849 [49], the global reaction being:

$$
2 \mathrm{RCOO}^{-} \rightarrow \mathrm{R}-\mathrm{R}+2 \mathrm{CO}_{2}+2 e^{-}
$$

Among all the detailed mechanisms proposed subsequently [50,51], only the mechanism involving the decarboxylation of the acyloradical intermediate [52] can be viably retained:

$$
\begin{aligned}
& R \mathrm{COO}^{-} \rightarrow \mathrm{RCOO}^{*}+e^{-} \\
& R \mathrm{COO}^{\circ} \rightarrow R^{\bullet}+\mathrm{CO}_{2} \\
& R^{\bullet}+R^{\bullet} \rightarrow \mathrm{RR}
\end{aligned}
$$

This theory was completed more recently by L. Eberson [53], who showed that radicals could undergo a further oxidation forming the carbonium ions from which a range of other products can be derived:

$$
\begin{aligned}
& R^{\bullet} \underset{R^{+}}{\underset{\text { Nucleophile }}{\longrightarrow}} R-R^{+}+e^{-} \\
& R^{+}+R H-H_{2}
\end{aligned}
$$

Where $\mathrm{RH}-\mathrm{H} 2$ is the unsaturated form of $\mathrm{RH}$. 
A very large number of by-products can be obtained such as $\mathrm{RH}, \mathrm{RH}-\mathrm{H}_{2}$, $\mathrm{ROH}, \mathrm{ROOCR}$ or ROMe derived from disproportionation, rearrangement, or reaction of intermediates with species present in solution.

The Kolbe synthesis has been the subject of a great number of publications since its original disclosure. Problems associated with kinetic or adsorption aspects are still being solved [54-56]. Very complete reviews $[57,58]$ show the influence of different experimental parameters on the yields of electrosynthesis products. From this it should be noticed that the reaction occurs at a very high anode potential, suppressing in some cases the oxidation of the solvent. Current densities greater than $25 \mathrm{~A} / \mathrm{dm}^{2}$ are often recommended. The electrode material giving the best results in aqueous or non aqueous solvents is smooth platinum. Although aqueous solutions do not limit the reaction, organic media are often chosen to ease the separation process. The $\mathrm{pH}$ of the electrolyte should be slightly acidic to avoid the formation of carbonium ions. Temperature has very little effect on the reaction. Finally it is worth remembering that the highest yields are obtained with starting materials containing long alkyl chains.

Applications of this synthesis in the industry include the production of dimethylsebacate, an important starting material for many compounds:

$2 \mathrm{CH}_{3} \mathrm{OOC}-\left(\mathrm{CH}_{2}\right)_{4}-\mathrm{COO}^{-} \rightarrow \mathrm{CH}_{3} \mathrm{OOC}-\left(\mathrm{CH}_{2}\right)_{8}-\mathrm{COOCH}_{3}+2 \mathrm{CO}_{2}+2 e^{-}$

There exist no efficient and economical chemical routes for this conversion, except by using ricinoleic acid contained in castor oil. It was shown however that high material or current yields could be obtained with capillary gap or vibrating cells [59]. BASF built a capillary gap cell 
pilot plant able to produce 100 tonnes a year [6]. With bipolar platinum graphite electrodes, material yield could reach $80 \%$ for a current efficiency of $64 \%$ and an energy consumption of $4 \mathrm{kWh} . \mathrm{kg}^{-1}$. Similar results were obtained by a Russian group [60]. Experiments carried out in methanol showed that monomethyl adipate should only be partially neutralised with base, for example $\mathrm{Na}_{2} \mathrm{CO}_{3}$ or $\mathrm{NaOCH}_{3}$ [61].

\section{5-2 Calibration and preliminary experiments}

\section{5-2-1 Investigation of the electrochemical system}

Monomethyl adipate has to be partially neutralised to react at the electrode and also to provide conducting species in the electrolyte. This can be done by adding sodium hydroxide. The titration curves given in figure 5.1 proves that one mole of sodium hydroxide is needed to react with one mole of monomethyl adipate.

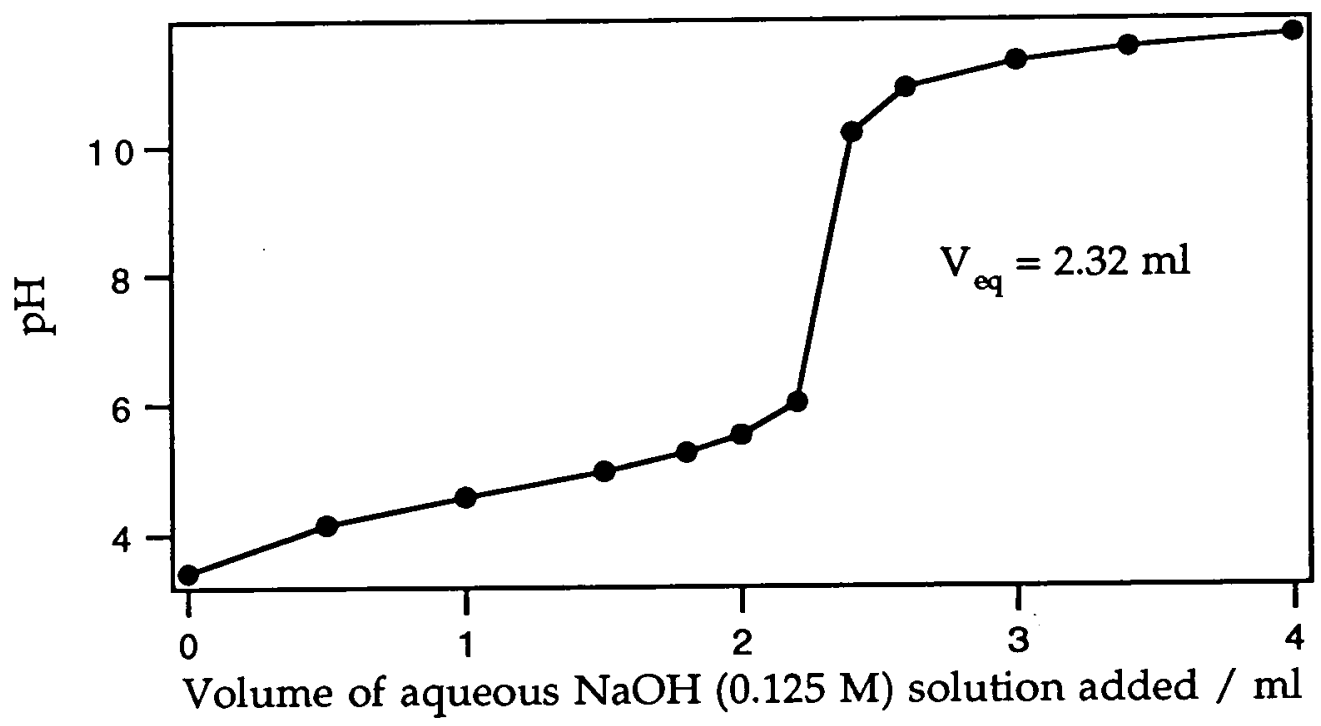

Figure 5.1: Potentiometric neutralisation of monomethyl adipate in water $(0.28 \mathrm{mmol})$, by sodium hydroxide $(0.125 \mathrm{M})$. 
At the equivalent point, $0.29 \mathrm{mmol}$ of sodium hydroxide solution is added, which corresponds well with the $0.28 \mathrm{mmol}$ monomethyl adipate initially present in the solution. J. Haufe and F. Beck [62] showed that in capillary gap cells, material and current yields could be increased by minimising the fraction of neutralised monomethyl adipate. This fraction was chosen in the range $10 \%$ to $50 \%$.

The Kolbe reaction was first studied with a three electrode system. The potential of a smooth platinum electrode was linearly swept between 0 and $6 \mathrm{~V}$ with respect to the potential of a calomel reference electrode. The corresponding voltammogram can be found in figure 5.2, and is characteristic of the behaviour of the smooth platinum for the Kolbe reaction. The methanol starts to oxidise at approximately $2 \mathrm{~V}$ and oxygen is formed at the electrode. The gas evolution stops after $4 \mathrm{~V}$, where the oxidation of monomethyl adipate takes place.

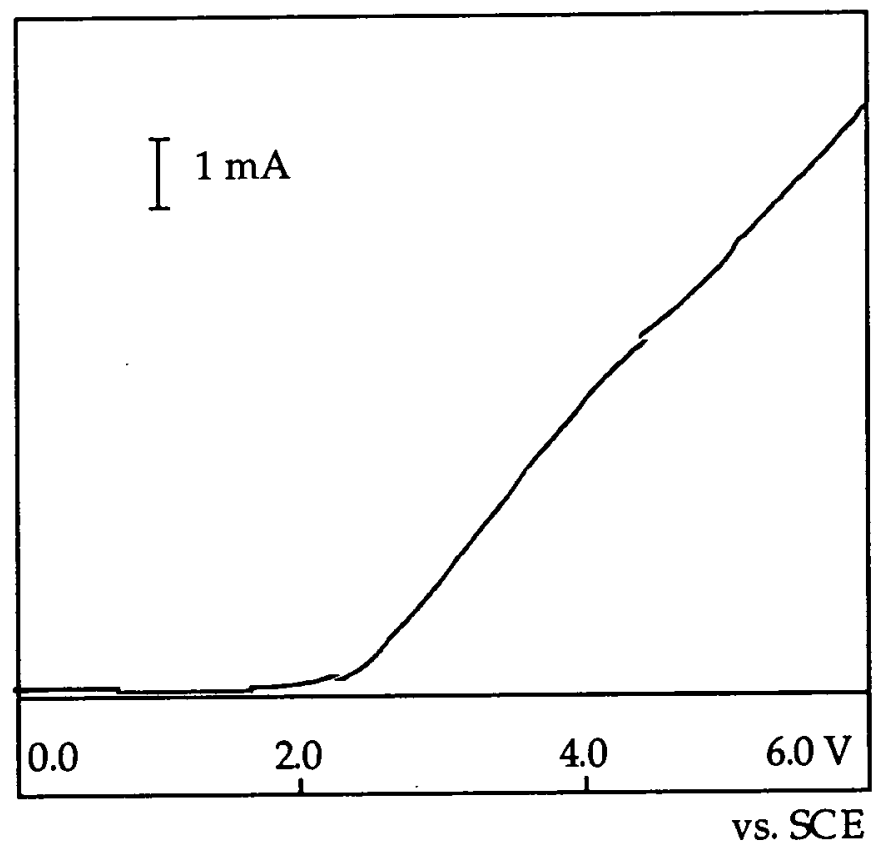

Figure 5.2: Voltammogram of monomethyl adipate, $100 \mathrm{~g} \cdot \mathrm{dm}^{-3}$, neutralised at $50 \%$ with sodium hydroxide in methanol, recorded with a $2.80 \mathrm{~mm}$ shiny platinum disc working electrode and a calomel reference electrode at $100 \mathrm{mV} \cdot \mathrm{sec}^{-1}$. 
When the shiny disc electrode was replaced by a $1 \mathrm{~cm}^{2}$ platinum printed electrode, the methanol oxidation also began at approximately $2 \mathrm{~V}$, but it is not stopped by the Kolbe reaction. As a result it is not possible to determine the minimum potential at which the electrode should be set for the reaction to take place.

\section{5-2-2 Product and reactant analysis}

Syntheses were performed in methanol with $100 \mathrm{~g} / 1$ monomethyl adipate partially neutralised with methanolic sodium hydroxide. Samples were regularly extracted and directly analysed by gas chromatography. The temperature of the oven was set initially at $100^{\circ} \mathrm{C}$, and after the injection it was increased at a rate of $70^{\circ} \mathrm{C} \cdot \mathrm{min}^{-1}$. It was then maintained at $200^{\circ} \mathrm{C}$ for 7 minutes. In these conditions compounds could be separated in a relatively short time. Figure 5.3 shows a chromatogram recorded for a mixture containing monomethyl adipate (MMA) and dimethyl sebacate (DMS) at $10 \%$ volume in methanol. Retention times can be found in table 5.1. As can be seen in figure 5.4, the calibration graph obtained for DMS shows that the peak area is linearly proportional to the product concentration, and the lowest detectable amount is set at $0.01 \%$. The same establishment can be made for the MMA calibration. However one has to be very cautious with the monitoring of this compound, as MMA, in its neutralised form, is retained in the column.

Table 5.1: Retention of the compounds present in the electrolyte.

\begin{tabular}{cc}
\hline compound & retention time / min \\
\hline methanol & 0.6 \\
DMS & 3.5 \\
MMA & 5.2 \\
\hline
\end{tabular}




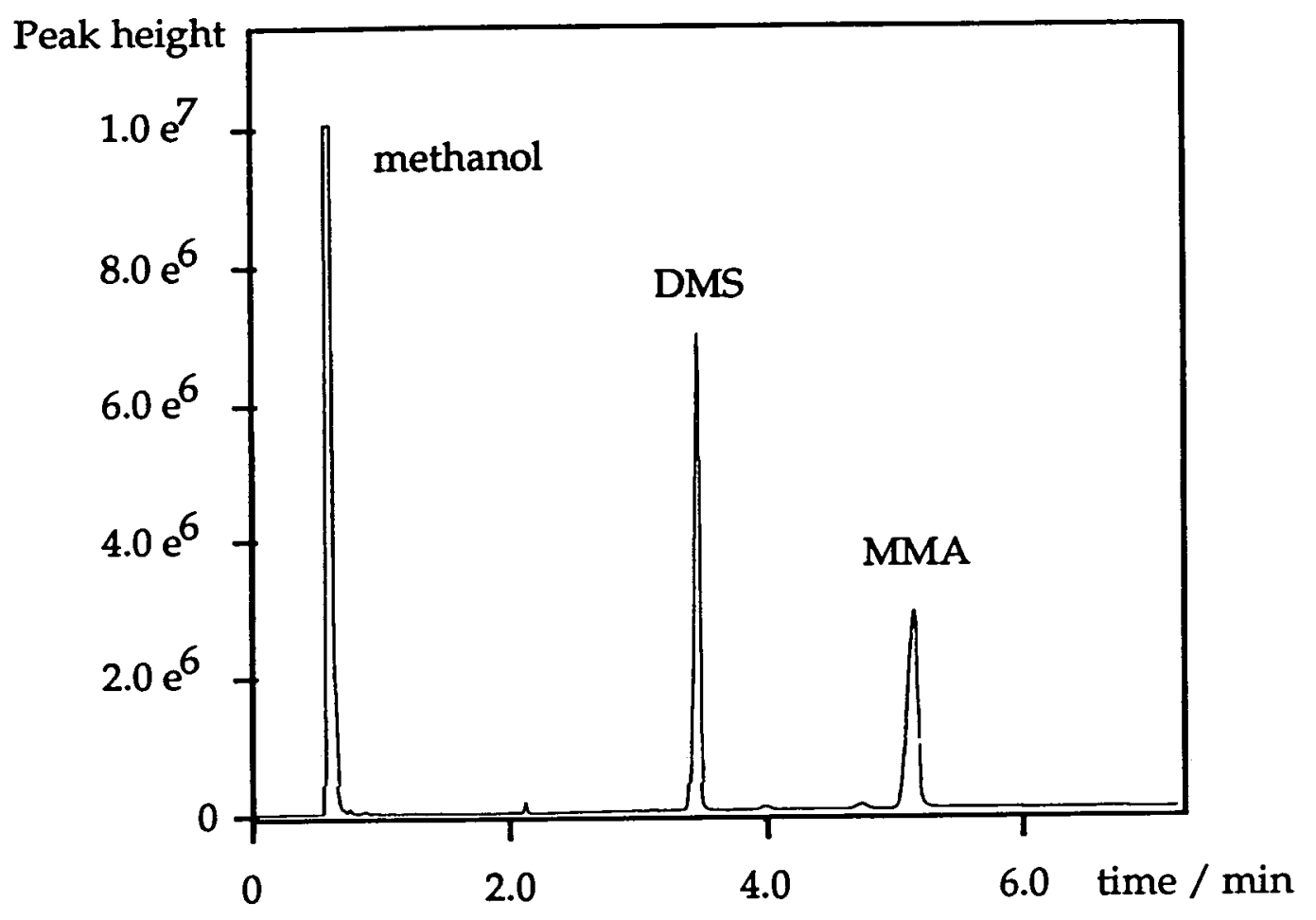

Figure 5.3: Gas chromatogram of a $0.5 \mu \mathrm{m}$ sample containing DMS and MMA at $10 \%$ volumetric in methanol.

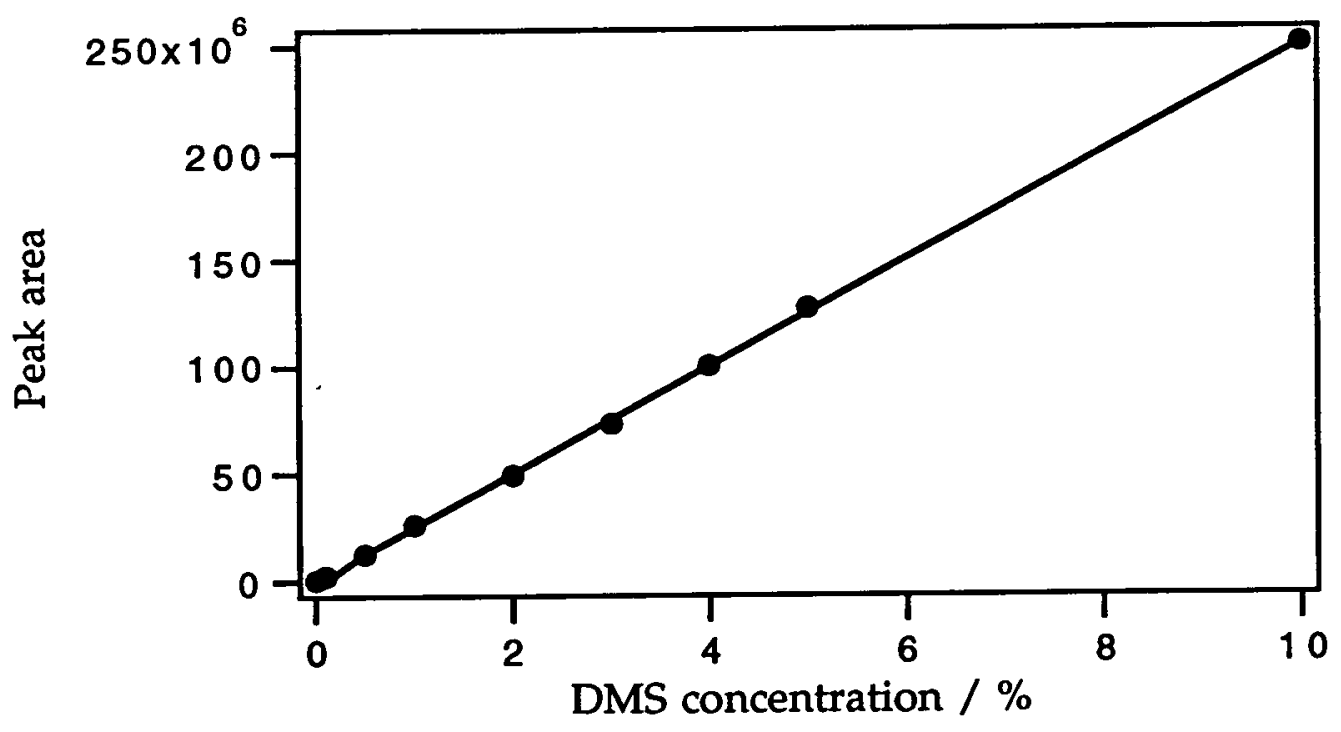

Figure 5.4: DMS calibration by Gas Chromatography. 


\section{5-3 Synthesis in a two parallel plate cell}

As for the methoxylation of furan, the Kolbe reaction was also performed with two parallel electrodes in a flow cell and with platinum arrays in a flow cell or in a tank cell at ambient temperature. The concentration of monomethyl adipate was kept at 100 g.dm -3 for all the electrosyntheses, but the percentage of neutralisation with sodium hydroxide was varied from 10 to $50 \%$.

The FM01 cell from ICI provides a platinum electro-deposited anode of $64 \mathrm{~cm}^{2}$, on which the Kolbe reaction can be carried out, the counter electrode is a stainless steel plate of equivalent surface area. The plateau corresponding to the methanol oxidation could be easily seen when the differential potential between the two plates was swept manually between 0 and $16 \mathrm{~V}$, as shown in figure 5.5:

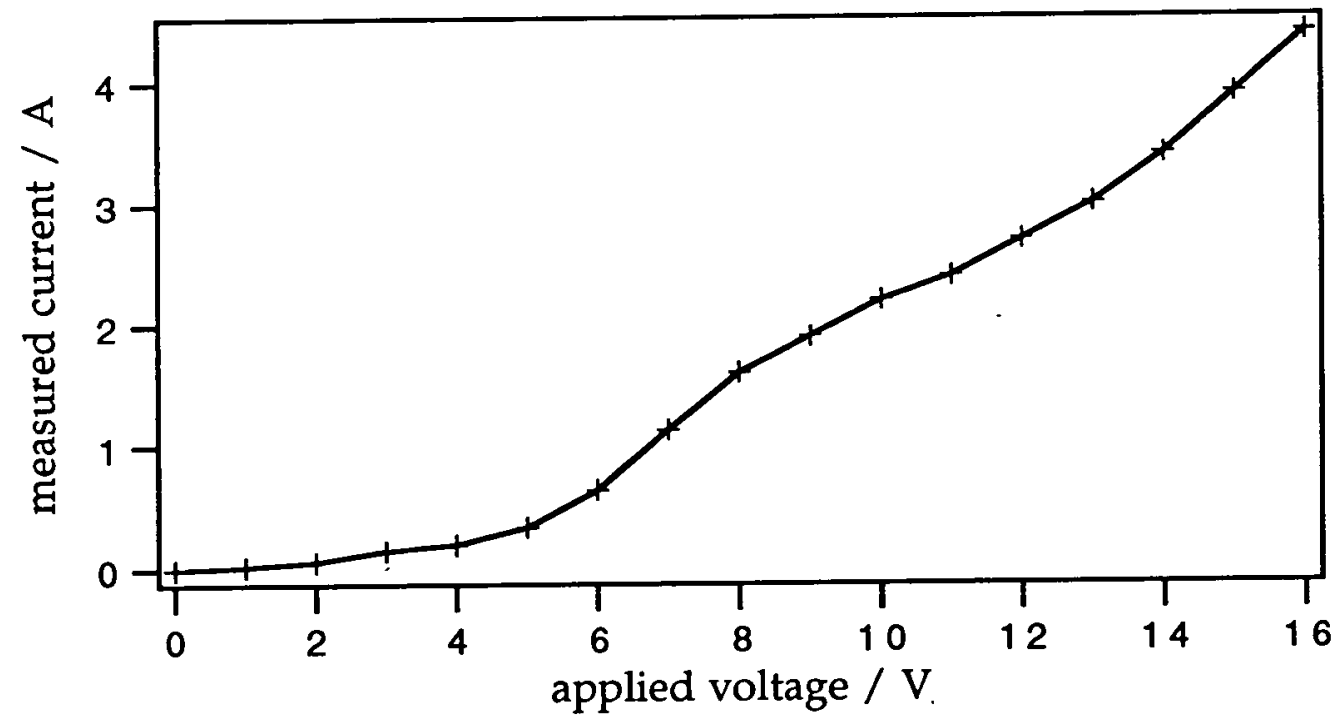

Figure 5.5: Voltammogram recorded with an electro-deposited platinum anode and a stainless steel cathode of $64 \mathrm{~cm}^{2}$, with a methanolic solution containing $100 \mathrm{~g} . \mathrm{dm}^{-3} \mathrm{MMA}$ neutralised at $50 \%$ with $\mathrm{NaOH}$, and flowing at $0.75 \mathrm{dm}^{3} \cdot \mathrm{min}^{-1}$. 
This voltammogram allows the determination of the minimum potential at which the electrosynthesis should be carried out. For example, an applied potential of $6 \mathrm{~V}$ would only give rise to the methanol oxidation. At $12 \mathrm{~V}$, however, the solvent oxidation would be minimised and the dimerisation of the monomethyl adipate should take place. This was the potential chosen for the electrosynthesis, while the flow rate was set at $0.75 \mathrm{dm}^{3} \cdot \mathrm{min}^{-1}$. The electrolyte volume was $0.3 \mathrm{dm}^{3}$. The current density was found to be fairly constant over the electrosynthesis and the mean value was $0.5 \mathrm{~A} \cdot \mathrm{dm}^{-2}$. The value of the amount of charge passed through the cell and the corresponding concentration of dimethyl sebacate are reported in table 5.2:

Table 5.2: Evolution of the DMS concentration with the amount of charge passed through the cell and the electrolysis time.

\begin{tabular}{ccc}
\hline time / hours & $\begin{array}{c}\text { amount of charge } \\
\text { passed through the } \\
\text { cell / C }\end{array}$ & $\begin{array}{c}\text { DMS } \\
\text { concentration } \\
/ \text { mol.dm }\end{array}$ \\
\hline 0 & 0 & 0.00 \\
0.58 & 5980 & 0.03 \\
1.66 & 19100 & 0.08 \\
2.5 & 27900 & 0.12 \\
3.3 & 39000 & 0.14 \\
4.6 & 55000 & 0.17 \\
5.5 & 66200 & 0.18 \\
\hline
\end{tabular}

As can be seen in figure 5.6, the concentration of DMS increases very regularly with the amount of charge passed through the cell, however, it appears to reach a maximum at $0.18 \mathrm{~mol}^{\mathrm{d} \mathrm{dm}^{-3}}$. At this point, the material 
yield is $58 \%$ for a current efficiency of $16 \%$ and an energy consumption of $17.5 \mathrm{kWh} . \mathrm{kg}^{-1}$.

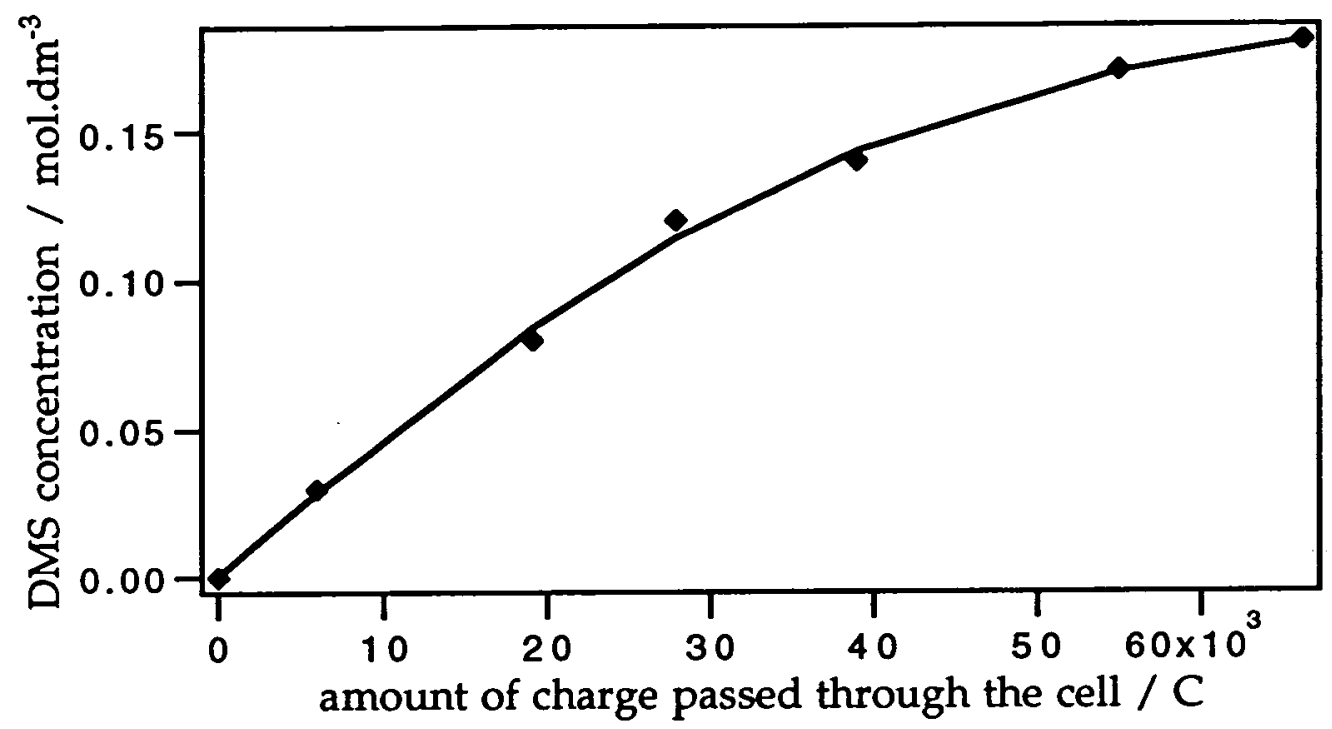

Figure 5.6: Evolution of the DMS concentration with the amount of charge passed through the FM01 cell.

Although these figures of merit do not compare positively with the performance of the capillary gap cell used by BASF, they constitute additional comparative data for electrosyntheses carried out on platinum coplanar band electrodes.

\section{5-4 Syntheses with platinum coplanar band electrodes}

Experiments were carried out with carefully washed and polished PT2 arrays placed in a tank cell or in flow cell 2. In contrast to the electro-deposited plate placed in the FM01 cell, no current plateau could be observed when the potential of the platinum arrays were swept between 0 and $16 \mathrm{~V}$. It is thus difficult to identify the value of the 
potential that should be applied. Different voltages were thus used and are reported in table 5.3, together with the flow, the electrolyte volume and the percentage at which MMA is neutralised.

Table 5.3: Experimental conditions for the dimerisation of MMA (100 g.dm $\left.{ }^{-3}\right)$, carried on PT2 arrays:

$\begin{array}{ccccc}\text { experiment } & \text { flow } & \text { electrolyte } & \text { Applied } & \% \\ & / \mathrm{dm}^{3} \cdot \mathrm{min}^{-1} & \text { volume / ml } & \text { voltage /V } & \text { neutralisation }\end{array}$

\begin{tabular}{ccccc}
\hline 1 & 0.25 & 250 & 12 & 10 \\
2 & 0.25 & 250 & 6 & 10 \\
3 & - & 120 & 12 & 50 \\
4 & - & 120 & 8 & 50 \\
\hline
\end{tabular}

Syntheses were carried out until stabilisation of the DMS concentration. The overall figures of merit, obtained for these experiments, are reported in table 5.4.

Table 5.4: Figures of merit obtained with platinum array PT2, for different experimental conditions:

\begin{tabular}{cccc}
\hline experiment & \% material yield & $\begin{array}{c}\text { \% current } \\
\text { efficiency }\end{array}$ & $\begin{array}{c}\text { energy } \\
\text { consumption } \\
\text { kWh.kg-1 }\end{array}$ \\
\hline 1 & 8 & 17 & 16.5 \\
2 & 7 & 8.5 & 16.4 \\
3 & 23 & 48 & 5.8 \\
4 & 11 & 47 & 4.0 \\
\hline
\end{tabular}


The immediate comment on these data is that the material yields obtained with the platinum coplanar band electrode array, are very low compared to the results obtained with the parallel plate electrodes or with the capillary gap cell ( $58 \%$ and the $80 \%$ respectively). This is clearly shown in figure 5.7, where the DMS concentration is plotted against the normalised amount of charge passed through the different cells.

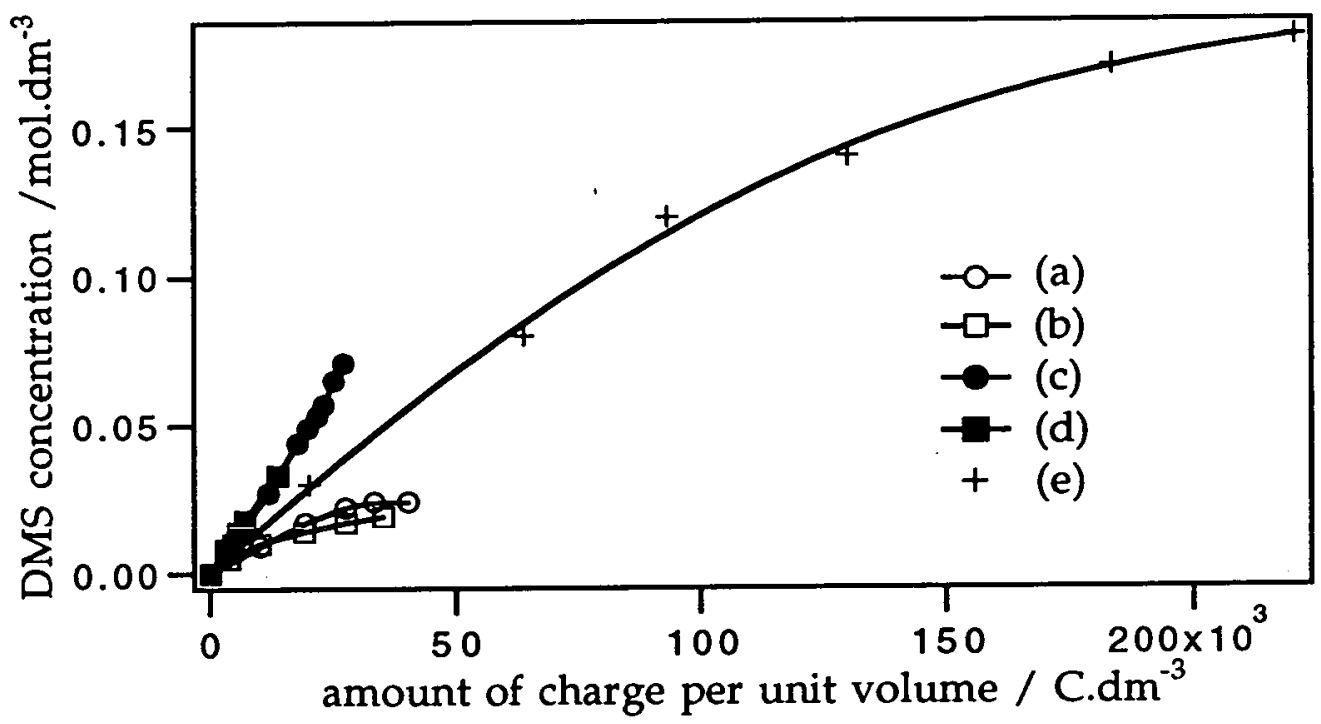

Figure 5.7: Evolution of the DMS concentration with the normalised amount of electricity passed through the cells: for the platinum array PT2 (a) experiment 1, (b) experiment 2, (c) experiment 3 and (d) experiment 4; and $(e)$ for the parallel plate electrodes in FM01.

The amount of neutralised MMA is an important factor as it is the determining factor for the conductivity of the solution. Experiments carried out in the tank cell and in the flow cell 2, show that the material yield almost doubled when the neutralisation coefficient is increased from 10 to $50 \%$. Of course it must be noted that these experiments are carried out in two different cells, but with the mass transport in the flow cell being more efficient than in the tank reactor, these arguments are still valid. 
In contrast with the material yield, current efficiency and energy consumption compare very favourably with the two parallel plate cells. For a $50 \%$ neutralisation, the current efficiency reaches $48 \%$, which is three times larger than the value obtained in the parallel plate cell. This figure is however inferior by $10 \%$ to the current efficiency obtained in the capillary gap cell. The energy consumption is also found to be significantly improved by using platinum arrays rather than the parallel plate electrodes, and furthermore, when the applied voltage is set at $8 \mathrm{~V}$, the process appears to be as economic as in the capillary gap cell, for an energy consumption of $4.0 \mathrm{kWh} . \mathrm{kg}^{-1}$. These figures could even be ameliorated by reducing the inter electrode distances. However, because of the poor material yield, this process is not competitive and no further experiments were carried out.

The reason for the mediocre MMA conversion is due to an electrode passivation, possibly enhanced by the electrode porosity and the non-turbulent regime. Indeed, the current density decreases very rapidly, as the electrosynthesis is performed, to reach a level where the increase in the DMS concentration is insignificant. This can be observed for all the experiments, and is illustrated by figures 5.8, 5.9, 5.10 and 5.11. The initial current densities, for the four experiments, vary in the range 20 to 7.5 A.dm-2. Although $20 \mathrm{~A} \cdot \mathrm{dm}^{-2}$ is the value obtained with the capillary gap cell, it is often advised to use higher voltages. This would however generate higher energy consumptions. F. Beck [63] also encountered electrode passivation problems and attributed them to the formation of polymers on the anode surface. This was found to be even more significant for long chain compounds. 


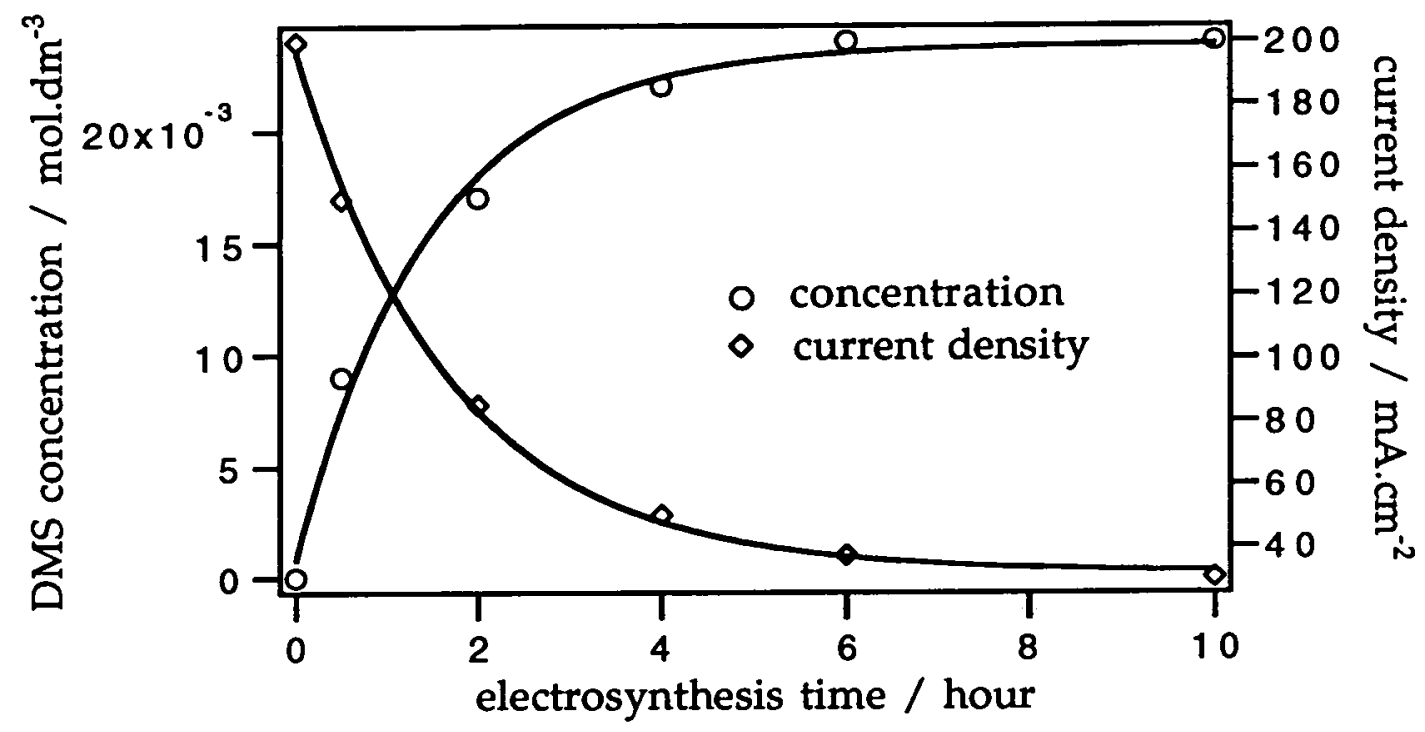

Figure 5.8: Evolution of the DMS concentration and the current density with the electrosynthesis time, for experiment 1.

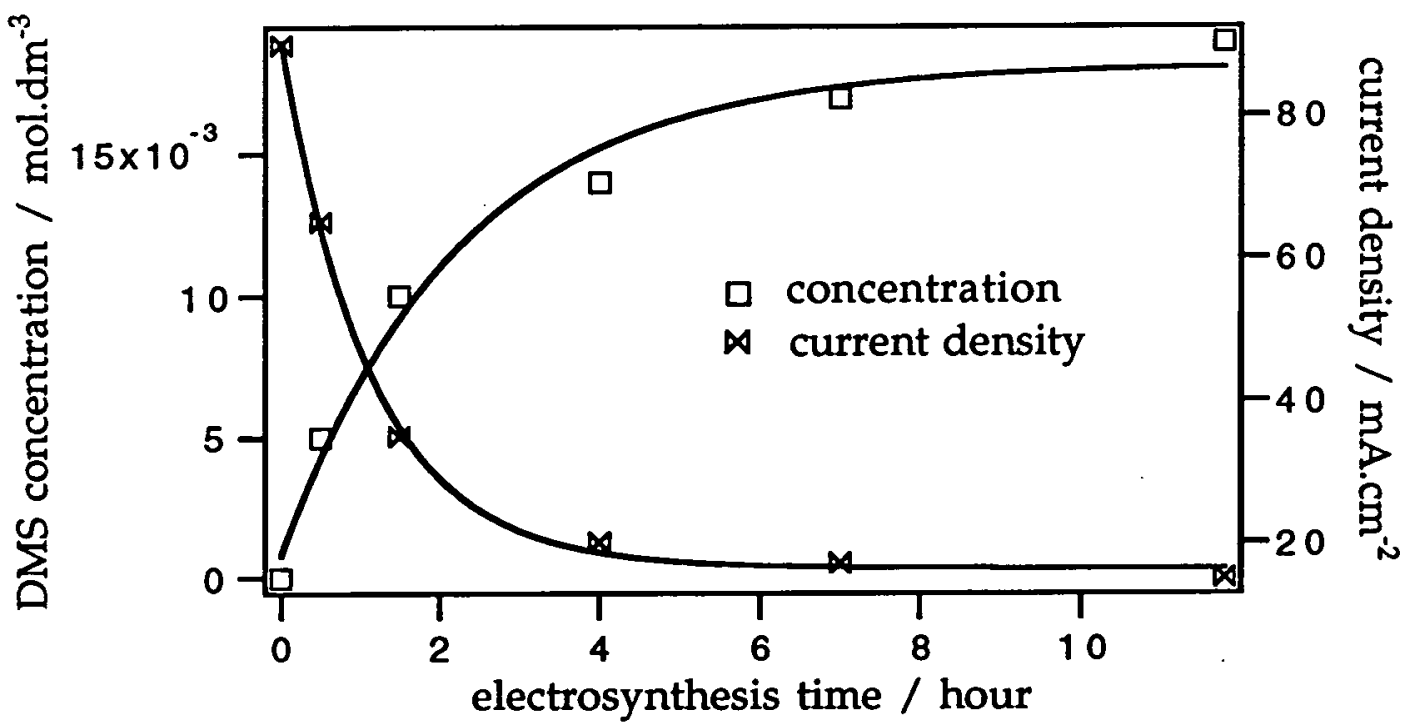

Figure 5.9: Evolution of the DMS concentration and the current density with the electrosynthesis time, for experiment 2. 


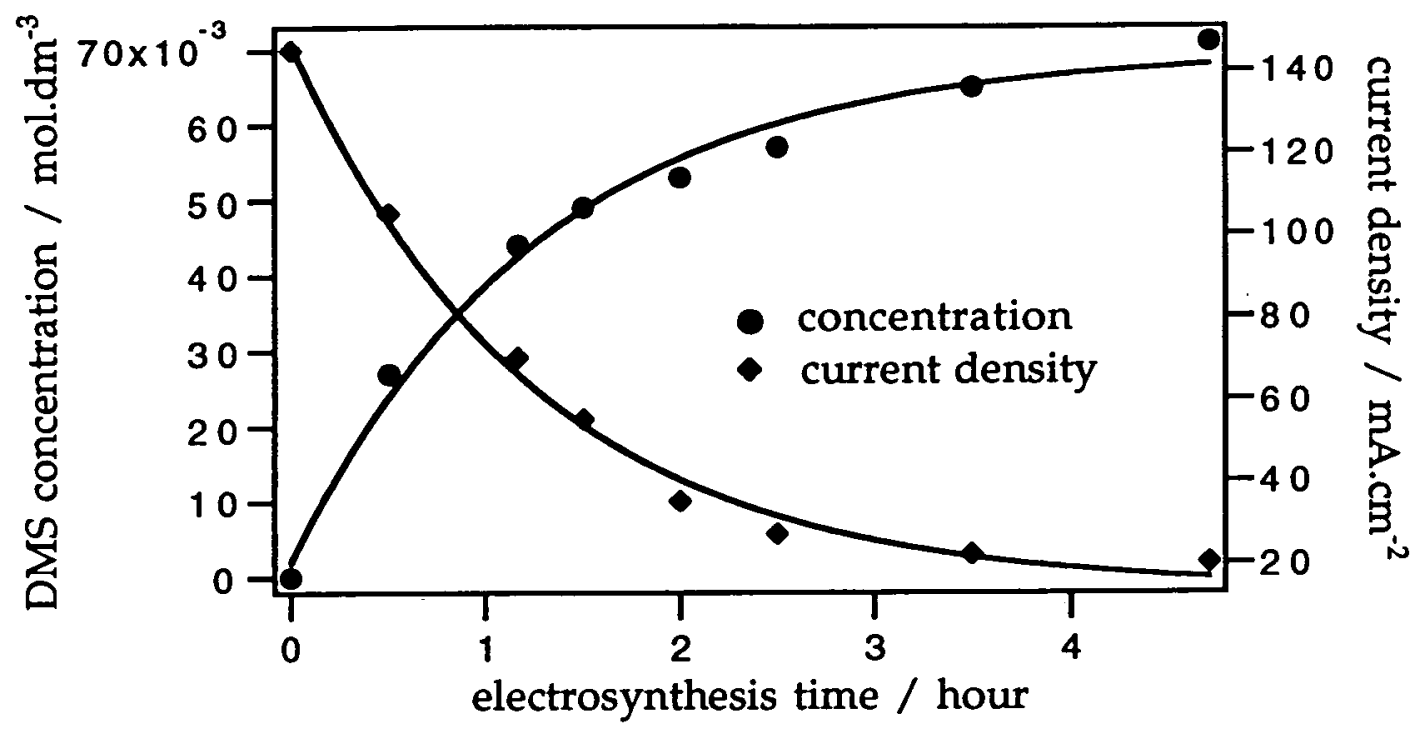

Figure 5.10: Evolution of the DMS concentration and the current density with the electrosynthesis time, for experiment 3.

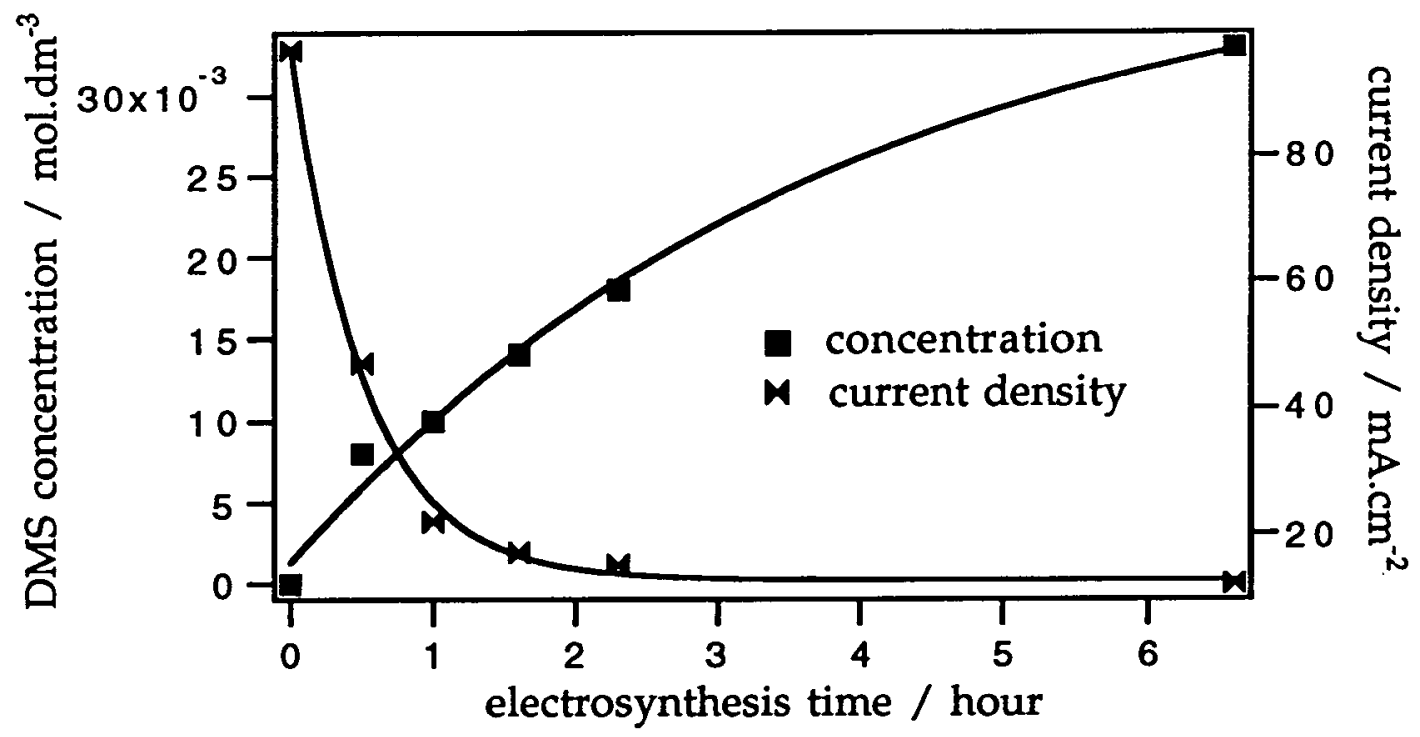

Figure 5.11: Evolution of the DMS concentration and the current density with the electrosynthesis time, for experiment 4. 
Recent experiments [53-55] have also shown that intermediates could adsorb on the platinum surface. In our case, a potential inverser was used but did not appear to limit the electrode coverage.

Carrying out the experiment at high current density (i.e. $125 \mathrm{~mA} . \mathrm{cm}^{-2}$ ) did not resolve this problem as the potential had to be significantly and constantly increased in order to keep the current at a constant value.

\section{5-5 Conclusion}

This work on the Kolbe synthesis shows that this reaction is not the most suitable to be carried out on platinum arrays. The advantage of having small inter electrode distances is verified as the reaction can be achieved with very competitive current yields and energy consumptions. However, the electrode material is found to be inappropriate for this application, due to the passivation of the electrode surface. 


\section{CHAPTER 6}

\section{The epoxidation of propylene}

\section{6-1 Bibliography}

The epoxidation of propylene is a very important operation in industrial synthesis as propylene oxide is a starting material used for the production of a wide range of compounds. Different approaches to this reaction can be found in the literature. Several classical chemical methods exist, but they have the disadvantages of being polluting or costly. The electrochemical route, however, was proven to produce propylene oxide with better rates and selectivities. The propylene boiling. point being below $-45^{\circ} \mathrm{C}$, the reaction could be carried out in either the gaseous or liquid phase.

M. Stoukides and C. G. Vayenas $[64,65]$ performed the reaction in the gaseous phase, at $400^{\circ} \mathrm{C}$ and under atmospheric pressure. A mixture of oxygen, propylene and nitrogen was passed through polarised porous polycrystalline silver films. Although nonpolarised silver can act as a catalyst, they showed that the rate and the selectivity of the reaction was improved by imposing a current through the silver electrodes in order to produce $\mathrm{O}^{2-}$. The enhancement factor was found to be 300 . However, the optimum rate of production was very low resulting in the unsuitability of this approach.

For the reaction to be carried out in the liquid phase, propylene has to be saturated in solutions containing bromide. Bromide is oxidised to bromine on the anode, which reacts with water to form hypobromous acid, which in turns reacts with propylene to form propylene 
bromohydrin. The hydroxide ions produced on the cathode are then necessary to complete the reaction, according to the scheme shown in figure 6.1:

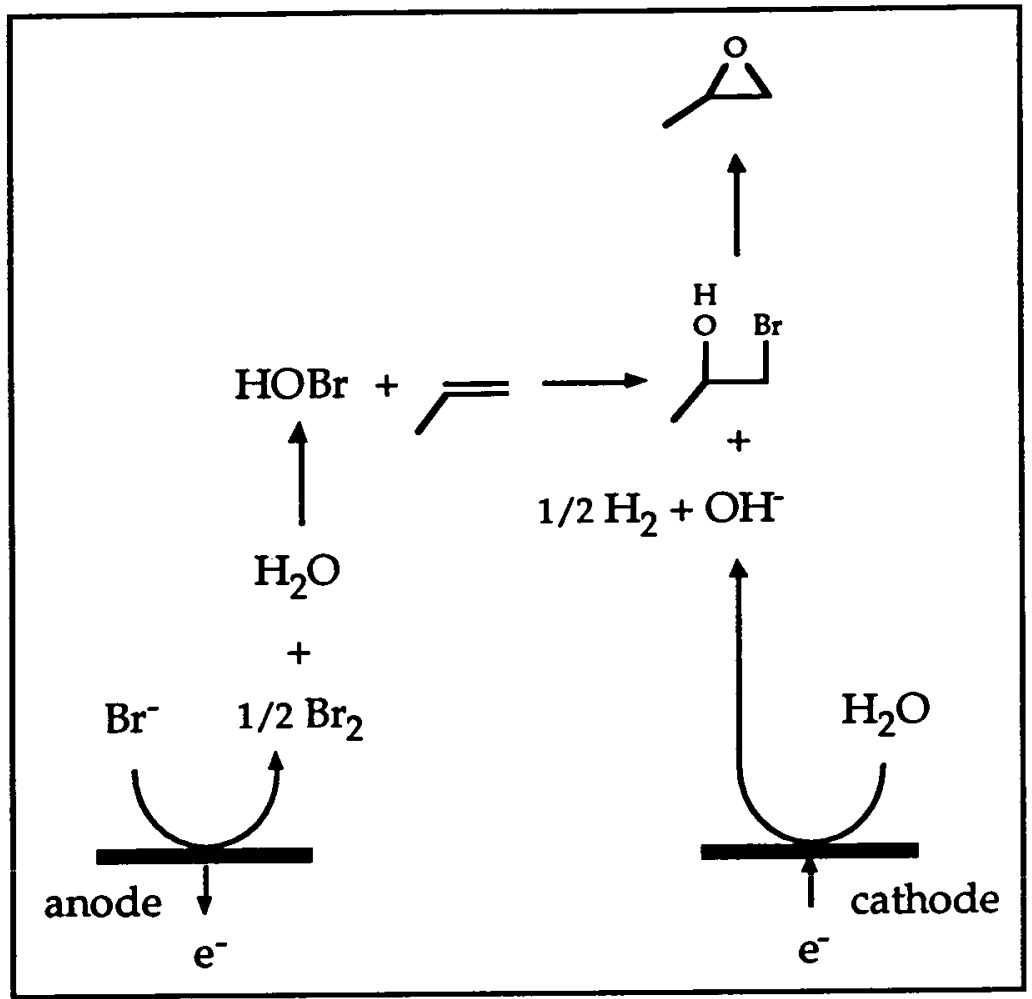

Figure 6.1: Reaction scheme for the propylene epoxidation.

This reaction is a classic example of a "paired electrosynthesis", as both the cathode and the anode products contribute usefully to the formation of the final product. The disadvantage of carrying out the synthesis in the liquid phase is that a large number of side reactions can be involved. K. Scott and B. Hayati [66] proposed that the most likely to occur as:

$$
\begin{aligned}
& \mathrm{HOBr} \rightleftharpoons \mathrm{H}^{+}+\mathrm{OBr}^{-} \\
& \mathrm{OBr}^{-}+\mathrm{H}_{2} \mathrm{O}+2 \mathrm{e}^{-} \longrightarrow \mathrm{Br}^{-}+2 \mathrm{OH}^{-}
\end{aligned}
$$




\section{$\mathrm{CH}_{3} \mathrm{CHCH}_{2}+\mathrm{Br}_{2} \longrightarrow \mathrm{CH}_{3} \mathrm{CHBrCH}_{2} \mathrm{Br}$ \\ $2 \mathrm{HOBr}+\mathrm{OBr}^{-} \longrightarrow \mathrm{BrO}_{3}^{-}+2 \mathrm{H}^{+}+2 \mathrm{Br}^{-}$}

These reactions were modelled in several simulations [66-68], and when kinetic constants were correctly chosen good agreements with experimental results were obtained. K. G. Ellis and R. E. W. Jansson [69] carried out the synthesis in a trickle tower and analysed the different by-products. 1,2-dibromopropane was the major by-product, especially for low $\mathrm{pH}$ values. A small amount of 1,2-propanediol and traces of 1-propanol, 2-propanol and dipropyl ethers were also found. Mechanisms for the formation of the latter products were proposed and discussed.

Several cells have been investigated for this particular reaction. Since propylene is sparingly soluble in aqueous solution, it had to be constantly introduced into the electrolyte. The temperature was usually kept below $15^{\circ} \mathrm{C}$ due to the low boiling point of propylene oxide $\left(34.3^{\circ} \mathrm{C}\right)$. It was shown that it was important to have good mixing regimes in order to facilitate the transport of bromohydrin to the alkaline catholyte layer [38]. Indeed the pump cell, where high mass transfer coefficients can be obtained $\left(4.10^{-3} \mathrm{~m}^{\left.-\sec ^{-1}\right)}\right.$, was proven to be very suitable for this synthesis [70]. A strong correlation between the production rate and the rotational Reynolds number was observed. For a cell constituting a fixed graphite anode and a rotating stainless steel cathode separated by $150 \mu \mathrm{m}$ and a sodium concentration of $0.2 \mathrm{M}$, the energy consumption could be decreased to $1.4 \mathrm{kWh} . \mathrm{kg}^{-1}$ for a production rate of $0.147 \mathrm{~mol} . \mathrm{h}^{-1} . \mathrm{dm}^{-2}$ and a current efficiency of $77 \%$. The value of the current efficiency could 
eventually reach $100 \%$ for an energy consumption of $2.7 \mathrm{kWh} . \mathrm{kg}^{-1}$ and a similar production rate.

The performance of bipolar packed beds were also investigated for this reaction. Carbon Raschig rings separated by $1 \mathrm{~mm}$ thick Nylon nets [69, 71, 72] and perforated graphite plates [73] were the two types of bipolar layers used. Increasing the sodium bromide concentration had the effect of decreasing the solution resistance and thus increasing the by-pass currents. The sodium bromide concentration had thus to be kept at low value in detriment to the production rate. With the perforated plates, a current efficiency of $80 \%$ could be obtained for an energy consumption of $4.8 \mathrm{kWh} . \mathrm{kg}^{-1}$. These figures were improved by use of Raschig rings instead of the perforated plates, as less dispersion occurs in the mixing regimes. For a concentration of $0.1 \mathrm{M}$ and an applied voltage of 3 to $3.5 \mathrm{~V}$ per layer, propylene oxide was produced with a current efficiency of $98 \%$ for an energy consumption of $2.9 \mathrm{kWh} . \mathrm{kg}^{-1}$ and a space time yield of 125 mol. $\mathrm{h}^{-1} \cdot \mathrm{m}^{-3}$. The space time yield could be improved by increasing the flow rate and the applied voltage, but this was accompanied with an increase in the energy consumption. In conclusion it was found that the trickle tower compared reasonably well with the pump cell for a lower investment price and simpler maintenance.

Finally R. C. Alkire and J. E. Tsai [74] proposed an alternating current electrosynthesis method. A sinusoidal current was applied between two platinum flag electrodes. The current efficiency was found to decrease when the frequency of the signal was varied from 0.1 to $50 \mathrm{~Hz}$. At $1 \mathrm{~Hz}$, for example, it had a value of $22 \%$. This cell was thus unable to compete favourably with the pump cell or the bipolar trickle tower. 


\section{6-2 Calibration and preliminary experiments}

The bromide oxidation $^{2}$ already been investigated in chapter 4 for the methoxylation of furan. Similar results were obtained when the solvent was replaced by de-ionised water. It is therefore not necessary to discuss experiments in details and to summarise the results, polarised curves determined for sodium bromide solutions with coplanar platinum arrays showed inflexion point at about $3 \mathrm{~V}$.

The composition of the electrolyte was monitored by gas chromatography. The temperature program consists of leaving the temperature at $30^{\circ} \mathrm{C}$ for two minutes, then increasing it to $200{ }^{\circ} \mathrm{C}$, with a ramp of $30^{\circ} \mathrm{C} \cdot \mathrm{min}^{-1}$, where it is kept for 1 minute to allow the elution of by-products. This temperature program is summarised by figure 6.2 :

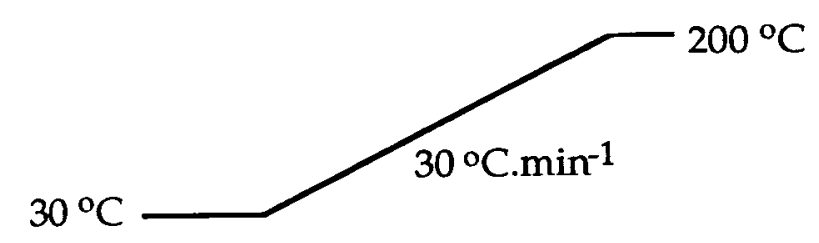

Figure 6.2: Temperature program for the chromatographic monitoring of propylene oxide and related by-products.

Under these conditions, all the products and by-products can be eluted within 8.7 minutes, which is a very reasonable time. The retention times of propylene, propylene oxide and the four potential by-products are reported in table 6.1. Calibration graphs plotted for the different compounds are represented in figure 6.3, and show that when $0.5 \mu l$ volumes are injected, a very linear relationship exists between the compound concentrations and the peak areas. The detection limit is set at $0.01 \%$. 
Table 6.1: Retention times for propylene oxide and other possible by-products.

\begin{tabular}{ll}
\hline compound & retention time / min \\
\hline propylene & 0.6 \\
propylene oxide & 1.0 \\
isopropanol & 2.6 \\
propanol & 3.5 \\
dibromopropane & 4.9 \\
propanediol & 6.6 \\
\hline
\end{tabular}

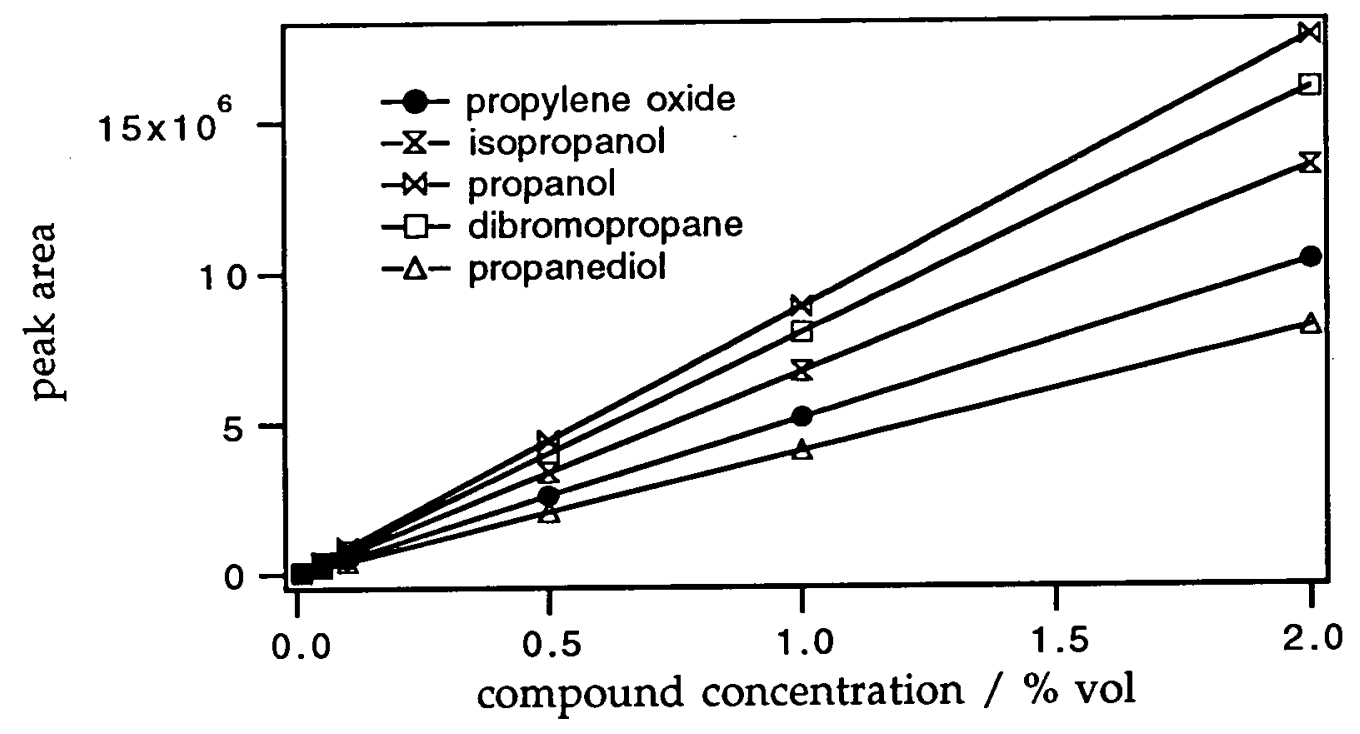

Figure 6.3: Calibration by gas chromatography for propylene oxide and related by-products.

Experimentally, only one by-product is obtained with the platinum coplanar band arrays, and from the retention time, it can be identified as dibromopropane. Figure 6.34 shows chromatograms recorded at successive times during an electrosynthesis: 


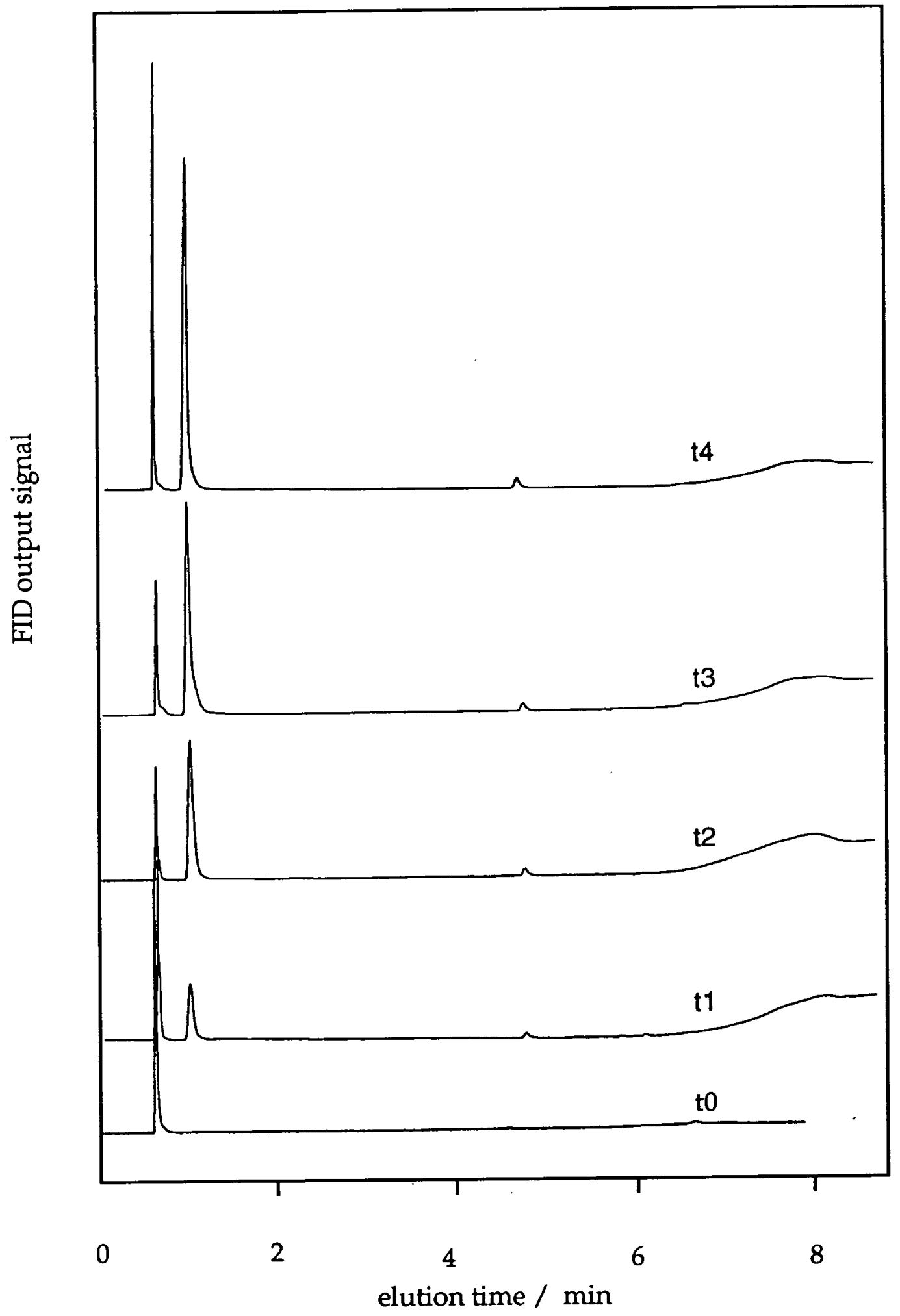

Figure 6.4: Gas chromatograms recorded at successive electrosynthesis times, showing the increase in the propylene oxide concentration. 


\section{6-3 Synthesis with coplanar interdigitated electrodes}

\section{6-3-1 Experimental results}

In contrast with the methoxylation of furan and the Kolbe reaction, the epoxidation of propylene is carried out in aqueous media. The possibility of performing the reaction with printed carbon electrodes was thus re-examined. The change in the solvent nature had unfortunately no effect on the electrode degradation, and the use of carbon ink was definitely abandoned for synthetic purposes.

Only the performances of platinum coplanar band arrays were then assessed for this reaction. The optimal experimental conditions were determined by investigating the effect of different parameters, such as the cell voltage, the temperature, the electrolyte flowrate, the sodium bromide concentration and the interelectrode distance. Syntheses were carried out either in the $250 \mathrm{ml}$ thermostated tank cell or in the flow cell 3 , with a total volume of $300 \mathrm{ml}$. These cells are described in chapter 2 . Propylene being sparingly soluble in water, the electrolyte was sparged with the gas for 30 minutes to ensure saturation. Propylene was then continuously passed through the solution during the electrosynthesis, which was stopped after 120 minutes. The composition of the electrolyte, together with the amount of charge and the current passed through the cell, were recorded continuously over the electrosynthesis periods. The $\mathrm{pH}$ was also measured and found to increase rapidly from 8.5 to 10.5 , within the first 30 minutes. Another common point for all the experiments, was the slight decrease in the current efficiency during the electrosynthesis time. It was explained by the loss of conductivity due to bromine formation, but as it never exceeded $5 \%$ of the original value, only the final values are reported in table 6.2, which is an overall table of the results obtained for different experiments. 
Table 6.2: Figures of merit for the propylene epoxidation with platinum coplanar band arrays in different experimental conditions:

\begin{tabular}{|c|c|c|c|c|c|c|c|c|c|c|}
\hline Exp & array & $\begin{array}{c}\text { cell } \\
\text { voltage } \\
\text { / V }\end{array}$ & $\begin{array}{c}{[\mathrm{NaBr}]} \\
/ \%\end{array}$ & $\begin{array}{c}\text { flow } \\
\mathrm{dm}^{3} \cdot \mathrm{min}^{-1}\end{array}$ & $\begin{array}{l}\text { tempe- } \\
\text { rature } \\
/{ }^{\circ} \mathrm{C}\end{array}$ & $\begin{array}{l}\text { current } \\
\text { density } \\
/ \text { mA.cm-2 }\end{array}$ & $\begin{array}{c}{[\mathrm{PO}]} \\
\text { mol.dm }\end{array}$ & $\begin{array}{c}\text { current } \\
\text { efficiency } \\
/ \%\end{array}$ & $\begin{array}{c}\text { energy } \\
\text { consumption } \\
/ \mathrm{kWh} \mathrm{kg}^{-1}\end{array}$ & $\begin{array}{l}\text { production } \\
\text { rate / } \\
\text { mol.h-1. } \mathrm{dm}^{-2}\end{array}$ \\
\hline צ' & PT2 & 3 & 1 & 0 & 8 & 38 & 0.0277 & 62 & 2.23 & 0.0866 \\
\hline (2) & PT2 & 3 & 1 & 0.15 & 8 & 42 & 0.0197 & 47 & 2.94 & 0.0738 \\
\hline 3. & PT2 & 3 & 1 & 0.25 & 8 & 50 & 0.0164 & 33 & 4.19 & 0.0615 \\
\hline i: & PT2 & 3 & 1 & 0.45 & 8 & 57 & 0.0143 & 25 & 5.53 & 0.0536 \\
\hline 5. & PT2 & 3 & 1 & 0.75 & 8 & 67 & 0.0168 & 25 & 5.53 & 0.0625 \\
\hline 6 & $\overline{\text { PT3 }}$ & 2.5 & $\overline{1}$ & - & 6 & 22 & 0.0203 & 62 & 1.86 & 0.0507 \\
\hline 7 & PT3 & 3 & 1 & - & 6 & 47 & 0.0477 & 68 & 2.04 & 0.1192 \\
\hline 8 & PT3 & 3.5 & 1 & - & 6 & 58 & 0.0599 & 69 & 2.34 & 0.1497 \\
\hline 9 & PT3 & 4 & 1 & - & 6 & 69 & 0.0690 & 67 & 2.75 & 0.1725 \\
\hline 10 & PT3 & 5 & 1 & - & 6 & 96 & 0.0659 & 46 & 5.02 & 0.1647 \\
\hline 11 & $\begin{array}{l}\text { PT3 } \\
\end{array}$ & 3 & $\overline{1}$ & - & $\begin{array}{l}0 \\
0\end{array}$ & 37 & 0.032 & 58 & 2.39 & 0.080 \\
\hline 28 & PT3 & 3 & 1 & - & 6 & 47 & 0.0477 & 68 & 2.04 & 0.1192 \\
\hline 18 & PT3 & 3 & 1 & - & 10 & 48 & 0.0489 & 68 & 2.04 & 0.1222 \\
\hline 18 & PT3 & 3 & 1 & - & 15 & 49 & 0.0446 & 61 & 2.26 & 0.115 \\
\hline 14 & PT3 & 3 & $\overline{0.2}$ & - & 6 & $\overline{11}$ & 0.0051 & 31 & 4.46 & 0.927 \\
\hline 15 & PT3 & 3 & 0.5 & - & 6 & 24 & 0.0215 & 60 & 2.31 & 0.0537 \\
\hline 7 & PT3 & 3 & 1 & - & 6 & 47 & 0.0477 & 68 & 2.04 & 0.1192 \\
\hline 16 & PT3 & 3 & 1.5 & - & 6 & 51 & 0.0518 & 68 & 2.04 & 0.1295 \\
\hline 17 & PT3 & 3 & 2 & - & 6 & 52 & 0.0458 & 59 & 2.35 & 0.1145 \\
\hline $7 \%$ & $\begin{array}{l}\text { PT1 } \\
\end{array}$ & $\overline{3}$ & 1 & - & 6 & 33 & 0.0154 & 52 & 2.66 & 0.0642 \\
\hline 188 & PT2 & 3 & 1 & - & 6 & 37 & 0.0274 & 62 & 2.23 & 0.0856 \\
\hline 27 & PT3 & 3 & 1 & - & 6 & 47 & 0.0477 & 68 & 2.04 & 0.1192 \\
\hline
\end{tabular}




\section{6-3-2 Effect of the convection on the cell performance}

The convection regimes are mainly dictated by the cell geometry and by the movement of the electrolyte. For example the mixing of the electrolyte in a pump cell is particularly efficient, but demands additional cost for the solution pumping and for maintenance. In contrast, the trickle tower presents a very straight forward approach, but only low convection regimes are accomplished. Despite this major difference and because of the small interelectrode distances, these two cells are particularly suitable for the epoxidation of propylene, which is a coupled reaction. Similarly, the coplanar band arrays should also be appropriate for this reaction. The first experiments (Exp. 1 - Exp. 5) were carried out with the platinum coplanar band array PT2, with the flow rate varied between 0 and $0.75 \mathrm{dm}^{3} \cdot \mathrm{min}^{-1}$. The influence of the flowrate on the current density has already been raised in chapter 3 , where it was demonstrated that a linear relationship exists between the logarithms of these two figures. This is confirmed here by plotting the limiting currents against the flow rate in a logarithmic scale as in figure 6.5:

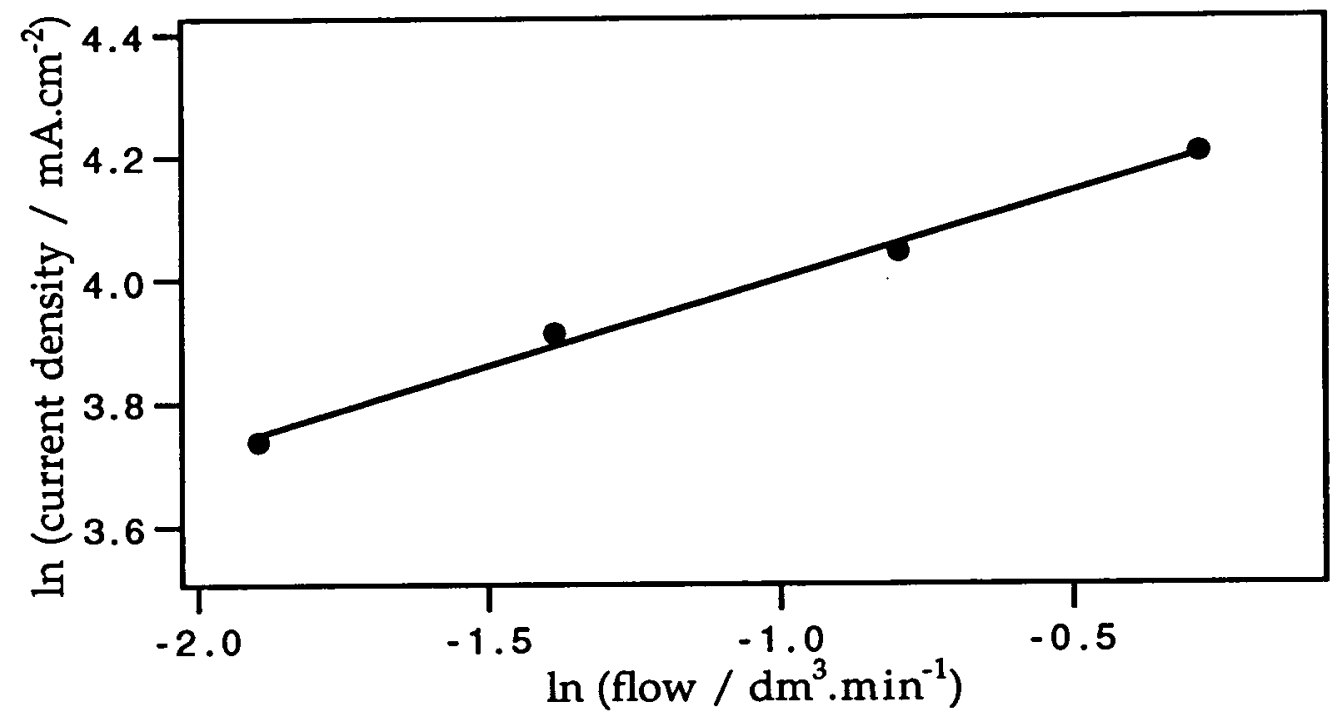

Figure 6.5: Logarithmic plot of the current density vs. the flowrate obtained with array PT2. 
Figure 6.6 represents the regular increase in the propylene oxide concentration as the normalised amount of charge passed through the cell is increased. Although current efficiencies can not be determined directly from this figure, it should be noticed that propylene oxide is produced with better efficiency when the liquid is not flowing through the cell. This is a very important observation as it proves that this reaction can be achieved successfully with coplanar band arrays immersed in a tank cell rather than in a flow cell, thus facilitating the maintenance and reducing the complexity of the cell.

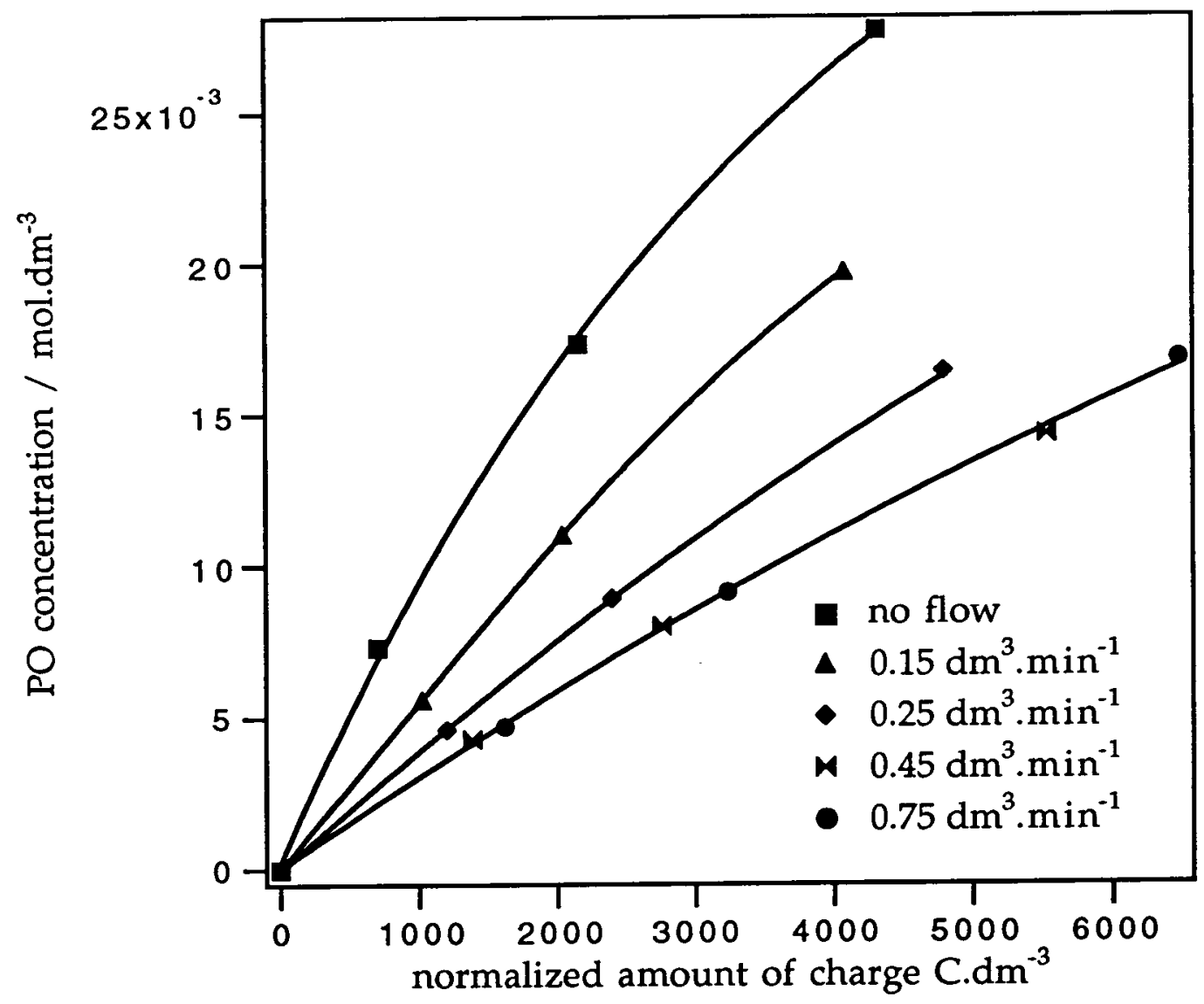

Figure 6.6: Evolution of the propylene oxide concentration with the normalised amount of charge passed through the cell. 
The latest statement is confirmed and quantified by comparison of the current efficiency values. Indeed the current efficiency is found to decrease from 62 to $25 \%$, as the flow is increased from 0 to $0.75 \mathrm{dm}^{3} \cdot \mathrm{min}^{-1}$. This big difference is explained by the loss of bromine. At high flow rates, the bromine produced at the anode is forced to flow away from the electrode surface. Although bromine can of course react with water to form hypobromous acid, which can subsequently react with propylene to form bromohydrin, the reaction of the bromohydrin with hydroxide ions in the bulk solution is not facilitated, as these ions are only produced at the cathode surface. Furthermore, the degradation of bromine to bromate would be favoured, leading to the complete loss of bromide. This would not be very perceptible over the electrosynthesis time, but could explained the slight decreases in the current densities.

The energy consumption being proportional to the inverse of the current efficiency, it can also be noticed that the energy required to form $1 \mathrm{~kg}$ of propylene oxide increases from 2.23 to $5.53 \mathrm{kWh}$, when the flow rate is increased from 0 to $0.75 \mathrm{dm}^{3} \cdot \mathrm{min}^{-1}$.

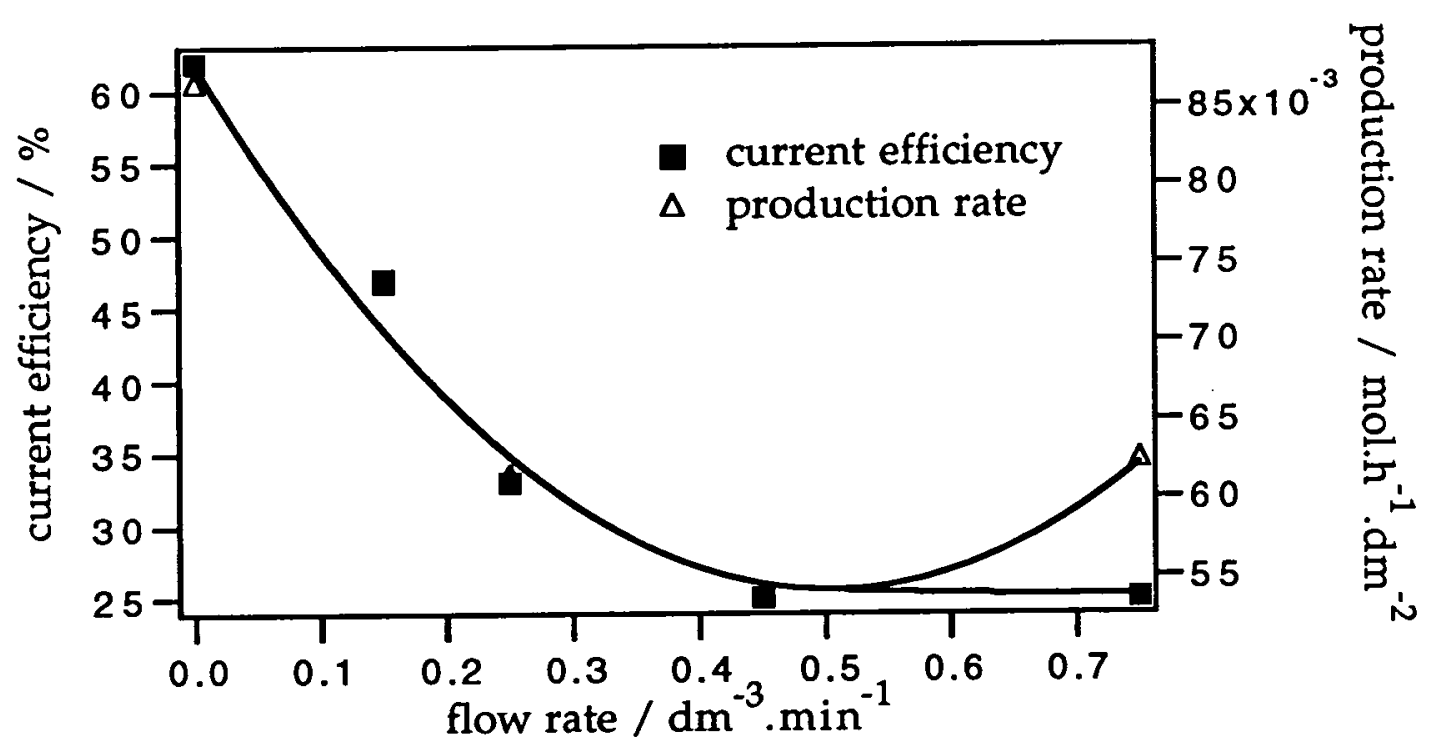

Figure 6.7: Variation of the current efficiency and the production rate with the flowrate, for experiments carried out with array PT2. 
Finally, as can be seen in figure 6.7 , it should be noticed that the general trend of the production rate is to decrease with flow rate, even though the current density is increasing. This clearly shows that the propylene epoxidation is a coupled reaction and that the synthesis should be performed with little agitation to allow reaction of the compounds produced at adjacent electrodes.

\section{6-3-3 Effect of the applied voltage on the cell performance}

The direct effect of the applied voltage on the current density is a well characterised phenomena. However, the determination of the optimal applied potential is not a straight forward task and often results in a compromise between high production rates and good current efficiencies. A series of experiments (Exp. 6 - Exp. 10) were thus carried out with the array PT3 in a tank cell, for different applied potentials.

Figure 6.8 shows the evolution of the propylene oxide concentration with the normalised amount of charge passed through the cell. The final amount of propylene oxide is found to steadily increase when the potential was increased from 2.5 to $4 \mathrm{~V}$, where it stabilises. After that value it can also be seen that another reaction occurs. Indeed, a larger quantity of electricity is used at $5 \mathrm{~V}$ rather than $4 \mathrm{~V}$, for the production of the same amount of propylene oxide.

In chapter 4, it was shown that with the platinum coplanar arrays, classical cyclic voltammetry was not a suitable method for the detection of the optimal potential range. However figure 6.9 represents a "zero scan rate" voltammogram obtained by plotting the current densities recorded for the experiments carried out at different cell potentials. This figure allows a definition of the potential range, where only the bromide oxidation occurs. 


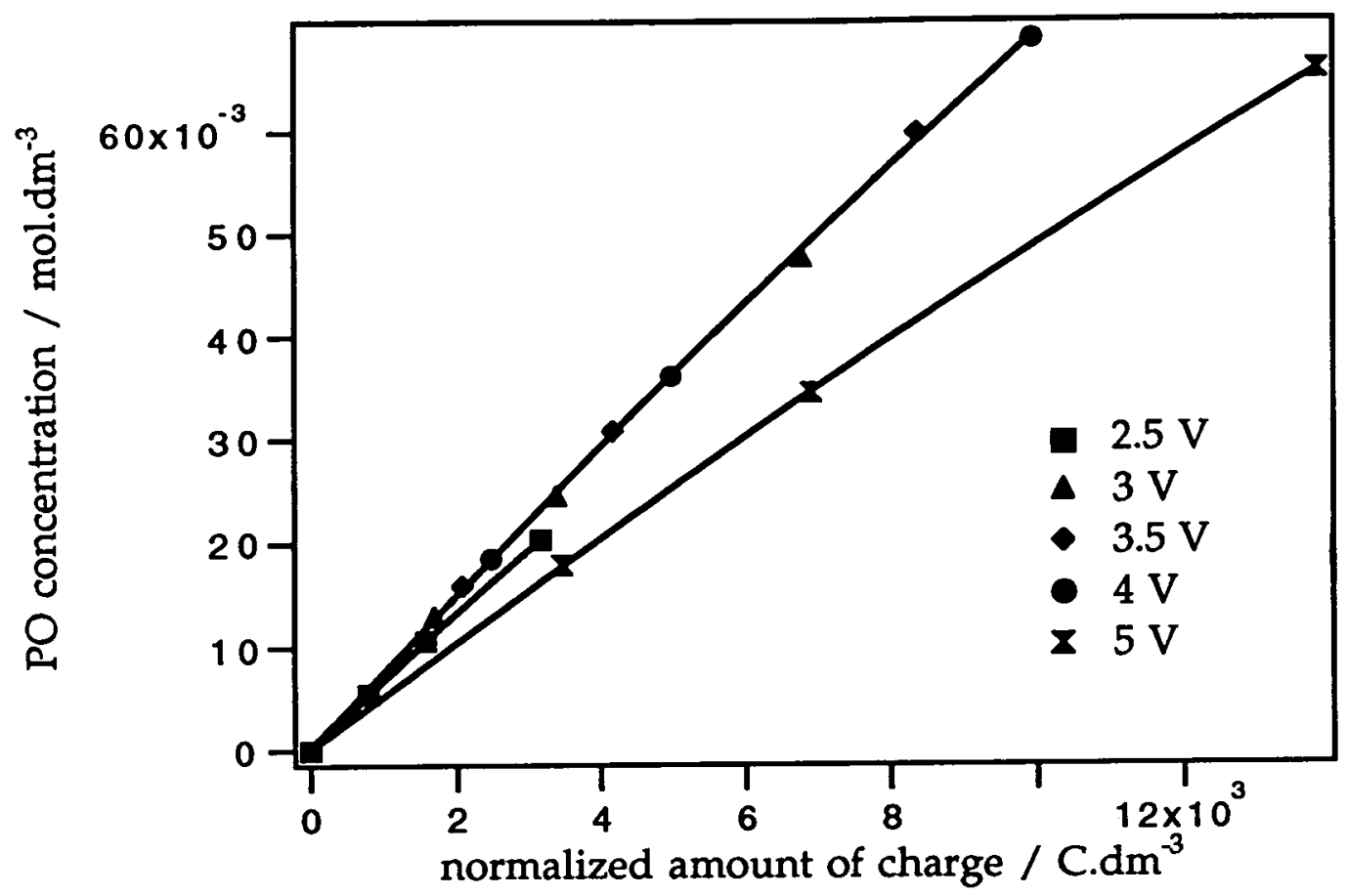

Figure 6.8: PO concentration evolution with the normalised amount of charge passed through the cell, for syntheses carried out in a tank cell with PT3.

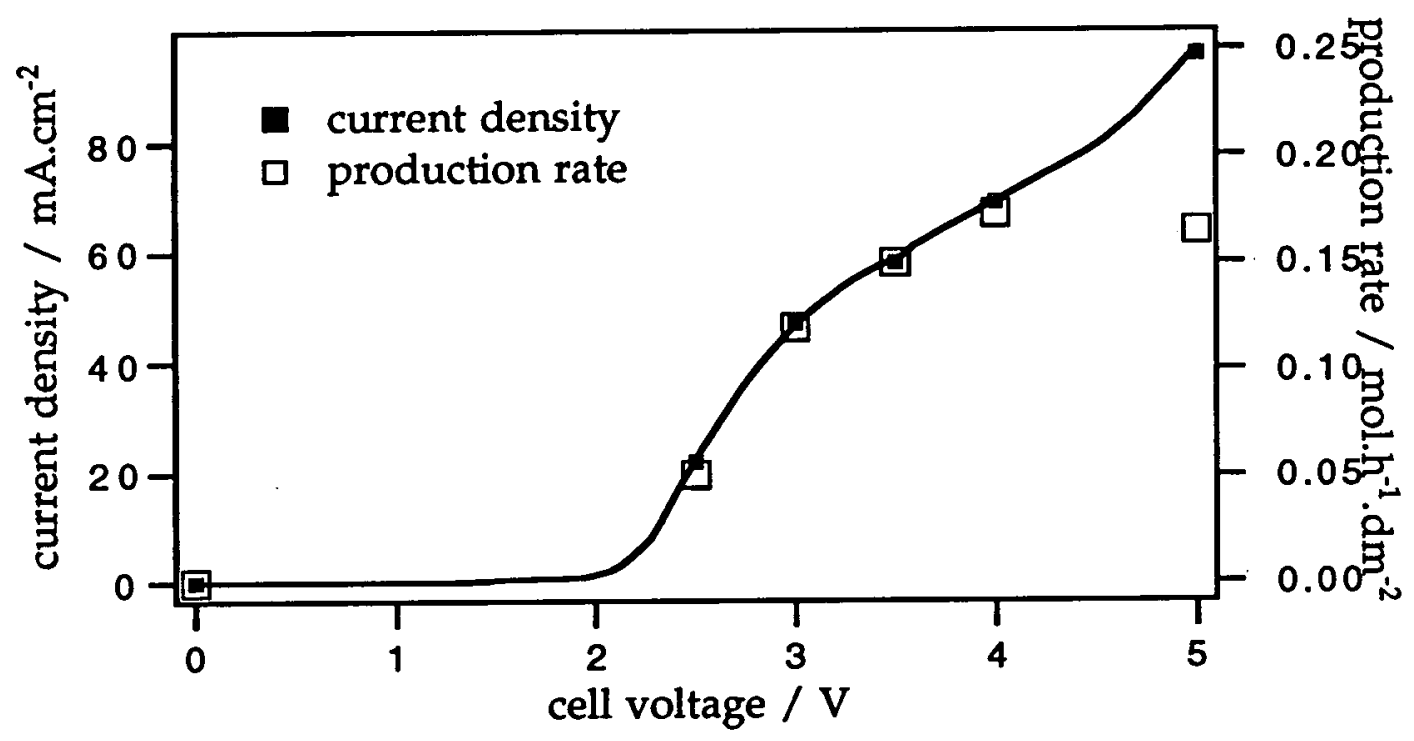

Figure 6.9: Current density and production rate as a function of the potential applied to the platinum array PT3, for propylene epoxidation in a tank reactor. 
The bromide oxidation starts to be effective at about $2 \mathrm{~V}$. At this potential, only this oxidation takes place. The amount of bromine produced, which is proportional to the current density increases very rapidly between 2 and $3 \mathrm{~V}$ and less rapidly after that value. Finally at $4 \mathrm{~V}$ and higher potentials, the oxidation of the solvent is occurring simultaneously.

Figure 6.9 also reports the value of the production rates, and clearly shows that until the solvent oxidation occurs, the amount of propylene oxide is directly related to the current density, and thus to the amount of bromine produced. As in figure 6.8 this plot emphasises that setting the potential at a value higher than $4 \mathrm{~V}$ has no positive effect on the production.

The solvent electrolysis has a direct effect on the current efficiency value. Current efficiencies, reported in figure 6.10 , are found to be fairly stable between 3 and $4 \mathrm{~V}$. But a severe decline, from 67 to $46 \%$, was observed when the potential was increased from 4 to $5 \mathrm{~V}$, or in other words, when the solvent oxidation takes place.

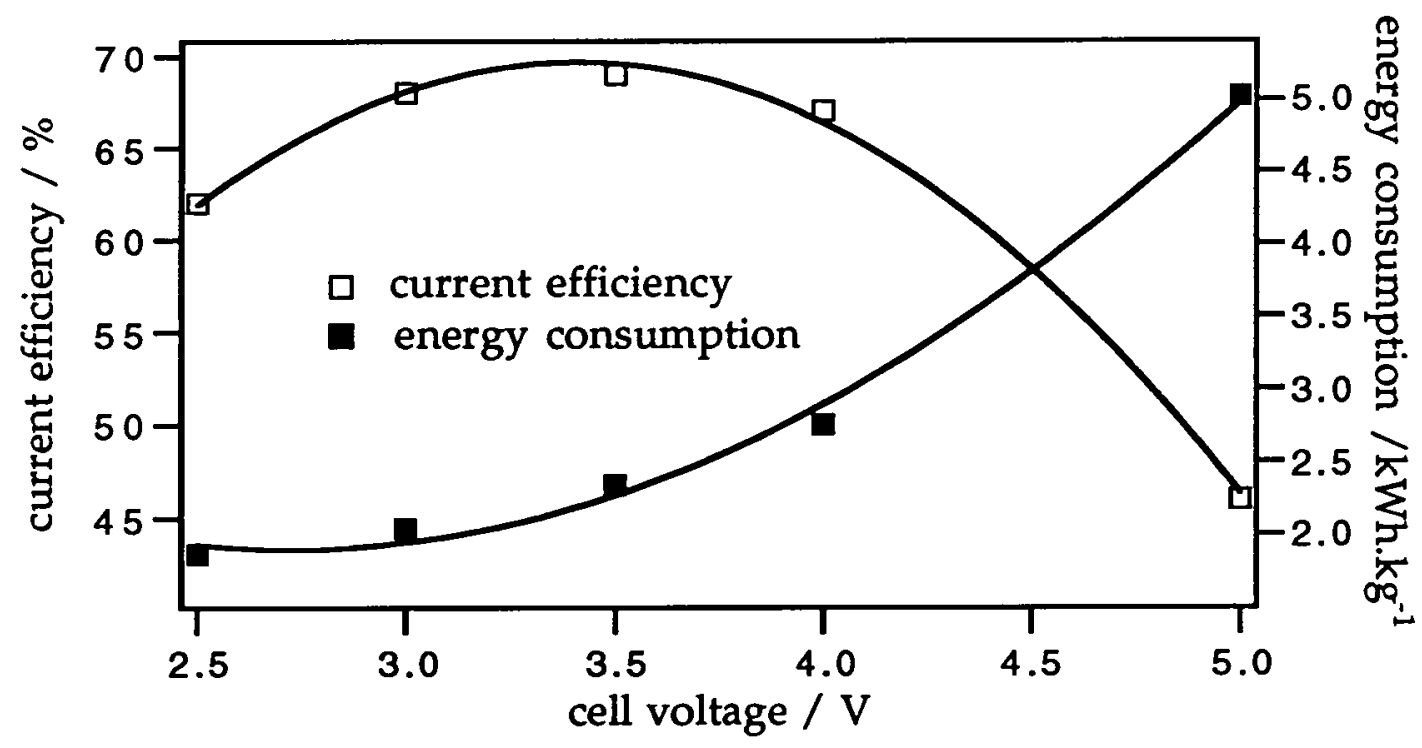

Figure 6.10: Current efficiency and energy consumption as a function of applied voltage for electrosyntheses carried out in a tank cell with PT3. 
Similarly the energy consumption was found to rise steadily until the potential of $4 \mathrm{~V}$ was reached, where it starts to increase dramatically.

To summarise these results it can be outlined that in the range 3 to $4 \mathrm{~V}$, little change is observed in the current efficiency (67-69\%). In contrast, the energy consumption and the production rate are both found to increase respectively from 2.0 to $2.75 \mathrm{kWh} . \mathrm{kg}^{-1}$, and from 0.12 to $0.17 \mathrm{~mol} \cdot \mathrm{h}^{-1} \cdot \mathrm{dm}^{-2}$. A compromise must thus be made to minimise the cost of the product and to optimise its rate of production. At $3.5 \mathrm{~V}$ for example, 0.15 mol.h-1. $\mathrm{dm}^{-2}$ can be produced for a energy consumption of 2.3 kWh. $\mathrm{kg}^{-1}$.

\section{6-3-4 Effect of the temperature on the cell performance}

Propylene oxide has a low boiling point $\left(34.3^{\circ} \mathrm{C}\right)$. Therefore it is necessary to perform the reaction at low temperature. The solubility of propylene is also higher at low temperature. However, at low temperature the rate of the epoxidation might be hindered.

The influence of the temperature on the different figures of merit was characterised by carrying out the reaction in a tank cell with the platinum array PT3 and at temperatures varying in the range 0 to $15^{\circ} \mathrm{C}$ (Exp. 7 , Exp. 11 - 13).

As can be seen in table 6.2 , unless working at very low temperature $\left(0^{\circ} \mathrm{C}\right)$, variation in the current densities can be neglected.

The evolution of the propylene oxide concentration with the normalised amount of charge passed through the cell is represented in figure 6.11. From this figure it should be noticed that for the range of temperature investigated, the amount of propylene oxide produced appears to be higher between 6 and $10^{\circ} \mathrm{C}$. 


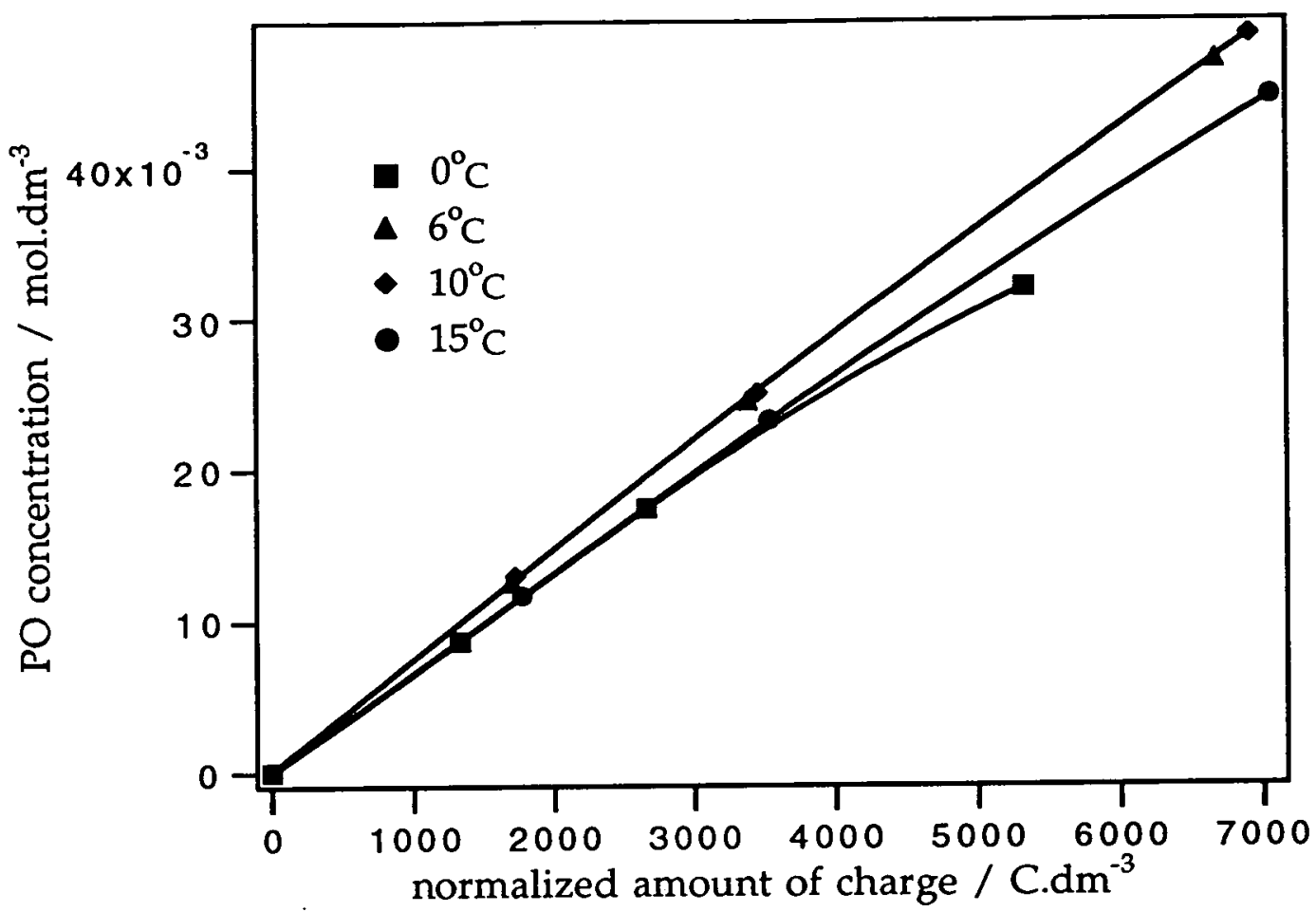

Figure 6.11: Evolution of the PO concentration with the normalised amount of charge passed through the cell, for experiments carried out in the tank cell with PT3.

As a result, the current efficiencies are found to vary between 58 and $68 \%$ and are optimised in the temperature range of 6 to $10^{\circ} \mathrm{C}$.

The effect of the temperature is also reflected by figure 6.12 , where the energy consumption and the production rate are reported vs. the cell temperature. The energy consumption rate varies between 2.0 and $2.4 \mathrm{kWh} . \mathrm{kg}^{-1}$, and the production rate, between 0.08 and 0.12 mol. $\mathrm{h}^{-1} \cdot \mathrm{dm}^{-2}$. Once again this figure shows that figures of merit are optimised for the intermediate temperatures. The optimal temperature can thus be set at $10^{\circ} \mathrm{C}$. 


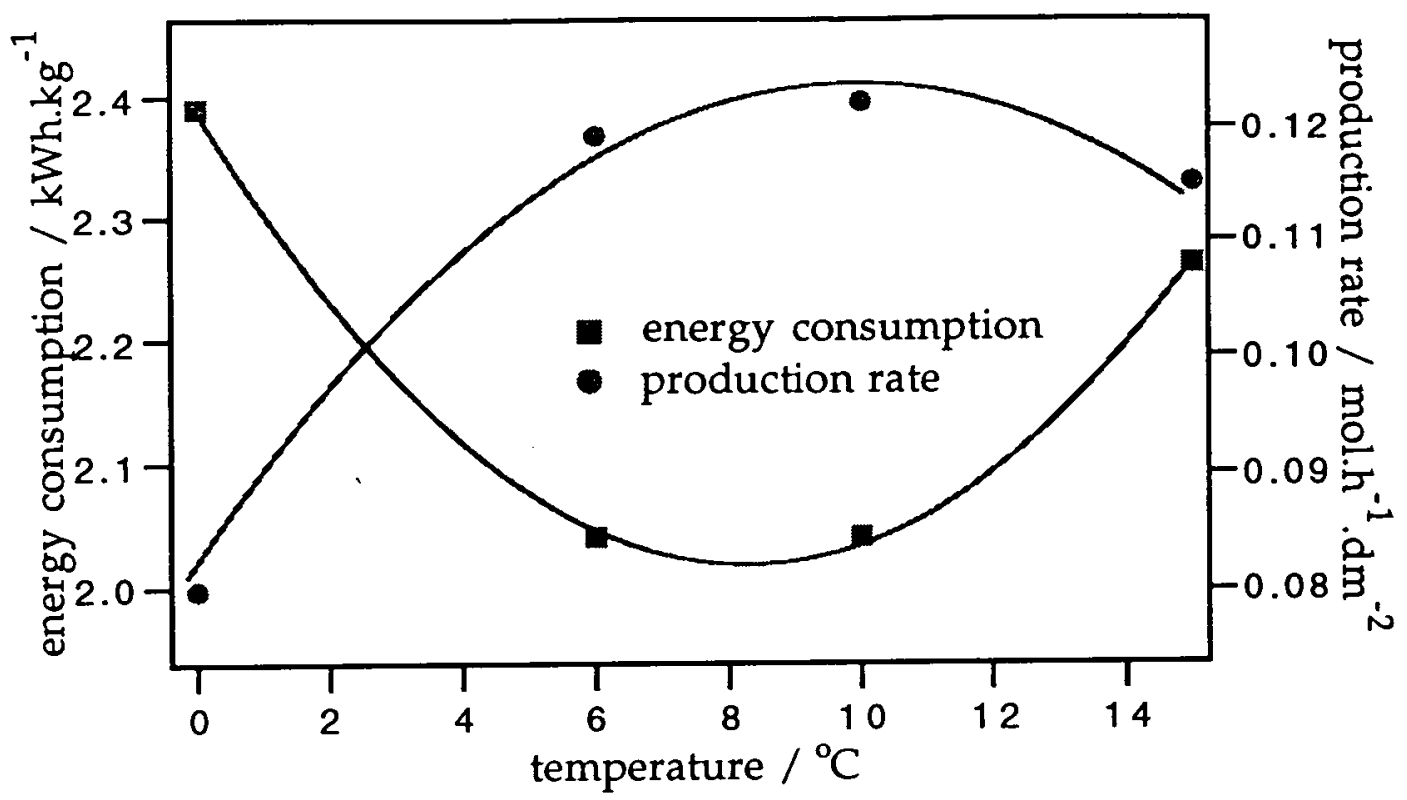

Figure 6.12: Effect of the temperature on the energy consumption and the production rate.

\section{6-3-5 Effect of sodium bromide concentration on the cell performance}

The sodium bromide concentration was the next parameter under investigation. Its influence on the figures of merit should be noticeable as the value of the concentration is a determining factor for the resistance of the electrolyte and for the amount of bromine produced at the electrodes. Exp. 7 and Exp. 14 - 17, were experiments carried out at $3 \mathrm{~V}$, in the tank reactor with platinum array PT3, and with the sodium bromide concentration varying in the range 0.2 to $2 \%$ (or 0.02 to $0.2 \mathrm{M}$ ).

As can be seen in figure 6.13, the propylene oxide concentration is proportional to the normalised amount of charge passed through the cell. Larger amounts of propylene oxide are produced when the concentration is set between 1 and $1.5 \%$, where the current efficiency appears to reach the highest value. 


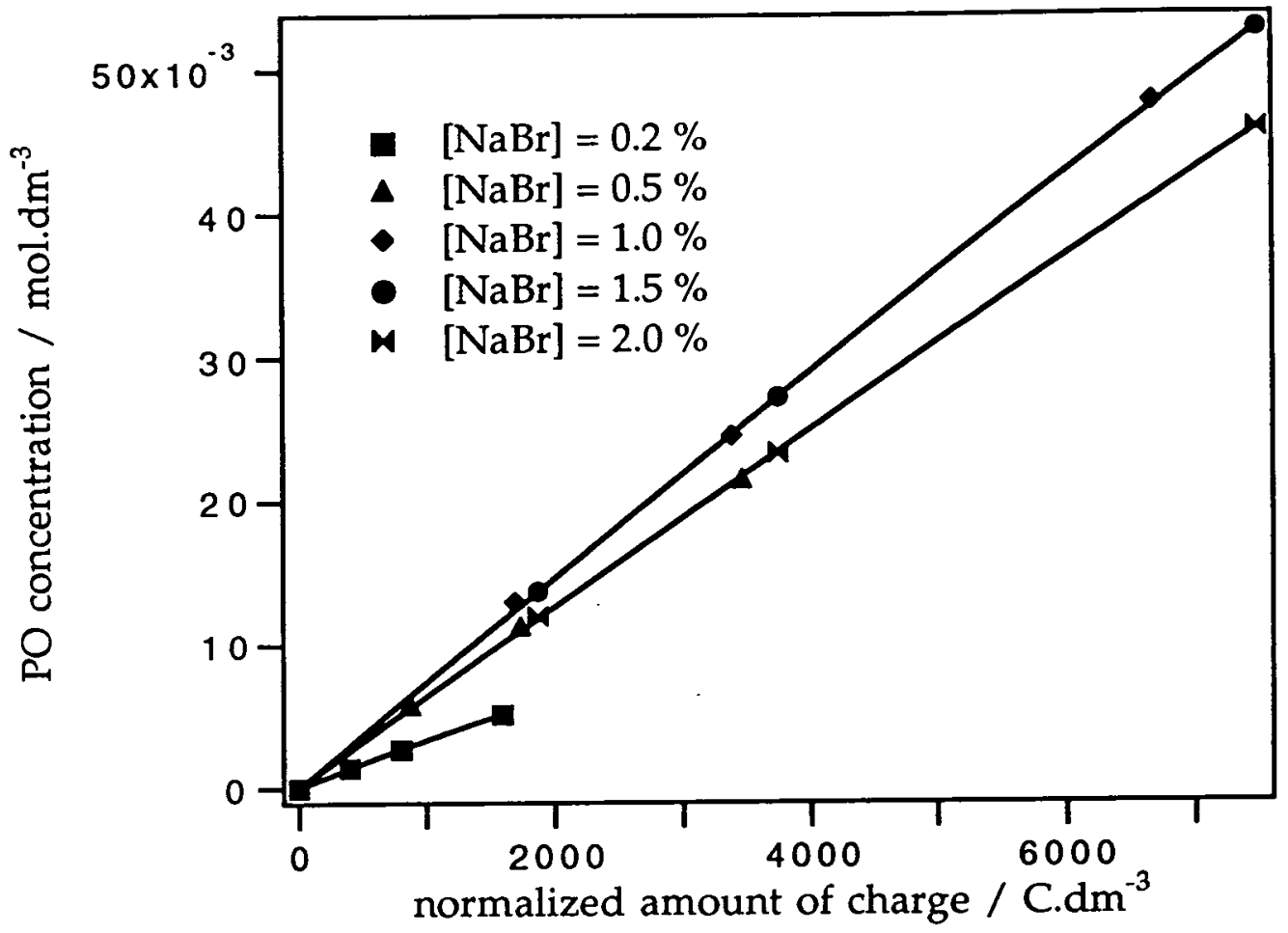

Figure 6.13: Evolution of the PO concentration with the normalised amount of charge passed through the cell, for experiments carried out at $3 \mathrm{~V}$ in tank cell with the platinum array PT3.

The first effect of increasing the sodium bromide concentration was to increase the amount of bromine produced at the anode. At potentials where only the oxidation of bromide occurs, $3 \mathrm{~V}$ for example, this quantity is proportional to the limiting current. This was verified experimentally and the results are reported in figure 6.14. At relatively low concentrations, the current density is linearly proportional to the electrolyte concentration. For more concentrated solutions, however, the increase in the current density becomes limited by the kinetics of the reactions contributing to the elimination of bromine produced in large quantities at the anode. It must be remembered that the quantity of absorbed propylene in the electrolyte is very low. 


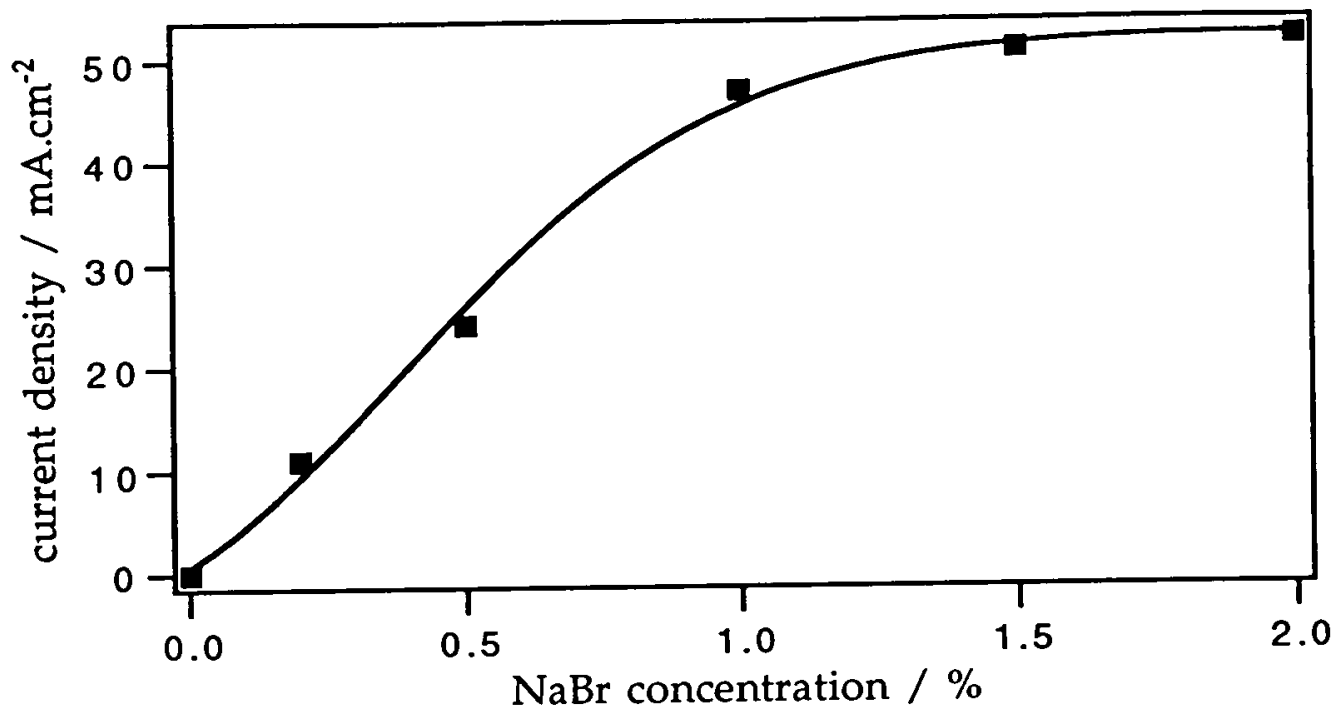

Figure 6.14: Variation of the current density with the sodium bromide concentration, for experiments carried out at $3 V$ in a tank cell and with the platinum array PT3.

Sodium bromide also acts as a supporting electrolyte. Its addition to the solution also has the effect of increasing the conductivity of the solution. The resistance between the anode and the cathode can be determined theoretically from equations (3.26) and (3.27) developed in chapter 3. For the range of concentrations investigated, the resistance was found to vary in the range 4.9 to $0.5 \Omega$, resulting in iR drop in the order of 0.15 to $0.20 \mathrm{~V}$. The small difference in the $\mathrm{i} R$ drop proves that this cell geometry could be particularly well suited for electrolytes of low conductivity.

As can be seen in figure 6.15, the variations of the production rate and the current density with the sodium bromide concentration are very comparable. The only difference is that the production rate starts to decrease at high values. At high concentrations, the rate of bromine formation is too large in comparison with the rate of propylene absorption, resulting in side reactions and product destruction. 


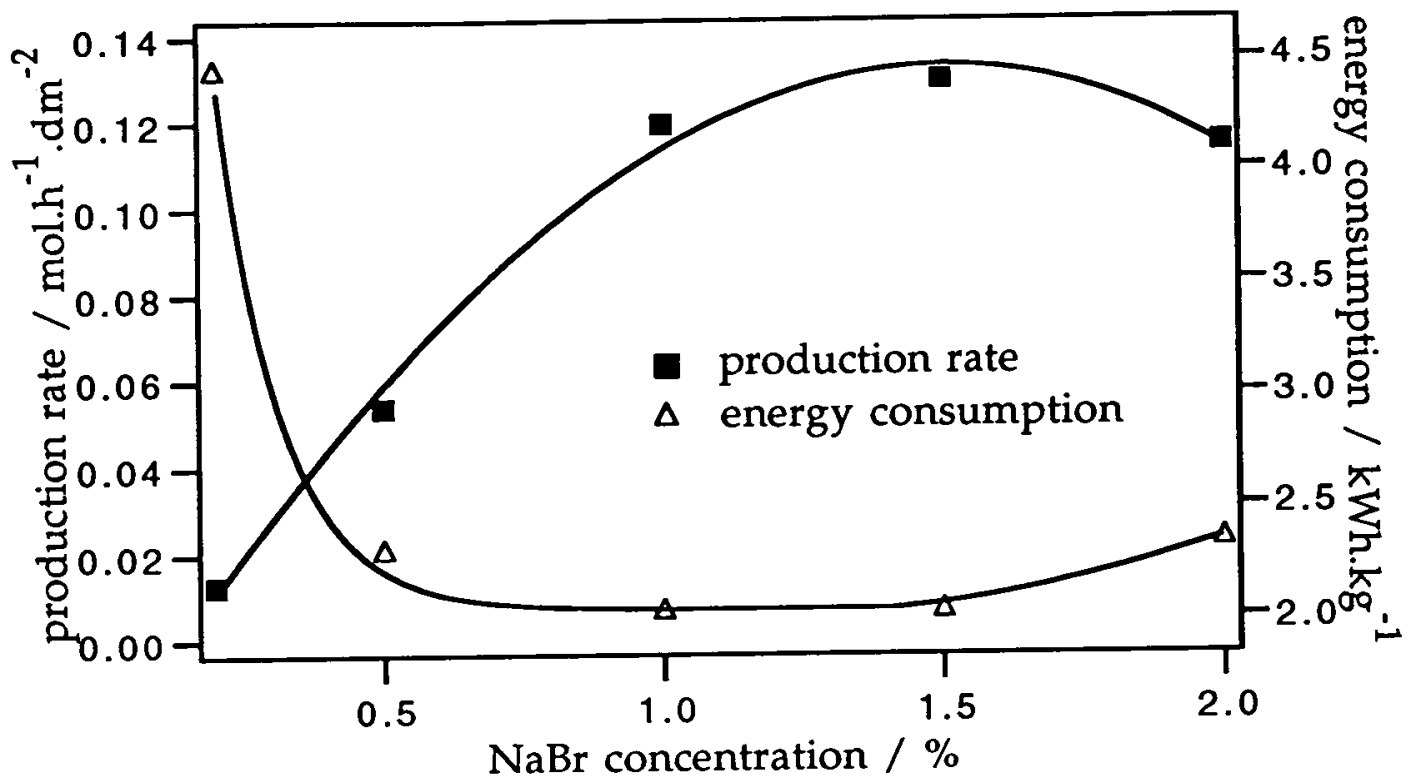

Figure 6.15: Variation of the figures of merit with the sodium bromide concentration, for syntheses carried out at $3 V$ in the tank cell reactor with platinum array PT3.

\section{6-3-6 Effect of the inter-electrode distance on the cell performance}

In the propylene epoxidation process, the anode and the cathode products react together to form propylene oxide. The inter-electrode distance should therefore have an effect on the synthesis performance. This was verified by varying the bandgap between $250 \mu \mathrm{m}$ and $1 \mathrm{~mm}$ (Exp. 7, Exp. 18 - 19). Figure 6.16 shows the decrease of the current density with the inter-electrode distance. This decrease can also be explained by the decrease in the ohmic drop. 


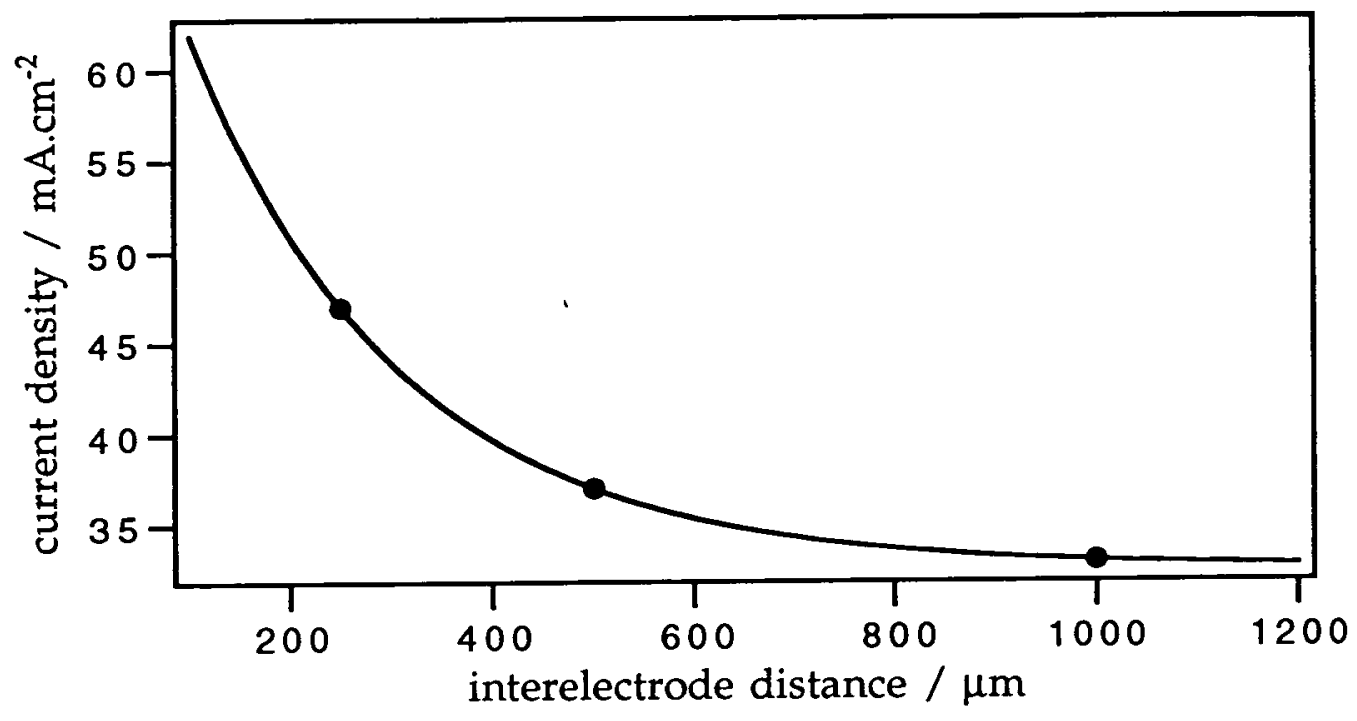

Figure 6.16: Variation of the current density with the inter-electrode distance, for syntheses carried out at $3 \mathrm{~V}$.

In figure 3.17, it can be seen that for any array, the amounts of propylene oxide formed during the syntheses are linearly proportional to the normalised amount of electricity passed though the cell.

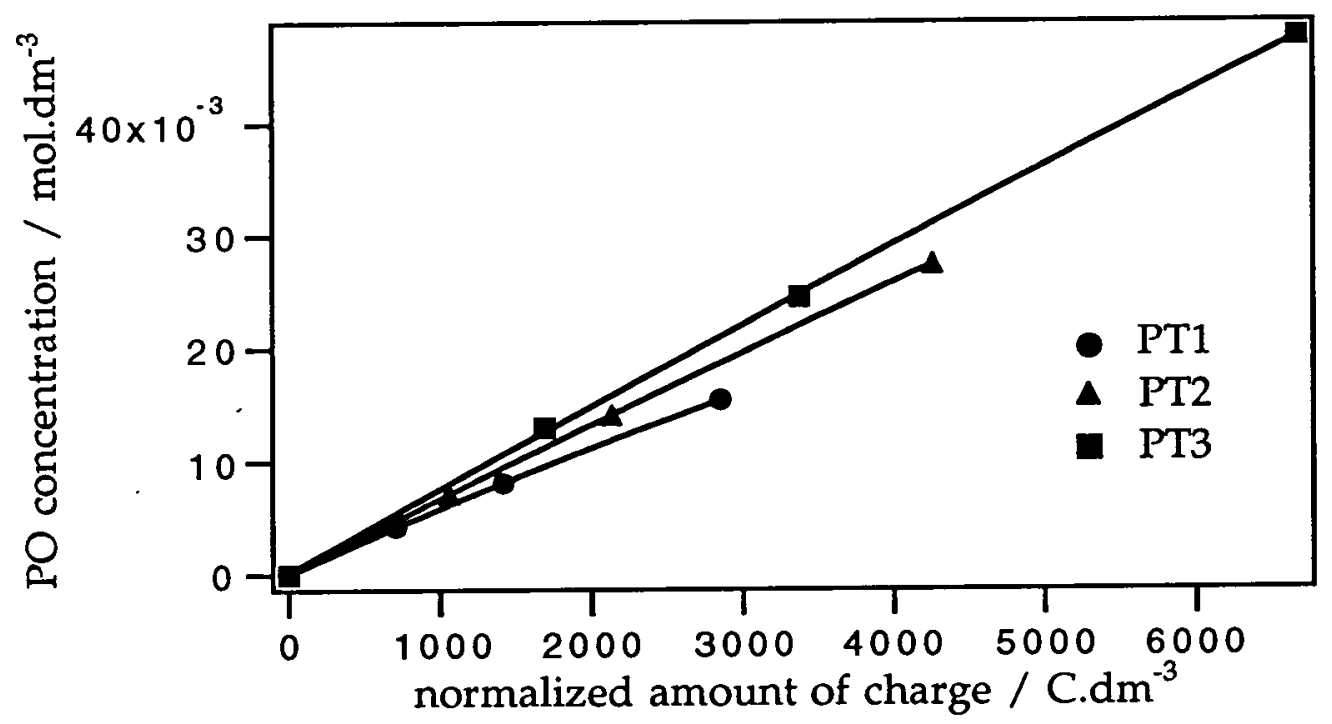

Figure 6.17: Evolution of the PO concentration with the normalised amount of charge passed though the cell, for different platinum arrays. 
From this figure the current efficiency can also be expected to be of lower amplitude for larger inter-electrode distances. Indeed as can be seen in table 6.2, the current efficiency decreased from 68 to $52 \%$ when the bandgap was changed from $250 \mu \mathrm{m}$ to $1 \mathrm{~mm}$. As a result the energy consumption was found to increase from 2.0 to $2.7 \mathrm{kWh} . \mathrm{kg}^{-1}$. It can also be established that the production rate is inversely proportional to the bandgap and varies in the range 0.06 to $0.12 \mathrm{~mol} . \mathrm{h}^{-1} . \mathrm{dm}^{-2}$. This is highlighted by figure 6.18 .

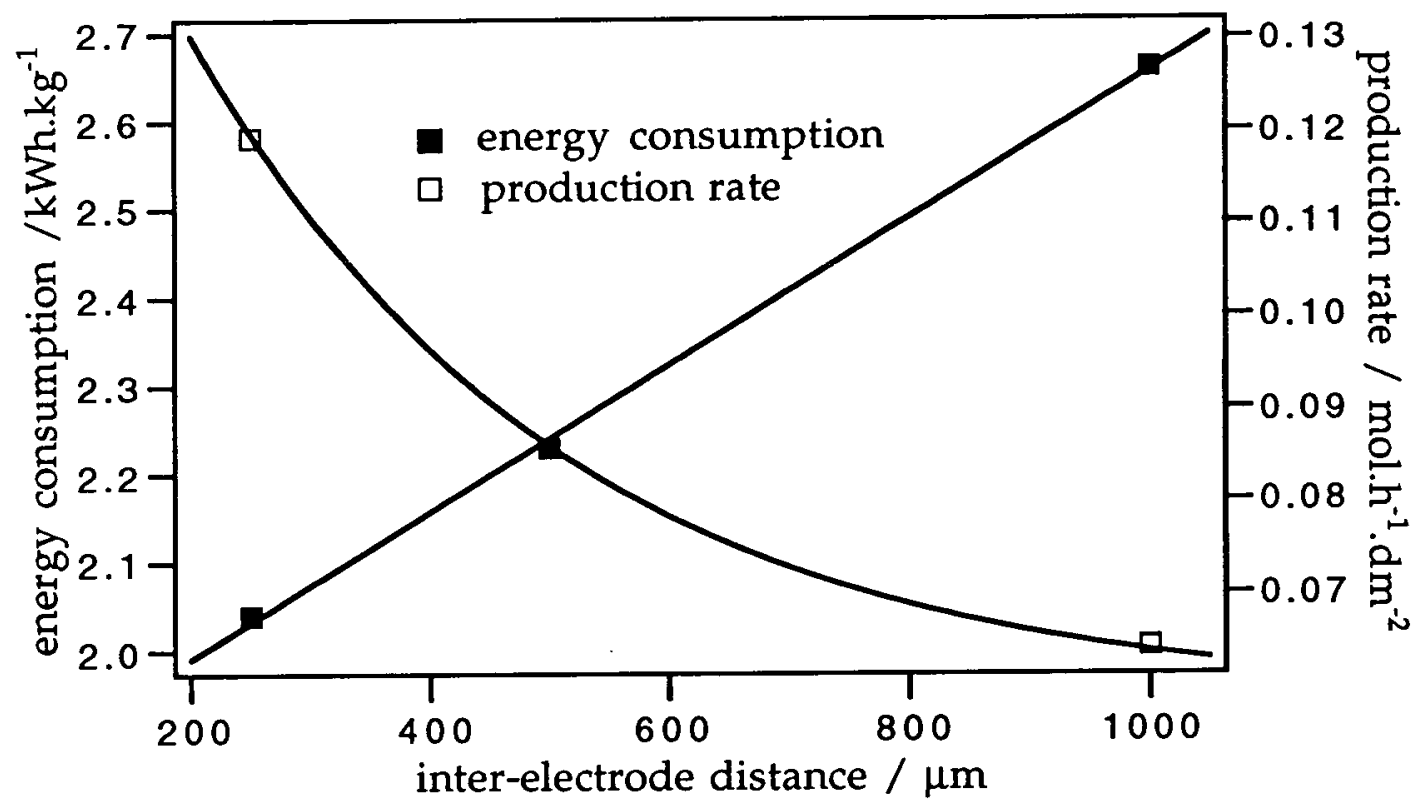

Figure 6.18: Variation of the energy consumption and the production rate with the inter-electrode distance.

From these results, it is clear that minimising the inter-electrode distance is important. For all the experiments carried out, this dimension was greater than to the thickness of the diffusion layer, estimated to be in the 
order of 50 to $100 \mu \mathrm{m}$ [48]. Until these values are reached, the dependence of the figures of merit with the inter-electrode distance is therefore expected to be consistent. The performance of the coplanar band electrodes should be improved by using such dimensions.

\section{6-4 Conclusion}

Again the carbon ink investigated was found to be unsuitable for such an application. The use of the platinum ink for the fabrication of coplanar band arrays was however very satisfying and no degradation in the electrode behaviour was noticeable over 100 hours of electrolysis. Similarly as for the methoxylation of furan, platinum arrays in a tank cell proved to be an efficient method for the epoxidation of propylene. The performances of the arrays depends on many factors, such as the flow conditions, the applied voltage, the cell temperature, the electrolyte concentration and the inter-electrode distance. The optimal conditions in a tank cell, although subject to the industrial objectives, can be obtained for an applied voltage of 3 to $3.5 \mathrm{~V}$, a temperature of $10^{\circ} \mathrm{C}$, a sodium concentration of $10 \%$ and minimum bandgap. The performance of a $250 \mu \mathrm{m}$ array are reported in table 6.3, and compared with the figures obtained with a pump cell and a trickle tower. The results obtained with the coplanar band array is slightly inferior to the pump cell figures of merit, but could be comparable or even better for an inter-electrode distance of $150 \mu \mathrm{m}$, which was the distance between electrodes of the pump cell. It should be emphasised that for such gaps, the pumping costs for the pump cell can not be neglected and also obstruction can easily occur. Electrodes separated by 50 to $100 \mu \mathrm{m}$ can be achieved by serigraphy, but only in a dust-free environment. When compared to the trickle tower, 
the coplanar band electrodes in a tank reactor are found to be a more economical process for the epoxidation of propylene.

Table 6.3: Comparative performances of different cell for the epoxidation of propylene.

\begin{tabular}{lccc}
\hline figures of merit & $\begin{array}{c}\text { PT3 in } \\
\text { a tank cell }\end{array}$ & $\begin{array}{c}\text { pump } \\
\text { cell }\end{array}$ & $\begin{array}{c}\text { trickle } \\
\text { tower }\end{array}$ \\
\hline energy consumption / $\mathrm{kWh} . \mathrm{kg}^{-1}$ & 2.0 & 1.4 & 2.9 \\
production rate / mol.h-1. $\mathrm{dm}^{-2}$ & 0.12 & 0.15 & - \\
\hline
\end{tabular}




\section{CHAPTER 7}

\section{Electrolysis of Sea Water}

\section{7-1 Bibliography}

The properties of sea water can be found in various textbooks [75]. It is present in huge quantity, indeed $72 \%$ of the total earth surface is covered by sea, and for uniform distribution 270 litres of water would be present per $\mathrm{cm}^{2}$. The concentration of the different species varies from one sea to another. In average salts are present at a concentration of $35 \mathrm{~g} \cdot \mathrm{dm}^{-3}$. The concentrations of the main salts are given by:

$\begin{array}{lrl}\mathrm{NaCl} & 27.21 \mathrm{~g} . \mathrm{dm}^{-3} \\ \mathrm{MgCl}_{2} & 3.81 \mathrm{~g} \cdot \mathrm{dm}^{-3} \\ \mathrm{MgSO}_{4} & 1.66 \mathrm{~g} \cdot \mathrm{dm}^{-3} \\ \mathrm{CaSO}_{4} & 1.26 \mathrm{~g} \cdot \mathrm{dm}^{-3}\end{array}$

The other species present are carbonates, chlorides, bromides, iodides and also oligo-elements such as aluminium, iron, manganese and copper. Finally, sea water is slightly alkaline, with $\mathrm{pH}$ values varying in the range 7.8 to 8.4 .

Because of its abundance and its high concentration of sodium chloride, sea water appears to be an ideal medium for the electrogeneration of active chlorine $\left(\mathrm{Cl}_{2}, \mathrm{HOCl}, \mathrm{ClO}^{-}\right)$. Hypochlorite is the term used to denote the sum of hypochlorous acid ( $\mathrm{HOCl}$ ) and hypochlorite anion ( $\left.\mathrm{ClO}^{-}\right)$. It is widely employed as a disinfectant, mainly for drinking water, sewage treatment and also in the food and beverage industries. Because of the 
environmental hazards associated with the transport and storage of chlorine, legislation is now more and more restrictive. As a result the interest in on-site generation has grown and hypochlorite generators are now commercially available [2] (i. e. Krebs, Sterelec, El-Tec...).

The main inconvenience of using sea water as a starting material is that it contains magnesium and calcium ions, which in local alkaline conditions, precipitate as hydroxides. This tarter is usually produced at the cathode, and tends to passivate the surface. Thermodynamic calculations carried out by C. Boxall and G. H. Kelsall [76] predict the precipitation of $\mathrm{Mg}(\mathrm{OH})_{2}$ and $\mathrm{Ca}(\mathrm{OH})_{2}$ at $\mathrm{pH}$ above 9 and 12.5 respectively. For the production of hypochlorite, two cell configurations are used: divided cells, with a cationic or an anionic membrane [77], or undivided cells [78-82]. Divided cells have the ability to produce hypochlorite at very high concentration (8-15\%) but require the use of very pure feeds and are therefore not very suitable for sea water. In contrast, in an undivided cell, the hypochlorite concentration is limited to $1 \%$ due to side reactions [79, $81,83,84]$. The different reactions occurring at the electrodes and in the bulk solution are described in a large number of reviews [85, 86]:

\section{Primary reactions:}

$\begin{array}{ll}\text { at the anode: } & 2 \mathrm{Cl}^{-}-2 \mathrm{e} \longrightarrow \mathrm{Cl}_{2} \\ \text { at the cathode: } & 2 \mathrm{H}_{2} \mathrm{O}+2 \mathrm{e} \longrightarrow 2 \mathrm{OH}^{-} \\ \text {in the bulk: } & \mathrm{Cl}_{2}+2 \mathrm{H}_{2} \mathrm{O} \rightleftharpoons \mathrm{HClO}+\mathrm{Cl}^{-}+\mathrm{H}_{3} \mathrm{O}^{+} \\ & \mathrm{HClO}+\mathrm{H}_{2} \mathrm{O} \rightleftharpoons \mathrm{ClO}^{-}+\mathrm{H}_{3} \mathrm{O}^{+}\end{array}$

The equilibrium constants for the two reversible reactions are $4.10^{-4} \mathrm{~mol}^{2} \mathrm{l}^{-2}$ and $3.10^{-4} \mathrm{~mol} \mathrm{l}^{-1}$ respectively. 


\section{Side reactions:}

at the anode:

$$
\begin{aligned}
6 \mathrm{ClO}^{-}+3 \mathrm{H}_{2} \mathrm{O}-6 \mathrm{e} \longrightarrow & 2 \mathrm{ClO}_{3}^{-}+4 \mathrm{Cl}^{-} \\
& +6 \mathrm{H}^{+}+3 / 2 \mathrm{O}_{2} \\
2 \mathrm{H}_{2} \mathrm{O} \longrightarrow \mathrm{O}_{2}+4 \mathrm{H}^{+}+ & 4 \mathrm{e}
\end{aligned}
$$

at the cathode: $\quad \mathrm{ClO}^{-}+\mathrm{H}_{2} \mathrm{O}+2 \mathrm{e} \longrightarrow \mathrm{Cl}^{-}+2 \mathrm{OH}^{-}$

in the bulk:

$$
\begin{aligned}
& 2 \mathrm{HOCl}+\mathrm{ClO}^{-} \longrightarrow \mathrm{ClO}_{3}^{-}+2 \mathrm{Cl}^{-}+2 \mathrm{H}^{+} \\
& 2 \mathrm{ClO}^{-} \longrightarrow 2 \mathrm{Cl}^{-}+\mathrm{O}_{2}
\end{aligned}
$$

In order to prevent or to limit the oxidation of water, Dimensionally Stable Anodes are often used. DSA electrodes are usually made of ruthenium or iridium dioxides plated on titanium. Their use favours chloride oxidation. The reduction of the hypochlorite can be limited by the formation of a $\mathrm{Mg}(\mathrm{OH})_{2}$ or $\mathrm{Ca}(\mathrm{OH})_{2}$ film, by increasing the anode to cathode ratio or eventually by using chromium plated cathodes [80], but because of pollution problems the last solution is often discarded.

In a parallel plate cell [79], it was shown that to optimise the current efficiency and the energy consumption it was necessary to minimise the current density and the sodium chloride concentration, and also to maximise the flow rate. In such conditions the current efficiency could reach $100 \%$, for an energy consumption of $0.23 \mathrm{kWh} . \mathrm{mol}^{-1}$, this was however to the detriment of the production rate.

The performance of three other undivided cells have been compared by G. H. Kelsall [87]. For all the reactions the $\mathrm{pH}$ was found to increase with electrolysis time and the current efficiency decreased with the hypochlorite concentration. The electrolyses were carried out with brine solutions or sea water with the $\mathrm{NaCl}$ concentration equivalent to the original concentration found in the sea. The current applied to a series of $\mathrm{Ti} / \mathrm{PbO}_{2}$ parallel plates connected in monopolar or in bipolar mode, was 
set at about $100 \mathrm{~mA} . \mathrm{cm}^{-2}$. Similar results were obtained with the two configurations, and for a conversion of $10 \%$ the energy consumption was in the order of $0.3-0.6 \mathrm{kWh}^{\mathrm{kg}} \mathrm{k}^{-1}$, and the space-time yield varied between 0.3 and $0.8 \mathrm{~mol} . \mathrm{m}^{-3} . \mathrm{s}^{-1}$. With a fluidised bed cell, made of carbon rods placed between a $\mathrm{Ti}-\mathrm{PbO}_{2}$ anode and a titanium mesh, the figures of merit obtained did not compare as favourably, as the energy consumption was found to be higher $\left(1.4-1.7 \mathrm{kWh} \cdot \mathrm{kg}^{-1}\right)$, and the space time yield lower ( 0.1 to $\left.0.6 \mathrm{~mol} \cdot \mathrm{m}^{-3} \cdot \mathrm{s}^{-1}\right)$. These figures are in good agreement with the results obtained by F. Goodridge et al for another fluidised bed cell [82]. In comparison with other cells, however, fluidised bed cells present the great advantage of avoiding the passivation of the electrodes by tarter, this due to the movement of the bed particles.

Finally it should be emphasised that, depending on the applications, even with a lack in the figures of merit optimisation can easily be compensated for, by a simple and long life-time reactor. For example, MERACTIVE ${ }^{\circledR}$ the on-site reactor commercialised by F-Tec is composed of DSA plate anodes immersed in a simple tank reactor. It is actually in use in Argelès for the disinfection of sand on the beach. It operates with reasonable

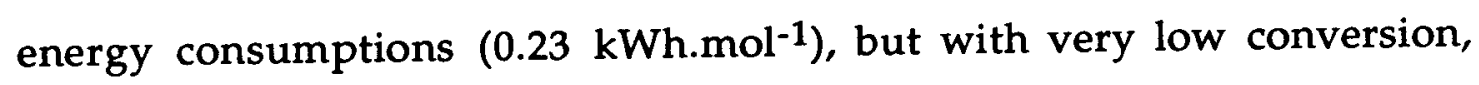
which is not a major inconvenience in such a case.

In chapter 4, for the methoxylation of furan with coplanar band electrodes, protons produced at the anodes could be neutralised by the methanolic ions produced at the adjacent electrode. Similarly, it was thought that for this reaction, hydroxide ions produced at the cathode could be neutralised by the chlorine produced at the anode to form hypochlorite. The use of new kinds of DSA electrodes was also investigated. These were made of a ruthenium dioxide ink printed on a platinum thick film. 


\section{7-2 Analysis of active chlorine}

As previously indicated the concentration of chlorine, hypochlorous acid and hypochloride ions varies with the value of the $\mathrm{pH}$. Figure 7.1 represents the evolution of the different species with variation of $\mathrm{pH}$. It was derived from the calculations carried out by D. Landolt and N. Ibl [88] and it can be seen that below $\mathrm{pH}=2$, only chlorine is present in the solution.

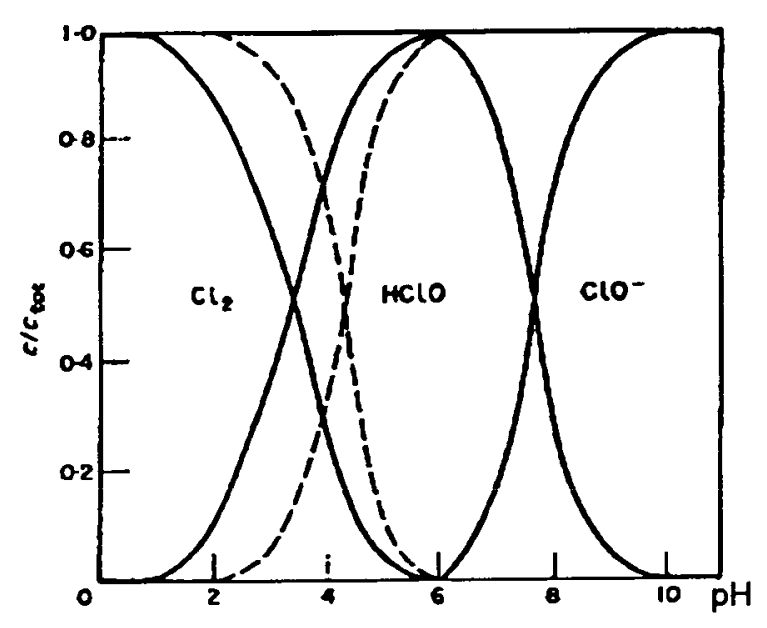

Figure 7.1: Influence of the $\mathrm{pH}$ on the concentrations of $\mathrm{Cl}_{2}, \mathrm{HClO}$ and $\mathrm{ClO}^{-}$, with $\mathrm{c}_{\text {tot }}=\mathrm{c}_{\mathrm{Cl}_{2}}+c_{\mathrm{HClO}}+c_{\mathrm{ClO}^{-}}$( $(\longrightarrow)$ in $\mathrm{H}_{2} \mathrm{O}$ with $c_{\mathrm{Cl}^{-}}=c_{\mathrm{HClO}}+c_{\mathrm{ClO}-}$ and (....-) in $4 \mathrm{M} \mathrm{NaCl}\left(c_{\mathrm{Cl}^{-}}{ }^{-\mathrm{HClO}^{+}}+c_{\mathrm{ClO}^{-}}\right)$

The active chloride concentration was determined by iodometry [89]. Potassium iodide was added in excess before adding sulphuric acid to take the $\mathrm{pH}$ down to a value of 2 . Chlorine then reacted with iodide to form iodine which was treated by a thiosulfate solution with a concentration in the range $5.10^{-2}$ to $5 \cdot 10^{-3} \mathrm{M}$. The principle reactions were:

$$
\begin{aligned}
& \left(\mathrm{Cl}_{2}, \mathrm{HOCl}, \mathrm{ClO}^{-}\right) \longrightarrow \mathrm{Cl}_{2} \\
& \mathrm{Cl}_{2}+2 \mathrm{I}^{-} \longrightarrow 2 \mathrm{Cl}^{-}+\mathrm{I}_{2} \\
& \mathrm{I}_{2}+2 \mathrm{~S}_{2} \mathrm{O}_{3}{ }^{2-} \longrightarrow 2 \mathrm{I}^{-}+\mathrm{S}_{2} \mathrm{O}_{4}{ }^{2-}
\end{aligned}
$$


Calibrations with standard solutions showed that hypochlorite could easily be detected for concentrations as low as $5.10^{-3} \mathrm{~mol}_{\text {. }} \mathrm{dm}^{-3}$.

\section{7-3 Investigation of a variety of electrode materials}

The fact that the production of chlorine is a more efficient process on DSA anodes is a well established fact. A new kind of selective anodes was developed here and compared with the performance of more classical electrodes. Syntheses were first carried out in a thermostated stirred tank cell with electrodes of $1 \mathrm{~cm}^{2}$ area until stabilisation of the hypochlorite concentration. The $35 \mathrm{ml}$ electrolyte was a brine solution containing sodium chloride at $0.5 \mathrm{M}$. For this first set of experiments, the current was set at $100 \mathrm{~mA} \cdot \mathrm{cm}^{-2}$. Two electrodes were obtained by printing platinum or ruthenium dioxide ink directly on alumina. The third electrode was made by printing a film of ruthenium dioxide on top of a film of platinum ink already printed on alumina. Finally the fourth electrode was a titanium electrode covered by a layer of iridium dioxide obtained with a spraying method [90]. The final concentrations can be found in table 7.1 and the concentration-time dependence profile can be seen in fig. 7.2.

Table 7.1: Maximum hypochlorite concentration obtained with four different electrodes.

\begin{tabular}{ccc}
\hline Experiment & anode material & $c_{\text {fin }} /$ mol.dm ${ }^{-3}$ \\
\hline Exp. 1 & $\mathrm{RuO}_{2}$ & 0.040 \\
Exp. 2 & $\mathrm{Pt}$ & 0.190 \\
Exp. 3 & $\mathrm{RuO}_{2}-\mathrm{Pt}$ & 0.230 \\
Exp. 4 & $\mathrm{IrO}_{2}-\mathrm{Ti}$ & 0.210 \\
\hline
\end{tabular}




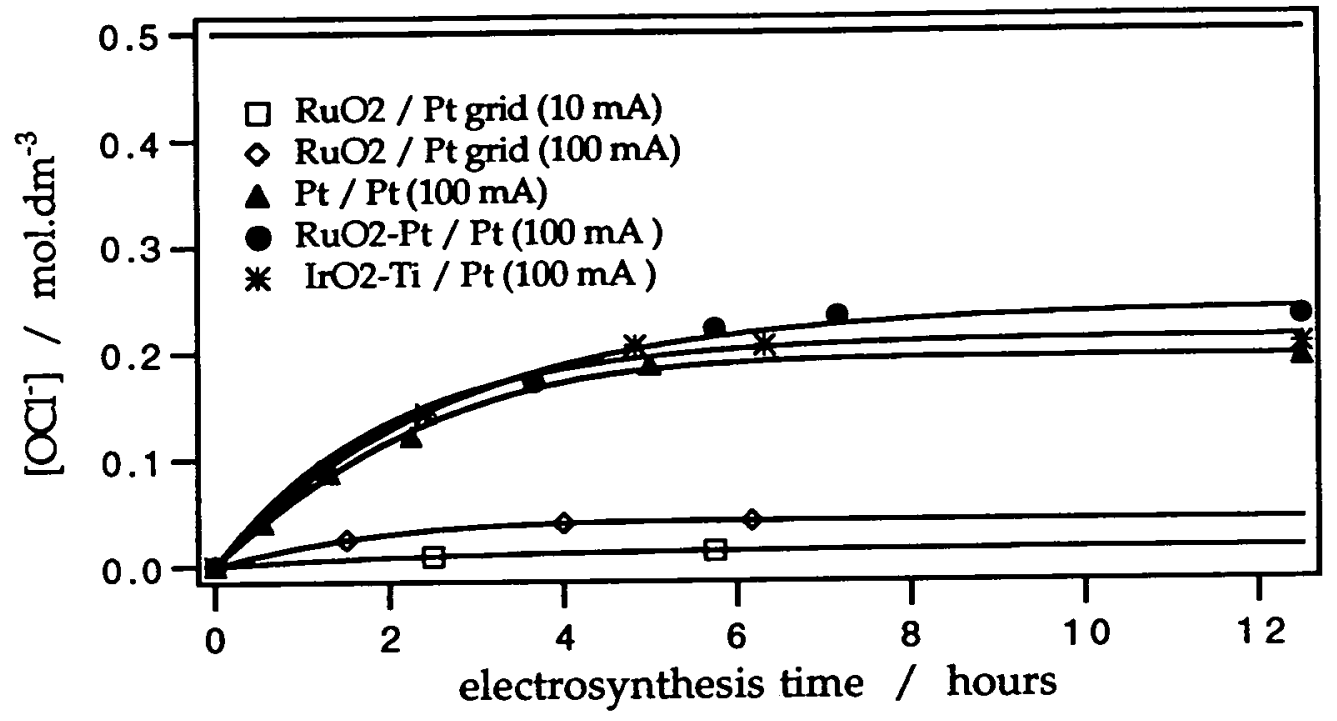

Figure 7.2: Evolution of the hypochlorite concentration with the electrosynthesis time, for different electrode materials, at 100 and $10 \mathrm{mA.cm}^{-2}$

Already from this first set of experiments, it can be seen that the ruthenium dioxide ink printed directly on alumina is not a very suitable anode as the amount of hypochlorite produced was small in comparison with the other electrodes. A deterioration of the ink was also observed. In contrast very good results were obtained with the ruthenium dioxide ink printed on an alumina substrate covered with a platinum thick film. Indeed when compared to a simple platinum thick film, an improvement was noticed and furthermore, its behaviour could be assigned to the iridium dioxide - titanium electrode.

From fig. 7.2, it can also be deduced that the maximum concentration obtainable was approximately half of the expected concentration if no side reactions were occurring. Considering that the reaction was carried out in an undivided cell, this sort of result is characteristic of a reversible reaction of the type: 
$k 1$ and $k 2$ being the rate constants of the reduction and of the oxidation respectively. Such reversible systems were studied by Y. Malherbe [91] who developed simulation programs to determine the rate constants. On this basis the ISIM program shown in appendix 2 was used to see if there was any correlation with our system. The principle of this simulation was to consider the evolution of the concentrations to be dependent on the rate of consumption and accumulation:

$$
\begin{aligned}
\frac{\mathrm{dS}}{\mathrm{dt}} & =- \text { rate of consumption }+ \text { rate of accumulation } \\
\therefore \quad \frac{\mathrm{dS}}{\mathrm{dt}} & =-\mathrm{k} 1 \text { Asp } \mathrm{S}+\mathrm{k} 2 \text { Asp } P
\end{aligned}
$$

Where $\mathrm{S}$ and $\mathrm{P}$ are the concentrations of reactant and product in mol. $\mathrm{m}^{-3}$, $\mathrm{k} 1$ and $\mathrm{k} 2$ are the rate constants in $\mathrm{m}_{\mathrm{s}} \mathrm{s}^{-1}$ and Asp is the ratio of the electrode area to the electrolyte volume in $\mathrm{m}^{-1}$. The boundary conditions, at the initial time are: $\mathrm{S}=500 \mathrm{~mol} \cdot \mathrm{m}^{-3}, \mathrm{P}=500-\mathrm{S}=0 \mathrm{~mol} \cdot \mathrm{m}^{-3}$.

Figure 7.3 shows concentration-time profiles for the last three experiments, obtained by simulation for different $k 1$ and $k 2$ values and compared to the experimental values. Although the fit is not always perfect, the values of $k 1$ and $k 2$ can easily be estimated to be in the range 1.5 to $2.510^{-5} \mathrm{~m} . \mathrm{s}^{-1}$, which corresponds well to the mass transfer values expected for laminar flow.

But the main conclusion from these experiments is that electrolyses in undivided cells should thus be stopped at low conversion (i. e. 10 to $25 \%$ ) in order to keep the figures of merit in a reasonable range. 

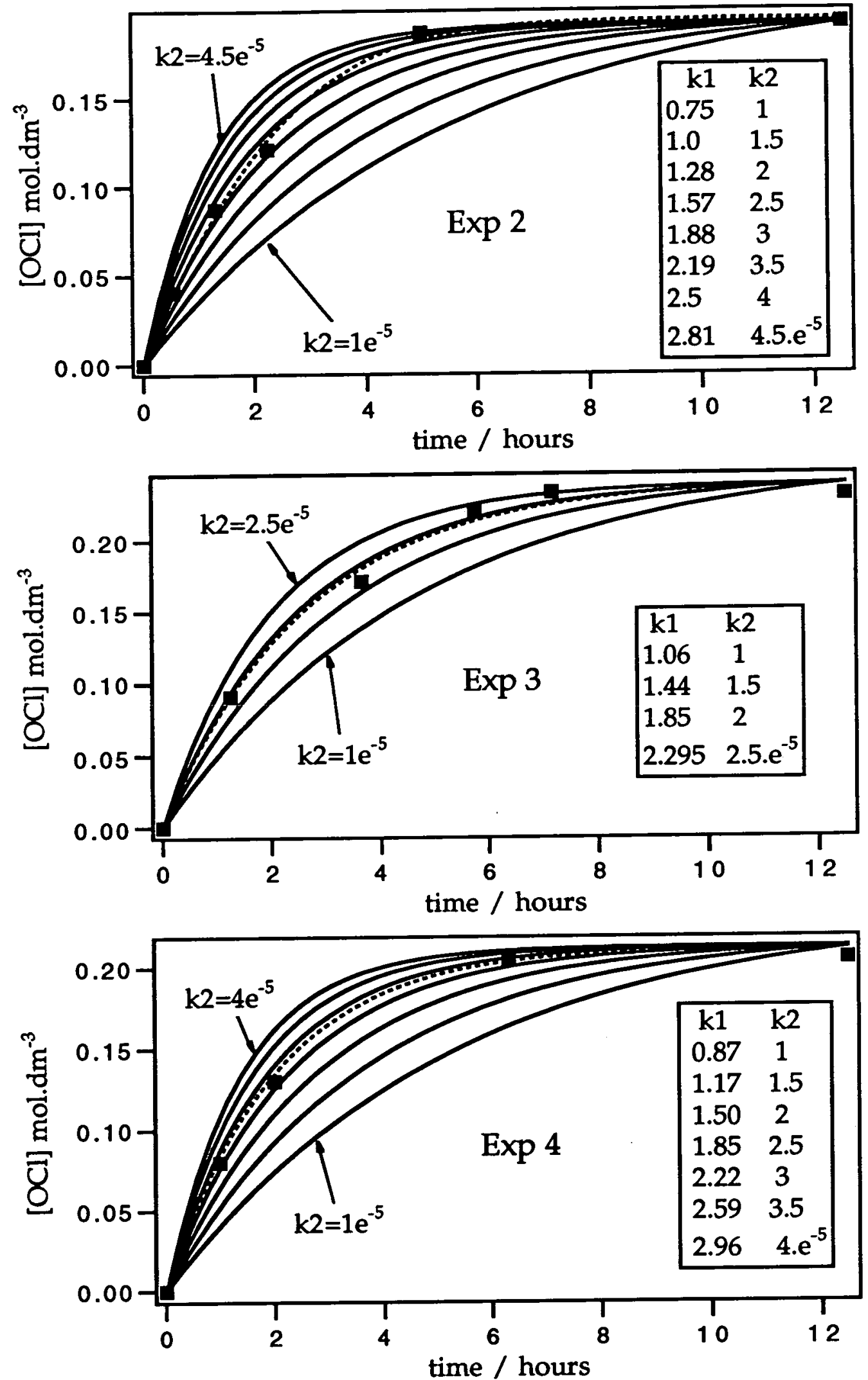

Figure 7.3: Simulation of the evolution of the hypochlorite concentration with time, for different rate constant values. 
Another set of experiments was carried out only with the iridium and the ruthenium dioxide electrodes at different current densities. Figure 7.4 shows the evolution of the conversion of sodium chloride in hypochlorite with the electrosynthesis time. The $\mathrm{IrO}_{2}-\mathrm{Pt}$ electrode was obtained by successively spraying and curing a solution of iridium chloride on a $1 \mathrm{~cm}^{2}$ printed platinum electrode. Four layers of iridium dioxide were deposited.

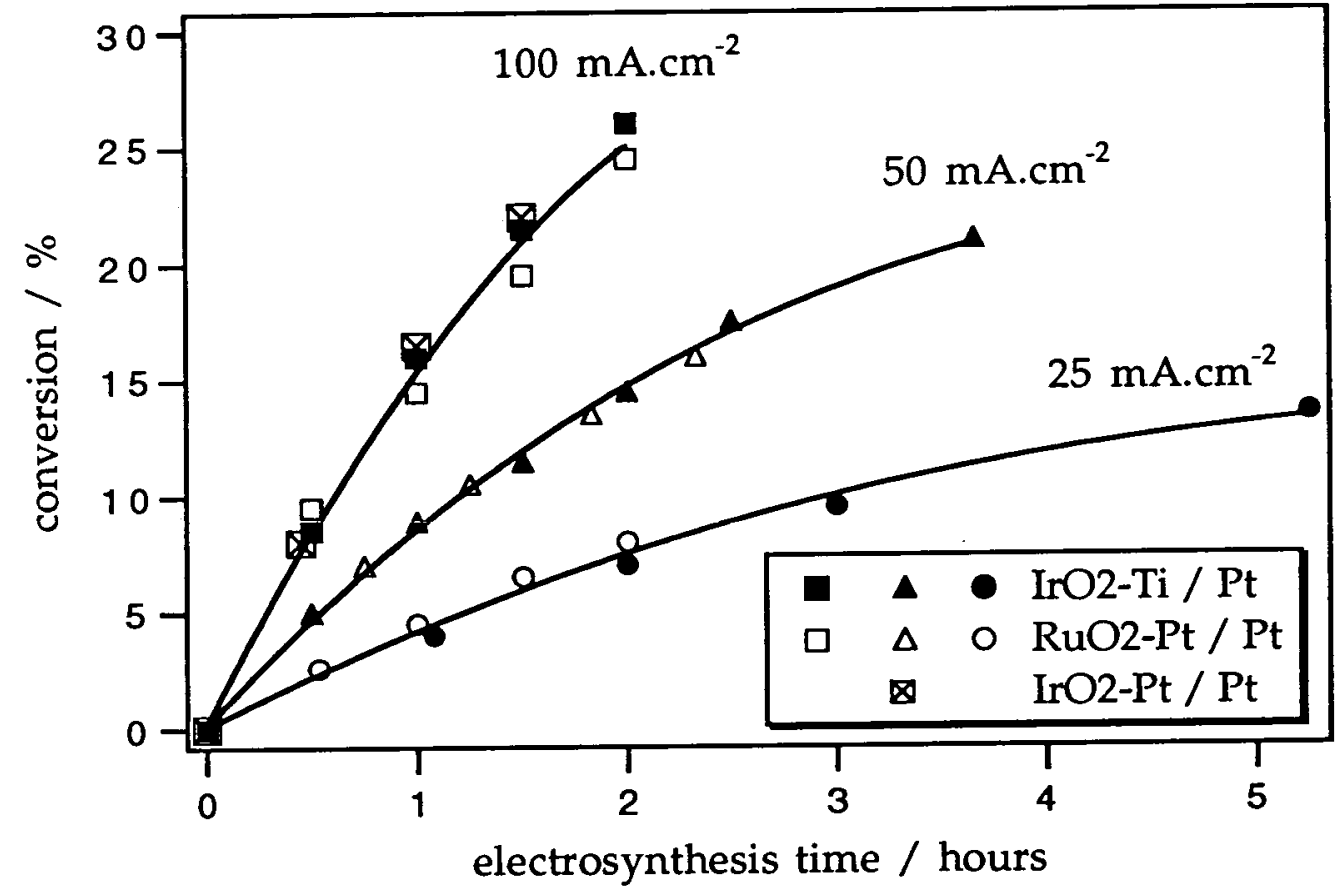

Figure 7.4: Evolution of the conversion with respect to the electrosynthesis time, for different current densities and different electrode materials.

As expected the conversion at a given time was higher for large current densities. From this figure it can also be seen that the two types of electrode behaved very similarly. In figures 7.5 and 7.6 , the current efficiency is represented as a function of the conversion, at different current densities, for the iridium dioxide - titanium and for the ruthenium dioxide electrodes. For all the experiments, current efficiency 
was found to decrease linearly with the conversion. At infinitely small conversion current efficiency could be estimated at $100 \%$. Its decrease was more pronounced for small current densities, and as with experiments carried out in a parallel plate cell [81], the current efficiency was optimised for high values of current densities.

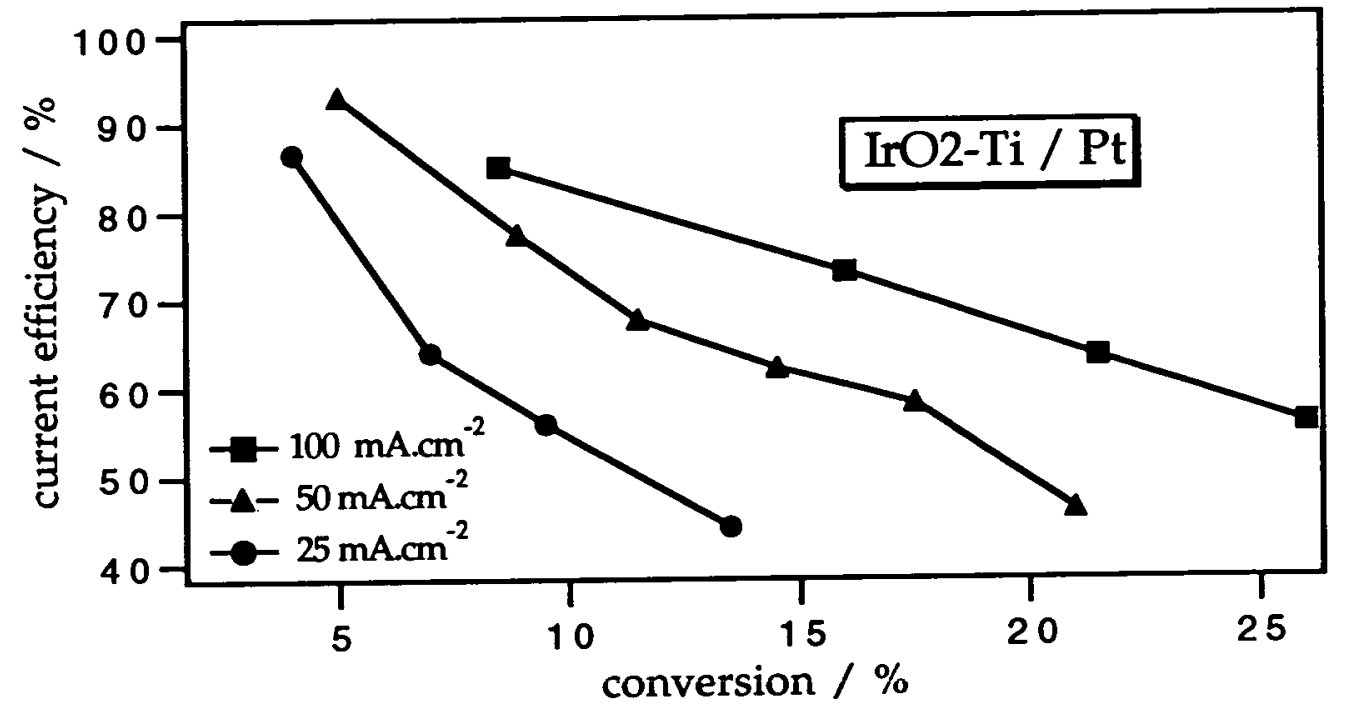

Figure 7.5: Evolution of the current efficiency with the conversion with an $\mathrm{IrO}_{2}-\mathrm{Ti}$ electrode for different current densities.

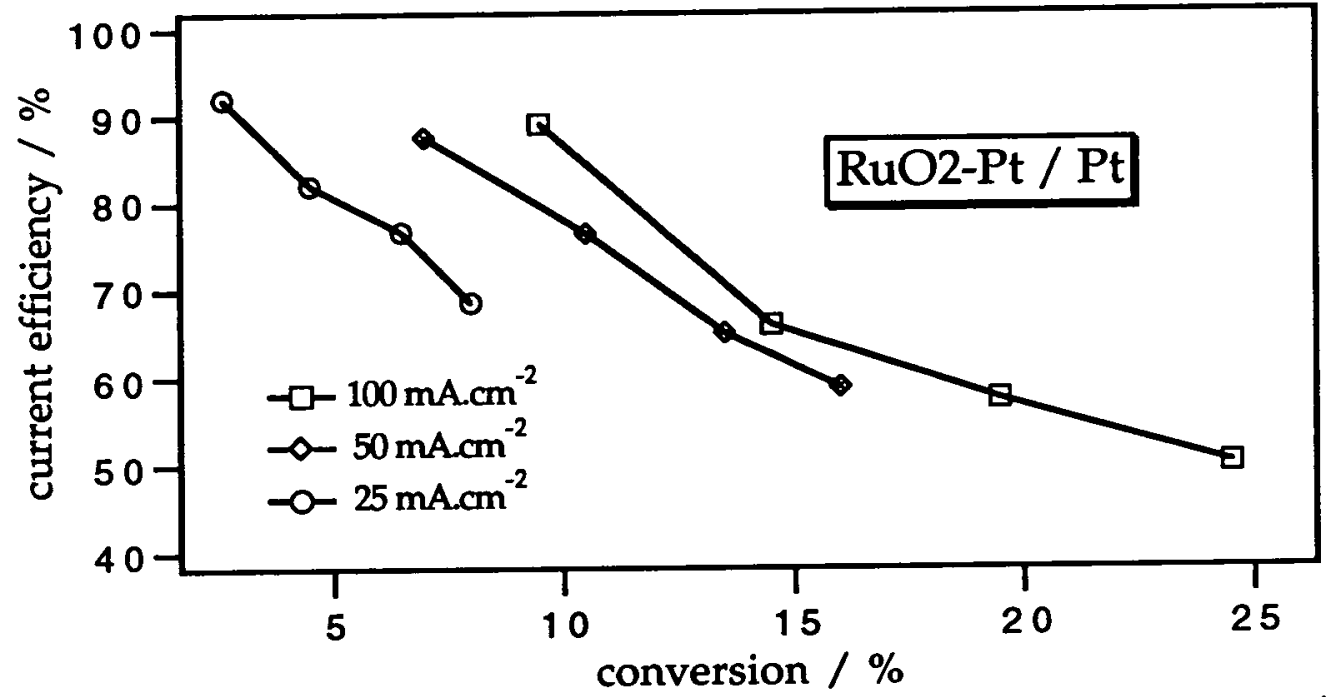

Figure 7.6: Evolution of the current efficiency with the conversion with an $\mathrm{RuO}_{2}-\mathrm{Pt}$ electrode for different current densities. 


\section{7-4 Electrolysis with coplanar band arrays}

The behaviour of the platinum coplanar band arrays PT3 and PT4 was studied for the electrolysis of a brine solution $(0.5 \mathrm{M} \mathrm{NaCl})$ and synthetic sea water $\left(0.5 \mathrm{M} \mathrm{NaCl}, 0.040 \mathrm{M} \mathrm{MgCl}, 0.014 \mathrm{M} \mathrm{MgSO}_{4}\right.$ and $0.009 \mathrm{M}$ $\mathrm{CaSO}_{4}$ ). Experiments were carried out in an agitated tank cell and in flow cell 3 . Only $3 \mathrm{~cm}^{2}$ of each electrode (anode and cathode) were exposed. The electrolysis of sea water was also performed with two square printed platinum electrodes to make a comparison possible. The experimental conditions for the different electrolyses are given in table 7.2

Table 7.2: experimental conditions for the electrolysis of brine solution with PT4.

\begin{tabular}{|c|c|c|c|c|c|}
\hline Exp? & Array: & : electrolyge & electroly ye & ?: & 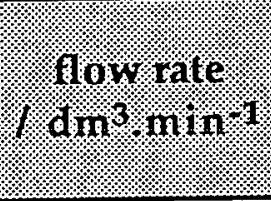 \\
\hline B1 & PT4 & 165 & brine & 400 & - \\
\hline B2 & PT4 & 165 & brine & 100 & - \\
\hline B3 & PT4 & 300 & brine & 100 & 0.6 \\
\hline B4 & $\mathrm{Pt}$ & 35 & brine & 100 & - \\
\hline B5 & PT3 & 165 & brine & 100 & - \\
\hline S1 & PT4 & 165 & art. sea water & 100 & - \\
\hline S2 & PT3 & 165 & art. sea water & 100 & - \\
\hline S3 & Pt & 35 & art. sea water & 100 & - \\
\hline
\end{tabular}


Experiments were first carried out in the brine solution. Figure 7.7 shows the evolution of the conversion with the electrolysis time obtained with the platinum array PT4.

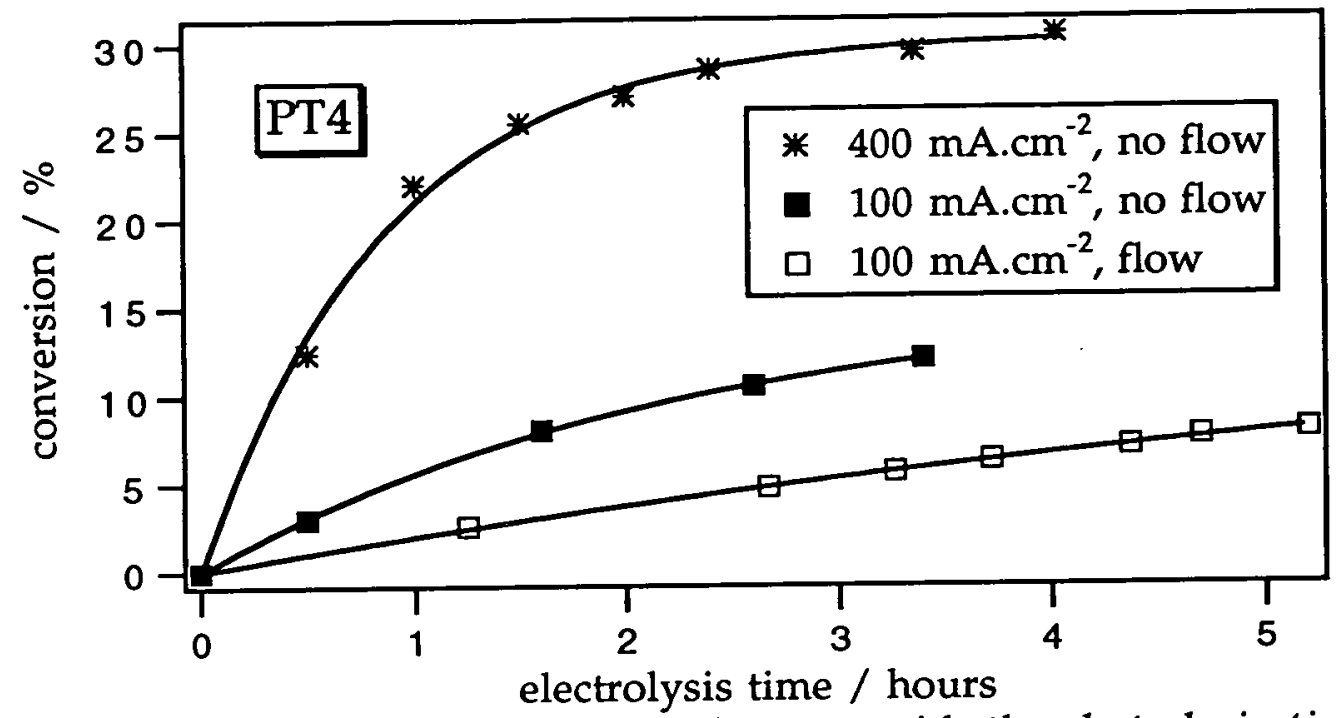

Figure 7.7: Evolution of the conversion rate with the electrolysis time for the electrolysis of brine with the platinum array PT4, for different flow regimes and different current densities.

The influence of the current density on the conversion profile here is very evident. The maximum conversion rate is very rapidly obtained for a $400 \mathrm{~mA} \cdot \mathrm{cm}^{-2}$ current density and appears to reach a higher value than with a current density of $100 \mathrm{~mA} \cdot \mathrm{cm}^{-2}$. But even in the most advantageous case, the conversion is distinctly less than $38 \%$, which was the result obtained with square printed platinum electrodes separated by $1 \mathrm{~cm}$ (cf. paragraph 7-2). In the case of the PT4 array, anodes and cathodes are separated by only $250 \mu \mathrm{m}$. This could thus facilitate the cathodic reduction of the hypochlorite ions produced at the anode, and would be a explanation for the decrease in the rates of conversion.

It is however difficult to evaluate the effect of the flow rate on the conversion rate, for the simple reason that the electrolyte volumes 
differed.. A graph of the current efficiency against the conversion rate is more revealing and is shown in figure 7.8.

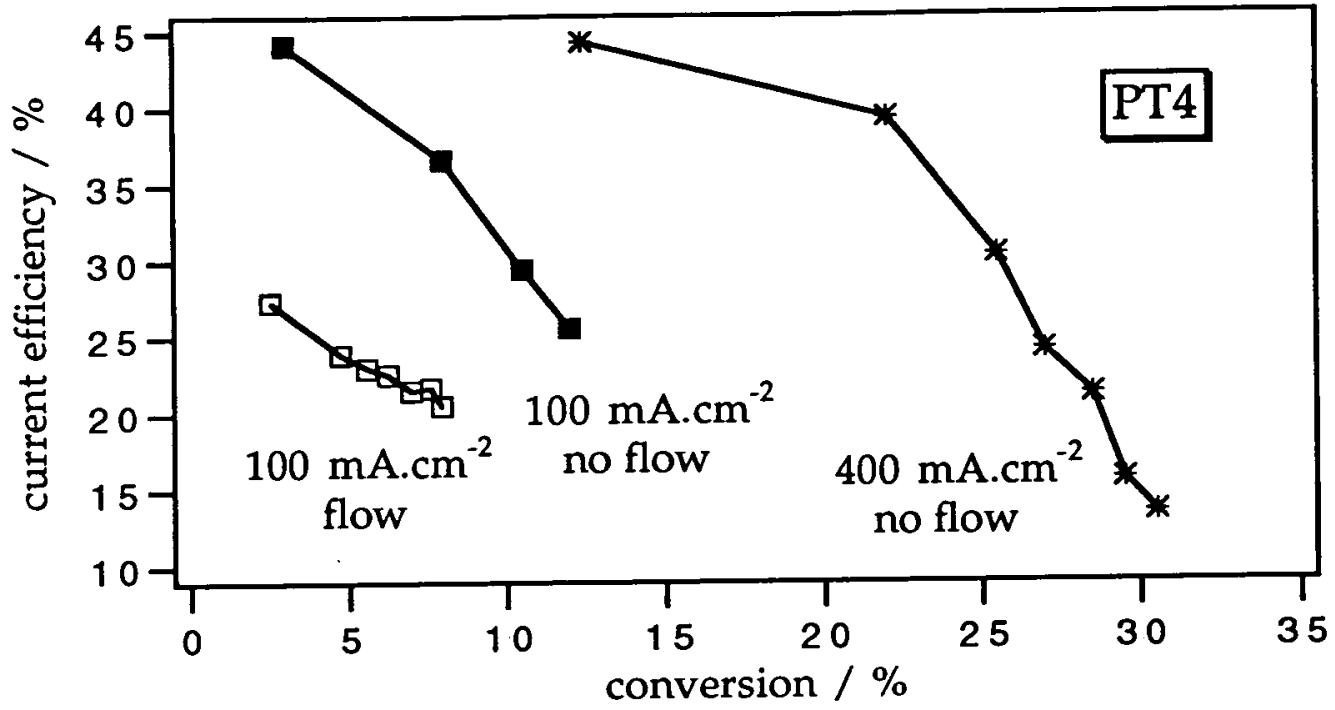

Figure 7.8: Evolution of the current efficiency with the conversion for the electrolysis of brine with the platinum array PT4, for different flow regimes and different current densities.

Similarly as for the $\mathrm{IrO}_{2}-\mathrm{Ti}$ and the $\mathrm{RuO}_{2}-\mathrm{Pt}$ square electrodes, the method was more efficient for high current densities.

Because of the facilitated hypochlorite ion reduction, the current efficiencies obtained with the coplanar array PT4 were much lower than with the more distant square electrodes. This effect was even more pronounced when the array was placed in a flow cell. In this case the hypochlorite ions produced at one anode were forced to flow on to the successive cathodes and less dispersion towards the bulk solution occurred. This proves that small inter-electrode gaps are not always preferable, especially for reversible reactions. But in the case of the electrolysis of sea water, the use of such arrays could still have the advantage of limiting the formation of tarter. 
The behaviour of the PT3 and the PT4 arrays were identical, showing that in this case, the width of the band had no effect on the results obtained.

To follow this study, experiments were then carried out in the agitated tank reactor with synthetic sea water and at a current density of $100 \mathrm{~mA} . \mathrm{cm}^{-2}$. Again PT3 and PT4 appeared to behave very similarly. The pH of the solution increased during the electrolyses, but never reached 9, the value at which $\mathrm{Mg}(\mathrm{OH})_{2}$ can be formed. Nevertheless, because of local alkaline conditions, the formation of tarter patches on the cathode surface was noticed after an hour of electrolysis. However only a portion of the cathode surface was covered. The patches were then transformed into blisters and subsequently were detached from the electrode surface. Simultaneously, other patches were formed so that the electrode coverage did not appear to develop further. In figure 7.9, it can be seen that for both arrays, the hypochlorite concentration increase was more effective in the synthetic sea water than in the brine solution.

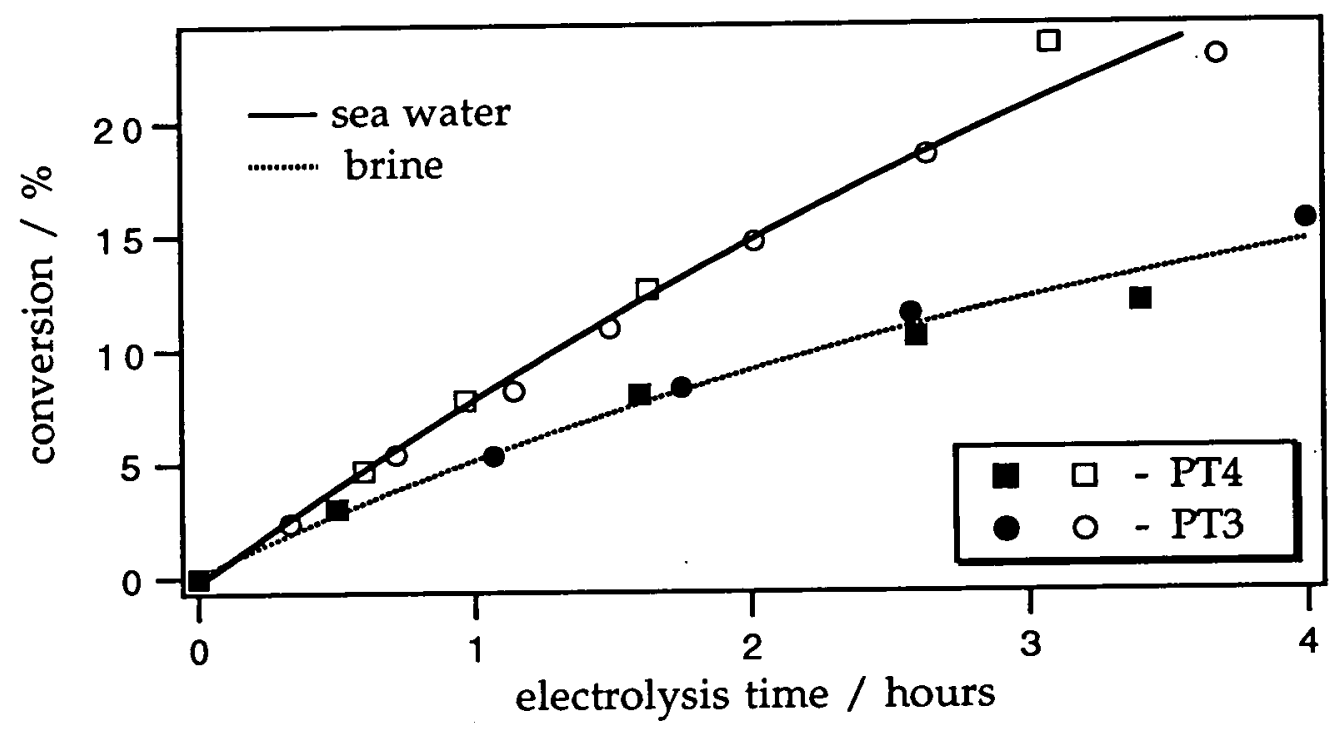

Figure 7.9: Evolution of the conversion rate with electrolysis time for reactions carried out in synthetic sea water and in brine with arrays PT3 and PT4 
When the electrolysis was carried out with square platinum electrodes, as can be seen in figure 7.10, the addition of magnesium and calcium salts also had the effect of increasing the conversion rates. Tarter was also found to deposit on the electrode border, but in contrast with the platinum arrays, the layer grew steadily with time. Photographs of the electrodes can be found in figure 7.11.

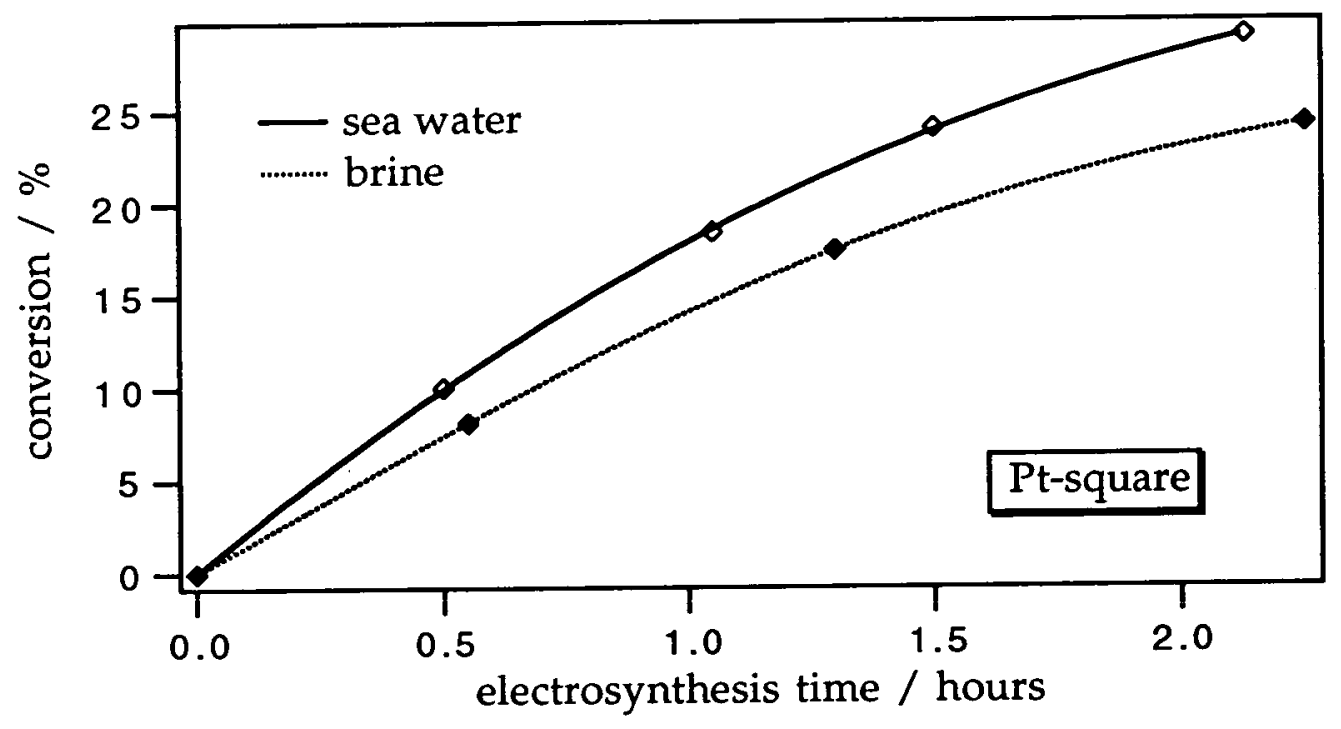

Figure 7.10: Evolution of the conversion rate with electrolysis time for reactions carried out in synthetic sea water and in brine with square platinum electrodes separated by $1 \mathrm{~cm}$.

The increase in the sodium chloride conversion in sea water was also observed by G. H. Kelsall [79], and could easily be explained by the inhibition of the hypochlorite cathodic reduction due to the formation of a $\mathrm{Mg}(\mathrm{OH})_{2}$ and $\mathrm{Ca}(\mathrm{OH})_{2}$ film reducing the cathode / anode area ratio.

Consequently, as can be seen in figures 7.12 and 7.13, the presence of magnesium and calcium salts also have an effect on the current efficiency profiles, for both the platinum arrays and the square electrodes. Since the hypochlorite reduction is limited by the formation of tarter, the current 


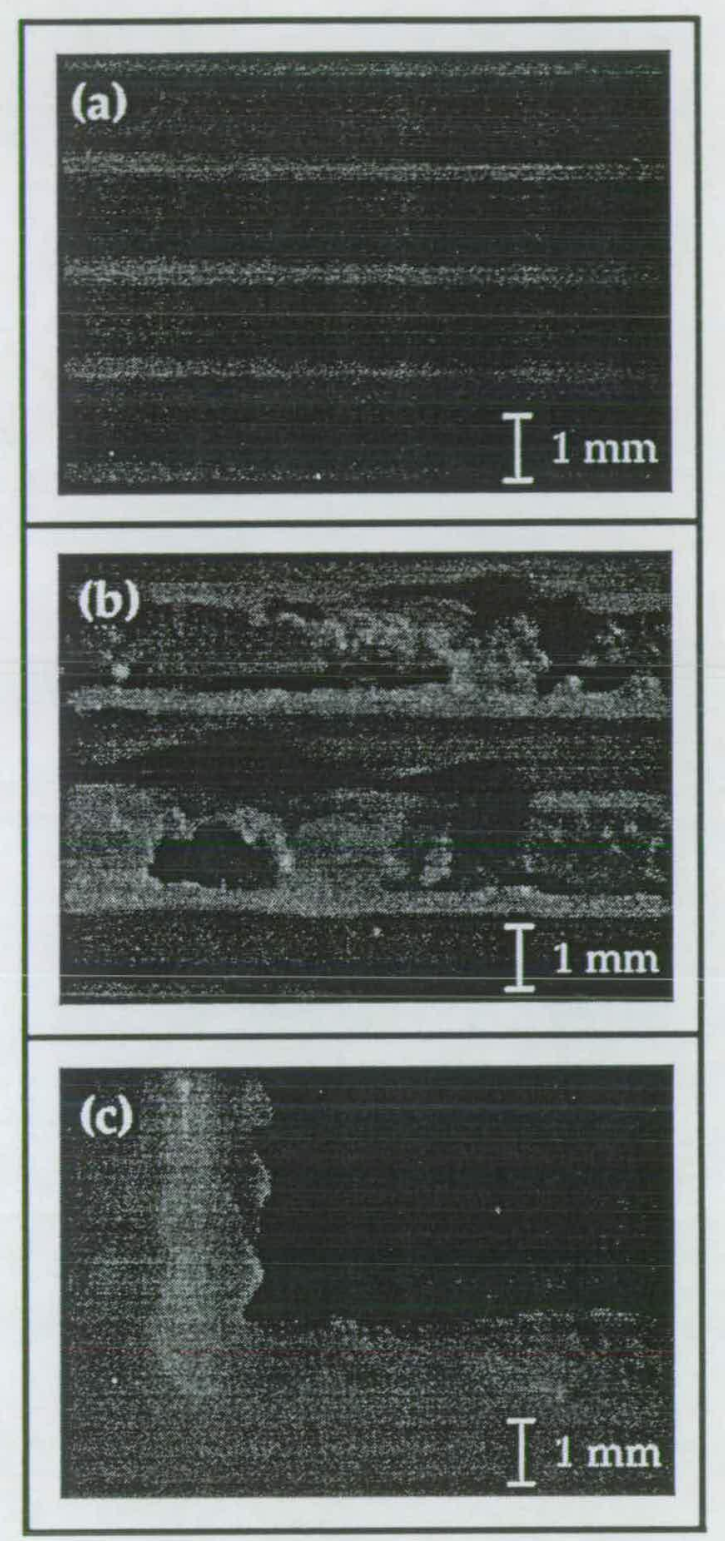

Figure 11: Photographs of platinum electrodes, (a) PT3 before use (b) PT3 after 2 hours electrolysis and (c) square electrode after 2 hours electolysis 
efficiency increased as the concentration of $\mathrm{Mg}^{2+}$ and $\mathrm{Ca}^{2+}$ increased. Furthermore, in the case of the arrays, the active cathodic surface appears constant and the current efficiency was practically stabilised at a value of approximately $55 \%$ for conversions between 0 and $20 \%$.

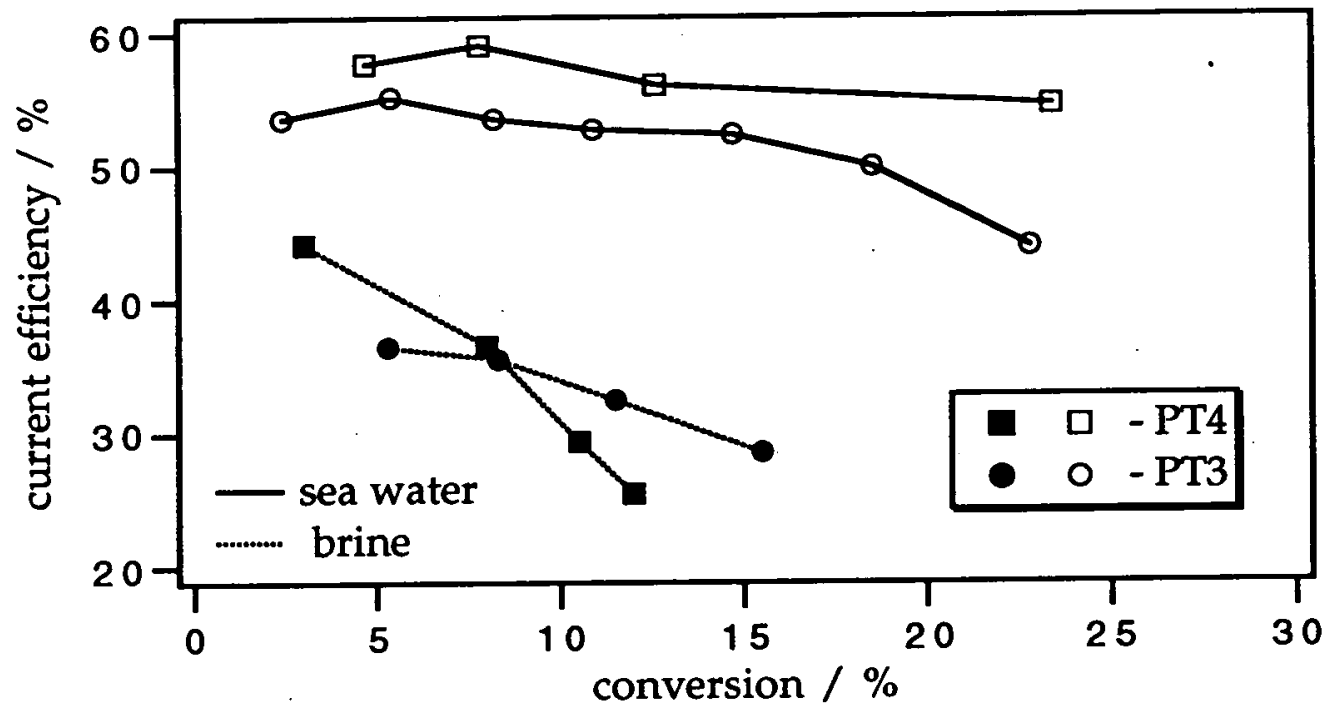

Figure 7.12: Evolution of the current efficiency with the conversion, for electrolyses carried out in brine and in sea water, with the platinum arrays PT3 and PT4.

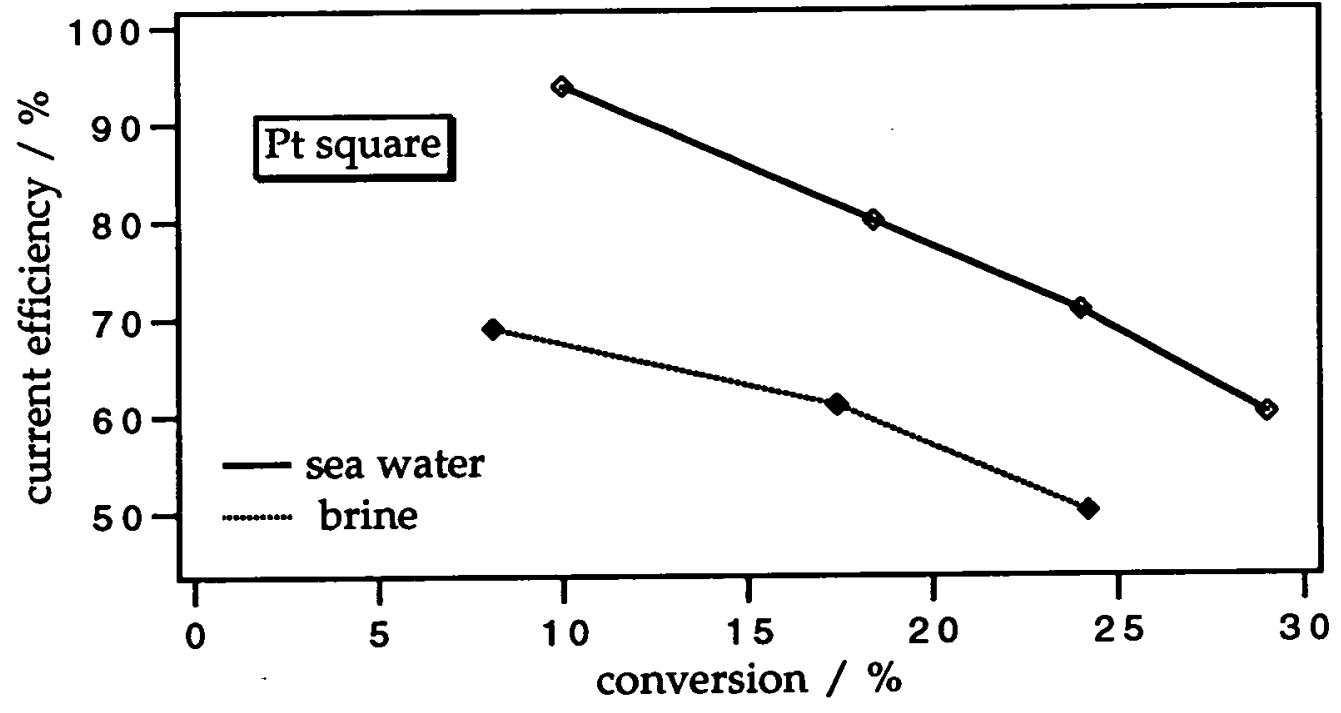

Figure 7.13: Evolution of the current efficiency with the conversion, for electrolyses carried out in brine and in sea water, with two platinum square electrodes. 
The current efficiency values were naturally higher with two electrodes separated by $1 \mathrm{~cm}$, than with coplanar band electrodes separated by $250 \mu \mathrm{m}$, at least for small conversions. The principle advantage of using a coplanar configuration was the detachment of the tarter films from the cathode surface, allowing the arrays to be used over a long electrolysis time.

\section{7-5 Conclusion and further work}

The application of the coplanar band electrodes for the electrolysis of sea water is very promising. From the experiments carried out in a brine solution, it was shown that a large portion of the hypochlorite ions produced at the anode were reduced at the adjacent cathodes. However, when magnesium and calcium salts were added at concentrations equal to that of sea water, it was found that this side reaction was inhibited by the formation of tarter at the cathode. The hypochlorite reduction could also be limited by reducing the cathode / anode ratio or increasing the inter-electrode distance. This would however require further investigations. The advantages of the coplanar band electrodes with small inter-electrode gaps, in comparison with more widely separated parallel square electrodes, is that the tarter deposition was limited by the efficient mixing regimes at the electrode surface. The electrode passivation could therefore be avoided.

In this chapter, it was also demonstrated that good quality DSA electrodes could successfully be obtained by successively screen printing platinum and $\mathrm{RuO}_{2}$ inks, or by coating printed platinum films with iridium. These techniques should now be investigated for the fabrication of coplanar DSA-platinum band electrodes, allowing a predictable gain in the current efficiencies. 


\section{APPENDIX 1}

$/^{*}$ simulation of the resistance between 2 coplanar band electrodes

\#include <stdio.h>

\#include <math.h>

\#define width $\quad 10$

\#define xlim 15

\#define xdim 30

\#define ydim 45

$/^{*}$ important: $x \operatorname{dim}=2^{*} x \lim$

$45 \quad l^{*}$ important: ydim $>$ xlim

\#define dim 50

$/ *$ important : dim $>$ ydim

*

\#define nt

\#define lambda $\quad 0.25$
int
i, j, it, nx0, nx1;
double
O[dim][dim], N[dim][dim],Curren, c[nt], Cgeom;
void calcul1(), calcul2(), calcul3();
FILE *fp1, *fp2, *fp3;

$\operatorname{main}()\{$

$I^{*}$ matrix initialisations

$/^{*}$ on the electrodes

for $(\mathrm{i}=0 ; \mathrm{i}<=$ width; $\mathrm{i}++) \mathrm{l}$

$\mathrm{O}[\mathrm{i}][0]=2$;

$\mathrm{O}[\mathrm{xdim}-\mathrm{i}][0]=0$;

$N[i][0]=2$;

$\mathrm{N}[\mathrm{xdim}-\mathrm{i}][0]=0$;

\}

$l^{*}$ between the electrodes and on the substrate

for ( $i=$ width $+1 ; i<x$ dim-width; $i++)($

$\mathrm{O}[\mathrm{i}][0]=1$;

$\mathrm{N}[\mathrm{i}][0]=1$;

\}

$/ *$ general case

for $(i=0 ; i<=x d i m ; i++)$

for $(j=1 ; j<=y \operatorname{dim} ; j++)\{$

$\mathrm{O}[\mathrm{i}][\mathrm{j}]=1 . ;$

$\mathrm{N}[\mathrm{i}][\mathrm{j}]=1$.;

\} 
$I^{*}$ between the electrodes and on the substrate $\mathrm{nx} 0=\mathrm{it}$; if ( $\mathrm{n} \times 0>$ xlim-width-1) $\mathrm{nx} 0=\mathrm{xlim}$-width-1; for $(i=w i d t h+1, j=0 ; i<=$ width $+n \times 0 ; i++)$ calcul 1() ;

$I^{*}$ on the sides ( $\mathrm{i}=0$ ou $\left.\times \mathrm{dim}\right)$ $\mathrm{nx} 1=\mathrm{it}$; if ( $\mathrm{nx} 1>\mathrm{ydim}) \mathrm{nx} 1=\mathrm{ydim}$; for $(j=1 ; j<=n \times 1 ; j++)$ calcul2();

$I^{*}$ general case

for $(i=1 ; i<=$ width $+n \times 0 ; i++)$

for $(j=1 ; j<=n \times 1 ; j++)$ calcul3();

$I^{*}$ replacement of the old matrix for $(i=0 ; i<=x \operatorname{dim} ; \mathrm{i}++)$

for $(j=0 ; j<y d i m ; j++)$

$\mathrm{O}[\mathrm{i}][\mathrm{j}]=\mathrm{N}[\mathrm{i}][\mathrm{j}]$;

$/^{*}$ integration du courant

for ( $i=x$ dim-width $+1 ; i<x d i m$; $i++$ )

Curren $+=\mathrm{N}[\mathrm{i}][1]$;

Curren $+=(\mathrm{N}[$ xdim-width $][1]+\mathrm{N}[\mathrm{xdim}][1]) / 2$;

$c[i t]=$ Curren;

$I^{*}$ creation of files and result presentation printf ("\n\n"); printf("width: \%d, gap: \%d, iterations: \%d $\backslash n$ ", width, xlim-width, nt);

Cgeom $=2 / c[n t]$;

printf("Cgeom obtained = \%f $\backslash n$ ", Cgeom);

fp1=fopen ("resist.data","w");

fprintf (fp1, "\%4.3f \n", Cgeom);

fclose(fp1); 


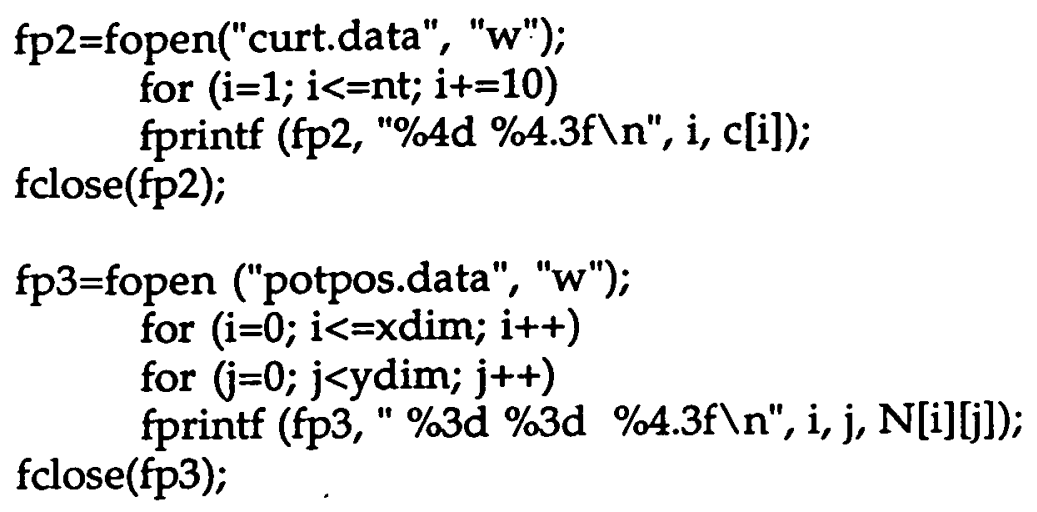

void calcul1) (

$\mathrm{N}[\mathrm{i}][0]=\mathrm{O}[\mathrm{i}][0]+$ lambda * $\left(\mathrm{O}[\mathrm{i}-1][0]+\mathrm{O}[\mathrm{i}+1][0]+\mathrm{O}[\mathrm{i}][1]-3^{*} \mathrm{O}[\mathrm{i}][0]\right) ;$

$\mathrm{N}[\mathrm{xdim}-\mathrm{i}][0]=\mathrm{O}[\mathrm{xdim}-\mathrm{i}][0]+\mathrm{lambda} *(\mathrm{O}[\mathrm{xdim}-\mathrm{i}-1][0]+$

$\left.\left.\mathrm{O}[\mathrm{xdim}-\mathrm{i}+1][0]+\mathrm{O}[\mathrm{xdim}-\mathrm{i}][1]-3^{*} \mathrm{O}[\mathrm{xdim}-\mathrm{i}][0]\right) ;\right\}$

void calcul2() (

$\mathrm{N}[0][\mathrm{j}]=\mathrm{O}[0][\mathrm{j}]+$ lambda * $\left(\mathrm{O}[0][\mathrm{j}-1]+\mathrm{O}[0][\mathrm{j}+1]+\mathrm{O}[1][\mathrm{j}]-3^{*} \mathrm{O}[0][\mathrm{j}]\right)$

$\mathrm{N}[\mathrm{xdim}][\mathrm{j}]=\mathrm{O}[\mathrm{xdim}][\mathrm{j}]+\mathrm{lambda} *(\mathrm{O}[\mathrm{xdim}][\mathrm{j}-1]+\mathrm{O}[\mathrm{xdim}][\mathrm{j}+1]$

+ O[xdim - 1][i] $\left.\left.]-3^{*} \mathrm{O}[\mathrm{xdim}][\mathrm{j}]\right) ;\right\}$

void calcul30 (

$N[i][j]=O[i][j]+$ lambda * $(O[i][j-1]+O[i][j+1]+O[i-1][j]+O[i+1][j]$ $\left.-4^{*} \mathrm{O}[\mathrm{i}][\mathrm{j}]\right)$;

$\mathrm{N}[\mathrm{xdim}-\mathrm{i}][\mathrm{j}]=\mathrm{O}[\mathrm{xdim}-\mathrm{i}][\mathrm{j}]+\mathrm{lambda} *(\mathrm{O}[\mathrm{xdim}-\mathrm{i}][\mathrm{j}-1]+\mathrm{O}[\mathrm{xdim}-\mathrm{i}][\mathrm{j}+1]$ $\left.\left.+O[x \operatorname{dim}-\mathrm{i}-1][j]+\mathrm{O}[\mathrm{xdim}-\mathrm{i}+1][\mathrm{j}]-4^{*} \mathrm{O}[\mathrm{xdim}-\mathrm{i}][\mathrm{j}]\right) ;\right\}$ 


\section{APPENDIX 2}

:REVERSIBLE REACTION

Constant $k 1=5 e-5, k 2=5 e-5$

Constant Asp=2.857

Constant Cint $=1000$, tfin $=45000$

1 SIM; INTERACT; RESET; GOTO 1

INITIAL

$S=500$

$P=0$

DYNAMIC

$S^{\prime}=-K 1^{*} A s p^{*} S+K 2^{*} A s p^{* P}$

$\mathrm{P}=500-\mathrm{S}$

IF(S.LT.0.0)S $=0.0$

$\operatorname{IF}(P . L T .0 .0) P=0.0$

PLOT T,P,0,TFIN,0,500

OUTPUT T,S,P

Prepare T,S,P 


\section{Publications}

C. Belmont and H. H. Girault, Coplanar interdigitated band electrodes for electrosynthesis - part 1: evaluation of the ohmic loss. Journal of applied electrochemistry, 24/5 (1994), in press.

C. Belmont and H. H. Girault, Coplanar interdigitated band electrodes for electrosynthesis - part 2: methoxylation of furan. Journal of applied electrochemistry, 24/5 (1994), in press. 


\section{Courses and conferences attended}

Departmental colloquia (Edinburgh University)

Departmental colloquia (E. P. F. L.)

Physical chemistry postgraduate lectures

Electro-engineering postgraduate lectures

German for chemists, test passed in 1991

Butler meeting, Edinburgh University, 1991

Electrochimie et environnement SEE meeting, Paris, 1991

Spring informal meeting, Southampton University, 1991 


\section{REFERENCES}

1. J. D. Genders and D. Pletcher, Electrosynthesis from laboratory to pilot to production, The Electrosynthesis Company Inc. (1990).

2. D. Pletcher and F. C. Walsh, Industrial electrochemistry, second edition, Chapman and Hall Ltd (1990).

3. J. Chaussard, l'actualité chimique, juin-juillet (1985) 55.

4. D. E. Danly, AIChE Symp. Series, 204 (1981) 39.

5. J. E. Colman, AIChE Symp. Series, 204 (1981) 244.

6. F. Wenisch, H. Nohe, H. Hannebaum, R. K. Horn, M. Stroezel and D. Degner, AIChE Symp. Series, 185 (1979) 14.

7. H. V. K. Udupa, AIChE Symp. Series, 185 (1979) 26.

8. P. M. Robertson and N. Ibl, J. Applied Electrochem., 7 (1977) 323.

9. P. Robertson, P. Cettou, D. Matic, F. Schwager, A. Stork and N. Ibl, AIChE Symp. Series, 185 (1979) 115.

10. P. Seiler, P. M. Robertson, Chimia, 36 (1982) 305.

11. J. Y. Bareau and F. Coeuret, J. Appl. Electrochem., 9 (1979) 737.

12. A. T. Kuhn and R. W. Houghton, Electrochim. Acta, 19 (1974) 733.

13. K. Scott, J. Appl. Electrochem., 11 (1981) 339.

14. E. A. El-Ghaoui, R. E. W. Jansson, C. Moreland, J. Appl. Electrochem., 12 (1982) 69.

15. E. A. El-Ghaoui, R. E. W. Janson, J. Appl. Electrochem., 12 (1982) 75.

16. S. Ehdaie, M. Fleischmann, R. E. W. Jansson, J. Appl. Electrochem., 12 (1982) 59.

17. F. Cœuret and A. Storck, Eléments de génie électrochimique, Technique et Documentation (1984).

18. F. Walsh, A first course in Electrochemical Engineering, The Electrochemical Consultancy (1993).

19. R. M. Wightman, Anal. Chem., 53 (1981) 1125R. 
20. M. I. Montenegro, M. A. Queiros and J. L. Daschbar, Microelectrodes: Theory and Applications, NATO ASI series, 197 (1991).

21. R. M. Whightman and D. O. Wipf, Electroanal. Chem., 15 (1989) 267.

22. M. Fleischman, S. Pons, D. R. Rolison and P. P. Schmidt, Ultramicroelectrodes, Datatech Systems, Morganton, NC (1987).

23. K. R. Wehmeyer, M. R. Deakin and R. M. Wightman, Anal. Chem., 57 (1985) 1913.

24. A. J. Bard, J. A. Crayston, G. P. Kittlesen, T.V. Shea and M. S. Wrighton, Anal. Chem., 58 (1986) 2321.

25. K. Aoki, K. Tokuda and H. Matsuda, J. Electroanal. Chem., 217 (1987) 33.

26. J. L. Anderson, K. K. Whiten, J. D. Brewster, T. Y. Ou and W. K. Nonidez, Anal. Chem., 57 (1985) 1366.

27. D. J. Pickett and B. R. Stanmore, J. Appl. Electrochem., 2 (1972) 151.

28. K. Aoki, M. Morita, O. Niwa and H. Tabei, J. Electroanal. Chem., 256 (1988) 269.

29. B. J. Seddon, H. H. Girault and M. J. Eddowes, J. Electroanal. Chem., 266 (1989) 227.

30. B. J. Seddon, PhD thesis, University of Edinburgh, U.K., (1989).

31. Y. Duhirel, B. Beden, J. M. Léger and C. Lamy, Electrochim. Acta, 37 (1992) 665.

32. A. Papoutsis, J. M. Léger and C. Lamy, J. Electroanal. Chem., 234 (1987) 315.

33. H. S. Carlsaw and J. C. Jaeger, Conduction of Heat in Solids, Oxford University Press, London, (1959).

34. A. Angot, Compléments de Mathématiques à l'usage de l'Electrotechnique et des Télécommunications, Editions de la Revue Optique, Paris, (1957).

35. B. Fosset, C. A. Amatore, J. E. Bartelt, A. C. Michael and R. M. Wightman, Anal. Chem., 63 (1991) 306.

36. N. Clauson-Kaas, F. Limborg and K. Glens, Acta Chem. Scand., 6 (1952) 531.

37. R. E. W. Jansson and N. Tomov, Chem. Ind. (London), 3 (1978) 96. 
38. R. E. W. Jansson and M. Fleischmann, AIChE Symp. Series, 185 (1979) 2.

39. N. R. Tomov and R. E. W. Jansson, J. Chem. Tech. Biotechnol., 30 (1980) 110.

40. K. Kusakabe, S. Morooka and Y. Kato, J. Chem. Eng. Jpn., 19 (1986) 43.

41. A. J. Bellamy and B. R. Simpson, Chem. Ind. (London), 21 (1982) 863.

42. V. Krishnan, A. Muthukumaran and H. V. K. Udupa, Trans. SAEST, 14 (1979) 39.

43. E. Raoult, J. Sarrazin and A. Tallec, J. Appl. Electrochem., 15 (1985) 85.

44. K. H. Simmrock, R. Gregel, R. Fabiunke, J. Jörissen and M. Köhler, Proc. Electrochem. Soc., 88 (1988) 383.

45. C. Moinet, J. Sarrazin and A. Tallec, Bull. Soc. Chim. Fr., 1 (1983) 184.

46. M. J. Medeiros, M. I. Montenegro and D. Pletcher, Port. Electrochim. Acta, 7 (1989) 47.

47. F. B. Thomas, P. A. Ramachandran, M. P. Dudukovic and R. E. W. Jansson, J. Appl. Electrochem., 19 (1989) 856.

48. N. Ibl, Chem. Ing. Tech., 35 (1963) 353.

49. H. Kolbe, Ann. Chem., 69 (1849) 257.

50. C. Schall, Z. Electrochem., 3 (1896) 83.

51. S. Glasstone and A. Hickling, Chem. Rev., 25 (1939) 407.

52. A. Crum-Brown and J. Walker, Ann. Chem., 261 (1891) 107.

53. L. Eberson, Acta Chem. Scand., 17 (1963) 1196.

54. R. M. Cervino, W. E. Triaca and A. J. Arvia, J. Electroanal. Chem., 172 (1984) 255.

55. E. J. Vasini and M. C. Giordano, Electrochim. Acta, 34 (1989) 577.

56. Y. B. Vassiliev and V. A. Grinberg, J. Electroanal. Chem., 308 (1991) 1.

57. M. M. Baizer, Organic Electrochemistry, (1991).

58. Y. B. Vassiliev, E. P. Kovsman and G. N. Freidlin, Electrochim. Acta, 27 (1982) 937.

59. F. Beck, Elektroorganische Chemie, Verlag Chemie (1974). 
60. M. J. Fioschin and A. I. Kamnewa, Chem. Ind. (russ), (1960) 359.

61. F. Beck and H. Guthke, Chem. Ing. Tech. , 41 (1969) 943.

62. J. Haufe and F. Beck, Chem. Ing. Techn, 42 (1970) 170.

63. F. Beck, Electrochim. Acta, 18 (1973) 359.

64. M. Stoukides and C. G. Vayenas, J. Electrochem. Soc., 131 (1984) 839.

65. M. Stoukides and C. G. Vayenas, Int. Congr. Catal. Proc. $8^{\text {th }}, 4$ (1984) IV 827.

66. K. Scott and B. Hayati, Chem. Eng. Sc., 43 (1988) 1989.

67. R. C. Alkire and J. D. Lisius, J. Electrochem. Soc., 132 (1985) 1879.

68. K. Scott, J. Electroanal. Chem., 243 (1988) 1.

69. K. G. Ellis and R. E. W. Jansson, J. Appl. Electrochem., 13 (1983) 661.

70. J. Ghoroghchian, R. E. W. Jansson and D. Jones, J. Appl. Electrochem., 7 (1977) 437.

71. A. V. Boussoulengas, S. Ehdaie and R. E. W. Jansson, Chem. Ind. (London), 19 (1979) 670.

72. K. G. Ellis and R. E. W. Jansson, J. Appl. Electrochem., 11 (1981) 531.

73. T. C. Chou, J. J. Jow and S. T. Yu, Proc. Pac. Chem. Eng. Congr. 3rd, 2 (1983) 149.

74. R. C. Alkire and J. E. Tsai, J. Electrochem. Soc., 129 (1982) 1157.

75. P. Bellair and C. Pomerol, Eléments de géologie, 5 e edition, Armand Colin (1977).

76. C. Boxall and G. H. Kelsall, I. Chem. E. Symp. "Electrochemical Engineering and the Environment", 127 (1992) 59.

77. N. Krstajic, V. Nakic and M. Spasojevic, J. Appl. Electrochem., 21 (1991) 637.

78. J. M. Fresnel, French Patent, (1985) 8515284.

79. G. H. Kelsall, J. Appl. Electrochem., 14 (1984) 177.

80. N. Krstajic, V. Nakic and M. Spasojevic, J. Appl. Electrochem., 17 (1987) 77. 
81. P. M. Robertson, W. Gnehm and L. Ponto, J. Appl. Electrochem., 13 (1983) 307.

82. F. Goodridge, C. J. H. King and A. R. Wright, Electrochim. Acta, 22 (1977) 1087.

83. J. E. Bennett, Chem. Eng. Prog., 70 (1974) 60.

84. A. T. Kuhn and R. B. Lartey, Chem. Ing. Techn., 47 (1975) 129.

85. N. Ibl and H. Vogt, Comprehensive Treatise of Electrochemistry, edited by J. O'M. Bockris, B. E. Convay, E. Yeager and R. E. White, Plenum Press, 2 (1981) 167.

86. D. M. Novak, B. V. Tilak and B. E. Convay, Modern Aspects of Electrochemistry, edited by J. O'M. Bockris, B. E. Convay and R. E. White, Plenum Press, 14 (1982) 195.

87. G. H. Kelsall, I. Chem. E. Symp. "Electrochemical Engineering and the Environment", 127 (1992) 71.

88. D. Landolt and N. Ibl, Electrochim. Acta, 15 (1970) 1165.

89. G. Charlot, Chimie Analytique quantitative II- Méthodes sélectionnées d'analyses chimiques des éléments, Masson et Cie, Paris (1974).

90. C. Comninellis and G. P. Vercesi, J. Appl. Electrochem., 21 (1991) 136.

91. Y. Malherbe, PhD thesis, E. P. F. L. - CH (1994). 